\title{
A INFLUÊNCIA DO EVENTO-CHAVE NASCIMENTO DE CRIANÇAS NO COMPORTAMENTO DE VIAGEM INDIVIDUAL A PARTIR DA TEORIA "BIOGRAFIAS DE MOBILIDADE"
}

MARCELO PEREIRA ALMEIDA

DISSERTAÇÃO DE MESTRADO EM TRANSPORTES DEPARTAMENTO DE ENGENHARIA CIVIL E AMBIENTAL 
UNIVERSIDADE DE BRASÍLIA

FACULDADE DE TECNOLOGIA

DEPARTAMENTO DE ENGENHARIA CIVIL E AMBIENTAL

A INFLUÊNCIA DO EVENTO-CHAVE NASCIMENTO DE CRIANÇAS NO COMPORTAMENTO DE VIAGEM INDIVIDUAL A PARTIR DA TEORIA "BIOGRAFIAS DE MOBILIDADE"

MARCELO PEREIRA ALMEIDA

ORIENTADORA: FABIANA SERRA DE ARRUDA DISSERTAÇÃO DE MESTRADO EM TRANSPORTES

PUBLICAÇÃO: T. DM - 016/2016

BRASÍLIA/DF: JULHO DE 2016 
UNIVERSIDADE DE BRASÍLIA

FACULDADE DE TECNOLOGIA

DEPARTAMENTO DE ENGENHARIA CIVIL E AMBIENTAL

A INFLUÊNCIA DO EVENTO-CHAVE NASCIMENTO DE CRIANÇAS NO COMPORTAMENTO DE VIAGEM INDIVIDUAL A PARTIR DA TEORIA "BIOGRAFIAS DE MOBILIDADE"

\author{
MARCELO PEREIRA ALMEIDA
}

DISSERTAÇÃO DE MESTRAdO SUBMETIDA AO PROGRAMA DE PÓSGRADUAÇÃ̃O EM TRANSPORTES DO DEPARTAMENTO DE ENGENHARIA CIVIL E AMBIENTAL DA UNIVERDIDADE DE BRASÍLIA COMO PARTE DOS REQUISITOS NECESSÁRIOS PARA A OBTENÇÃO DO GRAU DE MESTRE EM TRANSPORTES.

APROVADO POR:

$\frac{\text { FADEIANA SERRA DE ARRUDA }}{\text { Profa. Dr'. Fabiana Serra de Arruda - PPGT/UnB }}$ (ORIENTADORA)

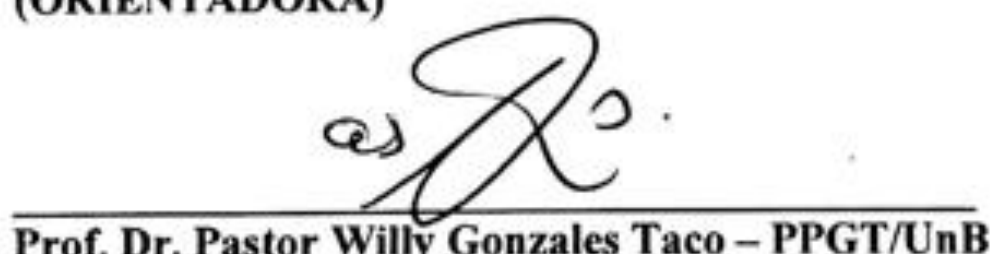
(EXAMINADOR INTERNO)

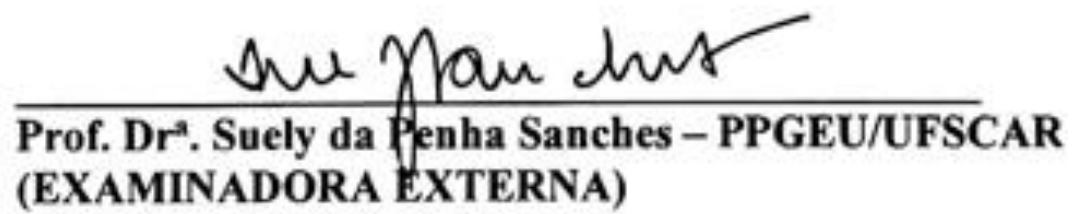

BRASÍLIA/DF, JULHO DE 2016. 


\section{FICHA CATALOGRÁFICA}

\section{ALMEIDA, MARCELO PEREIRA}

A influência do evento-chave nascimento de crianças no comportamento de viagem individual a partir da teoria "Biografias de Mobilidade". [Distrito Federal] 2016. xvi, 172p., 210 x 297 mm (ENC/FT/UnB, Mestre, Transportes, 2016).

Dissertação de Mestrado - Universidade de Brasília. Faculdade de Tecnologia. Departamento de Engenharia Civil e Ambiental.

1. Comportamento de Viagem

2. Biografias de Mobilidade
3. Evento-Chave
4. Tomada de decisão
5. Escolha do Meio de Transporte

\section{REFERÊNCIA BIBLIOGRÁFICA}

ALMEIDA, M. P. (2016). A influência do evento-chave nascimento de crianças no comportamento de viagem individual a partir da teoria "Biografias de Mobilidade". Dissertação de Mestrado em Transportes, Publicação T.DM-016/2016, Departamento de Engenharia Civil e Ambiental, Universidade de Brasília, DF, 172p.

\section{CESSÃO DE DIREITOS}

AUTOR: Marcelo Pereira Almeida.

TÍTULO: A influência do evento-chave nascimento de crianças no comportamento de viagem individual a partir da teoria "Biografias de Mobilidade".

GRAU: Mestre

ANO: 2016

É concedida à Universidade de Brasília permissão para reproduzir cópias desta dissertação de mestrado e para emprestar ou vender tais cópias somente para propósitos acadêmicos e científicos. O autor reserva outros direitos de publicação e nenhuma parte desta dissertação pode ser reproduzida sem autorização por escrito do autor.

\footnotetext{
Marcelo Pereira Almeida

marceloalmeidagyn@gmail.com

marceloalmeidagyn@hotmail.com
} 


\section{DEDICATÓRIA}

A Deus por ser a inteligência suprema e a causa primária de todas as coisas. 


\section{AGRADECIMENTOS}

Elevo um especial agradecimento a Deus, por nunca ter desanimado ou desistido. Pela Sua infinita sabedoria ao tratar as minhas limitações, me dedicando tempo e paciência. Eu tenho sido muito abençoado através de grandes planos, aquisições e pela presença de algumas pessoas ao longo do meu processo de desenvolvimento. Ainda que eu quisesse, não poderia falar ou listar a todos, pois são tantos, que não podem ser contados. Sei que não há ninguém igual a Ti, mas muito obrigado por todas as pessoas que passaram ou ainda irão cruzar o meu caminho.

Meus sinceros agradecimentos aos meus pais Luiz Antônio e Ivonilde Almeida pelo lar que eles construíram, através do companheirismo, generosidade, humildade e simplicidade. À minha irmã Marcia Scott e ao meu irmão Luiz P. Antônio, eu os dedico o meu profundo respeito, pois nós conquistamos imensuráveis valores ao longo desta experiência familiar, através da dedicação e do amor dos nossos pais. Temos tanto a agradecer pelo lar que construímos e pela oportunidade de viver neste núcleo familiar.

Em especial, agradeço aos meus avós que dedicaram o amor e o suor na educação dos meus pais. Felizmente, mais tarde, fui contemplado com a oportunidade de conhecê-los e senti as suas qualidades expressadas através do carinho. A vocês o meu mais profundo respeito. Agradeço também aos meus familiares Adriana Inácio, Ana Carolina Almeida de Castro, Laudimilha Almeida, Marcos Severo, Neide Abreu e Telma Faleiros pelos estímulos, ajudas e a perseverança em todas as etapas desta pesquisa e ao longo da vida.

À minha mãe intelectual, a minha orientadora a Profa. Dr ${ }^{a}$. Fabiana Serra de Arruda. Os seus ensinamentos foram muito além dos conteúdos curriculares. Muito obrigado pela sua dedicação, paciência, conversas fraternas, exemplo de vida profissional acadêmica e pelo carinho ao segurar as minhas mãos na confecção desta pesquisa em vários momentos. Agradeço também por confiar os seus alunos da graduação em Engenharia Civil, para que pudéssemos trabalhar juntos, entre eles eu destaco o André Segovia, que foi extremamente fundamental no processo de desenvolvimento deste trabalho.

Agradeço imensamente ao Prof. Dr. José Matsuo Shimoishi, Prof. Dr. Pastor Willy

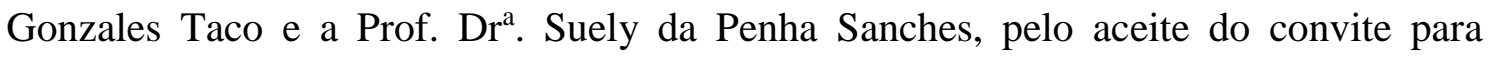


examinar esta pesquisa. Sou grato por todas as contribuições e direcionamentos apontados. Estendo os agradecimentos a todos do corpo docente do Programa de PósGraduação em Transportes. Obrigado pelos ensinamentos, reflexões e pela prontidão em tirar as dúvidas mesmo fora da sala de aula.

Estendo um especial agradecimento a todos os meus outros mestres, desde as minhas educadoras iniciais até os doutores de hoje em dia. Muitos souberam despertar a minha admiração aos estudos de uma forma particular, e vários se tornaram uma referência para mim. Sou uma construção de todos vocês e, atualmente, eu percebo o quanto cada um foi útil ao seu tempo.

Meu especial agradecimento aos meus colegas das turmas de mestrandos e doutorandos de 2013 e 2014, anos em que fui aluno especial e regular, respectivamente. Nas linhas desta pesquisa há um pouco de cada um de vocês. De forma particular, agradeço à Aline Maia, Fabiana Barbosa, Fabiane Santos, Gal Rodrigues, Gerardo Souza, Gisele Ortolani, Ingrid Saldanha, Juan Pablo España, Luca Assunção, Marcus Nylander, Marise Takano, Raphael Vanderlei, Robert Ramon, Zuleide Feitosa, e aos meus irmãos: Ivo Almeida e Tharcia Vasconcelos.

Aos funcionários da Universidade de Brasília com os quais convivi, especialmente os do Programa de Pós-Graduação em Transportes, em especial as secretárias Camila Lucena e Lucinete Santos, e do CEFTRU agradeço a cooperação sempre pontual do Daniel Maranhão, Janaína Cardoso e Weudes Evangelista.

Há pessoas que marcaram a minha vida, que despertaram algo especial e particular, que abriram os meus olhos de uma forma irreversível e transformaram a minha maneira de ver o mundo. Meus mais nobres agradecimentos a vocês: Claudia Raia (pela carinhosa atenção nos nossos encontros), Clayton Redmerski (pelo apoio inicial e pelas primeiras correções), Eduardo Augusto (por trazer ao meu mundo a magia da música e do teatro), Francisco Moreira (pelo companheirismo, lealdade, generosidade, espiritualidade), Patrícia Chanely (pela maestria nas palavras escritas que sempre encantam o meu coração), Rejane Braga (pelo suporte inicial em Brasília e por todos os olhares de carinho e compreensão), Roman Amestigon (pela simplicidade e a atenção no tratamento das coisas pequenas e simples), Veronica Pessoa (pela ternura, olhar meigo e por sempre 
acreditar nas minhas capacidades, mesmo quando eu não me sinto capaz) e Wellington Souza (pela amizade e oportunidade de olhar para o lado é saber que você está em todos os momentos ao longo do caminho). Obrigado a todos vocês pela simpatia e pela comunhão de pensamentos. Vocês formam a minha família espiritual, e sempre serão essenciais na minha caminhada rumo à evolução.

Ao Conselho Nacional de Desenvolvimento Científico e Tecnológico (CNPq) pela concessão da bolsa de Mestrado.

Por fim, agradeço a todos que me ajudaram e torceram por mim. 


\section{RESUMO}

A teoria "Biografias de Mobilidade" apresenta uma abordagem comportamental ao analisar as trajetórias do curso de vida do indivíduo, em uma análise longitudinal. A teoria assume que a existência de eventos específicos (chamados de eventos-chave) pode proporcionar mudanças consideráveis no comportamento de viagens, inclusive alterando os padrões de viagens, as características de mobilidade e os deslocamentos familiares e individuais. Assim, com base nessa teoria, o comportamento individual pode ser explicado pela ocorrência de eventos-chave que causem significativas mudanças na forma como esses indivíduos planejam seus deslocamentos. Esses eventos-chave podem gerar mudanças na vida pessoal do indivíduo que, por consequência, irão desencadear um processo de reconsideração do comportamento atual. Neste sentido, esta pesquisa tem como objetivo analisar o comportamento de viagem e a escolha do meio de transporte em um domicílio, a partir do evento-chave "nascimento de crianças", tendo como base a teoria "Biografias de Mobilidade". A pergunta de pesquisa se baseia na necessidade de analisar qual a influência do evento-chave nascimento de criança no comportamento de viagem e na tomada de decisão em um domicílio no contexto das cidades brasileiras. Para tanto, é importante analisar certos estágios e eventos na trajetória do curso de vida, tendo o domicílio como unidade de tomada de decisão. Para atender ao objetivo, foi formulado um método cuja aplicação coletou 234 registros domiciliares, através de um instrumento de pesquisa adaptado a partir de um estudo holandês e outro germânico, que teve uma abordagem longitudinal, com etapa retrospectiva. Os resultados mostram que o eventochave afeta o comportamento de viagem, a realização dos deslocamentos e o processo de tomada de decisão quanto à escolha do meio de transporte.

Palavras-chaves: Comportamento de Viagem; Biografias de Mobilidade;

Evento-Chave; Tomada de Decisão; Escolha do Meio de Transporte. 


\begin{abstract}
The theory "Mobility Biographies" uses a behavioral approach to analyze the trajectories of an individual's life course in a longitudinal analysis. The theory assumes that the occurrence of specific events (called key events) can result in considerable changes in travel behavior, including travel patterns, and the displacements of family and the individual. Based on this theory, the occurrence of key events cause significant changes in the way these individuals plan their offsets. These key events can generate changes in the personal life of an individual, consequently, triggering a reconsideration of the current behavior. As a result, this research aims to analyze the travel behavior and choice of means of transportation in a home, taking into consideration the key event "birth of children," based on the theory "Mobility Biographies". The research purpose is based on the need to analyze the key event "birth of children," and its influence in the travel behavior and decision making in a home in the context of Brazilian cities. Therefore, it is important to analyze certain stages and events having home as decision-making unit. To achieve this goal, it was formulated a method whose application has collected 234 home records, through an instrument adapted research from a Dutch study and other German, which had a longitudinal approach with a retrospective step. The results show that the key event affects travel behavior, shifts in location and the process of decision making regarding the choice of means of transportation.
\end{abstract}

Key words: Travel Behavior; Mobility Biographies; Key Event; Decision Making; Choice of Transport Modes. 


\section{SUMÁRIO}

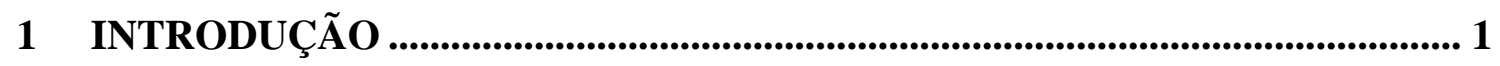

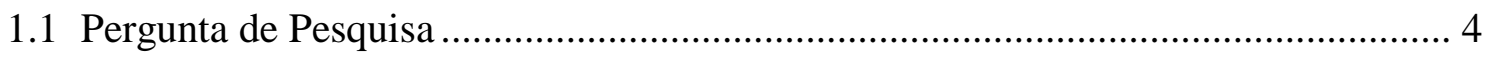

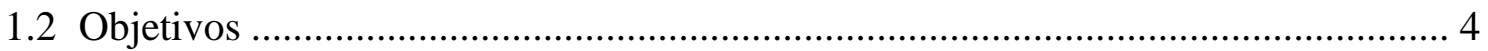

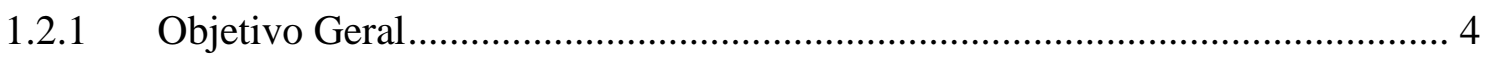

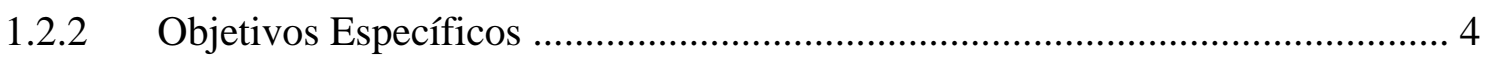

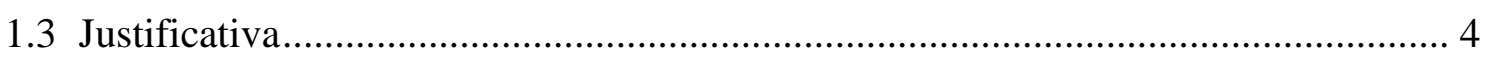

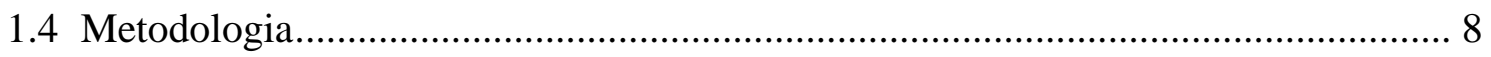

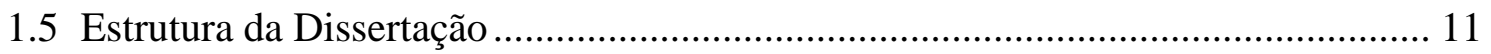

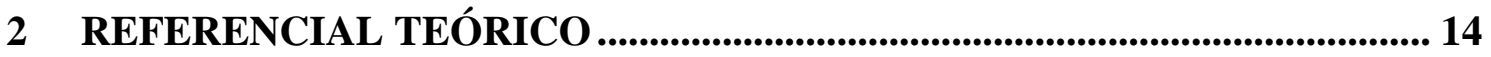

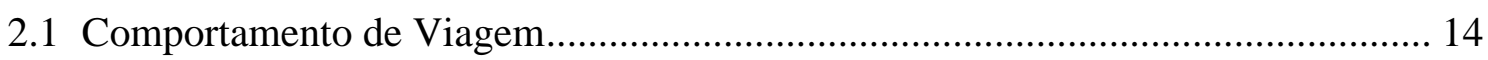

2.1.1 Estudos nacionais que envolvem fatores comportamentais em pesquisas de

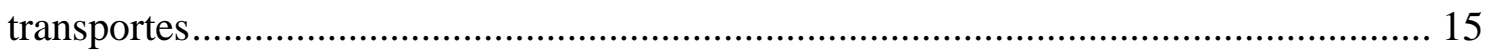

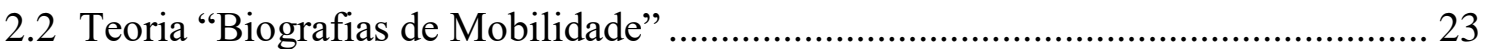

2.3 A Influência dos Eventos-Chave no Comportamento de Viagem ao Longo da

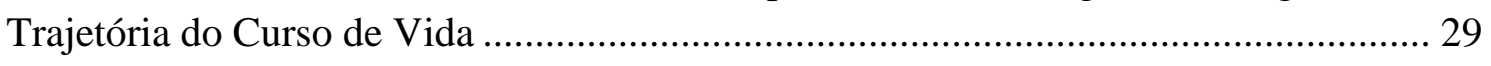

2.4 O Evento-Chave Nascimento de Crianças ................................................................ 33

2.5 A Temporalidade no Contexto da Teoria "Biografias de Mobilidade"................... 37

2.6 Técnicas Aplicadas à Teoria "Biografias de Mobilidade" para a Captação dos

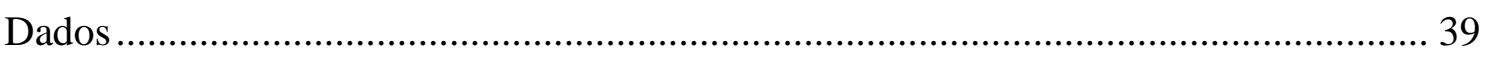

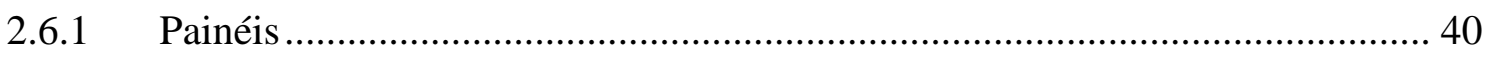

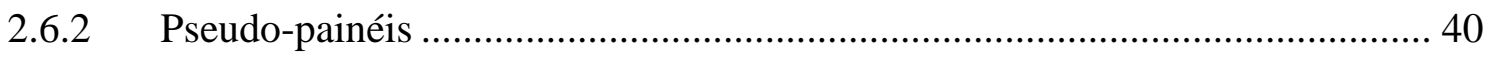

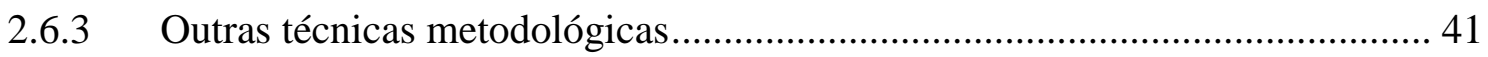

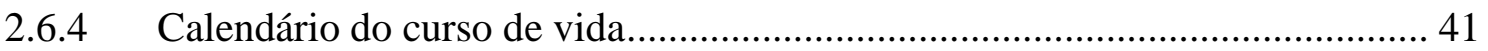

2.6.5 Entrevistas narrativas em etapas retrospectivas ....................................... 42

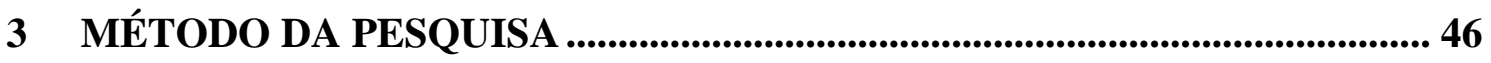

3.1 Delimitação Teórica e Espacial da Área de Estudo - $1^{\mathrm{a}}$ Etapa ............................... 47

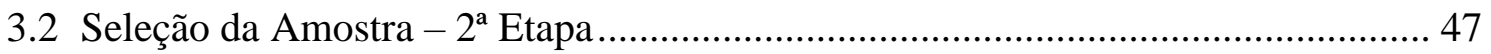

3.3 Elaboração do Instrumento de Pesquisa - $3^{\text {a }}$ Etapa.................................................. 48

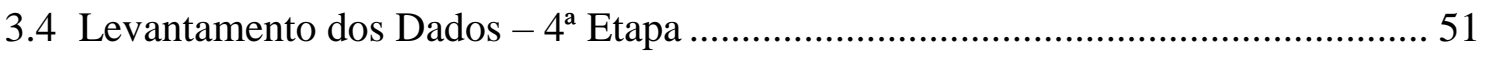

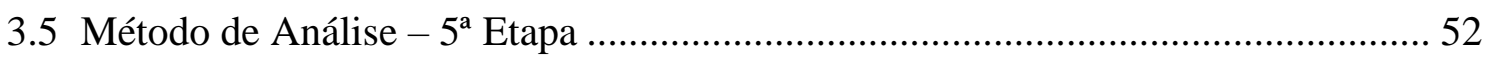

3.5.1 A técnica multivariada de análise de agrupamento - (Cluster) ....................... 53

3.5.2 Análise por correspondência - (Anacor - Correspondence Analysis) ............. 57 
3.5.3 Teste de McNemar para a significância de mudanças - (McNemar's Test) .... 59

3.5.4 Estatística Descritiva - (Descriptive Statistics) ............................................. 62

3.5.5 Teste de Proporção - (Proportion Test) ........................................................... 63

3.5.6 Ranking médio para escala likert - (RM Likert Scale $)$................................. 63

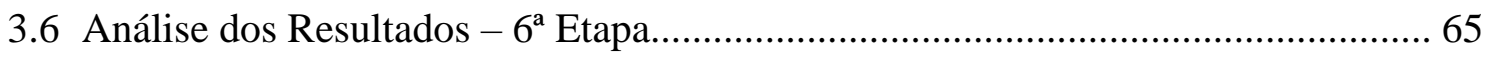

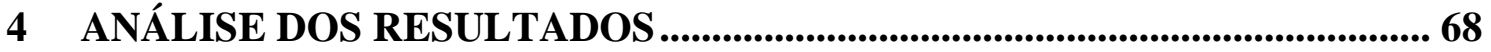

4.1 Descrição das Amostras para a Caracterização do Perfil dos Respondentes .......... 68

4.2 Como o Evento-chave Afeta o Comportamento de Viagem .................................. 72

4.3 Como o Evento-chave Afeta a Realização dos Deslocamentos ............................... 76

4.4 Como Ocorre a Tomada de Decisão quanto à Escolha do Meio de Transporte num

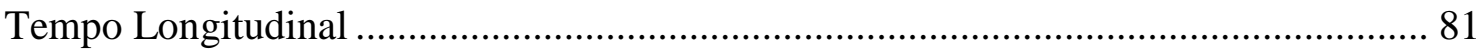

4.5 A Análise do Evento-chave na Perspectiva do Ambiente Profissional e na

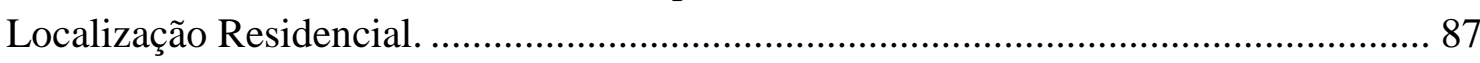

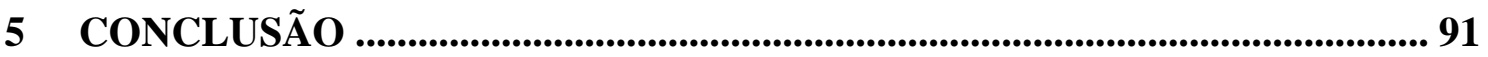

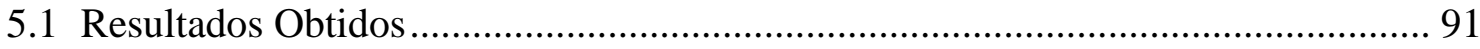

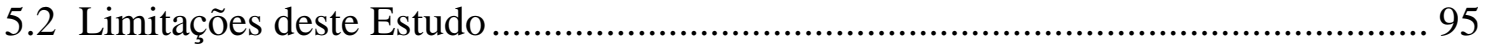

5.3 Sugestões e Recomendações para Estudos Futuros ............................................... 95

6 REFERÊNCIAS BIBLIOGRÁFICAS .......................................................... 97

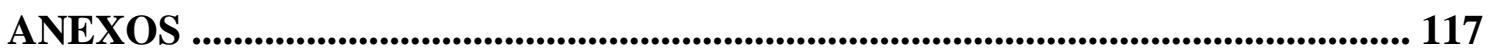




\section{LISTA DE ABREVIATURAS}

ABEP - Associação Brasileira de Empresa de Pesquisa

CCEB - Critério de Classificação Econômica Brasil

CHAID - Chi Square Automatic Interaction Detection

FGV - Fundação Getúlio Vargas

IBGE - Instituto Brasileiro de Geografia e Estatística

RM - Ranking Médio

SPSS - Statistical Package for the Social Sciences 


\section{LISTA DE FIGURAS}

Figura 1- Detalhamento metodológico quanto ao nível da pesquisa ........................... 10

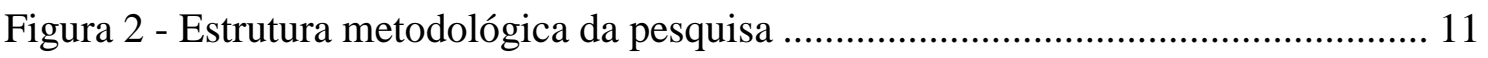

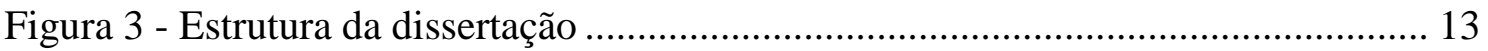

Figura 4 - Estrutura conceitual da teoria "Biografias de Mobilidade" .......................... 23

Figura 5 - Modelo de inter-relações entre as biografias ................................................ 25

Figura 6 - Estrutura conceitual da teoria "Biografias de Mobilidade" aplicada ao evento-

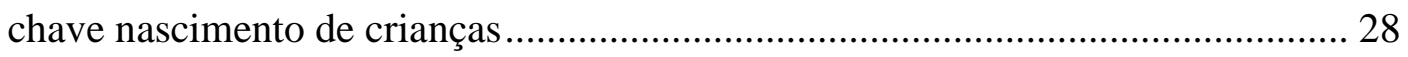

Figura 7 - Modelo conceitual de eventos-chave e incidentes críticos ........................... 30

Figura 8 - Etapas e fases da formulação do método ......................................................... 46

Figura 9 - Divisão hierárquica na Análise Cluster ...................................................... 54

Figura 10 - Procedimentos Hierárquicos Aglomerativos e Divisivos ........................... 55

Figura 11 - Método do Vizinho Mais Próximo ou Ligação Individual ......................... 56

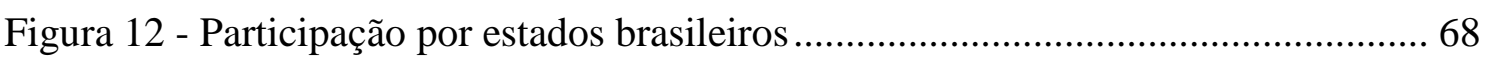

Figura 13 - Nível de instrução dos(as) participantes ................................................ 70

Figura 14 - Renda bruta familiar dos(as) participantes ............................................. 70

Figura 15 - Agrupamento entre renda e meio de transporte ............................................ 71

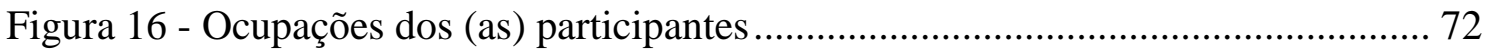

Figura 17 - Quantidades de automóveis (Antes do nascimento) ..................................... 74

Figura 18 - Quantidade de automóveis (Após o nascimento) ……................................ 75

Figura 19 - Atividades diárias (compromissos) após o nascimento ............................... 77

Figura 20 - Atividades diárias (compromissos) do(a) companheiro(a) ou cônjuge após o

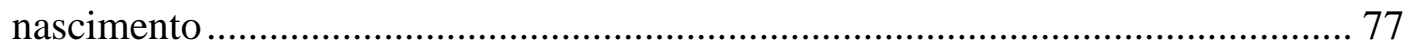

Figura 21 - Deslocamentos após o nascimento ……................................................... 78

Figura 22- Deslocamentos do(a) companheiro(a) ou cônjuge após o nascimento ........ 79

Figura 23 - Mapa perceptual de atividades e deslocamentos após o nascimento............ 79

Figura 24 - Mapa perceptual de atividades e deslocamentos do(a) companheiro(a) ou cônjuge após o nascimento

Figura 25 - Modo de transportes utilizado com maior frequência antes do nascimento 81 Figura 26 - Modo de transportes utilizado com maior frequência após o nascimento... 82 Figura 27 - Principal meio de transporte utilizado nos deslocamentos das crianças...... 86 Figura 28 - Utilização de outro meio de transporte nos deslocamentos das crianças .... 87 
Figura 29 - Situação do trabalho, na perspectiva do respondente, após o nascimento das

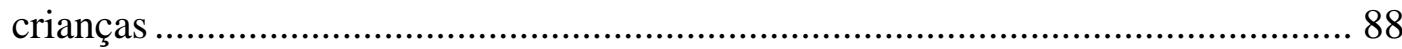

Figura 30- Situação do trabalho, na perspectiva do(a) companheiro(a) ou cônjuge, após o nascimento de crianças 


\section{LISTA DE TABELAS}

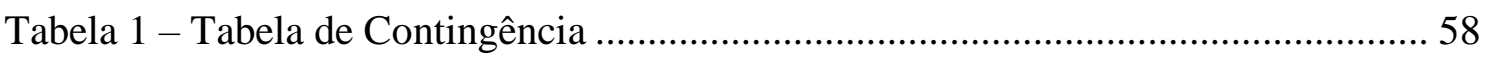

Tabela 2 - Tábua de quatro casas para a prova de significância de mudanças............. 61

Tabela 3 - Carteira de habilitação antes do nascimento e após o nascimento ................ 73

Tabela 4 - Gênero e a carteira de habilitação (antes do nascimento) ............................. 73

Tabela 5 - Gênero e a carteira de habilitação (após o nascimento) ................................ 74

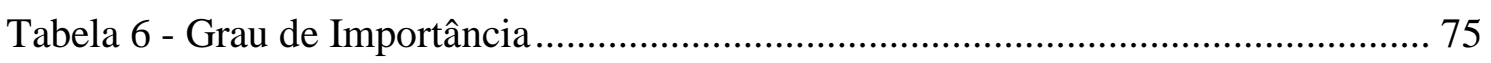

Tabela 7 - Resultados Teste McNemar para cada transporte ....................................... 82

Tabela 8 - Resultados Teste de Proporção para cada transporte ................................... 83

Tabela 9 - Frequências do meio de transporte automóvel (Dirigindo) ........................... 83

Tabela 10 - Frequências do meio de transporte ônibus ................................................. 84

Tabela 11 - Influência na tomada de decisão da escolha do meio de transporte do(a) respondente e do(a) companheiro(a) ou Cônjuge (Após o Nascimento)................. 86

Tabela 12 - Situação da localização residencial na perspectiva do respondente após o

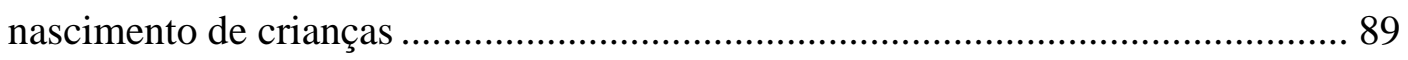

Tabela 13 - Situação da localização residencial na perspectiva do(a) companheiro(a) ou

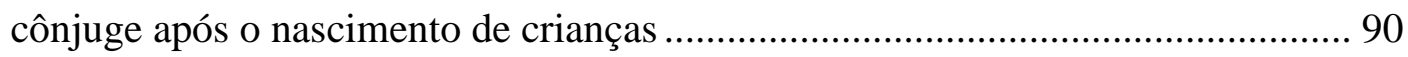




\section{LISTA DE QUADROS}

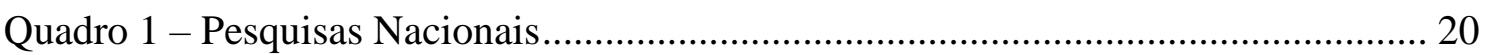

Quadro 2 - Biografias Parciais e Eventos-Chave......................................................... 32

Quadro 3 - Parâmetros para Análise do Ranking Médio .............................................. 65 


\section{INTRODUÇÃO}

Desde a década de 70, com os estudos desenvolvidos por Chapin (1974) e Hägerstrand (1975), já se evidenciava a importância de analisar o comportamento de viagem tendo como foco as experiências individuais. Pensar no comportamento de viagem, numa perspectiva em que o indivíduo seja o agente da tomada de decisão, contribui favoravelmente para um planejamento mais humano e adequado (Lanzerdorf, 2010; Freitas, 2012; Alves, 2014).

Nas últimas décadas, ocorreram avanços significativos nos estudos voltados para o comportamento dos indivíduos na realização das viagens. As análises desagregadas passaram a ter visibilidade e os modelos comportamentais ganharam significância e reconhecimento nas modelagens de transportes (Ettema, 1996; Arruda, 2000; Taco 2003; Arruda, 2005; Paiva Junior, 2006; Carvalho, 2013; Silveira, 2013, Souza e Loureiro, 2014).

Segundo Ortúzar e Willumsen (2011), as análises desagregadas, comumente usadas na modelagem comportamental, foram empregadas para suprir as falhas dos modelos tradicionais, como com foco na análise agregada. Os modelos comportamentais possibilitam a análise desagregada da realização das viagens, de modo a entender quais os fatores que explicam o comportamento de um indivíduo, família ou grupo no processo de tomada de decisão (Paiva Junior, 2006; Takano 2010; Souza e Loureiro, 2014).

A tomada de decisão está presente em todas as atividades humanas ao longo do tempo. A busca por melhores resultados deve conduzir a uma decisão mais satisfatória. Por este motivo, o processo decisório deve ser considerado de maneira particular, pois em função das decisões tomadas as consequências podem ser as mais variadas possíveis. De maneira a evitar uma tomada de decisão inconsciente, faz-se necessário entender o problema, bem como as diversas variáveis (características sociais, econômicas, entre outras) que fazem parte do processo (Rodrigues, 2013).

As pesquisas de viagem que envolvem estudos longitudinais (abordagens que analisam as variações dentro de uma mesma amostra em um intervalo de tempo) oferecem 
subsídios para o entendimento do comportamento individual no processo de tomada de decisão. Por meio dos estudos longitudinais, os pesquisadores encontram maior facilidade para compreender as alterações comportamentais e, assim, estabelecem as relações de causa e efeito entre as variáveis (Buck et al., 1995, Diggle et al., 2002; Hochman et al., 2005; Costa, 2014).

Assim, a avaliação temporal ao longo da trajetória do curso de vida do indivíduo é importante dentro dos estudos em comportamento, pois permite uma compreensão mais profunda sobre as relações entre as variáveis, destacando a importância de entender as necessidades e os desejos do indivíduo para cada situação (Lanzendorf, 2003; Hochman, 2005; Rodrigues, 2012; Costa, 2014). Segundo Carlindo (2008), as trajetórias de vida são as referências inapagáveis das experiências vivenciadas ao longo do processo de formação pessoal e profissional.

A teoria intitulada "Biografias de Mobilidade" (Lanzerdorf, 2003; Scheiner, 2012) apresenta uma abordagem comportamental que analisa as trajetórias do curso de vida do indivíduo, em uma análise longitudinal. A teoria assume a existência de eventos-chave que proporcionam mudanças consideráveis no comportamento de viagens e, consequentemente, no deslocamento individual.

Assim, com base nessa teoria, o comportamento individual pode ser explicado pela ocorrência de eventos específicos (chamados de eventos-chave) que causem significativas mudanças na forma como esse indivíduo planeja seus deslocamentos (Lanzerdorf, 2003; Scheiner, 2007; Lanzerdorf, 2010; 2015). Esses eventos-chave podem gerar mudanças na vida pessoal do indivíduo que, por consequência, desencadearão um processo de reconsideração do comportamento atual (Lanzerdorf, 2003). São exemplos de eventos-chave: a mudança residencial, primeiro emprego, situação do vínculo empregatício, retirada da carteira de motorista, nascimento do filho e outros acontecimentos que marcam e alteram a trajetória do curso de vida.

Entende-se que a teoria "Biografias de Mobilidade" enfatiza a importância de certos estágios e eventos no curso da vida individual e do domicílio para o comportamento de viagens (Lanzendorf, 2003; 2010; 2015). Dessa maneira, o direcionamento adotado na 
realização do estudo permeará a composição do domicílio, considerando a experiência familiar, de forma que o evento-chave a ser pesquisado seja o nascimento de criança.

Segundo Taco (2003), a inclusão das características individuais atreladas às características domiciliares alteram os comportamentos e as inter-relações entre os indivíduos, de modo que o domicílio influencia as decisões de realização de atividade e, consequentemente, das viagens. Apoia essa ideia Silva (2011), ao analisar o domicílio como unidade de tomada de decisão, ao verificar que a decisão individual pode ser influenciada pelos outros membros da família.

A composição do domicílio e a idade dos membros familiares afetam significativamente as atividades do indivíduo e as decisões referentes às viagens (Chapin, 1974; Jones et al., 1983; Pitombo, 2003; Taco 2003). A inter-relação entre os membros do domicílio determinam a agenda de atividades do indivíduo que, por sua vez, pode afetar a agenda de atividades de outro membro do domicílio (Arruda, 2010).

Com isso, a família e as outras estruturas sociais influenciam o comportamento dos indivíduos (Pitombo, 2003; Silva, 2006; 2011). Apontamentos realizados por Pitombo (2003), Silva (2006; 2011) e Arruda (2010) já evidenciaram que a presença de crianças pode influenciar a programação domiciliar, pois altera a rotina da família, uma vez que a realização de atividades da criança depende do encadeamento de viagem dos pais.

A influência nas decisões individuais (escolha do meio de transporte, aquisição de veículo, entre outras) sobre viagens são associadas ao contexto domiciliar, tanto que o ambiente familiar é uma variável relevante na análise de viagens. Em linhas gerais, ainda segundo Silva (2006; 2011), os indivíduos atuam dentro de um contexto familiar, repartindo as obrigações e dividindo as experiências com outros membros do domicílio (Arruda 2005; Coelho Jr. 2009; Timmermans et al., 2003; Takano, 2010; Silva, 2011), e a existência de crianças em um domicílio altera a rotina dos indivíduos que o compõem, sendo um evento relevante para estudos na área do comportamento de viagem individual.

A presente dissertação, fundamentada na Teoria "Biografias da Mobilidade" (Lanzendorf, 2003; 2010), pretende estudar a relação entre o comportamento de viagem 
individual e a ocorrência do nascimento de criança no domicílio, a partir de análises desagregadas.

\subsection{Pergunta de Pesquisa}

Qual a influência do evento-chave "nascimento de criança" no comportamento de viagem e na tomada de decisão, em relação à escolha do meio de transporte, em um domicílio no contexto das cidades brasileiras?

\subsection{Objetivos}

\subsubsection{Objetivo Geral}

Analisar o comportamento de viagem e a escolha do meio de transporte em um domicílio, a partir do evento-chave "nascimento de criança", tendo como base a teoria "Biografias de Mobilidade".

\subsubsection{Objetivos Específicos}

- Analisar como um evento-chave afeta o comportamento de viagem e a realização dos deslocamentos;

- Analisar a tomada de decisão quanto à escolha do meio de transporte em uma perspectiva de tempo longitudinal;

- Adaptar os instrumentos de pesquisa utilizados por Oakil (2013) e Lanzendorf (2010) para uma aplicação no cenário brasileiro.

\subsection{Justificativa}

Os estudos realizados por Mayer e Tuma, na década de 90, evidenciaram que a análise da trajetória do curso de vida pode ser melhor compreendida quando se estudam os eventos. Os apontamentos desses estudiosos propiciaram os estudos iniciais do alemão Martin Lanzendorf nas definições da teoria "Biografias de Mobilidade". 
Para Lanzendorf (2003), os estudos de eventos possibilitam uma nova perspectiva para o entendimento do comportamento de viagem dos indivíduos, pois a existência de eventos em determinado momento da vida altera consideravelmente o padrão de viagem diária ou as formas de se locomover. Para o pesquisador, a importância em analisar os eventos deve-se à possibilidade de explicar o comportamento das pessoas ao assumir que existem eventos nessas trajetórias que alteram certos momentos da vida do indivíduo de forma considerável.

Os apontamentos de Timmermans et al. (2003) também evidenciam a relevância de análise do evento e do incidente crítico (evento não planejado), pois algumas escolhas, como o meio de transporte, não são influenciadas apenas pelas decisões de planejamento, mas pela ocorrência de eventos ou incidentes críticos que alteram o comportamento de viagem, desencadeando um processo de reconsideração do comportamento atual.

A pesquisa de Klöckner (2004) ressalta que a análise dos eventos ao longo da vida oferece uma nova perspectiva quanto ao modo de viajar, inclusive ressalta que os estudos de eventos devem se concentrar no intervalo temporal da trajetória do curso de vida total dos indivíduos, pois os resultados mostraram uma considerável diferença nas reações dos indivíduos ao analisá-las na perspectiva do ciclo de vida (idades). Segundo a pesquisadora, a vida não é linear, isto é, há períodos de estabilidade e de mudanças repentinas, em que novas decisões precisam ser realizadas sobre as formas de locomoção.

Já os estudos de Frändberg (2006) não referenciam o estudo de Lanzendorf (2003), Timmermans et al. (2003) e nem Klöckner (2004), mas demonstram a importância de analisar os eventos em seus contextos sociais e históricos, pois fornecem importantes contribuições sobre os padrões de viagem e a compreensão dos fenômenos sociais.

Para Scheiner (2007), os eventos estão interligados entre si e não podem ser considerados isoladamente. Para o pesquisador, essa não é apenas uma questão de fundo teórico, mas que tem implicações práticas no desenvolvimento das pesquisas empíricas. Para reforçar essa ideia de interligação entre os eventos, observe o nascimento de crianças. Com a ocorrência desse evento, inevitavelmente outros eventos precisam ser considerados, como: obtenção da carteira de motorista, aquisição de veículo, mudança de emprego, movimentos residenciais, entre outros. 
Em 2010, Lanzendorf analisou o evento-chave nascimento de criança. O estudo teve como objetivo a análise da mudança e como estas mudanças se relacionaram com o comportamento de viagem após o nascimento dos filhos. Em seu estudo, o pesquisador verificou que os eventos que mais afetaram o comportamento de viagem foram o nascimento de crianças e a mudança residencial.

Ainda segundo o autor, o evento nascimento da criança é mais notável no comportamento de viagem das mulheres. Mesmo existindo diferenças entre elas, em geral, a maioria fica em casa e são as responsáveis pelos cuidados dos filhos, de forma a não continuar a sua carreira profissional. Inclusive os resultados mostram um contraste à crença comum de que o aumento da família, com a chegada da criança, contribui para a aquisição do carro.

Scheiner (2013) também verificou que o evento nascimento de criança apresenta uma maior representatividade para as mães. Porém, seus estudos mostraram que os modos mais utilizados são os veículos (as mães sendo motoristas) e a realização de caminhadas, confirmando que o bebê não precisa ser apenas conduzido por carro.

A relevância do nascimento de criança para Oakil (2013), é que este evento pode influenciar os indivíduos ou as famílias a reconsiderarem as possibilidades de ocorrência de outros eventos, como uma mudança residencial, ou decidir por outros modos de transportes. Consequentemente, as decisões para os deslocamentos geram impacto no comportamento de viagem.

Segundo Bhat et al. (2011), a influência familiar na escolha do meio de transporte para as decisões de deslocamento da criança pode influenciar outras crianças geograficamente próximas, através da interação e da observação das ações realizadas. Ainda segundo Bhat et al. (2012), pouco se sabe sobre os fatores que moldam as atitudes dos pais em relação aos filhos para se deslocar. Sabe-se que o ambiente sociodemográfico, as percepções dos pais, as restrições nos deslocamentos, entre outras coisas, desempenham um papel crucial na decisão de escolha do meio de transporte com os quais seus filhos se deslocarão.

As restrições nos deslocamentos de um indivíduo podem incluir, entre outras, a estrutura familiar, as tarefas diárias pertinentes a cada membro, os recursos financeiros disponíveis 
no domicílio, as restrições de tempo do indivíduo, o período de funcionamento dos estabelecimentos (Vespucci, 2014), as rotinas familiares (Silva, 2011) e as disponibilidades de modo de transporte (Arruda, 2000), de acordo com as atividades que precisam ser exercidas. (Kitamura et al., 1997; Freire, 2013).

Segundo Santos (2009 A), a estrutura familiar, em especial a infância, tornou-se o centro de discussão para o Estado, para as políticas não governamentais, para os representantes da ciência (psicólogos, antropólogos, historiadores, sociólogos, educadores), alcançando espaço, inclusive, nos meios de comunicação. Para Bhat (2014), os estudos de demanda de viagem que envolvem crianças, considerando a estrutura domiciliar, contribuem para o redesenho das políticas governamentais e facilitam a redução do conflito existente entre o trabalho e a família.

Dessa forma, verifica-se a importância de analisar a experiência individual quanto à tomada de decisão, entendendo as variáveis relacionadas à mobilidade no âmbito da estrutura familiar. Para isso, a análise do domicílio é importante, pois as atividades das crianças influenciam e afetam a organização da estrutura familiar.

O presente estudo pretende investigar essa área, numa perspectiva da teoria de "Biografias de Mobilidade" no cenário brasileiro. Certo de que, a partir do conhecimento mais aprofundado desta realidade serão possíveis melhores políticas e programas de fortalecimento às famílias com filhos, espera-se contribuir para a análise deste eventochave, ao verificar qual o comportamento de viagem e a influência na trajetória de vida de um indivíduo para a tomada de decisão.

É justamente quando se explora tais temáticas que existe a possibilidade do aprendizado quanto às questões socioeconômicas e a influência da estrutura familiar na produção de viagens, capturando os efeitos das interações temporais, muitas vezes não observadas, mas que potencialmente contribuem para a influência na decisão familiar.

Espera-se que essa investigação possa contribuir para melhores diretrizes às avaliações de políticas e outras intervenções sobre o comportamento de viagem, tendo como finalidade produzir subsídio para os formuladores de políticas e planejadores na 
implementação de meios sustentáveis para a realização dos deslocamentos (Lanzendorf, 2010).

Outra importante contribuição é a investigação acadêmica atribuída ao Grupo de Pesquisa “Comportamento em Transporte e Novas Tecnologias", vinculado ao Programa de PósGraduação em Transportes da Universidade de Brasília - PPGT/UnB. Dentre os vários estudos desenvolvidos pelo grupo de pesquisa, esse tem como objetivo contribuir com as discussões sobre a abordagem comportamental de viagem e a tomada de decisão quanto à escolha do modo de transporte para os deslocamentos, a partir da análise do eventochave.

Embora existam outros estudos de comportamento de viagem realizados de forma desagregada que permeiam outras teorias como o estilo de vida, ciclo de vida, comportamento planejado, entre outras, essa investigação é pertinente, pois não há registros até o momento da utilização dessa teoria em cenário brasileiro.

Deseja-se que este estudo desenvolva possibilidades futuras de aprimoramento e aprofundamento quanto à teoria "Biografias de Mobilidade". Entende-se que os resultados podem contribuir para as políticas públicas quanto às implementações a serem realizadas e nas pesquisas acadêmicas voltadas ao transporte e ao comportamento de viagem.

\subsection{Metodologia}

Para atender aos objetivos propostos, optou-se por um delineamento de pesquisa primária (Hochman, 2005), isto é, propõe-se um inquérito estruturado a ser aplicado aos indivíduos que tenham passado pelo evento-chave (Saks e Allsop, 2011). A pesquisa apresenta uma perspectiva à abordagem de uma teoria ao analisar um evento-chave, de tal forma que faz correlações importantes ao domicílio e à estrutura familiar, proporcionando descrições de novidades de maneira que enriqueça o conhecimento sobre o assunto (Bicas, 2008).

O nível da pesquisa é composto por dois estilos: estudo exploratório e descritivo. O primeiro, devido ao tema escolhido necessitar de desenvolvimento e esclarecimento de 
ideias e conceitos, pois é pouco explorado (Gil, 2012). O segundo, pelo objetivo de estudar as características de determinada população e a relação entre as variáveis (sociais, econômicas, escolha do meio de transporte, entre outras), pretendendo determinar a natureza dessa relação sem interferir na realidade, apenas interpretando e descrevendo os fatos (Deslandes et al., 2010; Gil, 2012; Silva 2015).

Ainda segundo Gil (2012), as pesquisas descritivas são, juntamente com as exploratórias, as que habitualmente são realizadas pelos pesquisadores sociais preocupados com a atuação prática. São também as mais solicitadas por organizações, instituições e empresas.

A abordagem utilizada nessa dissertação é a do tipo longitudinal (Diggle et al., 2002; Hochman, 2005; Costa, 2014), pois pretende analisar as variações de uma mesma amostra em um intervalo de tempo. Em pesquisas longitudinais, essa característica é possível, fato que difere das pesquisas transversais (Buck et al., 1995; Hochman, 2005; Bordalo, 2006).

A abordagem longitudinal é tipicamente observacional, e os estudos são dos tipos casecontrol, estudo de coorte, retrospectivo e prospectivo (Buck et al., 1995; Diggle et al., 2002). Para essa investigação, a etapa retrospectiva (Timmermans et al., 2003; Lanzendorf, 2010; Sheiner, 2012; Oakil, 2013) fará parte da composição do instrumento de pesquisa, pois, ao analisar a trajetória do curso de vida, verifica-se que existem datas significativas, marcadas por eventos específicos (casamento, nascimento de filhos, mudança no trabalho, divórcio) que acontecem com baixa frequência e são fáceis de serem lembradas com razoável precisão (Buck et al., 1995; Timmermans et al., 2003; Freitas, 2012; Lanzendorf, 2003, 2010, 2015). Segundo Lanzendorf (2010), em métodos retrospectivos, as vantagens de pesquisas qualitativas incluem uma visão passada sobre as mudanças de fatores em situações relevantes que foram tomadas. Já as desvantagens de serem levados à prática ocorrem devido à densidade dos questionários e pelas dificuldades no tratamento da informação (Ferrand, 1999).

A seguir, é apresentado o detalhamento deste processo metodológico de pesquisa por meio da Figura 1: 


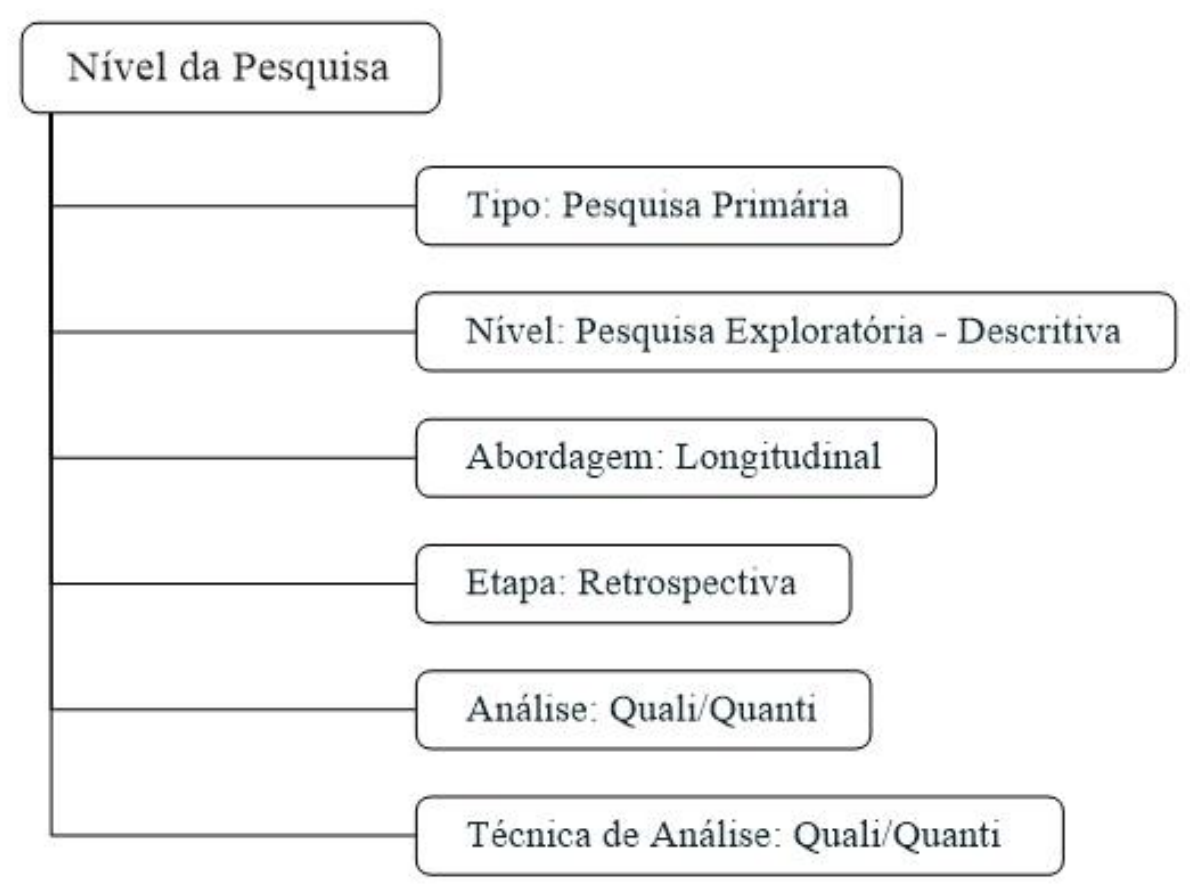

Figura 1- Detalhamento metodológico quanto ao nível da pesquisa Fonte: Elaborado pelo autor

Com a intenção de atingir a finalidade desejada, o instrumento de pesquisa será um questionário com abordagens retrospectivas e atuais. A coleta de dados ocorrerá em uma amostragem intencional (Triviños, 1987; Manzini 1990/1991; Deslandes et al., 2010), isto é, em domicílios localizados em território nacional, em que existam filhos que sejam dependentes dos pais e cujo primeiro filho tenha até 6 anos de idade.

A análise dos dados será realizada utilizando técnicas estatísticas conjuntamente a análises multivariadas. Das técnicas estatísticas, serão utilizados o teste de McNemar, teste de proporção, a média ponderada para escala likerd, além da estatística descritiva para levantamento de frequências. Quanto às análises multivariadas, serão utilizadas a análise por correspondência e análise de Cluster, conhecida também como a técnica de agrupamento. É uma ferramenta de classificação utilizada em diferentes grupos, que coliga segundo uma função conforme as semelhanças. A técnica possibilita um bom desempenho na análise de variáveis qualitativas e quantitativas ao mesmo tempo.

Já a análise por correspondência é bastante utilizada para dados categóricos. Sua utilização justifica-se devido à sua natureza técnica descritiva e exploratória, que simplifica dados complexos, além de detectar as relações entre os pares de variáveis 
(Czermainski, 2004). Outras vantagens encontradas que justificam as escolhas é que o Centro Interdisciplinar de Estudos em Transportes (CEFTRU) disponibiliza o programa, $\mathrm{o}$ acesso a tutoriais e facilita o apoio à pesquisa acadêmica.

Para alcançar o objetivo proposto, o método do trabalho científico desta pesquisa será dividido em três partes: a revisão bibliográfica da pesquisa exploratória, formulação e aplicação do método e análise dos resultados. Segue uma representação desta estrutura por meio da Figura 2:

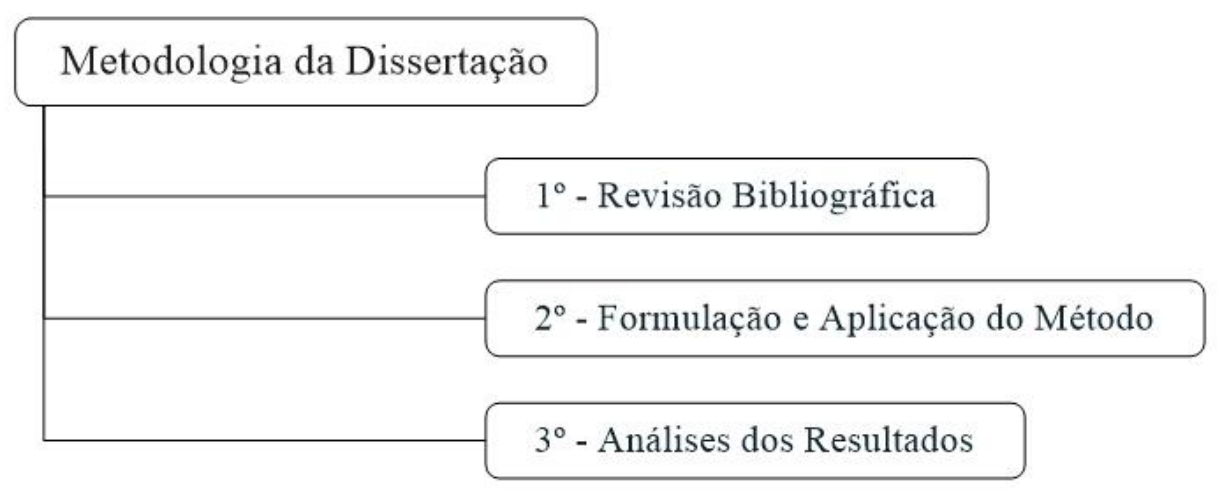

Figura 2 - Estrutura metodológica da pesquisa Fonte: Elaborado pelo autor

A primeira parte consiste no levantamento bibliográfico por meio de consultas a livros, sites de interesse, observatórios de pesquisas, teses, dissertações e estudos técnicos. Deverão ser consultados estudos nacionais e internacionais referentes às pesquisas comportamentais em transportes.

A segunda parte será a formulação e aplicação do método, e envolverá etapas como a delimitação da área de estudo, seleção da amostra, elaboração do instrumento de pesquisa, levantamento dos dados, método de análise e a análise dos resultados.

A terceira parte abrangerá os procedimentos de compreensão e interpretação dos dados. O objetivo desta parte é analisar os resultados do estudo.

\subsection{Estrutura da Dissertação}

O presente trabalho está dividido em cinco capítulos, a saber: 
Capítulo 1 - Este capítulo é a primeira parte do estudo, chamado de introdutório. Será apresentada a introdução, a pergunta de pesquisa, os objetivos, a justificativa, o procedimento metodológico a ser aplicado e a estrutura da dissertação.

Capítulo 2 - No segundo capítulo, é apresentada a revisão bibliográfica, onde serão levantados os estudos científicos que nortearão o desenvolvimento da pesquisa. Momento oportuno para revisitar as pesquisas já realizadas que abordaram o comportamento de viagem, a teoria "Biografias de Mobilidade" e as principais técnicas aplicadas a ela, além de elucidar outros conceitos decorrentes da teoria, como a influência dos eventos-chave no comportamento de viagem e domínio de vida.

Capítulo 3 - O terceiro capítulo é destinado à elaboração e aplicação do método. Ambos serão apoiados pelo referencial teórico e a busca de respostas aos objetivos estipulados.

Capítulo 4 - Este capítulo é dedicado à análise dos resultados e discussões realizadas. Os resultados obtidos têm a finalidade de validar a aplicação do método em relação ao alcance dos objetivos, bem como discussões acerca destes resultados.

Capítulo 5 - Este capítulo trata da conclusão. Serão apresentados os principais resultados obtidos, as considerações acerca das limitações do estudo, e as sugestões e recomendações para os estudos futuros que se sistematizam dentro do tema desenvolvido.

A seguir, uma representação desta estrutura por meio da Figura 3: 


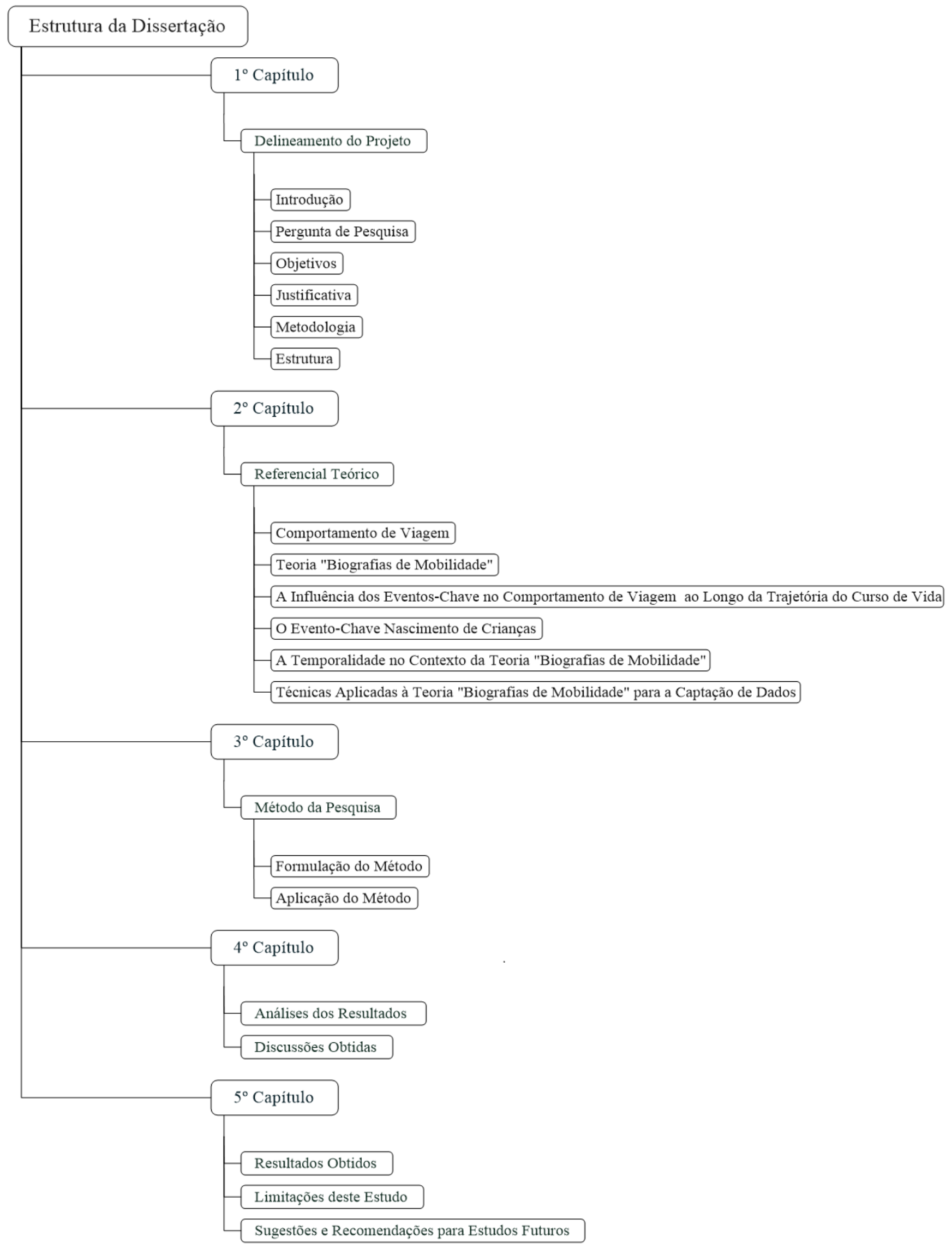

Figura 3 - Estrutura da dissertação Fonte: Elaborado pelo autor 


\section{REFERENCIAL TEÓRICO}

\subsection{Comportamento de Viagem}

Segundo Hagerstrand (1975), somente a partir da década de 70 os estudos de comportamento de viagem ganharam destaque. Os trabalhos realizados anteriormente tinham outra dimensão e eram examinados no nível macro, com dados agregados (Sheiner, 2007). As decisões eram tomadas tendo a infraestrutura como base para a tomada de decisão. As perspectivas de mudança nas análises ocorreram somente no início dos anos 70, com o reconhecimento da geografia espaço-temporal ao conceito do comportamento de viagem (Hagerstrand, 1975).

Essa mudança possibilitou a análise no nível individual (Sheiner, 2007), e as pesquisas começaram a ser examinadas a partir de dados desagregados. Consequentemente, uma melhor compreensão do comportamento de viagem, ao considerar aspectos individuais (idade, sexo, localização residencial, renda etc), proporcionou melhores resultados para sistemas de transportes sustentáveis (Lanzendorf, 2010).

Scheiner (2013) apresenta duas formas para se analisar o comportamento de viagem. Na primeira, o foco não está na interação dos eventos-chave ao longo da trajetória do curso de vida do indivíduo, mas sim no incentivo para a realização da viagem. Já a segunda tem o foco na abordagem da biografia de mobilidade, e se concentra na mudança do comportamento de viagem associada à ocorrência de eventos ao longo do curso de vida (Lanzendorf, 2003; Timmermans et al., 2003; Scheiner, 2007; Lanzendorf, 2010; Scheiner, 2014 A; Lanzendorf, 2015).

A ocorrência de eventos como as mudanças de localização residencial, local de trabalho e estudo e os locais de realização das atividades não mudam de forma repentina, mas ao acontecerem, podem alterar o comportamento de viagem que já se encontrava relativamente estável. Para os indivíduos que possuem comportamentos de viagens mais consolidados, a médio e longos prazos podem acontecer mudanças notáveis, que precisam ser aceitas, mesmo que forçosamente (falecimento de um familiar). Desse modo, tanto os compromissos a curto, médio e longo prazos estão sujeitos às mudanças em um determinado momento (Scheiner, 2007; 2013). 
As ocorrências de eventos afetam a trajetória do curso da vida e influenciam o comportamento de viagem (Lanzendorf, 2003; 2010; 2015). Porém, a influência no comportamento de viagem não é caracterizada somente pela ocorrência do evento, mas também pelas adaptações às circunstâncias (Scheiner, 2013), por exemplo, a opção por formas sustentáveis de mobilidade, entre outras.

Para uma melhor compreensão da influência no comportamento de viagem, Scheiner (2007) defende que os estudos de comportamento de viagem devem analisar os processos biográficos, que são caracterizados pelos eventos na biografia individual (ou doméstica) relacionados com a forma da mobilidade espacial. Ao analisar a biografia individual, os principais eventos são caracterizados pela formação familiar, nascimento de criança, separação, entre outros. Nessa mesma análise, na biografia de emprego, deve ser considerada a escolha de uma profissão ou a escolha de um local de emprego.

No tocante à forma da mobilidade espacial, os estudos de Lanzendorf (2003) enfatizaram uma abordagem mais ampla ao comportamento de viagem, não apenas voltada para as circunstâncias pessoais e as condições externas (tendências demográficas, avanços tecnológicos, melhorias das políticas) em um determinado ponto no espaço, mas também abordando os processos biográficos, para a compreensão de questões, relacionadas ao comportamento de viagem (Lanzendorf, 2003; Scheiner, 2007; 2013).

Embora as pesquisas de comportamento de viagem utilizem diferentes referenciais teóricos para investigar como os indivíduos se deslocam, um fator é comum a todas as teorias a atribuição de fatores comportamentais.

\subsubsection{Estudos nacionais que envolvem fatores comportamentais em pesquisas de transportes}

No âmbito das pesquisas nacionais voltadas aos estudos comportamentais, um dos primeiros trabalhos desenvolvidos buscou verificar a relação entre padrões de viagem encadeadas e características socioeconômicas (Ichikawa, 2002). O minerador de dados utilizado foi a árvore de decisão $(C H A I D)$. Os dados foram obtidos por uma pesquisa 
origem e destino, em 1987, na Região Metropolitana de São Paulo, realizada pelo METRÔ-SP. Como resultado, foi demonstrado que indivíduos que têm atributos de viagens e socioeconômicos semelhantes não se comportam de maneira similar nos padrões de viagens encadeadas.

Pitombo (2003) deu seguimento à proposta de Ichikawa (2002), tendo como objetivo a análise do comportamento individual de grupos homogêneos referente às características socioeconômicas e padrões de viagens encadeadas, envolvendo um número maior de atributos (modos de viagens utilizados, a sequência de atividades desempenhadas, o período do dia e o tempo de viagem). Através da mineração de dados, a pesquisadora utilizou a técnica da árvore de decisão com os recursos do software S-Plus 2000 como ferramenta de análise para estabelecer as relações entre os atributos de viagem e as características socioeconômicas associadas aos indivíduos. As análises realizadas compararam grupos específicos com determinadas características semelhantes e com apenas uma variável de diferenciação. Com isso, os resultados obtidos mostraram diferenças no comportamento de viagem relacionadas a algumas variáveis socioeconômicas, tais como estudo, trabalho, tamanho da família, sexo, idade, situação familiar, salário médio e número de automóveis.

Taco (2003) apresentou o resultado da aplicação de um modelo individual de geração de padrões de viagens, através de redes neurais artificiais (RNA), para reconhecer e reproduzir padrões de comportamento individual no encadeamento de viagens a pé. Os dados foram de uma pesquisa origem e destino, de 1987, realizada na Região Metropolitana de São Paulo, pelo METRÔ-SP. Segundo o autor, apesar dos resultados na classificação geral dos padrões serem abaixo do nível desejado, foi necessária uma avaliação da representatividade dos padrões que as redes reproduziram. Com isso, os padrões com maior frequência resultam nos de maior importância. Outra importante contribuição está no avanço do estudo de modelagem desenvolvido, de forma que os resultados oriundos passaram a fazer mais sentido quando conhecidos os comportamentos das variáveis utilizadas. Como sugestão, o autor diz que: "todo modelador deve ter um conhecimento profundo e sensibilidade a respeito das variáveis do modelo".

Sousa (2004) mostrou que os comportamentos dos viajantes urbanos são influenciados pelas políticas urbanas regionais e características socioeconômicas e espaciais da região. 
Utilizou-se da aplicação do minerador de dados Árvore de Decisão e Classificação, através do software S-Plus 6.1. A pesquisa apresentou a análise de três Pesquisas Origem e Destino realizadas na Região Metropolitana de São Paulo, pelo METRÔ-SP, em 1997; pela EMDURB, em 1997, na cidade de Bauru e pela JICA/Governo do Estado do Pará, na Região Metropolitana de Belém, em 2000.

Arruda (2005) abordou dois temas: os modelos baseados em atividades e as complexas inter-relações entre características do uso do solo. Ao analisá-los separadamente, verificase que frequentes pesquisadores abordaram os temas, porém o grande feito da pesquisadora foi interligá-los. O objetivo versou entre a modelagem baseada em atividade e as características do uso do solo nas decisões individuais sobre quais atividades e viagens realizar. Embora o estudo não tenha apresentado resultados conclusivos sobre a inter-relação transporte e uso do solo, trouxe contribuições à academia nos campos conceitual, metodológico e tecnológico. A análise é singular no estudo de transporte, inclusive, atualmente, ainda é a única aplicação direta no Brasil de um modelo baseado em atividades para a investigação das relações de uso do solo. Esse estudo serve de guia e incentivo para que outros pesquisadores aprofundem os conhecimentos nos modelos baseados em atividades para a modelagem da demanda em transportes.

Silva (2006) mostrou que o minerador de dados pode ser utilizado como uma ferramenta para a previsão dos padrões de viagens, inclusive sobre mudanças comportamentais dos indivíduos. Com o intuito de desenvolver o estudo, os dados foram obtidos através da Pesquisa Origem e Destino, na Região Metropolitana de São Paulo, nos anos de 1987 e 1997, pelo METRÔ-SP. O pesquisador aplicou a técnica da Árvore de Decisão, através do software S-PLUS 6.1. No final do estudo, o pesquisador concluiu que em 92,2\% das áreas analisadas, o minerador de dados pode ser utilizado como ferramenta para as previsões dos padrões de viagem.

Pitombo (2007) desenvolveu a pesquisa tendo como objetivo a análise do comportamento individual, no tocante ao encadeamento de viagem, sob a perspectiva de três tipos de variáveis: características socioeconômicas, participação em atividades e uso do solo. Os dados foram extraídos da Pesquisa Origem e Destino da Região Metropolitana de São Paulo, no ano de 1997. Para alcançar os resultados, a pesquisadora utilizou-se de técnicas de Análise Multivariadas. Os resultados mostraram que as variáveis socioeconômicas 
afetam os modos de transporte utilizados para a realização de viagens. Já as variáveis de participação em atividades interferem na sequência de motivos de viagem. E, por fim, as variáveis de uso do solo influenciam a sequência de destinos escolhidos. O estudo também contribuiu consideravelmente no meio acadêmico ao apresentar as influências de referidas variáveis no deslocamento dos indivíduos.

Takano (2010) analisou a influência da forma urbana no comportamento de viagem ao estudar o padrão do encadeamento de viagem. A pesquisadora utilizou-se da formulação de um modelo de regressão logística e analisou a influência no comportamento de viagem, tendo como base os padrões de encadeamento de viagem dos usuários de transporte público na avenida W3 Sul, situada no Plano Piloto, em Brasília - DF. Este estudo demonstrou que os usuários de transporte público, em sua maioria, tendem a realizar viagens pendulares e são pouco propensos ao encadeamento de viagens.

Silva (2011) propôs a verificação da condição entre a acessibilidade e o comportamento dos indivíduos referentes ao padrão de viagens. Em outras palavras, se a acessibilidade influencia o comportamento dos padrões de viagens encadeadas desempenhados pelos indivíduos. O estudo foi realizado na cidade de Uberlândia/MG. Os dados foram coletados em três diferentes fontes: Pesquisa Origem e Destino, por meio de pesquisas domiciliares, conduzida pela Universidade Federal de Uberlândia; dados sobre uso do solo, obtidos do Ministério do Trabalho e Emprego e, por fim, dados do sistema de transportes, obtidos pela UFU junto à prefeitura. O estudo contou com técnicas de modelagem do comportamento individual referentes às decisões sobre padrões de viagem. O resultado mostrou que há a influência do comportamento dos padrões de viagens encadeadas desempenhadas pelos indivíduos.

Silva (2013) identificou e entendeu como as diferentes formas de estilo de vida (idade, gênero, entre outros) influenciam a escolha do modo de transporte. Os dados coletados foram de abrangência nacional, sendo levantados pelo IPEA (2010), e identificam as tendências dos indivíduos quanto às decisões de mobilidade. $\mathrm{O}$ pesquisador utilizou-se da análise de classes latentes (LCA) e verificou que há uma relação na escolha do modo de transporte e no estilo de vida da população. 
Pelos estudos referidos, observa-se que o comportamento de viagem é resultante de um processo de tomada de decisão em que o indivíduo escolhe qual a melhor forma de se deslocar, segundo as suas características individuais, possibilidades econômicas, oportunidades disponíveis, motivações pessoais e fatores restritivos, tais como idade, gênero, posição no domicílio, espaço e tempo para a realização e participação de atividades.

Verifica-se que as pesquisas iniciais, desenvolvidas no cenário brasileiro, não apresentaram o termo comportamento de viagem, embora alguns estudos permearam por fatores comportamentais ao relacionar as variáveis socioeconômicas, estudos de demandas e realização de deslocamentos para enfocar padrões de viagem e atividade. $\mathrm{O}$ Quadro 1 apresenta alguns estudos nacionais, a partir de aspectos comportamentais em pesquisas de transportes. 
Quadro 1 - Pesquisas Nacionais

\begin{tabular}{|c|c|c|c|}
\hline \multirow[t]{2}{*}{ Autor, Ano } & $\begin{array}{l}\text { Estudos brasileiros que permeiam por fatores comportamentais em pesquisas de } \\
\text { transportes }\end{array}$ & \multirow[t]{2}{*}{$\mathbf{M} / \mathbf{D}$} & \multirow[t]{2}{*}{ Instituição / Local } \\
\hline & $\begin{array}{c}\text { Título } \\
\end{array}$ & & \\
\hline Arruda, 2000 & Integração dos modos não motorizável nos modelos de planejamento dos transportes & Mestrado & $\begin{array}{l}\text { Universidade Federal de São Carlos, } \\
\text { São Carlos - SP }\end{array}$ \\
\hline Ichikawa, 2002 & $\begin{array}{l}\text { Aplicação de minerador de dados na obtenção de relações entre padrões de encadeamento } \\
\text { de viagens codificadas e características sócio-econômicas }\end{array}$ & Mestrado & $\begin{array}{l}\text { Escola de Engenharia de São Carlos, } \\
\text { São Carlos - SP }\end{array}$ \\
\hline Pitombo, 2003 & $\begin{array}{l}\text { Análise do comportamento subjacente ao encadeamento de viagens através do uso de } \\
\text { minerador de dados }\end{array}$ & Mestrado & $\begin{array}{l}\text { Escola de Engenharia de São Carlos, } \\
\text { São Carlos - SP }\end{array}$ \\
\hline Taco, 2003 & $\begin{array}{l}\text { Redes neurais artificiais aplicadas na modelagem individual de padrões de viagens } \\
\text { encadeadas a pé }\end{array}$ & Doutorado & $\begin{array}{l}\text { Escola de Engenharia de São Carlos, } \\
\text { São Carlos - SP }\end{array}$ \\
\hline Sousa, 2004 & Análise Comparativa do encadeamento de viagens de três áreas urbanas & Mestrado & $\begin{array}{l}\text { Escola de Engenharia de São Carlos, } \\
\text { São Carlos - SP }\end{array}$ \\
\hline Arruda, 2005 & $\begin{array}{l}\text { Aplicação de um modelo baseado em atividades para análise da relação uso do solo e } \\
\text { transportes no contexto brasileiro }\end{array}$ & Doutorado & $\begin{array}{l}\text { Escola de Engenharia de São Carlos, } \\
\text { São Carlos - SP }\end{array}$ \\
\hline Silva, 2006 & $\begin{array}{l}\text { Verificação da aplicabilidade da técnica de mineração de dados na previsão da demanda } \\
\text { por transporte de passageiros urbanos usando dados da Região Metropolitana de São } \\
\text { Paulo }\end{array}$ & Mestrado & $\begin{array}{l}\text { Escola de Engenharia de São Carlos, } \\
\text { São Carlos - SP }\end{array}$ \\
\hline Junior, 2006 & $\begin{array}{l}\text { Segmentação e modelagem comportamental de usuários dos serviços de transporte } \\
\text { urbano brasileiros }\end{array}$ & Doutorado & $\begin{array}{l}\text { Escola Politécnica da Universidade de } \\
\text { São Paulo, São Paulo }\end{array}$ \\
\hline Pitombo, 2007 & $\begin{array}{l}\text { Estudos de relações entre variáveis socioeconômicas, de uso do solo, participação em } \\
\text { atividades e padrões de viagens encadeadas urbanas }\end{array}$ & Doutorado & $\begin{array}{l}\text { Escola de Engenharia de São Carlos, } \\
\text { São Carlos - SP }\end{array}$ \\
\hline Colella, 2008 & Comportamento dos motoristas em interseções semaforizadas & Mestrado & $\begin{array}{l}\text { Escola de Engenharia de São Carlos, } \\
\text { São Carlos - SP }\end{array}$ \\
\hline Deus, 2008 & $\begin{array}{l}\text { A influência da forma urbana no comportamento de viagens das pessoas: estudo de caso } \\
\text { em Uberlândia, MG }\end{array}$ & Mestrado & $\begin{array}{l}\text { Universidade Federal de São Carlos, } \\
\text { São Carlos - SP }\end{array}$ \\
\hline Baria, 2009 & $\begin{array}{l}\text { Percepção da sociedade e dos especialistas sobre os benefícios dos sistemas de } \\
\text { transportes públicos urbanos sobre trilhos }\end{array}$ & Mestrado & $\begin{array}{l}\text { Escola de Engenharia de São Carlos, } \\
\text { São Carlos - SP }\end{array}$ \\
\hline Santos, 2009 & $\begin{array}{l}\text { Análise da influência da variação espacial da oferta de um modo de transporte público } \\
\text { urbano no comportamento de viagem de seus usuários }\end{array}$ & Mestrado & $\begin{array}{l}\text { Universidade de Brasília, Brasília - } \\
\text { DF }\end{array}$ \\
\hline Terrabuio Junior, 2010 & $\begin{array}{l}\text { Análise da demanda por transporte coletivo em quatro cidades médias do Estado de São } \\
\text { Paulo }\end{array}$ & Mestrado & $\begin{array}{l}\text { Escola de Engenharia de São Carlos, } \\
\text { São Carlos - SP }\end{array}$ \\
\hline Moura, 2010 & Estudos dos impactos causados por pólos geradores de viagens na circulação de pedestres & Mestrado & $\begin{array}{l}\text { Universidade de Brasília, Brasília - } \\
\text { DF }\end{array}$ \\
\hline
\end{tabular}


Quadro 1 - Pesquisas Nacionais

\begin{tabular}{|c|c|c|c|}
\hline \multirow[t]{2}{*}{ Autor, Ano } & $\begin{array}{l}\text { Estudos brasileiros que permeiam por fatores comportamentais em pesquisas de } \\
\text { transportes }\end{array}$ & \multirow[t]{2}{*}{$\mathbf{M} / \mathbf{D}$} & \multirow[t]{2}{*}{ Instituição / Local } \\
\hline & Título & & \\
\hline Takano, 2010 & $\begin{array}{l}\text { Análise da influência da forma urbana no comportamento de viagens encadeadas com } \\
\text { base em padrões de atividades }\end{array}$ & Mestrado & $\begin{array}{l}\text { Universidade de Brasília, Brasília - } \\
\text { DF }\end{array}$ \\
\hline Leite, 2011 & $\begin{array}{l}\text { Análise do comportamento de viagens dos usuários de bicicleta em área rural: Estudo de } \\
\text { caso em área rural de Teresina }\end{array}$ & Mestrado & $\begin{array}{l}\text { Universidade de Brasília, Brasília - } \\
\text { DF }\end{array}$ \\
\hline Silva, 2011 & $\begin{array}{l}\text { Estudo da incorporação da acessibilidade à atividade na análise de demanda por viagens } \\
\text { encadeadas }\end{array}$ & Doutorado & $\begin{array}{l}\text { Escola de Engenharia de São Carlos, } \\
\text { São Carlos - SP }\end{array}$ \\
\hline Ferreira, 2012 & Análise dos padrões de viagens do idoso em relação ao transporte público & Mestrado & $\begin{array}{l}\text { Universidade de Brasília, Brasília - } \\
\text { DF }\end{array}$ \\
\hline Medrano, 2012 & Modelagem de padrões de viagens e expansão urbana & Mestrado & $\begin{array}{l}\text { Universidade de Brasília, Brasília - } \\
\text { DF }\end{array}$ \\
\hline Silva, 2013 & A influência do estilo de vida nas escolhas de transportes: uma análise de classes latentes & Doutorado & $\begin{array}{l}\text { Universidade de Brasília, Brasília - } \\
\text { DF }\end{array}$ \\
\hline Paiva, 2013 & Fatores que influenciam no uso da bicicleta de forma integrada com o metrô & Doutorado & $\begin{array}{l}\text { Universidade de Brasília, Brasília - } \\
\text { DF }\end{array}$ \\
\hline Andrade, 2013 & Sinistros de trânsito em fluxos de veículos que se cruzam em cruzamentos ortogonais & Mestrado & $\begin{array}{l}\text { Universidade de Brasília, Brasília - } \\
\text { DF }\end{array}$ \\
\hline Pinto, 2013 & Avaliação do comportamento de risco de motoristas no cenário brasileiro & Mestrado & $\begin{array}{l}\text { Universidade de Brasília, } \\
\text { Brasília - DF }\end{array}$ \\
\hline Santos, 2013 & $\begin{array}{l}\text { Viagem de lazer na cidade e teoria da atividade: uma abordagem sociohistórica em } \\
\text { comportamento para viagens }\end{array}$ & Doutorado & $\begin{array}{l}\text { Universidade de Brasília, Brasília - } \\
\text { DF }\end{array}$ \\
\hline Alves, 2014 & $\begin{array}{l}\text { O comportamento de viagens de acesso a aeroportos considerando a confiabilidade do } \\
\text { tempo de viagem }\end{array}$ & Doutorado & $\begin{array}{l}\text { Escola Politécnica da Universidade de } \\
\text { São Paulo, São Paulo - SP }\end{array}$ \\
\hline Vespucci, 2014 & Impacto dos Shopping Centers sobre os padrões individuais de atividades e viagens & Doutorado & $\begin{array}{l}\text { Escola Politécnica da Universidade de } \\
\text { São Paulo, São Paulo - SP }\end{array}$ \\
\hline Araujo, 2014 & A influência da infraestrutura cicloviária no comportamento de viagens por bicicleta & Mestrado & $\begin{array}{l}\text { Universidade de Brasília, Brasília - } \\
\text { DF }\end{array}$ \\
\hline Silva, 2014 & $\begin{array}{l}\text { Fatores de estresse para motorista e usuários do transporte coletivo do Distrito Federal e a } \\
\text { percepção de um em relação ao outro }\end{array}$ & Mestrado & $\begin{array}{l}\text { Universidade de Brasília, Brasília - } \\
\text { DF }\end{array}$ \\
\hline Velloso, 2014 & $\begin{array}{l}\text { Estudos dos Fatores Intrínsecos e ambientais que afetam o comportamento do condutor } \\
\text { em relação ao respeito à velocidade limite em vias urbanas }\end{array}$ & Doutorado & $\begin{array}{l}\text { Universidade de Brasília, Brasília - } \\
\text { DF }\end{array}$ \\
\hline
\end{tabular}


Quadro 1 - Pesquisas Nacionais

\begin{tabular}{|c|c|c|c|}
\hline \multirow[t]{2}{*}{ Autor, Ano } & $\begin{array}{l}\text { Estudos brasileiros que permeiam por fatores comportamentais em pesquisas de } \\
\text { transportes }\end{array}$ & \multirow[t]{2}{*}{$\mathbf{M} / \mathbf{D}$} & \multirow[t]{2}{*}{ Instituição / Local } \\
\hline & Título & & \\
\hline Pereira, 2015 & $\begin{array}{l}\text { Fatores viários que afetam a fiscalização eletrônica de avanço de sinal vermelho em } \\
\text { interseções urbanas }\end{array}$ & Mestrado & $\begin{array}{l}\text { Universidade de Brasília, Brasília - } \\
\text { DF }\end{array}$ \\
\hline Martins, 2015 & $\begin{array}{l}\text { Índice de avaliação da qualidade do transporte público por ônibus a partir da definição de } \\
\text { serviço adequado }\end{array}$ & Mestrado & $\begin{array}{l}\text { Universidade de Brasília, Brasília - } \\
\text { DF }\end{array}$ \\
\hline Bertazzo, 2016 & $\begin{array}{l}\text { Procedimento para estudo da escolha modal em viagens realizadas por estudantes de } \\
\text { instituições de ensino médio, mediado pela psicologia social }\end{array}$ & Doutorado & $\begin{array}{l}\text { Universidade de Brasília, Brasília - } \\
\text { DF }\end{array}$ \\
\hline Medrano, 2016 & $\begin{array}{l}\text { O modelo intencional de transporte: contribuições da ontologia de Bunge para } \\
\text { formalização da teoria de comportamento em transporte }\end{array}$ & Doutorado & $\begin{array}{l}\text { Universidade de Brasília, Brasília - } \\
\text { DF }\end{array}$ \\
\hline
\end{tabular}

Fonte: Elaborado pelo autor 


\subsection{Teoria "Biografias de Mobilidade"}

Os estudos desenvolvidos por Mayer e Tuma, na década de 90, contribuíram para um melhor entendimento da trajetória do curso de vida. Esses autores afirmam que, ao estudar o curso de vida, há o interesse de análise do evento, pois ao longo da vida ocorrem eventos que alteram a trajetória do curso de vida do indivíduo (Mayer e Tuma, 1990; Lanzendorf, 2003).

Apontamentos como os de Mayer e Tuma (1990), com abordagem da análise histórica de evento na pesquisa do curso de vida, possibilitaram os primeiros estudos do alemão Martin Lanzendorf nas acepções da teoria "Biografias de Mobilidade". O estudo trouxe uma nova perspectiva para o entendimento do tema ao apresentar as informações de que o comportamento das pessoas pode ser explicado por sua continuidade ao longo do tempo de vida e por eventos específicos que envolvem grandes mudanças em outros domínios da vida (Lanzendorf, 2003).

Para um melhor entendimento da teoria "Biografias de Mobilidade", o pesquisador Martin Lanzendorf modificou e adicionou uma dimensão temporal às trajetórias do curso de vida. Após esta reestruturação proposta por Lanzendorf em (2003), a teoria subdividese em três domínios de vida (estilo de vida, acessibilidade e mobilidade). A esses domínios foi adicionada a dimensão temporal, para demostrar que ao longo do tempo existem eventos que modificam o comportamento dos indivíduos. A Figura 4 ilustra essas subdivisões:

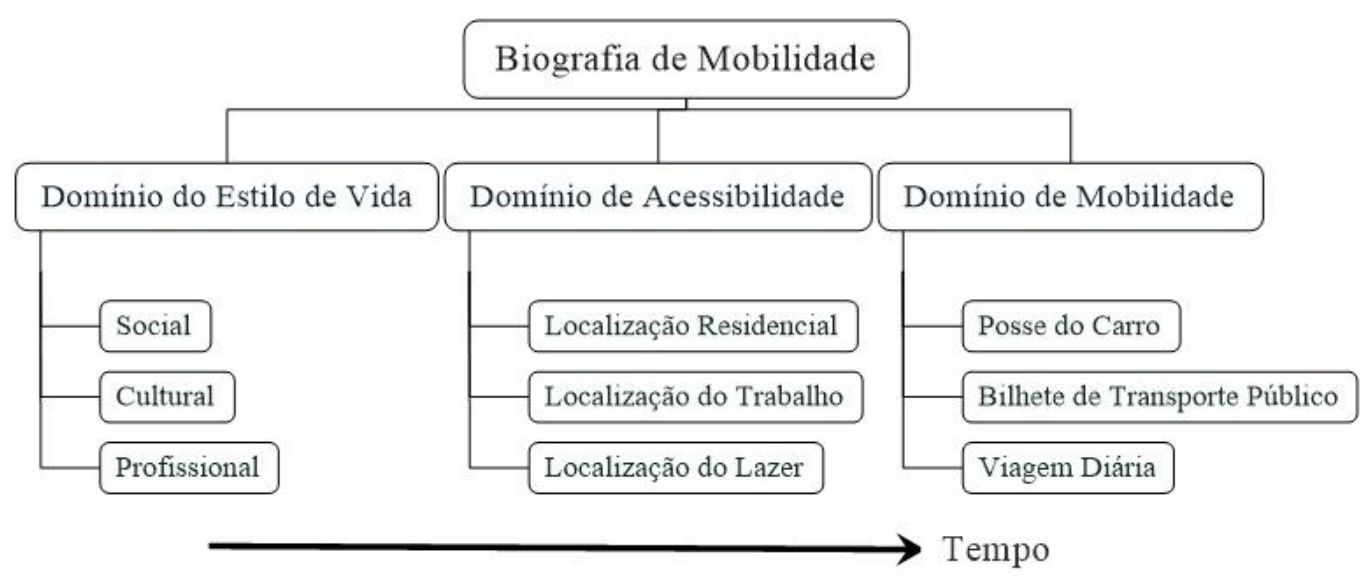

Figura 4 - Estrutura conceitual da teoria "Biografias de Mobilidade" Fonte: Adaptado de Lanzendorf (2003) 
A classificação realizada por Lanzendorf (2003) acontece da seguinte forma: primeiro, domínio do estilo de vida referindo-se aos subdomínios do ambiente social, cultural, político e profissional, por exemplo, a formação da família, o lazer e a carreira profissional; segundo, o domínio de acessibilidade, com a representação de localização residencial, do trabalho, do lazer ou outras atividades; e o terceiro, o domínio da mobilidade, com a disponibilidade de modos (propriedade do carro, bilhete para o transporte público). A estas estruturas hierárquicas, espera-se que o domínio do estilo de vida e de acessibilidade afetem a Biografia de Mobilidade, sendo que estes efeitos podem ocorrer de forma reversa também (Lanzendorf, 2003).

A teoria "Biografias de Mobilidade" refere-se à trajetória do curso de vida e assume que existem eventos que, em determinado momento na vida do indivíduo, alteram consideravelmente os padrões de viagens diárias ou as características de mobilidade (Lanzendorf, 2003; 2010).

O estudo de Frändberg (2006), apesar de não referenciar a teoria defendida por Lanzendorf (2003), ao descrever a abordagem dos métodos biográficos, concluiu que o uso de biografias de mobilidade fornece uma oportunidade para estudar as transições do curso da vida e suas implicações nas mudanças de comportamento de viagem. A pesquisa analisou os deslocamentos internacionais, de longa distância, de alunos suíços do último ano do ensino secundarista. Os estudantes relataram, através de pesquisas retrospectivas, as viagens internacionais realizadas durante a infância e a adolescência. Verificou-se que as viagens de longa distância são eventos raros para a maioria dos indivíduos e, consequentemente, fáceis de serem lembradas.

Ao analisar a vida destes indivíduos em seus contextos sociais e históricos, os métodos biográficos tiveram uma especial contribuição para a compreensão dos fenômenos sociais e forneceram importantes contribuições sobre os padrões de viagem. A abordagem biográfica estudada por Frädberg proporcionou novas formas de informações, que podem contribuir para uma melhor compreensão da mobilidade e do comportamento de viagem.

Já a abordagem teórica apresentada por Scheiner (2007) retornou à teoria defendida por Lanzendorf (2003). O termo "biografia de mobilidade" descreve o desenvolvimento da demanda de viagem, que inclui a demanda por carro ou outros meios de transporte, ao 
longo do curso de vida individual (Scheiner, 2007). Para o autor, a demanda de viagens, em um nível individual, é relativamente estável em médio prazo, porém, ao longo do curso de vida, há mudanças significativas nas ocorrências de certos eventos-chave. Estes eventos-chave são caracterizados pela mudança residencial, mudança de trabalho, nascimento dos filhos, entre outros.

Para Scheiner (2007), a teoria "Biografias de Mobilidade" é um campo do conhecimento empírico voltado para as pesquisas em transporte cujo processo está incorporado a outras biografias parciais (biografia residencial, biografia de emprego, biografia doméstica, entre outras). Ainda segundo o autor, existem as inter-relações entre a biografia de mobilidade e as biografias parciais, conforme pode ser analisado na Figura 5, que examina a relação de interdependência entre a biografia de mobilidade e as biografias parciais (biografia de emprego, biografia residencial, biografia doméstica). As biografias parciais podem afetar a biografia de mobilidade através dos eventos. Já na biografia de mobilidade, há uma distinção entre a disponibilidade do meio de transporte (escolha do modo de viagem e a observação da rotina) e o comportamento de viagem (Scheiner, 2007).

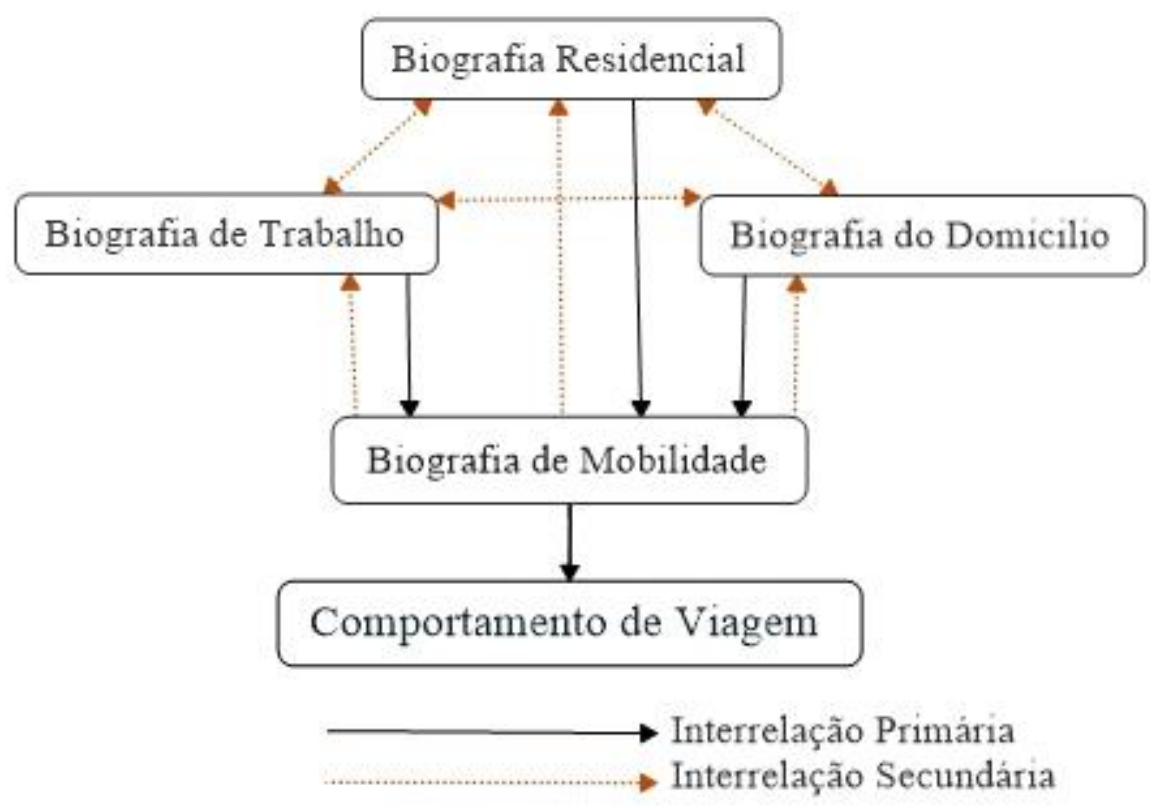

Figura 5 - Modelo de inter-relações entre as biografias Fonte: Adaptado de Scheiner (2006) 
As análises desses processos (biografia de mobilidade e biografias parciais) proporcionam desafios substanciais para os estudos de comportamento de viagem. Segundo Scheiner (2007), os conhecimentos empíricos obtidos justificam os esforços empregados, pela complexidade de captação e análise dos dados longitudinais, pois a teoria oferece o suporte necessário para o entendimento da mobilidade através das análises do comportamento de viagem. Ainda segundo o autor, as pesquisas realizadas têm apresentado resultados satisfatórios na análise da demanda de viagem.

Para Scheiner (2007), a importância da teoria está no levantamento de novas questões, que consequentemente permitem uma visão profunda no estudo da demanda de viagem. Outra relevância é referente à sensibilidade dos grupos populacionais às opiniões políticas, quanto à análise do impacto para a mudança de comportamento. Ainda segundo o autor, as mudanças no comportamento de viagem são um indicador importante para a quebra do hábito, e as mudanças na demanda de viagens não ocorrem de forma arbitrária, mas apresentam certa relação com importantes eventos-chave ao longo da trajetória do curso de vida. Então, para um melhor entendimento destas questões, a teoria possibilita uma nova visão, de forma substancial, para a compreensão do comportamento e da demanda de viagem e suas respectivas mudanças (Scheiner, 2007).

Outra relevante contribuição da teoria é a análise das inter-relações entre as biografias parciais em relação a uma série de eventos-chave biográficos (Scheiner, 2007; Oakil 2013). Estas inter-relações entre as biografias (Scheiner, 2007) e os eventos (Oakil 2013) no estudo da demanda de viagem podem fornecer diretrizes para o entendimento da mobilidade nos diferentes grupos populacionais. Scheiner (2007) confirma esta ideia ao verificar que há poucas pesquisas sobre a biografia doméstica no tocante à demanda de viagem. O tema é relativamente novo e tem recebido pouca importância nas análises de comportamento de viagem (Oakil 2013).

Para Scheiner (2007), numa primeira análise, a percepção que se tem da teoria é uma pesquisa de abordagem individualista, como se a biografia "pertencesse a um indivíduo". No entanto, ao ampliar essa análise para outras condições externas, esta percepção é alterada. Para ele, essas condições externas não podem ser analisadas num nível individual, sujeitas a mudanças ao longo do curso de vida, como por exemplo, a indisponibilidade de carro após um processo de divórcio. Pelo contrário, as condições 
externas referem-se a tendências demográficas (por exemplo, aumento no número de divórcios, incremento da participação da mulher no mercado de trabalho, maior taxa de natalidade em classes econômicas mais baixas), aos avanços tecnológicos e às condições de melhoria das políticas para toda a população, tal qual no desenvolvimento da telecomunicação, que possibilitou um potencial aumento da separação espacial entre o trabalho e a residência.

Para Lanzendorf (2010), um dos objetivos principais da abordagem biografia de mobilidade é enfatizar a importância de certos estágios e eventos na trajetória do curso da vida individual e do domicílio (familiar) para o comportamento de viagem. Dessa forma, o termo biografia de mobilidade refere-se à trajetória do curso de vida, que está diretamente relacionada ao comportamento de viagem individual, tais como a posse do carro, aquisição da carteira de motorista, a disponibilidade de bilhete para utilização do transporte público, entre outros.

Ainda para o autor, a trajetória do curso de vida pode apresentar um período de relativa estabilidade, porém um evento chave pode mudá-la (nascimento de uma criança, por exemplo). A partir deste evento, verifica-se a necessidade de reorganização, pois uma série de tarefas passará a existir. Em geral, em famílias tradicionais, a mulher faz uma pausa na sua carreira profissional, pouco antes e durante algum tempo após o parto. Já, o homem, em geral, continua sua carreira profissional. Porém, ao longo desse período, evidentemente eles precisam se reorganizar e adaptar-se aos padrões de atividade e viagem para a necessidade do recém-nascido (Lanzendorf, 2010).

Os estudos de Franke (2004) e Lanzendorf (2010) sugerem uma hipótese geral para a Biografia de Mobilidade: que a teoria seja semelhante a um funil, isto equivale dizer que, ao longo da vida, os jovens têm mais disponibilidade de opções para as realizações de escolhas e, gradativamente, ao longo dos anos, com o aumento das faixas etárias, estas opções diminuem consideravelmente. Com isso, as ocorrências de eventos devem diminuir, devido à estabilidade de escolhas e realizações das alternativas (Franke, 2004; Lanzendorf, 2010). Lanzendorf (2003) já havia comentado essa particularidade, quando estudou as idades e os efeitos da geração, classificando essa característica como um efeito de geração. 
Para Lanzendorf et al. (2015), outro objetivo da biografia de mobilidade consiste na integração entre os eventos, as decisões de mobilidade individuais e o contexto das escolhas ao se analisar o domínio de vida dos indivíduos. Esta abordagem introduz uma nova perspectiva no estudo do comportamento de viagem (Lanzendorf, 2003). Além disso, procura traçar a inter-relação entre essas escolhas com os principais eventos ao longo do curso de vida do indivíduo (Lanzendorf, 2015).

Dessa forma, o presente estudo está fundamentado na teoria "Biografias da Mobilidade" (Lanzendorf, 2003; 2010; 2015), e pretende estudar a relação entre o comportamento de viagem no domínio do estilo de vida, ao analisar o subdomínio social a partir da composição do domicílio, levando em consideração a estrutura familiar e o evento-chave nascimento de criança, conforme ilustrado na Figura 6. Pretende-se analisar a teoria referida na busca por aprendizado quanto às questões socioeconômicas e a influência da estrutura familiar na produção de viagens, levando em consideração as interações temporais, muitas vezes não observadas, mas que potencialmente contribuem para a influência na decisão familiar.

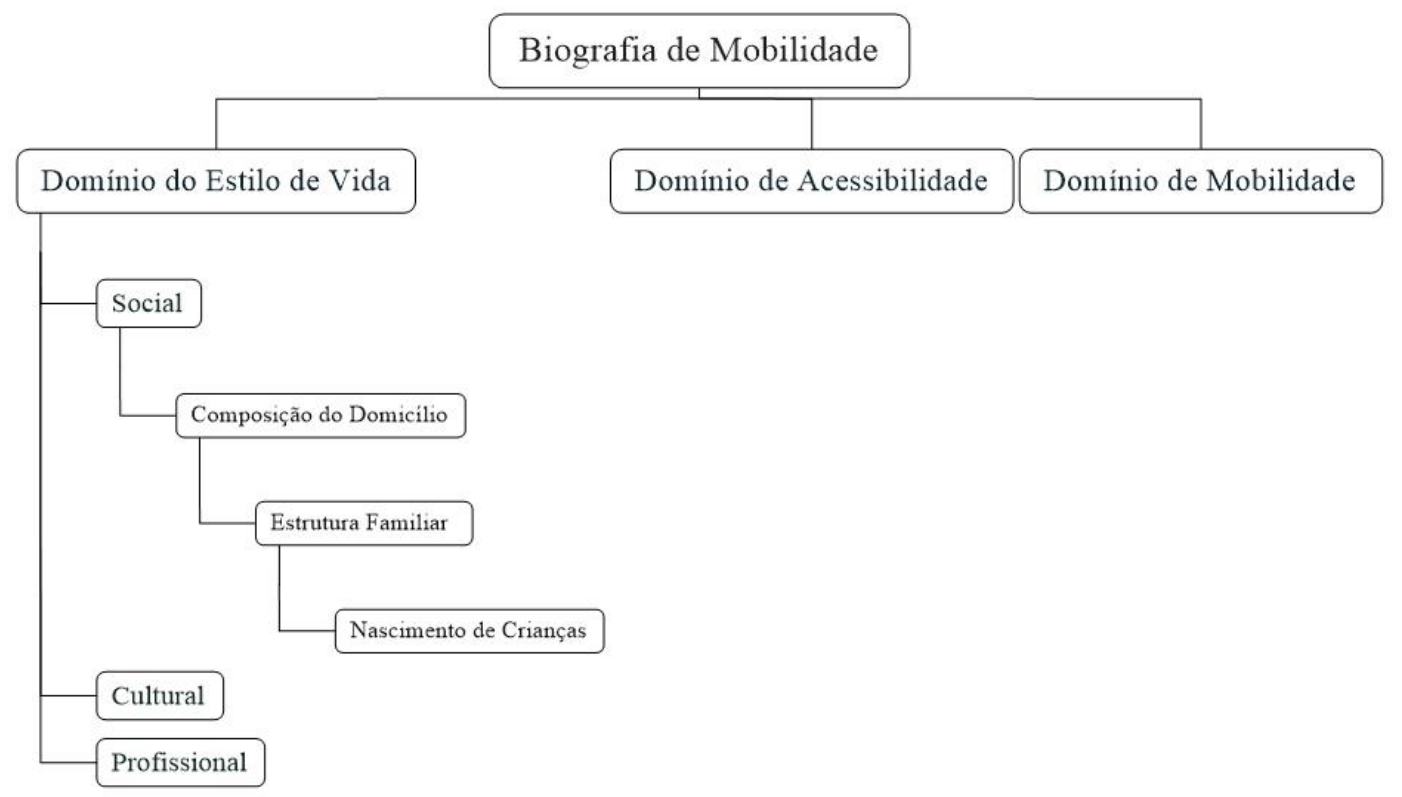

Figura 6 - Estrutura conceitual da teoria "Biografias de Mobilidade" aplicada ao evento-chave nascimento de crianças

Fonte: Elaborado pelo autor

Sabe-se que houveram outras formas de analisar semelhantes questões, independente da teoria utilizada. Entende-se que cada indivíduo tem seus desejos, necessidades e obrigações, e precisa realizar viagens para executar as atividades, por isso a importância 
de analisar os aspectos individuais e comportamentais à luz de uma teoria que melhor compreenda como os indivíduos são afetados e decidem se locomover, na interação com as alternativas de escolha de transporte e mobilidade.

\subsection{A Influência dos Eventos-Chave no Comportamento de Viagem ao Longo da Trajetória do Curso de Vida}

Para Lanzendorf (2003), os eventos podem influenciar as mudanças de hábitos de viagem, sendo que os hábitos são os responsáveis pela parte principal do comportamento de viagem. O comportamento habitual pode sofrer alterações ao longo do tempo, em algumas circunstâncias de forma imediata ou num tempo defasado, como acontece com alguns eventos ao longo do curso de vida. Dessa forma, a importância em analisar os eventos deve-se à possibilidade de explicar o comportamento das pessoas ao assumir que existem eventos nessas trajetórias que alteram certos momentos da vida do indivíduo de forma considerável (Lanzendorf, 2003).

Os estudos de Timmermans et al. (2003) também ressaltam a importância de análise do evento, pois a escolha do modo de transporte não é influenciada apenas pelas decisões de planejamento, mas pela ocorrência de eventos que alteram o comportamento de viagem. No estudo, o autor apresenta uma distinção entre os termos "Evento-Chave" e "Incidente Crítico". O evento-chave seria a ocorrência de uma grande mudança na vida pessoal que vai desencadear um processo de reconsideração do comportamento atual, como, por exemplo, a aquisição da carteira de motorista. Já o incidente crítico seria um evento com grande impacto sobre a atitude do indivíduo, algo inesperado ou não planejado, como o envolvimento em um acidente.

A pesquisa foi realizada com 173 entrevistados, que relataram 309 eventos e incidentes críticos que mais influenciaram seu comportamento na escolha do modo. O estudo apresentou três questionamentos específicos: como os eventos-chave e os incidentes críticos influenciam as características e a quantidade de alternativas de modos num conjunto de escolhas? Como os eventos-chave e os incidentes críticos influenciam as atitudes das pessoas nas alternativas de modos disponíveis? E, por fim, como os eventos- 
chaves e os incidentes críticos influenciam a escolha do modo de transporte? (Timmermans et al., 2003).

Os resultados mostraram a influência dos eventos-chave e dos incidentes críticos no comportamento de viagem dos indivíduos, sendo os mais frequentes: a mudança de um lugar para outro, início da carreira profissional, mudança na situação do trabalho, aquisição da carteira de motorista e a compra do carro. $\mathrm{O}$ estudo apontou, ainda, que uma possível mudança nas alternativas de transporte muda a atitude de escolha do modo. Por fim, as características pessoais (sexo, idade, profissão e nível educacional), de infraestrutura, sistema de tráfego, condições meteorológicas e segurança influenciam decisivamente a opção de escolha do modo (Timmermans et al., 2003), conforme pode ser verificado na Figura 7.

Evidencia-se que alguns estudos de comportamento de viagem apresentam análises de fatores situacionais, pessoais e culturais, como hábito, atitudes, motivação, as características psicológicas, preferências, percepção, entre outros. A pesquisa de Timmermans et al. (2003) evidenciou aspectos como alternativas e atitudes, inseridas no universo das características pessoais e outras características.

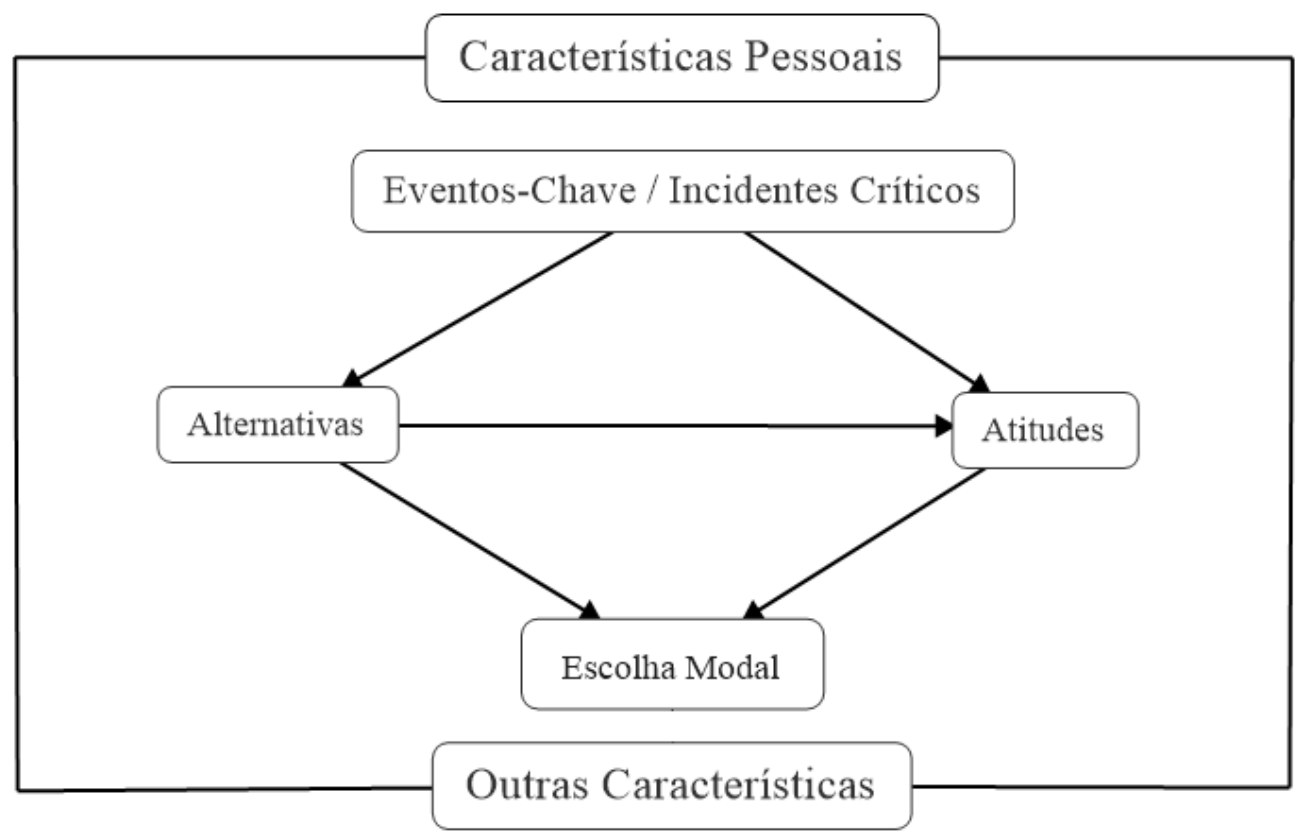

Figura 7 - Modelo conceitual de eventos-chave e incidentes críticos Fonte: Timmermans et al. (2003) 
Klöckner (2004) realizou um estudo exploratório para testar quais são os eventos que influenciam nas escolhas do modo de viagem. Essa pesquisa foi realizada com 91 participantes germânicos, com idades entre 19 e 62 anos. Os resultados identificaram que eventos como mudança para uma nova cidade, o início da vida escolar, aquisição da carteira de motorista, mudança para a o ensino médio, compra do primeiro carro e o início das atividades profissionais foram os eventos mais reportados nos questionamentos desta pesquisa. Numa análise mais detalhada, o estudo revelou uma coincidência entre os participantes com idade de 25 a 26 anos: para eles, os eventos da vida como ir morar com o parceiro, o nascimento do primeiro filho, início do primeiro emprego e a compra de um carro influenciam fortemente a escolha do modo de viagem (Klöckner, 2004).

As ocorrências de eventos como mudança (residencial e de trabalho), acidente, doença, nascimento dos filhos, entre outros, quebram as rotinas habituais e forçam os indivíduos a se reorganizarem. Para Klöckner (2004), a abordagem dos eventos de vida pressupõe que a vida não é um fluxo constante de experiência, isto é, a vida não é linear. Há períodos de estabilidade, que proporcionam o desenvolvimento de hábito, porém, há mudanças repentinas, em que novas tomadas de decisões precisam ser realizadas, ocasionando outras perspectivas sobre as formas de locomoção (Klöckner, 2004).

Esse estudo exploratório conclui que a análise dos eventos na trajetória do curso da vida oferece uma nova perspectiva quanto ao modo de viajar. Ressalta que a modelagem comportamental, ao analisar os eventos, deve concentrar-se no intervalo temporal da trajetória do curso de vida total dos indivíduos, pois os resultados mostraram uma considerável diferença ao analisar as reações de jovens adultos (por volta dos 35 anos) e das pessoas idosas. Além disso, os subgrupos podem reagir de forma totalmente diferente para o mesmo evento da vida. Por fim, o estudo sugere a realização de novas pesquisas, para melhor detalhamento de como os eventos da vida influenciam o comportamento dos indivíduos (Klöckner, 2004).

O estudo de Heine e Mautzs (2004), realizado no Reino Unido, mostra que os fatores que determinam a aquisição ou a troca de automóveis são menores para os adultos solteiros e famílias onde o chefe é uma mulher, mas aumentam com a renda, o número de adultos, o número de empregados e o número de filhos. Reforça essa ideia a análise de Scheiner (2007), ao expressar que a biografia doméstica desempenha um papel importante para a 
motorização das famílias, inclusive ao afirmar que a motorização em um domicílio muda consideravelmente com o aumento ou a redução no número de familiares. Ainda para o autor, com a chegada do primeiro filho, a dependência do carro fica mais intensa para as mães, e com o segundo, torna-se indispensável. Com isso, a aquisição de um segundo veículo ou a utilização do transporte público pelo pai fazem-se necessárias.

Segundo Scheiner (2007), os eventos estão interligados entre si e não podem ser considerados isoladamente. Para as pesquisas que analisam os eventos na perspectiva da teoria de "Mobilidade de Biografias", esta não é apenas uma questão de fundo teórico. Pelo contrário, tem implicações práticas no desenvolvimento das pesquisas empíricas. Para reforçar a ideia de interligação entre os eventos, deve ser observada a demanda de viagem nas relações entre a biografia individual e a mobilidade espacial: para analisar o evento nascimento de crianças (Lanzendorf, 2010), precisam ser considerados eventos como a aquisição de veículo (Klöckner, 2004), os movimentos residenciais (Oakil, 2013), entre outros eventos.

Para elucidar melhor a importância dos eventos relacionados às biografias parciais e sua influência no comportamento de viagem, o estudo de Scheiner (2007) apresenta uma divisão em três categorias, conforme o Quadro 2:

Quadro 2 - Biografias Parciais e Eventos-Chave

\begin{tabular}{|l|l|l|}
\hline Biografia Individual & Biografia de Emprego & Mobilidade Espacial \\
\hline Saída da residência dos pais & Entrada no mercado de trabalho & Tirar a carteira de motorista \\
\hline $\begin{array}{l}\text { Formação de família } \\
\text { (casamento) }\end{array}$ & $\begin{array}{l}\text { Entrada ou formação } \\
\text { universitária }\end{array}$ & Compra do veículo \\
\hline Nascimento de Criança & Mudança de emprego & Venda do veículo \\
\hline Divórcio & Aposentadoria & Movimento Residencial \\
\hline
\end{tabular}

Para Scheiner (2007), essas categorias podem ser entendidas como momentos biográficos-chave que estão ligados a determinados eventos. Lanzendorf (2003) já havia identificado alguns desses eventos e analisado a relevância no estudo em transporte ao relacioná-los à trajetória do curso da vida. 


\subsection{O Evento-Chave Nascimento de Crianças}

Ao analisar diferentes contextos socioeconômicos que vivem em áreas urbanas, Ferrinho e Craveiro (2011) observaram que as representações nem sempre são coincidentes entre as mulheres, no que diz respeito à fecundidade e às necessidades e formas de utilização dos cuidados de saúde reprodutiva. Há uma imprecisão em quantificar qual a idade ideal para ter filhos. Nos dias atuais, quando há planejamento familiar, essa decisão vem sendo tomada após algumas condições, como: estabilidade financeira do casal, finalização dos estudos, aquisição da casa própria, entre outras.

Porém, Cockerham (1988) verifica que os pobres são mais imediatos nas suas ações. Mas, o que se observa, inclusive nos estudos de Whitehead e Szelag (2000), é que as atitudes e decisões num mesmo grupo cultural e étnico nunca são homogêneas.

Em 2010, Lanzendorf analisou o evento-chave nascimento de criança na cidade de Leipzig, na Alemanha. Ao analisar 20 domicílios com crianças com menos de 6 anos de idade, foi realizada uma entrevista retrospectiva com 16 mães e 4 pais. O objetivo deste estudo foi analisar as mudanças e como estas se relacionaram e influenciaram o comportamento de viagem após o nascimento dos filhos. Nas 20 entrevistas realizadas, foram levantados 164 eventos-chave. Desses eventos, a mudança residencial e o nascimento de crianças foram os eventos que mais afetaram o comportamento de viagem.

Em Leipzig, os estudos de Lanzendorf (2010) observaram um contraste à crença comum que o nascimento de crianças, ou seja, o aumento da família, favorece a aquisição do carro. Nessa pesquisa qualitativa, desenvolvida através de um diário de viagem e uma entrevista estruturada, foi verificado que houve redução na utilização do carro e outras pessoas passaram a utilizá-lo com pouca frequência. Verificou-se, também, que mesmo após o nascimento da criança as mães não sentiram a necessidade de adquirir a carteira de habilitação, inclusive optando por realizar os deslocamentos através de bicicleta, bonde, transporte público ou sendo passageiras em veículo automotivo.

Ainda segundo o autor, os efeitos do nascimento de criança no comportamento de viagem das mulheres são notáveis, conforme evidenciado também nos estudos de Heine em (2001). Há diferenças entre elas, mas a maioria das mães entrevistadas não continua com 
a sua carreira profissional depois do nascimento do primeiro filho. Em geral, elas ficam em casa, como as responsáveis pelos cuidados dos filhos e manutenção do lar, ou trabalham meio período (Heine, 2001; Lanzendorf, 2010).

Os resultados de Heine em 2001 mostram que nos domicílios que possuem apenas um carro, em geral, as mães assumem a posse do veículo e seus parceiros passam a utilizar o transporte público ou vão de bicicleta para o trabalho. Já os resultados de Lanzendorf (2010) mostram um contraste à crença comum de que o aumento da família, com a chegada da criança, contribui para a aquisição do carro. Algumas mães reduziram o uso de carro e outras passaram a usar com pouca frequência, tanto antes como depois do nascimento da criança.

Scheiner (2013), ao estudar as alterações quanto ao modo de viagem de um ano para o outro, utilizou a base de dados da "German Mobility Panel (GMP) 1994-2008”, em que famílias e seus membros são convidados a responder um diário de viagem, durante três anos consecutivos em três intervalos de tempo distintos. $\mathrm{O}$ autor verificou que o evento nascimento de criança apresenta uma maior representatividade para as mães. Os modos mais utilizados são os veículos (as mães sendo motoristas) e a realização de caminhadas. Esta informação confirma as expectativas de que o bebê não precisa ser apenas conduzido por carro. Os resultados apresentaram uma diminuição em todos os modos, mas foi significativa no uso da bicicleta, possivelmente por fatores socioeconômicos (educação), aquisição da carteira de motorista e posse de carro. As mudanças são fortemente de gêneros, pois, para os pais, o evento nascimento de criança não parece ter um efeito sobre o uso dos modos, exceto na utilização do ciclismo e do transporte público.

O estudo de Oakil (2013) afirma que a ocorrência de determinados eventos na trajetória de vida pode influenciar os indivíduos ou as famílias a reconsiderar a possibilidade de uma mudança residencial ou optar por outros modos de transporte. Alguns eventos como a troca de emprego (Lanzendorf et al., 2015), posse do carro, localização residencial (Scheiner, 2012; Oakil, 2013), nascimento do filho (Klöckner, 2004; Lanzendorf, 2010; Scheiner 2014 A) e aquisição da carteira de motorista (Klöckner, 2004) influenciam a trajetória de vida (Lanzendorf, 2003; Scheiner, 2007). Consequentemente, as decisões para os deslocamentos geram impacto no comportamento de viagem, em especial no modo de alterar as decisões de escolhas (Lanzendorf et al., 2015). Dessa forma, ao 
analisar os eventos e os seus impactos sobre os padrões diários de atividade e de viagem, há uma significativa contribuição para a mudança no foco da análise baseada em atividade e nos padrões de viagem ao longo de vários horizontes temporais (Oakil, 2013).

Para Oakil (2013), são relevantes as pesquisas que estudam os eventos no ciclo de vida para a compreensão das dinâmicas dos padrões de atividade e viagem. Porém, o autor aponta a existência de algumas lacunas nos estudos realizados. Em primeiro lugar, as pesquisas não apresentaram uma abordagem detalhada das dependências temporais interrelacionadas à trajetória de vida e às decisões de mobilidade. As abordagens analisam associações temporais, com defasagens nas respostas, e assumem que eventos anteriores podem influenciar as decisões futuras, mas ignoram a possibilidade de um comportamento proativo e as várias dependências temporais em um único evento.

Para exemplificar, Oakil (2013) avalia eventos como a mudança residencial e a posse do carro. Estes eventos podem acontecer simultaneamente ou em tempos diferentes, dependendo das características do chefe de domicílio. Em segundo, as análises das mudanças de modos de transporte, em relação à trajetória de vida, são raras. Embora seja compreensível que as decisões na trajetória de vida, tais como mudança residencial e a troca de trabalho, podem ter implicações nas decisões de mudança de modo.

No âmbito das pesquisas nacionais, há alguns estudos apoiados pelas teorias do ciclo de vida e estilo de vida. O mais antigo, desenvolvido por Takano (2010), versa com uma contribuição ao estudo da teoria do estágio no ciclo de vida e a análise da influência da forma urbana no comportamento de viagens, tendo como unidade de análise o padrão de encadeamento de viagem. Como resultado, descobriu-se que a maioria dos usuários realizam viagens pendulares e são pouco propensos a encadearem as viagens. Já o outro estudo, feito por Silva (2013), identificou como as diferentes formas de estilos de vida (idade, gênero, entre outros) influenciam a escolha do modo de transporte.

As pesquisas de Chatterjee et al. (2014) utilizaram uma representativa base de dados da população do Reino Unido, os quais foram extraídos da UK House Longitudinal Study (UKHLS) juntamente com os dados locais espaciais do Census e de outras fontes de dados. Os dados possibilitaram a análise do contexto espacial e as mudanças do comportamento de viagem em associação com os eventos da vida. Os resultados 
apresentam que as mudanças no comportamento de viagem são mais possíveis de acontecer em momentos de transição do que em circunstâncias estáveis. A conclusão de uma análise exploratória evidenciou uma forte associação entre a mudança na posse do carro e a mudança dos modos de transporte, com os seguintes eventos da vida: mudança residencial, mudança de emprego, mudanças na estrutura familiar, aposentadoria e o nascimento de crianças. Porém, em curto prazo, o evento nascimento de criança não representou uma influência significativa na aquisição de um carro.

Ao estudar as mudanças nos padrões de atividades e viagem ao longo do tempo, a partir de uma perspectiva de gêneros, Scheiner (2014 A) evidenciou uma nítida diferença na análise dos eventos por gênero, chegando a sugerir que os homens e as mulheres são diferentemente afetados por eventos ao longo do curso de vida. A pesquisa teve como fonte de análise os dados da pesquisa domiciliar “German Mobility Panel (GMP) 19942012”. Verificou-se que eventos-chave (nascimento de criança, a entrada no mercado de trabalho, as mudanças no contexto espacial), a acessibilidade e a mobilidade apresentam significativa diferença por gênero. O diário de viagem é utilizado para coletar informações sobre os deslocamentos realizados durante a semana, ou em determinado intervalo de tempo específico. O instrumento de pesquisa em questão leva em consideração as características sociodemográficas, as referências do contexto espacial no tocante à residência, trabalho e escola.

Após a realização da pesquisa, os dados foram submetidos a modelos de regressão para detectar os efeitos no conjunto de eventos do curso da vida. Os resultados mostram que as viagens realizadas pelas mulheres são mais complexas e aumentam mais que as dos homens ao longo do tempo. Existem poucos eventos que exibem a distinção específica de gênero. Os filhos, ao saírem da casa dos pais, ocasionam a diminuição dos padrões de atividades, isso se deve ao compartilhamento familiar das atividades. O número e a idade dos filhos são considerados fatores de impacto na repartição do trabalho familiar. As mães têm maiores obrigações familiares e estas responsabilidades aumentam com o número de filhos e, gradativamente, diminuem com a idade do filho mais novo (McGinnity e Russel, 2008; Scheiner 2014 A).

Segundo Vespucci (2014), há estudos que indicam que as mulheres dirigem menos. Em função disso, utilizam mais o transporte coletivo, realizam viagens mais curtas, priorizam 
a manutenção da casa e os cuidados com a família e são mais afetadas pela presença de crianças na residência (Wachs 1987; Rosenbloom, 1987; Mallet, 1999; Pitombo, 2003; Silva, 2006; Silva 2011). Já Pitombo (2003) informa que as mulheres classificadas como não cônjuges e não chefes de família efetuam um maior número de viagens diárias, possivelmente por motivo de trabalho, enquanto as mulheres cônjuges ou chefes apresentam uma diminuição no número de viagens, provavelmente pela presença de criança.

Para as pesquisas de transportes, o entendimento dos dados longitudinais facilita a compreensão do comportamento de viagem (Lanzendorf et al., 2015), no intuito de suplementar as extensas análises realizadas com dados de painéis (Scheiner, 2013; Scheiner, 2014 A).

Para a análise de dados quantitativos, numa etapa retrospectiva, foi comentada por Lanzendorf et al. (2015) uma técnica de abordagem longitudinal que coleta dados temporais, chamada de calendário do curso de vida. Ela é adequada para o estudo da trajetória de vida no contexto da pesquisa de transporte, pois fornece informações sobre os eventos-chave e as inter-relações entre eles. Outra característica desta técnica é o relato cronológico dos eventos, com isso, as informações obtidas são sequenciais de maneira temporal (Lanzendorf et al., 2015). No item 2.5, esta técnica será abordada com melhor detalhamento.

\subsection{A Temporalidade no Contexto da Teoria "Biografias de Mobilidade"}

Segundo Scheiner (2007), alguns questionamentos referentes ao estudo do comportamento de viagem, ao longo do tempo, precisam ser melhor explorados quando se trata da ocorrência de eventos-chave. De fato, existem certos questionamentos que poderiam obter melhores análises se fossem submetidos à teoria referida. Para reforçar a ideia, têm-se como exemplos algumas questões: a) como é influenciado o comportamento de viagem, a partir do nascimento de criança, e quais as consequências na tomada de decisão em um domicílio? b) qual a mudança no comportamento de viagem de um domicílio devido à motorização, após o nascimento de criança? (Scheiner, 2007). 
Questionamentos como os referidos anteriormente não ocorreram principalmente pela falta de compreensão das mudanças comportamentais do indivíduo, através de alguns limitantes. O primeiro foi em função das poucas investigações dos efeitos de decisões em longo prazo. O segundo, devido às pesquisas de viagens estarem limitadas a cortes transversais, em vez de dados longitudinais (Lanzendorf, 2003; 2015). Além disso, a pesquisa de viagem se concentra mais em correlações estatísticas do que em relações causais. E, por fim, à falta de dados longitudinais viáveis e representativos (Lanzendorf, 2003, 2015).

Para Scheiner (2007), nas abordagens transversais, as causas e os efeitos da demanda por viagem não podem ser separadas umas das outras, na medida em que elas são modificadas por si só. Para exemplificar, o autor cita que a realização de viagens ocorre com maior frequência para os proprietários de veículos do que para os indivíduos que não possuem carro. O efeito desta observação empírica tem levado a uma maior interpretação da mobilidade do veículo privado. Porém, análise mais sofisticada leva à conclusão contrária. A realização de viagens está mais relacionada com as pessoas que possuem compromissos e desenvolvem atividades do que com a posse de carro. Este é também o motivo pelo qual os indivíduos tendem a comprar um veículo motorizado. Portanto, a razão e o impacto não podem ser inferidos por uma análise transversal.

Segundo Scheiner (2007), "Biografias de Mobilidade contribui para a reconstrução da demanda de viagens individual ao analisar as consequências dos eventos-chave no curso da vida. Esta reconstrução, no tocante aos processos temporais, encontra um importante - embora não suficiente - critério para as demonstrações de inter-relações sobre a causalidade, que não é realizada pelas abordagens transversais”.

Assim sendo, (Sheiner, 2007) esclarece que o foco principal de pesquisa de comportamento de viagem encontra-se em dados transversais. Os estudos realizados ao longo do tempo foram examinados no nível macro, admitindo apenas dados agregados, de maneira que os estudos transversais não favorecem as análises de tendências temporais no nível individual.

Para Lanzendorf (2010), a maioria das pesquisas de transportes que utilizam dados transversais negligencia a dimensão temporal da tomada de decisão das viagens, pois 
ignora os efeitos das experiências aprendidas anteriormente e os eventos-chave no curso de vida das pessoas e dos domicílios, quanto às decisões de mobilidade. Os estudos baseados nas relações sociodemográficas que não analisam o processo de tomada de decisão, com base na evolução do povo e em características individuais, frequentemente limitam sua compreensão causal (Scheiner, 2007; Lanzendorf, 2010).

Compreende-se que o processo de mudança do comportamento e as inter-relações entre os eventos, as biografias parciais, contextos espaciais e o comportamento de viagem só podem ser compreendidos usando dados longitudinais (Lanzendorf et al., 2015). A unidade de investigação em praticamente todas as pesquisas de abordagens longitudinais é o indivíduo, o que contrasta com os estudos transversais (Buck et al., 1995). Outra característica essencial de pesquisa longitudinal é que os indivíduos são analisados repetidamente ao longo do tempo (Diggle et al., 2002).

Como desvantagens, verifica-se que a abordagem longitudinal retrospectiva é frequentemente difícil de ser levada à prática, pois informações sobre eventos passados são dependentes de recordações dos respondentes. Com isso, a precisão dessas lembranças é questionável (Buck et al., 1995). Outro inconveniente é devido à densidade dos questionários quanto às dificuldades de tratamento da informação (Ferrand, 1999). Essas ideias são reforçadas por Scheiner (2007); para o pesquisador, o motivo principal dos poucos estudos longitudinais é a falta de painéis ou dados retrospectivos num nível individual. Com isso, os estudos empíricos são complexos, além do alto custo relacionado às despesas, tempo e esforço.

\subsection{Técnicas Aplicadas à Teoria "Biografias de Mobilidade" para a Captação dos Dados}

A teoria traz a necessidade da coleta de dados longitudinal (Lanzendorf, 2003; Scheiner, 2007; Lanzendorf et al., 2015). Os dados tradicionalmente coletados por corte transversal, como diários de atividades, entrevistas, questionários, entre outros, não são suficientes para que as análises nessa teoria possam ser realizadas, pois a teoria precisa reconhecer o histórico temporal do entrevistado e como são tomadas as decisões ao longo do tempo. Assim, para o atendimento da coleta dos dados desta teoria, o emprego de algumas 
técnicas pode ser realizado, como: estudos de painéis, pseudo-painéis a partir da construção de séries temporais, pesquisa de preferências declaradas, diários de viagem, calendário do curso de vida e entrevistas narrativas a partir de pesquisas de etapa retrospectivas (Lanzendorf, 2003; Frändberg, 2006; Scheiner, 2007; Axhausen 2008; Lanzendorf, 2010; Lanzendorf et al., 2015).

\subsubsection{Painéis}

Os estudos de painéis são caracterizados pela pesquisa repetida e contínua, tendo a mesma amostra. São várias as vantagens dessa metodologia, como a confiabilidade da medida, pois acompanham regularmente as tendências da população, inclusive no registro de informações oriundas das receitas e despesas e, consequentemente, há redução de imprecisões de acontecimentos passados. Além disso, possibilita uma favorável análise estatística, pois a avaliação do evento de interesse e a realização da pesquisa contribuem para uma triagem padrão, para minimizar os erros de amostragem.

Várias desvantagens podem ocorrer, tais como seletividade e taxa de abandono (Lanzendorf et al., 2015). Com isso, há redução no número de participantes, pois eventos como mudança residencial, falecimento, entre outros, certamente influenciam a representatividade da amostra, inclusive podendo torná-la tendenciosa. Como a pesquisa é realizada por etapas temporais, os inquiridos são interrogados em intervalos (ou continuamente) em todo o período de estudo.

Com isso, os resultados preliminares demoram a ser divulgados às políticas de planejamento. E, por fim, a realização de questionamentos repetidos aos participantes poderia influenciar suas atitudes, de maneira que as mudanças observadas não seriam apenas resultado dos fatores analisados, mas de outros mecanismos, que seriam difíceis de distinguir (Lanzendorf, 2003; Frändberg, 2006).

\subsubsection{Pseudo-painéis}

Os pseudo-painéis, a partir de séries temporais, têm como vantagem a utilização de dados existentes, inclusive de longos períodos de tempo e, portanto, possibilitam avaliar os efeitos em longo prazo (Lanzendorf, 2003). Com relação aos custos, são baixos; salvo a necessidade de realização de nova pesquisa, tendo que ser extraídos novos dados. 
Como desvantagens, apresentam estruturas agregadas e não permitem avaliar as mudanças de comportamento do indivíduo (Lanzendorf, 2003). Esta metodologia não atende genuinamente uma abordagem biográfica, pois as observações referem-se ao desenvolvimento de gerações inteiras e não de trajetórias de vida individual (Scheiner, 2007).

Outra desvantagem, segundo Lanzendorf (2003), é quanto ao direcionamento da pesquisa: como são oriundos de séries temporais, os dados não são ajustáveis para o tema e não especificam suficientemente o problema. Como consequência, os principais eventos biográficos sobre demanda de viagem não podem ser analisados (Scheiner, 2007) e existem problemas metodológicos (Lanzendorf et al., 2015).

\subsubsection{Outras técnicas metodológicas}

Devido à ausência de dados longitudinais, Lanzendorf et al. (2015) analisou outras metodologias empregadas na investigação do transporte, as quais podem avaliar as mudanças no comportamento de viagem no decorrer de períodos mais longos.

Dentre essas metodologias, destacam-se: primeiro, os diários de viagem, para capturar a variabilidade e ritmo do comportamento de viagem diária; e segundo, a pesquisa de preferência declarada, que, em geral, é conduzida para estudar o impacto de certos eventos como a mudança residencial.

\subsubsection{Calendário do curso de vida}

O calendário do curso de vida é uma técnica metodológica para pesquisa retrospectiva que busca reunir dados longitudinais (Lanzendorf et al., 2015). A organização das informações a serem coletadas está distribuída ao longo de dois eixos. O eixo horizontal é designado para o tempo (anos), e o eixo vertical para eventos. As relações entre os eixos formam as grades. A grade categoriza os eventos individualmente e coloca-os relacionados aos anos, de forma estrutural. A Estrutura possibilita uma melhor recordação pessoal, diminuindo o problema de memória. Os entrevistados ficam mais confortáveis para refletir sobre o acontecimento dos eventos e anotá-los de forma cronológica (Lanzendorf et al., 2015). 
O calendário do curso de vida começa pelos eventos autobiográficos familiares. As categorias obedecem à seguinte ordem estrutural: histórico familiar, localizações residenciais, escolares e de trabalho, número de pessoas no domicílio, modos de transporte utilizados para a escola e trabalho, registro do atual e dos carros anteriores (Lanzendorf et al., 2015). Para melhor entendimento, os quadros H.1 e H.2, no instrumento de pesquisa $\mathrm{n}^{\circ} 1$, do Anexo $\mathrm{H}$ - Instrumentos de pesquisa, ilustram um modelo dessa técnica.

Essa técnica de pesquisa retrospectiva pode coletar dados quantitativos para abordagem longitudinal sobre o comportamento de viagem. Além disso, é considerado um instrumento mais eficiente em comparação ao dado de painel para avaliar as biografias de mobilidade. Fornece informações sobre os eventos-chave, as inter-relações entre os eventos, as mudanças na escolha de meios de transporte e a alteração no número de carros. Essas informações apresentam uma importante aplicabilidade para a análise das biografias de mobilidade. Além disso, fornece informações sequenciais dos principais eventos (Lanzendorf et al., 2015).

Os dados coletados são promissores, pois geram uma riqueza de informação e, consequentemente, produzem consideráveis resultados. Estas combinações permitem uma visão mais profunda nas decisões em longo prazo, como mudança residencial, composição do domicílio e posse do carro. Além disso, poderiam ser utilizadas para estudar os efeitos da socialização sobre o comportamento de viagem (Lanzendorf et al. 2015).

\subsubsection{Entrevistas narrativas em etapas retrospectivas}

As entrevistas narrativas são comumente utilizadas nas pesquisas retrospectivas (Lanzendorf, 2003, 2010 e 2015). Para Lanzendorf (2003), as entrevistas retrospectivas que possuem uma análise qualitativa são relevantes ferramentas na área da pesquisa de viagens. Através do método qualitativo, consegue-se entender a complexidade dos fatores emocionais que influenciam o comportamento (Grosvenor, 2000). 
Os dados de uma pesquisa retrospectiva podem ser extraídos de análises quantitativas e qualitativas (Lanzendorf, 2003; Lanzendorf et al., 2015). Lanzendorf (2003) defende que a confiabilidade de uma pesquisa qualitativa retrospectiva relacionada à teoria "Biografias de Mobilidade" é alta. A qualidade das respostas é boa, pois a capacidade dos indivíduos de lembrar o comportamento passado aumenta a confiabilidade das respostas a questionários retrospectivos (Axhausen, 2008; Lanzendorf, 2010). Já para uma pesquisa quantitativa, a questão de confiabilidade necessita ser verificada e respondida, em primeiro lugar, por testes como o nível de significância estatística, entre outros (Lanzendorf, 2003).

Axhausen (2008) avalia que a etapa retrospectiva aplicada à biografia de mobilidade avalia as principais fases da vida do entrevistado, com ênfase para os aspectos de viagem. As informações a serem coletadas pelo instrumento de pesquisa devem permear questionamentos que envolvam: local de residência, segunda residência (se houver), contato inicial com a escola e trabalho, situação empregatícia, local de trabalho, disponibilidade de modos de transporte, composição do domicílio, eventos domésticos, renda pessoal e familiar, os modos de transporte preferidos para locomoverem-se à escola e ao trabalho, e sugere adicionar perguntas sobre as redes pessoais (filiação a clube, a associações cívicas e políticas).

A realização de pesquisa face-a-face é o melhor método de estabelecer a confiabilidade do entrevistador e, consequentemente, do estudo, porém admite a dificuldade em ganhar a cooperação dos entrevistados, mesmo para perguntas simples. O estudo apontou também que a quantidade de questões pode sobrecarregar o entrevistado, mesmo que as perguntas sejam simples (Axhausen, 2008).

Ladkin (2002) argumenta que "eventos autobiográficos são lembrados com sucesso em todo o tempo de vida e, por conseguinte, informações biográficas pessoais são susceptíveis de serem lembradas". Consequentemente, as biografias parciais favorecem as recordações retrospectivas e questionamentos como: Qual era o modo de viagem para o trabalho? Qual era a disponibilidade do carro? Quais eram os locais de residência e trabalho? Quais foram as viagens internacionais realizadas? (Frändberg, 2006). Estas indagações têm uma qualidade aceitável (Scheiner, 2007). 
Segundo Buck et al. (1995), em pesquisas retrospectivas, o entrevistado é questionado apenas uma vez sobre as experiências passadas. As vantagens desse método são a simplicidade e a viabilidade de recurso para a realização. As informações são conseguidas em apenas uma pesquisa, sem a necessidade dos entrevistados serem rastreados. Outra vantagem é a imediata disponibilidade das informações, não sendo necessário esperar uma segunda entrevista para perceber a mudança.

Com o auxílio de técnicas adequadas, segundo Ladkin (2002), a recuperação da memória dos entrevistados pode ser melhorada, ou seja, sugere-se que os questionamentos sejam iniciados pelos eventos mais recentes, e, posteriormente, os eventos mais antigos serão rastreados. A intenção é que os acontecimentos retrospectivos, no tocante à mobilidade, possam ser lembrados com precisão, através da ocorrência dos eventos autobiográficos (Ladkin, 2002).

Para a confiabilidade do desempenho da memória no recolhimento dos dados, algumas condições devem ser atendidas: primeiro, o intervalo de tempo entre o evento a ser investigado e o questionamento retrospectivo não deve ser muito longo (Lanzendorf, 2010), pois pode haver influência do tempo decorrido. Quanto mais distante tiver sido a ocorrência do evento, mais fragmentada será a memória (Lanzendorf et al., 2015). Segundo, o evento deve ser importante para que o respondente lembre bem (Lanzendorf, 2010). A importância atribuída e a conotação afetiva de um evento passado são diretamente proporcionais à evocação do indivíduo (Lanzendorf et al., 2015). E, por fim, a idade e as condições de capacidade intelectual do respondente podem levar ao desempenho da evocação (Lanzendorf et al., 2015).

Para Clifton e Hand (2001), a análise qualitativa tem a capacidade de descobrir as relações causais, redefinindo as hipóteses e as estruturas do modelo antes de realizar inquéritos em larga escala, inclusive validações estatísticas (Mehndiratta, 2001). Reforça essa ideia Lanzendorf et al., (2015), quando diz que as entrevistas qualitativas servem para descobrir correlações relevantes e deduzir hipóteses, e as pesquisas de abordagens longitudinais em análises qualitativas devem ser favorecidas em detrimento de estudos com abordagens transversais. 
Os raros enfoques de análises qualitativas em pesquisa de transportes ocorreram por alguns fatores: pela necessidade de reconhecimento de métodos alternativos para um novo entendimento das viagens urbanas diárias (RØE, 2000); a natureza da pesquisa qualitativa tem sido criticada pela falta de rigor científico e a dificuldade de interpretação subjetiva ao explicar o comportamento de viagem (Clifton e Handy, 2001); pela complexidade da pesquisa qualitativa em termos de pressupostos, coleta, transcrição e análise de dados (Günther, 2006); e, por fim, devido à aplicabilidade da pesquisa qualitativa não procurar por identidades, mas por analogias e variações temáticas (Gomes et al. 2012).

A desvantagem da análise qualitativa, em etapa retrospectiva, é o demasiado tempo que o respondente leva para decidir sobre qual resposta atribuir ao questionamento formulado. Além disso, pode ocorrer dificuldade no recrutamento de participantes. Como solução para esse problema, algumas pesquisas precisam fornecer incentivos financeiros aos respondentes (Axhausen 2008; Oakil, 2013). Além disso, são necessários entrevistadores com habilidades técnicas para o desenvolvimento do estudo, o que consequentemente eleva o custo de realização da pesquisa (Lanzendorf, 2003). 


\section{MÉTODO DA PESQUISA}

Este capítulo apresenta o método aplicado para o desenvolvimento desta pesquisa. O objetivo principal é apresentar as etapas, as fases e as definições quanto às aplicações práticas das técnicas de análises. A Figura 8 apresenta a estrutura do método usado.

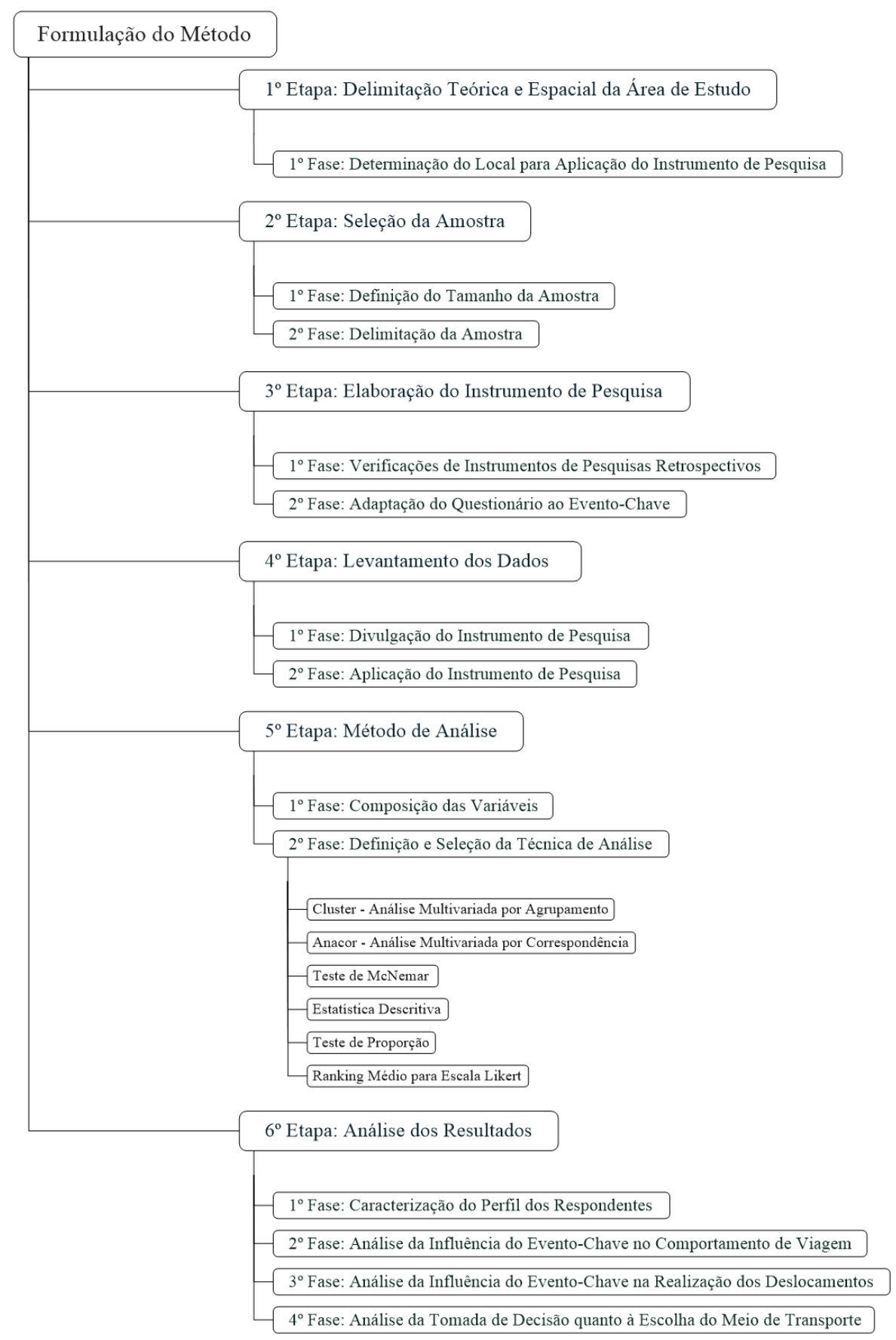

Figura 8 - Etapas e fases da formulação do método

Fonte: Elaborado pelo autor 


\subsection{Delimitação Teórica e Espacial da Área de Estudo - $1^{\mathrm{a}}$ Etapa}

O desenvolvimento desta pesquisa tem como delimitação teórica a área de planejamento em transporte que aborda o comportamento de viagem. Para isso, é utilizada uma teoria que possibilita a formulação e compreensão do comportamento de viagem através da ocorrência de eventos-chave. Conforme mencionado no capítulo introdutório deste estudo, a teoria será aplicada ao evento-chave "nascimento de crianças".

\section{$1^{a}$ Fase: Determinação do local para a aplicação do instrumento de pesquisa}

Para a realização desta pesquisa não houve delimitação espacial, isto é, a pesquisa não foi desenvolvida em apenas uma região geográfica especifica. A pretensão foi analisar os indivíduos (pais ou mães) que tenham passado pelo evento-chave e sejam domiciliados no território nacional. Através dos dados oriundos das diferentes regiões brasileiras, há a possibilidade de se avaliar as diferentes realidades. Com isso, ocorre o entendimento de como é realizada a mobilidade associada ao evento-chave pesquisado.

\subsection{Seleção da Amostra - 2a Etapa}

\section{$1^{a}$ Fase: Definição do tamanho da amostra}

A pesquisa qualitativa não se baseia no critério numérico para garantir sua representatividade (Deslandes et al., 2010). Um questionamento importante a ser realizado é: Quais indivíduos têm uma expressiva vinculação com o problema a ser investigado? Dessa forma, uma amostragem boa é aquela que possibilita abranger a totalidade do problema investigado em suas múltiplas dimensões (Minayo, 1992).

Analisar o sistema de mobilidade de pais ou mães abrange um universo tão grande de elementos, fatores e características, que torna complexo considerá-lo em sua totalidade. Dessa dificuldade decorrem alguns problemas, entre eles a capacidade de realizar uma coleta amostral que seja representativa. Então, esta pesquisa busca contribuir com o tema de estudo, a partir da verificação da viabilidade de aplicação da teoria. 
A seleção da amostra é destinada a indivíduos que tenham o(a) primeiro(a) filho(a) com até 6 anos de idade. Entende-se que o período de seis anos é adequado para que os pais se recordem do efeito ocorrido a partir do nascimento do primeiro filho. Outra recomendação é que os indivíduos já tenham passado pelo período de licença maternidade ou paternidade, pois este é um momento atípico em que os indivíduos não realizam os deslocamentos habituais. A licença maternidade ou paternidade é considerada uma fase de redução das atividades, para o cuidado com o recém-nascido.

Então, a temporalidade dos períodos de observação para este estudo serão dois intervalos específicos: antes e após o evento-chave. O período do parto será desconsiderado, por tratar-se de um momento particular. Em geral, nos últimos meses de gravidez e após o parto, compreendido o período da licença maternidade, as mulheres escolhem modos de viajar que melhor atendam às suas necessidades físicas (Lanzendof, 2010). Em muitos casos, essas escolhas são temporais, não representando a realidade. Após esses dois momentos, as atividades e os deslocamentos mudam, com isso, consequentemente, as responsabilidades e as prioridades alteram-se por opções que melhor atendam às exigências de segurança e as necessidades de locomoção.

\subsection{Elaboração do Instrumento de Pesquisa $-3^{\text {a }}$ Etapa}

O objetivo da elaboração do instrumento de pesquisa é subsidiar o estudo temporal através da abordagem longitudinal no ambiente domiciliar. A busca do entendimento de como e quais foram as consequências da tomada de decisão contribuíram para a estruturação do questionário. $\mathrm{O}$ instrumento é baseado em dois cenários: atual e retrospectivo. No primeiro, a intenção é verificar como está atualmente o comportamento de viagem e, no outro, como foi antes, isto é, o período que antecede o evento-chave. Para isso, faz-se necessário o conhecimento da estrutura familiar para o entendimento do processo de tomada de decisão na organização das atividades, realização dos deslocamentos e a escolha do meio de transporte (Arruda, 2005; Silva, 2011). Além desses dois cenários, um questionário socioeconômico também compõe a estrutura do instrumento de pesquisa. 
A elaboração do instrumento de pesquisa usado neste trabalho ocorreu a partir da adaptação de outros três questionários usados por pesquisadores internacionais. $\mathrm{O}$ primeiro foi desenvolvido por Oakil (2013) e os outros dois por Lanzendorf (2010). Todos estes instrumentos constam no Anexo $\mathrm{H}$ - Instrumentos de Pesquisa. O instrumento de pesquisa $n^{\circ} 2$ foi desenvolvido por Oakil (2013). Os instrumentos de pesquisa $n^{\circ} 3$ (Entrevista Guiada) e $\mathrm{n}^{\circ} 4$ (Diário de Atividade) foram desenvolvidos por Lanzendorf (2010). Posteriormente, estes questionários foram reformulados de maneira que atendessem à necessidade desta investigação.

No estudo holandês feito por Oakil (2013), o instrumento de pesquisa foi dividido em 3 partes, a saber: a primeira parte com perguntas sobre as informações gerais dos membros do domicílio; a segunda parte com informações pessoais sobre o passado, presente e futuro, através do questionário de vida, de forma que o entrevistado possa discorrer através de uma abordagem longitudinal sobre questionamentos como ocupação, renda familiar, residência e transporte; e a terceira parte apresentou dois tipos de questionamentos. O primeiro, referente à rede social de pessoas que são próximas, mas não pertencem à sua família, e a segunda parte, com as expectativas de mercado com relação ao transporte, habitação e trabalho.

No estudo germânico feito por Lanzendorf (2010), os instrumentos de pesquisa contaram com uma entrevista guiada e um diário de atividades. A entrevista guiada foi dividida em 3 partes e um pequeno questionário sociodemográfico. Na primeira parte, questiona-se a disponibilidade do uso do transporte e do espaço, com indagações sobre o cotidiano e tempo livre fora de casa. Na parte seguinte, formulam-se questões sobre a identificação da rotina, com perguntas sobre o comportamento em relação à locomoção e as mudanças no uso do meio de transporte. E, na última parte, averígua-se a demanda por eventos especiais, com perguntas voltadas para a situação da moradia, composição familiar, trabalho e carreira, e as relações de atividades exercidas no tempo livre.

Já o diário de atividade apresentava questionamentos do tipo: Qual a origem da viagem? Qual o horário de partida? O motivo da viagem? Qual o meio de transporte? Qual o tempo de espera? Havia acompanhantes na realização da viagem? Qual o horário de chegada? E 
o tempo de espera para a realização da próxima viagem? Como era um diário de atividades, os mesmos questionamentos se repetiam para as próximas viagens.

\section{$2^{a}$ Fase: Adaptação do questionário ao evento-chave}

O processo de adaptação do instrumento de pesquisa para a coleta dos dados foi gradativo e composto por várias etapas. A primeira etapa foi a tradução. Os instrumentos de pesquisa foram traduzidos do alemão e do holandês para o inglês, e em seguida para o português. $\mathrm{Na}$ segunda etapa foram analisadas as variáveis, para posteriormente selecionar aquelas que atendiam às diretrizes do estudo. Dessa forma, as variáveis que compõem o questionário são, em sua maioria, qualitativas, sendo poucas quantitativas. A última etapa da elaboração do instrumento foi caracterizada pela reformulação do eventochave pesquisado e pela adaptação ao cenário brasileiro.

O instrumento de pesquisa usado neste estudo é composto por quatro partes, conforme consta no Anexo $\mathrm{H}$ - Instrumento de Pesquisa $\mathrm{n}^{\circ}$ 5. As três primeiras partes são direcionadas ao respondente (pai ou mãe), e a última parte ao(a) companheiro(a) ou cônjuge, quando houver. A primeira parte está estruturada com os questionamentos referentes às informações socioeconômicas e à atual escolha do modo de transporte. A segunda parte é um questionário retrospectivo, que aborda a escolha do modo de transporte antes do nascimento do(a) primeiro(a) filho(a). A terceira parte é composta por indagações referentes às atividades, deslocamentos, influência, mudança residencial e de trabalho relacionadas ao período após o nascimento do(a) primeiro(a) filho(a). Já a última parte é direcionada ao(a) companheiro(a) ou cônjuge. Estas perguntas apresentavam semelhanças com os questionamentos feitos anteriormente, porém eram necessárias para verificar a influência do evento-chave na perspectiva do(a) companheiro(a) ou cônjuge. Como é uma pesquisa familiar, o domicílio é o local que influencia as tomadas de decisões para a realização das atividades e, consequentemente, para a viagem, então essa parte não poderia ser omitida.

O instrumento de pesquisa está adaptado tanto para as mães quanto para os pais responderem, e toda participação foi voluntária. Junto com o link foi enviada uma mensagem explicativa, a finalidade era informar que os resultados dos dados coletados seriam trabalhados de maneira confidencial, somente para fins acadêmicos. Foi 
informado, também, que a pesquisa não conferia riscos aos participantes, sendo a privacidade e a identificação mantidas em sigilo.

\subsection{Levantamento dos Dados $-4^{\text {a }}$ Etapa}

$1^{a}$ Fase: Divulgação do instrumento de pesquisa

Sabe-se que a presença da internet facilitou os afazeres na vida cotidiana de muitas pessoas, mas, além das atribuições diárias, verificou-se uma significativa contribuição à área da pesquisa. Com isso, as pesquisas qualitativas não escaparam aos efeitos da revolução digital e tecnológica (Flick, 2009). Então, para facilitar o processo de levantamento dos dados, o questionário foi hospedado numa plataforma virtual (https://wwww.onlinepesquisa.com/s/Biografia_de_Mobilidade). A aplicação do questionário ocorreu através de pesquisas on line, pois facilita o processo de divulgação da pesquisa e o levantamento dos dados.

O método utilizado para a divulgação é denominado de "bola-de-neve". Este termo foi definido por Berg (1998) para explicar a relação existente entre as amostras. A amostra inicial é formada pela rede pessoal, isto é, indivíduos próximos ao pesquisador que atendem aos requisitos da pesquisa. As recomendações de outros conhecidos, feitas pela amostra inicial, compõem a amostra coletada. E, por fim, a amostra final é composta pela amostra inicial e a amostra coletada.

\section{$2^{a}$ Fase: Aplicação do instrumento de pesquisa}

O levantamento dos dados ocorreu de forma assíncrona, isto é, o pesquisador envia o link de acesso ao questionário aos participantes, e eles respondem após algum tempo, não sendo necessário que ambos estejam on line simultaneamente. Para os entrevistados que atenderam às exigências da amostra, essa comunicação aconteceu por e-mail, através da rede social virtual do pesquisador e por mensagens via WhatsApp. O link ficou disponível ao acesso do respondente entre os dias 26/02/2016 e 15/03/2016. 


\subsection{Método de Análise - $5^{\mathrm{a}}$ Etapa}

\section{$1^{a}$ Fase: Composição das variáveis}

A definição das variáveis considerou o conjunto de fatores relacionados ao indivíduo e ao domicílio, permeando características socioeconômicas, tais como renda, composição familiar, escolaridade, ocupação, posse de automóvel, fatores motivacionais e influência na escolha do modo de transporte, os motivos de mudança residencial, entre outros. No quadro $1 \mathrm{G}$, no Anexo $\mathrm{G}$ - Variáveis, segue a descrição do nome e rótulo das variáveis utilizadas.

Para a variável renda desta pesquisa, foi utilizado o critério do Censo, do IBGE, que não define classes sociais, só renda. Comumente, muitas pessoas a serem pesquisadas distorcem os valores de quanto ganham. Então, para mensurar o poder aquisitivo foi estabelecida uma inovadora metodologia pela Associação Brasileira de Empresa de Pesquisa (ABEP), através da classificação da pirâmide social, conhecida como Critério de Classificação Econômica Brasil (CCEB). Esse critério apresenta um melhor refinamento detalhado das categorias, além de uma fundamentação mais lógica para designar o nível social, baseados em estudos acadêmicos desenvolvidos por Kamakura e Mazzon (2013). O critério é comumente utilizado em empresas, agências e veículos de comunicação.

Ao todo, são consideradas 35 (trinta e cinco) variáveis de natureza cultural, geográfica e demográfica, além de informações como: acesso a serviços da rede pública (saneamento, rede de iluminação), aquisição de bens e conforto doméstico (quantidade de banheiro, TVs, DVD player, geladeiras, freezers, automóveis, máquina de lavar e empregada mensalista). Esses itens valem pontos e definem a que classe pertencem.

No modelo apresentado pela ABEP ocorre a diferenciação das classes sociais ao longo do território brasileiro, sendo ajustada pela composição familiar e pela região geográfica de localização do domicílio. Até o momento não se tem informações de nenhum lugar do mundo que utilize um critério oficial de classificação socioeconômica analisando a composição familiar e o local de residência. Em geral, os critérios adotados são padrões e classificam o todo, sem levar em consideração as particularidades. 
$2^{a}$ Fase: Definição e seleção da técnica de análise

Tendo em vista a heterogeneidade das variáveis que compõem o instrumento de pesquisa, foram escolhidos os métodos de análise dos dados. Em seguida, definem-se os métodos, e após a definição será limitado o direcionado conferido às explicações, para atender os procedimentos necessários ao estudo.

O banco de dados obtido foi inserido no software IMB SPSS - Statistical Package for the Social Sciences - Statistics 22 para as obtenções dos resultados da análise de agrupamento (Cluster), Análise por correspondência (correspondence analysis) - Anacor, teste de McNemar (McNemar Test) e da estatística descritiva (Descriptive Statistics).

\subsubsection{A técnica multivariada de análise de agrupamento - (Cluster)}

A análise de agrupamento (Cluster) é conhecida como análise de conglomerados, classificação, agrupamento (Mingoti, 2005), e também é chamada de análise $Q$, construção de tipologia, análise de classificação e taxonomia numérica (Hair et al., 2009). Apesar das diversificações entre os nomes, há uma dimensão comum, o agrupamento de acordo com as características homogêneas ou heterogêneas do que se deseja classificar (Albuquerque, 2005; Linden, 2009; Hair et al., 2009).

É uma técnica de interdependência que permite análise de pesquisas qualitativas e quantitativas. O principal objetivo é agrupar os indivíduos, objetos, empresas, produtos, casos, elementos amostrais de uma população e os comportamentos em grupos, com base nas próprias características (variáveis). Essa análise possibilita que os elementos que possuem semelhantes características possam pertencer a um mesmo agrupamento, em função do grau de similaridade, a partir de variáveis predeterminadas. Classifica-se essa forma de agrupamento como grupos homogêneos. Desse mesmo modo, os elementos que não possuem as mesmas características são classificados como grupos heterogêneos, em função do grau de dissimilaridade. Segundo Fávero et al. (2009), a ideia principal é agrupar os objetos levando em consideração suas características, buscando uma estrutura específica natural desses objetos. 
As vantagens de utilização do método Cluster são: i) redução na dimensão de um conjunto de dados, reduzindo uma ampla gama de objetos à informação central do conjunto (Linden, 2009); ii) segmentação de indivíduos dentro de uma amostra de modo a formar conjuntos mutuamente excludentes que apresentem similaridades entre seus elementos (Hair et al., 2009); iii) avaliar múltiplas variáveis dentro de uma mesma amostra (Prata, 2007).

A análise de Cluster está presente em várias situações e áreas do conhecimento. Para Mingoti (2005), é comumente usada em áreas como a psicologia, em pesquisas de mercado, na ecologia e na ergonomia, entre outras. Para Fávero et al. (2009), a análise cluster pode ser aplicada em todas as áreas do conhecimento humano cujo objetivo seja segmentar as observações em grupos homogêneos (similaridade) ou heterogêneos (dissemelhança). Para Hair et al. (2009), a ideia é maximizar a homogeneidade dentro de grupos, ao mesmo tempo em que maximiza a heterogeneidade entre os grupos.

Os procedimentos de agrupamento são classificados em dois tipos: hierárquico e não hierárquico, conforme a Figura 9. A técnica hierárquica é utilizada em pesquisas exploratórias com o intuito de identificar possíveis agrupamentos, ela parte do princípio de que o processo de agrupamento tem (n) conglomerados. Já na técnica não hierárquica, o número de grupos deve ser pré-especificado pelo pesquisador (Mingoti, 2005).

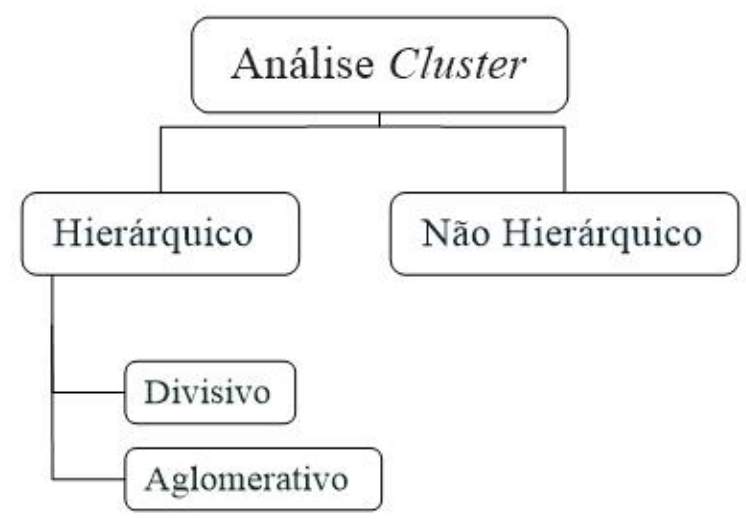

Figura 9 - Divisão hierárquica na Análise Cluster Fonte: Elaborado pelo autor

Derivam-se da técnica hierárquica dois procedimentos: Divisivo e Aglomerativo. Cada indivíduo (caso, objeto) inicia no próprio grupo e, a partir deste ponto, novos 
agrupamentos são realizados por similaridade nas etapas seguintes, de forma que dois indivíduos mais similares são agrupados primeiramente e, nas etapas seguintes, vão se agregando com os demais grupos de acordo com a proximidade, e em cada etapa subsequente reduz-se o número de agrupamento (Mingoti, 2005; Fávero et al., 2009). O procedimento hierárquico é apresentado na Figura 10.
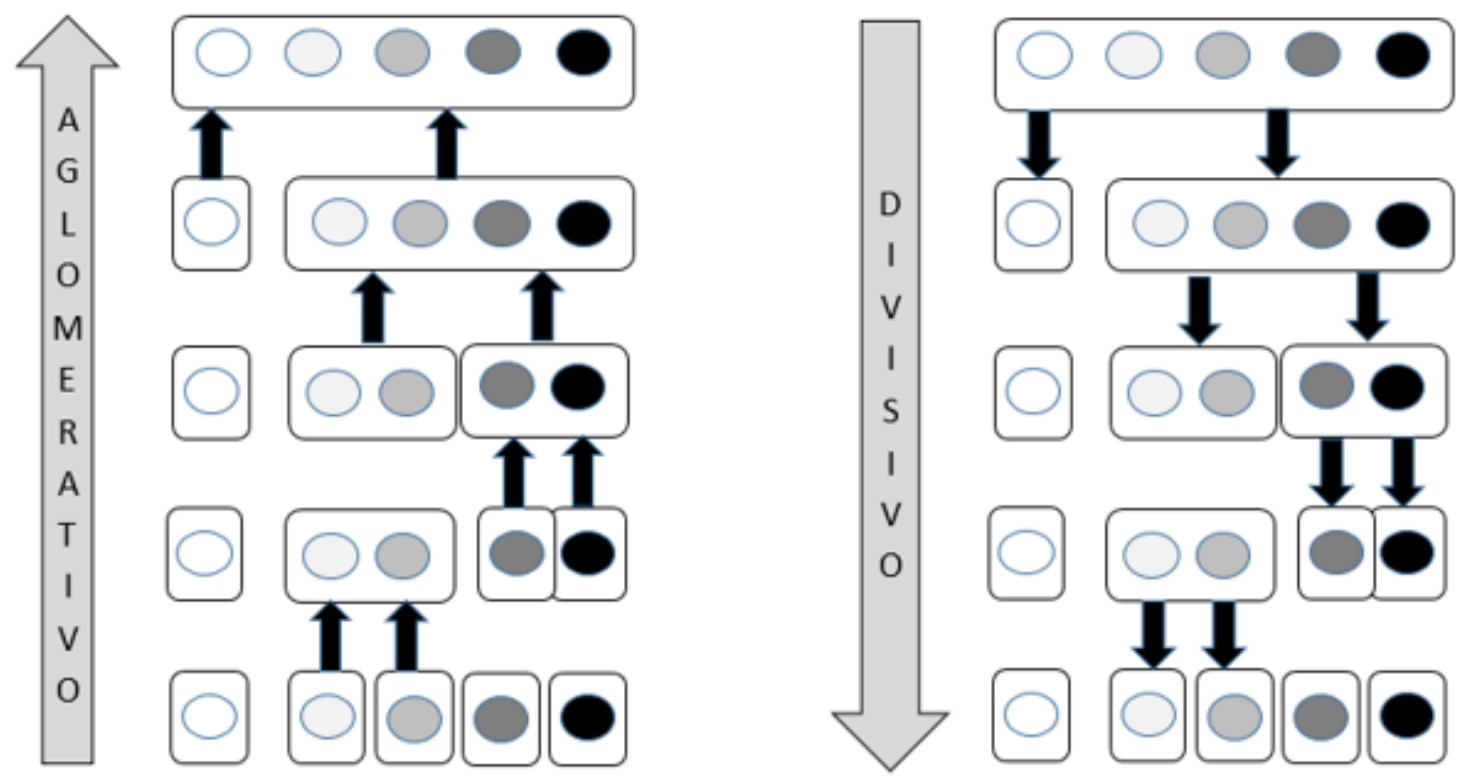

Figura 10 - Procedimentos Hierárquicos Aglomerativos e Divisivos Fonte: Mingoti (2005)

Sabe-se que a técnica de agrupamento é ampla, pois atende às várias especificações de acordo com as finalidades desejadas nos agrupamentos, porém, a partir daqui, o direcionamento adotado será limitado e atenderá aos procedimentos necessários para esse estudo.

Ainda segundo Hair et al. (2009), a ideia primordial é definir a estrutura dos dados colocando as observações mais similares em grupos. Para isso, alguns procedimentos são importantes: medição de similaridade, formação dos grupos e a determinação do número de agrupamento na solução final.

A medição de similaridade e a formação dos grupos é pelo método do vizinho mais próximo (Nearest Neighbor) ou ligação individual (Single Linkage), e pela distância quadrática euclidiana (Squared Euclidean Distance). Segundo Fávero et al. (2009), neste método, a distância entre dois indivíduos é representada pela menor distância entre todas 
as possibilidades de pares de indivíduos em dois grupos, em outras palavras, é formado pelos dois indivíduos que possuírem a distância mínima entre eles. Conforme verifica-se na Figura 11.

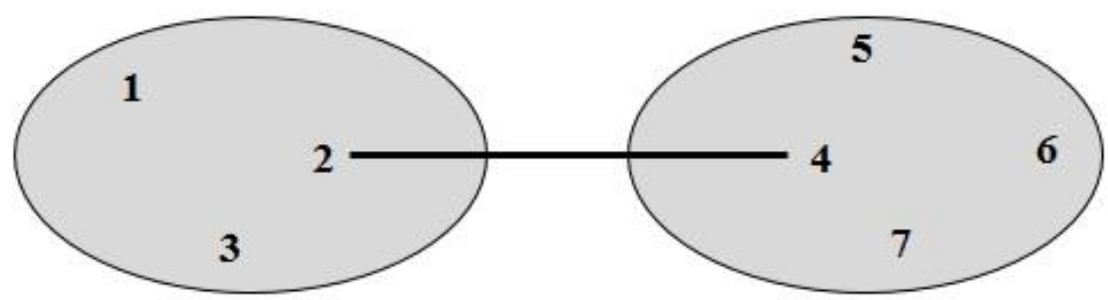

Figura 11 - Método do Vizinho Mais Próximo ou Ligação Individual Fonte: Fávero et. al. (2009)

Após a formação do primeiro agrupamento, faz-se necessário estabelecer qual será a distância computada para os próximos agrupamentos. Neste caso, é a distância quadrática euclidiana, pois além de comumente utilizada, também atende melhor a experimentos dessa natureza. Neste estudo a distância será definida conforme o resultado obtido em Equação 1. Verifica-se que existem várias medidas de similaridade ou dissimilaridade e cada uma produz um determinado tipo de agrupamento (Mingoti, 2005). Esses valores de similaridade ou dissimilaridade entre cada par de observações são representados pela matriz de proximidade (Fávero et al., 2009).

$$
d(i, j) k=\min \{d(i j), d(j k)\}
$$

Sendo:

$i$ e $j$ - Dois grupos

$k$ - Distância entre eles.

A determinação do número de agrupamento na solução final é representada graficamente pelo Dendrograma (Mingoti, 2005; Hair et al., 2009) ou Dandograma (Fávero et al., 2009). Nessa representação, cada indivíduo (caso, objeto) representa um eixo e o outro eixo representa os passos no procedimento hierárquico em uma escala de 0 a 25 , na qual é possível visualizar os elementos de cada cluster, de acordo com o corte que se deseja fazer, através de uma linha reta imaginária na posição vertical do dendrograma. 


\subsubsection{Análise por correspondência - (Anacor - Correspondence Analysis)}

É uma técnica exploratória de interdependência multivariada destinada ao estudo da relação entre duas variáveis qualitativas. Por ser usada com dados nominais em vez de dados métricos, essa técnica pode ser usada em muitas situações nas quais as técnicas multivariadas mais tradicionais são inadequadas (Hair et al., 2009). Por motivos como a redução dimensional e o mapeamento perceptual, a técnica vem tornando-se popular em vários trabalhos científicos. Devido à popularidade, alguns estudiosos chamam a Anacor de escalonamento (ou escore ótimo) e média recíproca (Fávero et al., 2009; Hair et al., 2009).

A Anacor exibe, através de uma representação gráfica em projeção plana, as relações multidimensionais das distâncias Qui-quadrado $\left(\chi^{2}\right)$ entre as variáveis categóricas (Fávero et al., 2009). Essa representação gráfica é bidimensional e recebe o nome de mapa perceptual (mapa espacial). Sua função é representar o padrão geral das medidas de similaridade (Hair et al., 2009). O mapa perceptual possibilita a representação visual das percepções sobre determinado objeto em duas ou mais dimensões (Fávero et al., 2009). Em outras palavras, cada objeto tem uma posição espacial nas dimensões do mapa perceptual, que reflete a preferência ou a similaridade em relação a outro objeto.

O Qui-quadrado $\left(\chi^{2}\right)$ é um teste de hipóteses destinado a calcular um valor de dispersão para duas variáveis nominais. É um teste não-paramétrico, isto é, não depende dos parâmetros populacionais, como média e variância. O princípio básico é comparar proporções, isto é, as possíveis divergências entre as frequências observadas e as esperadas para um certo evento. A análise dos dados é numa tabela de contingência (tabela cruzada ou de correspondência de variáveis não métricas ou categóricas), apresentada na Tabela 1, que compara as frequências reais das células da tabela com as frequências esperadas das mesmas. Segundo Hair et al. (2009), a frequência esperada de uma célula é baseada nas probabilidades marginais de sua linha e coluna (probabilidade de uma linha e coluna entre todas as linhas e colunas). 
Tabela 1 - Tabela de Contingência

\begin{tabular}{l}
\multicolumn{7}{c|}{} & \multicolumn{7}{c}{ Variável } \\
\cline { 2 - 9 } \\
\hline
\end{tabular}

Fonte: Fávero et al. (2009)

Sendo:

L - Categoria de Linhas da Variável A

J - Categoria de Coluna da Variável B

$n i j$ - $\mathrm{O}$ número de elementos que pertence à categoria $i$ da variável $\mathrm{A}$ e à categoria $j$ da variável B.

A matriz correspondência de $\mathrm{P}$ dimensão $\mathrm{L} x \mathrm{~J}$ das frequências relativas é constituída das proporções (Mingoti, 2005). Com isso, cada elemento será dividido por $n$. A soma dos elementos de P será igual a 1 (Fávero et al., 2009). Desse procedimento obtém-se a Equação 2.

$$
p_{i j}=\frac{n_{i j}}{n}, \quad P=\frac{1}{n}
$$

Sendo:

P - Matriz correspondente de dimensão L $x \mathrm{~J}$.

$p_{i j}-\mathrm{A}$ razão entre número de elementos que pertence à categoria $i$ da variável A e à categoria $j$ da variável B.

$n_{i j}-\mathrm{O}$ número de elementos que pertence à categoria $i$ e a categoria $j$ da variável $\mathrm{B}$. $n$ - O número de elementos.

Segundo Fávero et al. (2009), a Anacor para calcular a medida de associação e a criação do mapa perceptual consiste de duas etapas, primeiro utiliza-se do Qui-quadrado $\left(\chi^{2}\right)$ para padronizar as frequências e formar as bases à associação, realizando assim uma tabela de contingência (tabela cruzada ou de correspondência), que tem como objetivo calcular as frequências esperadas e o valor do Qui-quadrado $\left(\chi^{2}\right)$ para cada célula, levando em consideração as diferenças entre as frequências observadas e esperadas. 
Assim, numa segunda etapa, com as medidas padronizadas da associação, são criadas projeções ortogonais a partir da geração de uma medida em distância, para representar o grau de associação feito pelas distâncias do Qui-quadrado $\left(\chi^{2}\right)$ em um espaço dimensional, no qual a categoria é alocada. Com isso, verifica-se que as variáveis categóricas que se encontram próximas podem ser consideradas iguais perante as observações realizadas, independente de seus conteúdos semânticos (Fávero et al. 2009).

Em seguida é apresentado o resultado do Qui-quadrado Equação 3 para a mensuração do grau de associação entre linhas e colunas em uma tabela de contingência, cujas duas variáveis A e B são independentes, ou seja, não há associação entre as categorias e a equação da inércia Equação 4, por meio da substituição da expressão da estatística Quiquadrado (Fávero et al., 2009).

$$
\chi^{2}=\sum i, j \frac{(\mathrm{O} i j-\mathrm{E} i j)^{2}}{\mathrm{E} i j}
$$

Sendo:

Oij - Igual a nij representa o número de observações reais da célula $(i, j)$

Eij - Igual a npij representa o número esperado de observações na célula $(i, j)$

$$
\frac{\chi^{2}}{\mathrm{n}}=\frac{1}{\mathrm{n}} 1 \sum i, j \frac{(\mathrm{O} i j-\mathrm{E} i j)^{2}}{\mathrm{E} i j}
$$

Equação 4

Segundo Hair et al. (2009), a análise por correspondência apresenta às pesquisas diversas vantagens, entre elas: (1) a tabulação simples cruzada de múltiplas variáveis categóricas, cuja representação gráfica é em um espaço perceptual; (2) não retrata somente as relações entre linhas e colunas, mas também as relações entre as categorias de linhas e colunas; (3) o fornecimento de uma visão conjunta de categorias das linhas e colunas na mesma dimensionalidade. Em outras palavras, a análise por correspondência é uma poderosa ferramenta para dados não métricos que, frequentemente, não são o ponto focal das técnicas multivariadas.

\subsubsection{Teste de McNemar para a significância de mudanças - (McNemar's Test)}

Foi desenvolvido pelo psicólogo e estatístico norte-americano Quinn Michael McNemar, em 1947. O método é aplicável para analisar frequências (proporções) de duas amostras 
pareadas. Verifica-se que na análise de amostras pareadas, em geral, a precisão de uma comparação é aumentada. Sabe-se que duas amostras pareadas não são amostras independentes, mas sim correlacionadas. O teste de McNemar (McNemar Test) tem como objetivo analisar as situações do tipo "antes e depois". A mensuração deste teste ocorre no nível de escala nominal ou ordinal.

Para o teste estatístico de $\mathrm{McNemar}$, as variáveis não métricas precisam ser transformadas em variáveis métricas. Esse procedimento qualifica a variável como binária ou dicotômica, alguns estudos qualificam essa variável como dummy. Dessa forma, a variável recebe o valor de 1 ou 0, respeitando a característica particular (Fávero et al, (2009).

Feita essa transformação, o passo seguinte é verificar a significância estatística para o teste de McNemar. Para essa verificação, faz-se necessária a análise de algumas etapas (teste de hipótese, nível de significância, estimação do p-valor e a tomada de decisão). $\mathrm{O}$ teste de hipótese é uma inferência estatística cuja finalidade é decidir entre duas hipóteses $\left(H_{0}\right.$ e $\left.H_{1}\right)$, sendo $H_{0}$ a hipótese nula ou hipótese do estudo, que assume a inexistência de alteração ou mudança entre o "antes e depois". Por outro lado, $H_{1}$ é a hipótese alternativa ou hipótese do investigador, que é a predição deduzida do estudo que está sendo comprovado. Quando se deseja tomar uma decisão baseada em diferenças "antes e depois", testa-se a hipótese. Caso a hipótese nula $\left(H_{0}\right)$ não tenha evidência estatística, ela será rejeitada e a hipótese alternativa $\left(H_{1}\right)$ poderá ser aceita. (Hair et al., 2009; Siegel, 1956).

O passo seguinte é estabelecer o nível de significância (limite pré-estabelecido para afirmar que o desvio é decorrente do acaso ou não, corresponde ao risco de rejeitar uma hipótese verdadeira ou aceitar uma hipótese falsa). Em geral, os valores de $1 \%$ ou $5 \%$ correspondentes a 0,01 ou 0,05 são respectivamente os mais comuns nessas escolhas, por esse motivo o valor de 0,05 será o adotado nessa dissertação. Usar o nível de significância igual a 0,05 implica que há a probabilidade de $5 \mathrm{em} 100$ de que a hipótese seja rejeitada, quando deveria ser aceita, isto é, $95 \%$ de chance de ter tomado uma decisão acertada.

Após a escolha do nível de significância, precisa-se estimar o nível descritivo ou p-valor (medida estatística que possibilita a verificação da hipótese quanto à rejeição ou 
aceitação). Isso determina se o resultado está dentro do intervalo de valores na análise do evento que está sendo observado. O p-valor é utilizado para determinar se a hipótese nula deve ser rejeitada (Sweeney, 2013).

Segundo Hair et al. (2009), ao tomar uma decisão favorável ou contrária a uma hipótese, há apenas dois tipos de erros estatísticos (Erro do tipo I e do tipo II). O erro do tipo I rejeita-se $\left(H_{0}\right)$, quando $\left(H_{0}\right)$ é verdadeira, em outras palavras, rejeita incorretamente a hipótese nula, na presunção que exista uma diferença ou correlação quando, na verdade, não há. Já o erro do tipo II se aceita $\left(H_{0}\right)$, quando $\left(H_{0}\right)$ é falsa, isto significa dizer que é a probabilidade de falhar incorretamente na rejeição da hipótese nula; por outro enfoque, a probabilidade de não encontrar uma correlação ou diferença na média quando ela existe.

O teste de McNemar atende à especificação de análise do tipo "antes e depois”, conforme mencionado. $\mathrm{O}$ instrumento de pesquisa foi estruturado em dois cenários (atual e retrospectivo). O teste é adequado para análise do questionário. A partir daqui o direcionamento adotado atenderá aos fundamentos matemáticos do teste estatístico.

A seguir é apresentada uma tábua de frequência de quatro casas Tabela 2 para representar o conjunto de reações dos mesmos indivíduos. Os sinais de (+) e (-) representam as reações. Observe que os casos que acusam modificações estão nas células A e D, ambas as células representam o número total de indivíduos que acusam modificação. A perspectiva de acusar modificação em um sentido $\left(H_{0}\right)$ é $1 / 2(\mathrm{~A}+\mathrm{D})$, e consequentemente de acusar modificação no outro sentido $\left(H_{1}\right)$ é o mesmo. Com isso, a frequência esperada sob $\left(H_{0}\right)$, tanto na célula “A” quanto na “D”, é 1⁄2 (A+D) (McNemar, 1947, Siegel, 1956).

Tabela 2 -- Tábua de quatro casas para a prova de significância de mudanças.

\begin{tabular}{|c|c|c|c|}
\hline \multirow{4}{*}{ Depois } & \multicolumn{3}{|c|}{ Antes } \\
\hline & & - & + \\
\hline & + & A & B \\
\hline & - & $\mathrm{C}$ & D \\
\hline
\end{tabular}

Se “A e D" são os números de casos observados, e o número esperado de casos tanto na célula “A” quanto na "D” é $1 / 2(A+D)$, pela Equação 5 do Qui-quadrado $\left(\chi^{2}\right)$, tem- se: 


$$
\chi^{2}=\sum i=1 \frac{(\mathrm{O} i-\mathrm{E} i)^{2}}{\mathrm{E} i}
$$

Sendo:

O $i$ - Número de casos observados na categoria $(i)$

E $i$ - Número de casos esperado, na categoria $(i)$, sob $\left(H_{0}\right)$

Logo, reescrevendo "A e D" na equação do Qui-quadrado $\left(\chi^{2}\right)$, tem-se o resultado Equação 6 e a Equação 7:

$$
\begin{array}{cc}
\chi^{2}=\sum \mathrm{A}, \mathrm{D} \frac{(\mathrm{O}-\mathrm{E})^{2}}{\mathrm{E}} & \text { Equação } 6 \\
\chi^{2}=\frac{(\mathrm{A}-\mathrm{D})^{2}}{\mathrm{~A}+\mathrm{D}}, \text { com grau de liberdade igual a } 1 & \text { Equação } 7
\end{array}
$$

A correção de continuidade faz-se necessária porque utilizou-se uma distribuição contínua Qui-quadrado $\left(\chi^{2}\right)$ para aproximar uma distribuição discreta. Então, com a correção de continuidade, tem-se o resultado Equação 8 (McNemar, 1947, Siegel, 1956).

$$
\chi^{2}=\frac{(|\mathrm{A}-\mathrm{D}|-1)^{2}}{\mathrm{~A}+\mathrm{D}}, \text { com grau de liberdade igual a } 1 .
$$

Equação 8

\subsubsection{Estatística Descritiva - (Descriptive Statistics)}

A estatística descritiva é a etapa inicial da análise utilizada para descrever e resumir os dados. Com isso, as informações estatísticas dos dados estão sintetizadas e apresentadas em formatos de tabelas e gráficos. O objetivo é sintetizar as informações coletadas na pesquisa de campo. Em geral, para o leitor, a apresentação e interpretação dos dados tornam-se mais fáceis de serem compreendidas quando os dados são sintetizados em resumos tabulares, gráficos ou numéricos (Sweeney, 2013). 


\subsubsection{Teste de Proporção - (Proportion Test)}

Ao analisar duas amostras independentes de uma população de tamanhos $\mathrm{n}$ e m, atendendo ao princípio de $\mathrm{n}>30$ e $\mathrm{m}>30$, tem-se a probabilidade de sucesso $\mathrm{p} 1$ e $\mathrm{p} 2$, respectivamente, sendo $\mathrm{X}$ considerado o número de sucessos na amostra de tamanho $\mathrm{n}$, e Y o número de sucessos na amostra de tamanho m. Portanto, $X \sim B(n, p 1)$ e $Y \sim B(m, p 2)$. Dessa forma, há o interesse em verificar se as seguintes hipóteses estatísticas acontecem. $H_{0}$ - A proporção $P_{1}$ é igual a $P_{2}$ $H_{1}$ - A proporção $P_{1}$ é diferente a $P_{2}$ Com base nisso, a estatística do teste é definida pela Equação 9:

$$
\begin{gathered}
Z=\frac{\widehat{p_{1}}-\widehat{p_{2}}}{\sqrt{\frac{\widehat{p_{1}}\left(1-\widehat{p_{1}}\right)}{n_{1}}+\frac{\widehat{p_{2}}\left(1-\widehat{p_{2}}\right)}{n_{2}}}} \\
\sim \operatorname{Normal}(0,1)
\end{gathered}
$$

Sendo:

$\widehat{p_{1}}$ - Proporção amostral de $\mathrm{x}$

$\widehat{p_{2}}$ - Proporção amostral de y

$n_{1}$ - Tamanho amostral de $\mathrm{x}$

$n_{2}-$ Tamanho amostral de y

Em seguida, calcula-se a estatística do teste e compara-se com o $\mathrm{Z}$ da normal, com média 0 e desvio padrão 1 . Sendo o p-valor dado por: $2 \times P\left(\left|Z_{\text {obs }}\right|>Z_{\text {normal }}\right)$

\subsubsection{Ranking médio para escala likert - (RM Likert Scale)}

As escalas não comparativas de diferencial semântico e likert são comumente utilizadas por pesquisadores para medir as atitudes e conhecer o grau de conformidade. Nas escalas de diferencial semântico, os atributos são caracterizados por adjetivos antônimos, por exemplo, fácil/difícil, moderna/antiquada e, no caso de interesse deste estudo, sem importância/muito importante, de forma que o respondente assinala na escala o ponto que indica a descrição do objeto analisado naquele atributo, sendo opcional a disponibilização das descrições dos pontos intermediários (Samartini, 2006).

A escala de likert é similar à escala de diferencial semântico, porém os extremos da escala de likert são caracterizados por atributos do tipo discordo/concordo, de forma que o 
respondente assinala na escala o ponto de acordo com o nível de concordância com a afirmação feita. Em geral, ocorre a disponibilização das descrições dos pontos intermediários (Samartini, 2006).

O instrumento de pesquisa possui duas questões em escala não comparativa. A estrutura utilizada nestas duas questões apresentou maior similaridade com a estrutura da escala de likert, embora a terminologia utilizada (importância/muito importante) seja uma característica da escala de diferencial semântico. Então, será adotada ao longo deste trabalho a designação de escala de likert, mesmo tendo o entendimento que as questões apresentaram características de terminologia da escala de diferencial semântico e de estrutura da escala de likert.

As duas questões em escala não comparativas são de 5 pontos intermediários (Malhota, 2001; Tresca e De Rose JR, 2004; Cassiano, 2005), para mensurar o grau de importância atribuído ao modo de transporte. A primeira está no questionário de informações gerais e a outra no questionário retrospectivo. Além de analisá-las através da estatística descritiva (média aritmética, porcentagem, desvio padrão), ambas serão representadas através de tabelas, com o respectivo histograma.

Além disso, será calculado o ranking médio (RM), conforme o resultado Equação 10. Essa técnica tem uma abordagem quantitativa das pontuações atribuídas às respostas, relacionando-as à frequência das respostas dos respondentes (Werland, 2013). Para a composição do cálculo executa-se a média ponderada para cada um dos itens do questionário, dividindo-os pelo número total de sujeitos que responderam ao instrumento de pesquisa (Bonici e Junior, 2011; Werland, 2013).

$$
\mathrm{RM}=\sum \frac{(\mathrm{F} i . \mathrm{V} i)}{\mathrm{NS}}
$$

Sendo:

$\mathrm{F} i$ - Frequência observada de cada resposta para cada afirmação

Vi - Valor de cada resposta

NS - Número de sujeitos

Os resultados obtidos são convencionados conforme o Quadro 3. 
Quadro 3 - Parâmetros para Análise do Ranking Médio

\begin{tabular}{|c|c|c|}
\hline Valor Referencial & Atributos & Pontuações \\
\hline 1 & Sem importância & Até 1,5 \\
\hline 2 & Pouca importância & De 1,5 até 2,5 \\
\hline 3 & Indiferente & De 2,5 até 3,5 \\
\hline 4 & Importante & De 3,5 até 4,5 \\
\hline 5 & Muito importante & A partir de 4,5 \\
\hline
\end{tabular}

Fonte: Elaborado pelo autor

\subsection{Análise dos Resultados $-6^{\mathrm{a}}$ Etapa}

Todas as etapas da formulação do problema são relevantes para a produção do conhecimento empírico. $\mathrm{Na}$ análise dos resultados, tem-se o momento em que a pesquisa estabelece três relações importantes: primeiro, a compreensão com os dados coletados; segundo, o momento em que é respondida a pergunta formulada pelo problema; e, por fim, onde é ampliado o conhecimento sobre o assunto a ser pesquisado (Minayo, 1992).

A expectativa quanto à análise do resultado é que possam ser estabelecidas as relações de influência que o evento-chave proporciona no comportamento de viagem. Para isso, fazse necessária a análise das características individuais (levando em consideração as alterações ocasionadas pelo evento-chave), e as razões que influenciaram a tomada de decisão para a escolha do modo de transporte.

\section{$1^{a}$ Fase: Caracterização do perfil dos respondentes}

Espera-se da análise dos resultados a caracterização do perfil do entrevistado. Através desse levantamento, obtem-se um melhor entendimento sobre esse grupo de indivíduos. Para essa verificação, as variáveis a serem investigadas são: gênero, idade, posição (familiar) no domicílio, grau de instrução, ocupação principal, localidade de residência e renda. 
Sabe-se que a renda é um fator importante na tomada de decisão para a escolha do meio de transporte, conforme observado nos estudos de Ortúzar e Willumsem, (1994); Dargay e Hanly, (2004); Arruda, (2005); Household Behaviour and Environment, (2008); Takano, (2010) e Bertazzo e Jacques, (2012). Por esse motivo, realiza-se para a variável renda uma verificação descritiva e uma análise de agrupamento com o meio de transporte utilizado com maior frequência pelos respondentes. Ademais, o processo de tomada de decisão quanto à escolha do modo de transporte é observado mediante a análise de algumas variáveis, além da renda, que foram relacionadas ao instrumento de pesquisa.

\section{$2^{a}$ Fase: Análise da influência do evento-chave no comportamento de viagem}

A determinação da influência no comportamento de viagem será realizada através da análise das variáveis que foram inseridas no banco de dados. Conforme mencionado, são vários os fatores que influenciam o comportamento de viagem, associados à ocorrência do evento-chave "nascimento de crianças". Desse modo, as variáveis selecionadas buscam entender esse processo. Foram inseridas 26 variáveis no banco de dados do software IMB SPSS Statistics 22. As análises (agrupamento, correspondência, teste de McNemar e estatística descritiva) realizadas por esse programa computacional buscam entender essa alteração no exame de algumas dessas variáveis.

As variáveis como a obtenção da carteira de habilitação, a quantidade de veículos existentes nos domicílios, o grau de importância a fatores como segurança, tempo de deslocamento, conforto/conveniência, custo, flexibilidade, qualidade do sistema de transporte público, e questões ambientais como poluição do ar, consumo energético e ruídos, devem ser levadas em consideração para a análise do comportamento de viagem.

\section{$3^{a}$ Fase: Análise da influência do evento-chave na realização dos deslocamentos}

A presença de crianças pode alterar as rotinas familiares e, consequentemente, a realização dos deslocamentos. Para a realização das atividades das crianças, há a necessidade de reorganização da agenda de atividades e o encadeamento de viagem dos pais. Com isso, o domicílio torna-se uma unidade de tomada de decisão que pode ser influenciada pelos outros membros da família (Pitombo, 2003; Silva, 2006 e 2011). 
Segundo Arruda, (2010) a inter-relação entre os membros do domicílio pode determinar e afetar a agenda de atividades do indivíduo e dos outros membros do domicílio.

Desse modo, a família e as outras estruturas sociais influenciam o comportamento dos indivíduos na realização dos deslocamentos (Pitombo, 2003; Silva, 2006; 2011), e fatores como a composição do domicílio, a idade, o gênero, a posição familiar, a presença de crianças no domicílio, entre outros, afetam significativamente as atividades do indivíduo e as decisões referentes ao deslocamento (Chapin, 1974; Jones et al., 1983; Pitombo, 2003; Taco 2003).

$4^{a}$ Fase: Análise da tomada de decisão quanto à escolha do meio de transporte

A tomada de decisão está presente em todos os momentos da vida humana. As melhores escolhas para os resultados mais agradáveis são uma meta constante. Mas, para evitar escolhas equivocadas, faz-se necessário analisar as hipóteses e os fatores (variáveis) que fazem parte do processo.

O comportamento de viagem dos indivíduos leva em consideração as decisões de escolhas, de forma a estruturar a melhor maneira de utilizar um meio de transporte para realizar um deslocamento, com a finalidade de executar uma atividade. Verifica-se que o processo de organização pode ser influenciado regularmente. Dessa forma, a investigação é pela resposta de questões como se o nascimento do filho(a) influenciou no domicílio a escolha do meio de transporte e se existe a possibilidade de usar um outro meio de transporte para a realização dos deslocamentos. 


\section{ANÁLISE DOS RESULTADOS}

\subsection{Descrição das Amostras para a Caracterização do Perfil dos Respondentes}

O objetivo deste capítulo é apresentar os resultados obtidos a partir das análises realizadas. As descrições não serão demonstradas, necessariamente, seguindo a estrutura do questionário. Algumas tabelas e gráficos não serão apresentados neste capítulo, mas estarão disponíveis nos Anexos relacionados às análises, ao final do documento.

O banco de dados original contabilizou 269 amostras domiciliares. Porém, para a composição da análise, foram utilizados apenas 234 registros domiciliares, cujos questionários foram iniciados e respondidos até o final. As outras 35 amostras foram descartadas, pois o questionário não foi concluído.

Conforme mencionado no Capítulo 3, a pesquisa foi realizada em todo o território nacional, por meio de um questionário on line. Entre as localidades dos respondentes, o Distrito Federal liderou a pesquisa com $37.18 \%$ das participações, sendo seguido pelo estado de Goiás com 32.91\%. Os outros territórios brasileiros quantificaram 29,91\%, sendo que alguns estados como o Pará, São Paulo, Minas Gerais, Santa Catarina e Mato Grosso apresentaram participações mais efetivas, conforme ilustra a Figura 12.

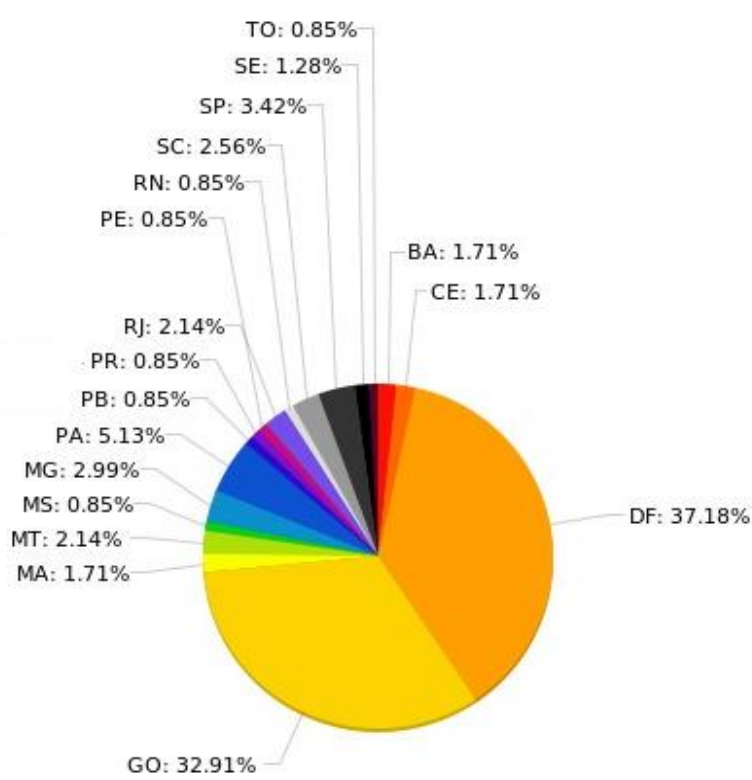

Figura 12 - Participação por estados brasileiros Fonte: Elaborado pelo autor 
Quanto ao gênero dos participantes, $83.76 \%$ são do sexo feminino e $16.24 \%$ são do sexo masculino. $\mathrm{O}$ instrumento de pesquisa estava acessível a ambos o sexo e contava com um questionário específico à coleta de informações sobre o companheiro(a) ou cônjuge, de forma a analisar a posição familiar do domicílio.

O conceito de chefia nas pesquisas domiciliares, segundo Sabóia e Soares (2004), tem apresentado um aumento da proporção de mulheres chefes de família. Para Calderan e Dill (2010), isso pode ser explicado pelas mudanças de paradigma que envolvem a família, pois está frequente as rupturas das relações conjugais. O fato é que há semelhanças, mas também diferenças, como apontado no estudo de Ferrinho e Craveiro (2011), acerca do papel do parceiro masculino no planejamento familiar e nas gravidezes.

Nesse tocante, $69.66 \%$ dos(as) respondentes informaram ser parceiro(a) ou cônjuge. Por outro lado, $26.50 \%$ assumiram o papel de chefe de família e $3.85 \%$ de filho(a), isto é, moram com os pais e possuem filhos(as). A análise da estatística descritiva pela frequência cruzada mostra que 152 mulheres (77.55\%), de um total de 196 mulheres entrevistadas, assumem o papel de parceiras, atribuindo aos seus companheiros ou cônjuges o título de chefe domiciliar.

Em relação à idade, verificou-se uma predominância maior entre as idades de 29 a 40 anos, conforme ilustra a Figura 1B contida no Anexo B - Caracterização do Perfil dos Respondentes. Quanto ao grau de instrução, observou-se que, predominantemente, os(as) respondentes possuem um alto grau de escolaridade, conforme observa-se na Figura 13. Das seis opções oferecidas, não houve ocorrências para a categoria "sem escolaridade", e apenas uma ocorrência para o ensino fundamental. A maioria dos dados eram pertencentes às categorias pós-graduação e ensino superior. 


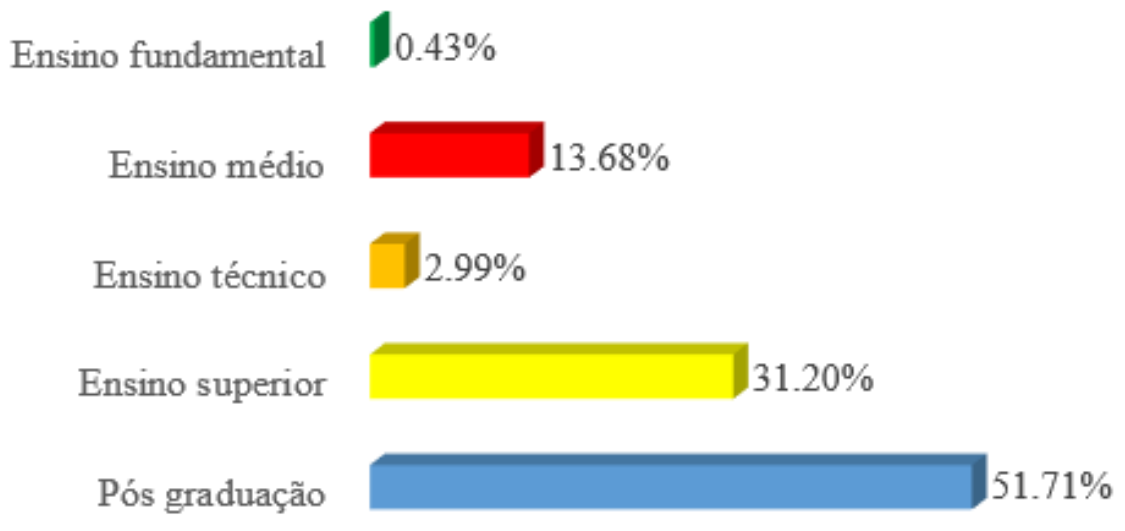

Figura 13 - Nível de instrução dos(as) participantes Fonte: Elaborado pelo autor

A variável renda foi organizada segundo o critério do IBGE, baseada no número de salários mínimos, que não difere muito da visão da Fundação Getúlio Vargas (FGV). Apenas uma única alteração foi realizada no instrumento de pesquisa, a inserção da opção sem rendimento. Em geral, nas pesquisas realizadas tradicionalmente não aparece essa opção, porém no momento da validação do questionário a opção foi sugerida de forma considerável. O resultado dessa opção não foi expressivo, enquanto outros resultados tiveram maior predominância, como as opções que designavam as faixas salariais entre 4 e 10 salários mínimos e 10 e 20 salários mínimos, conforme observado na Figura 14.

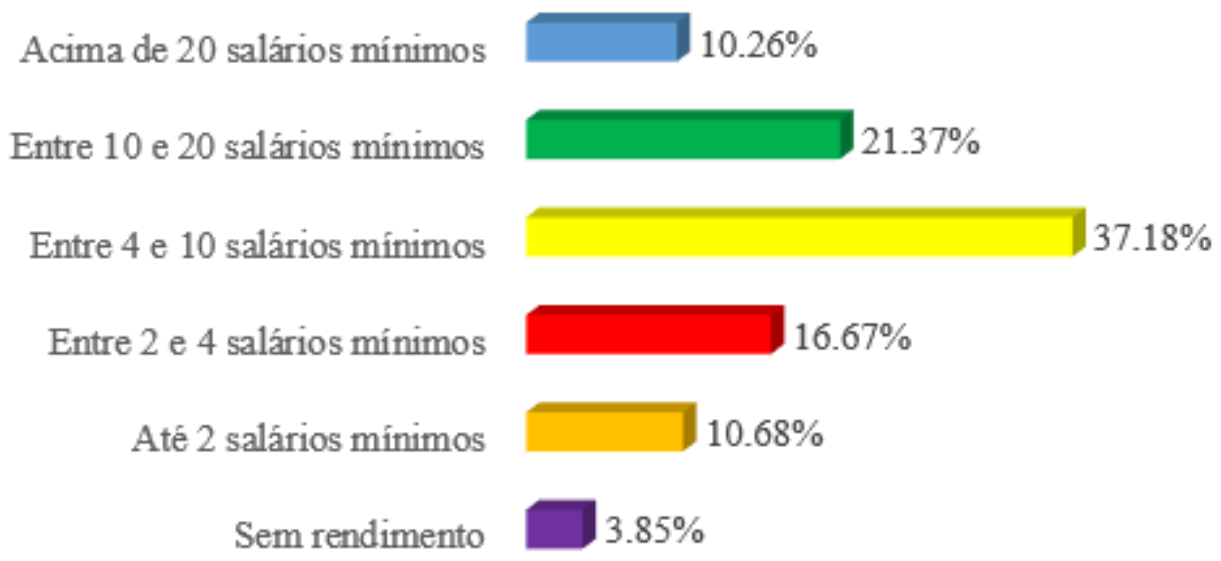

Figura 14 - Renda bruta familiar dos(as) participantes Fonte: Elaborado pelo autor

Ao investigar as variáveis renda e o meio de transporte utilizado com maior frequência, pela análise Cluster, verifica-se a formação de 3 (três) agrupamentos, conforme ilustrado na Figura 15 e nas tabelas $n^{\circ} 1 \mathrm{D}, 2 \mathrm{D}, 3 \mathrm{D}$ e 4D do Anexo D - Análise de Cluster. Notase que a variável renda tem uma relação com as escolhas dos meios de transportes. 


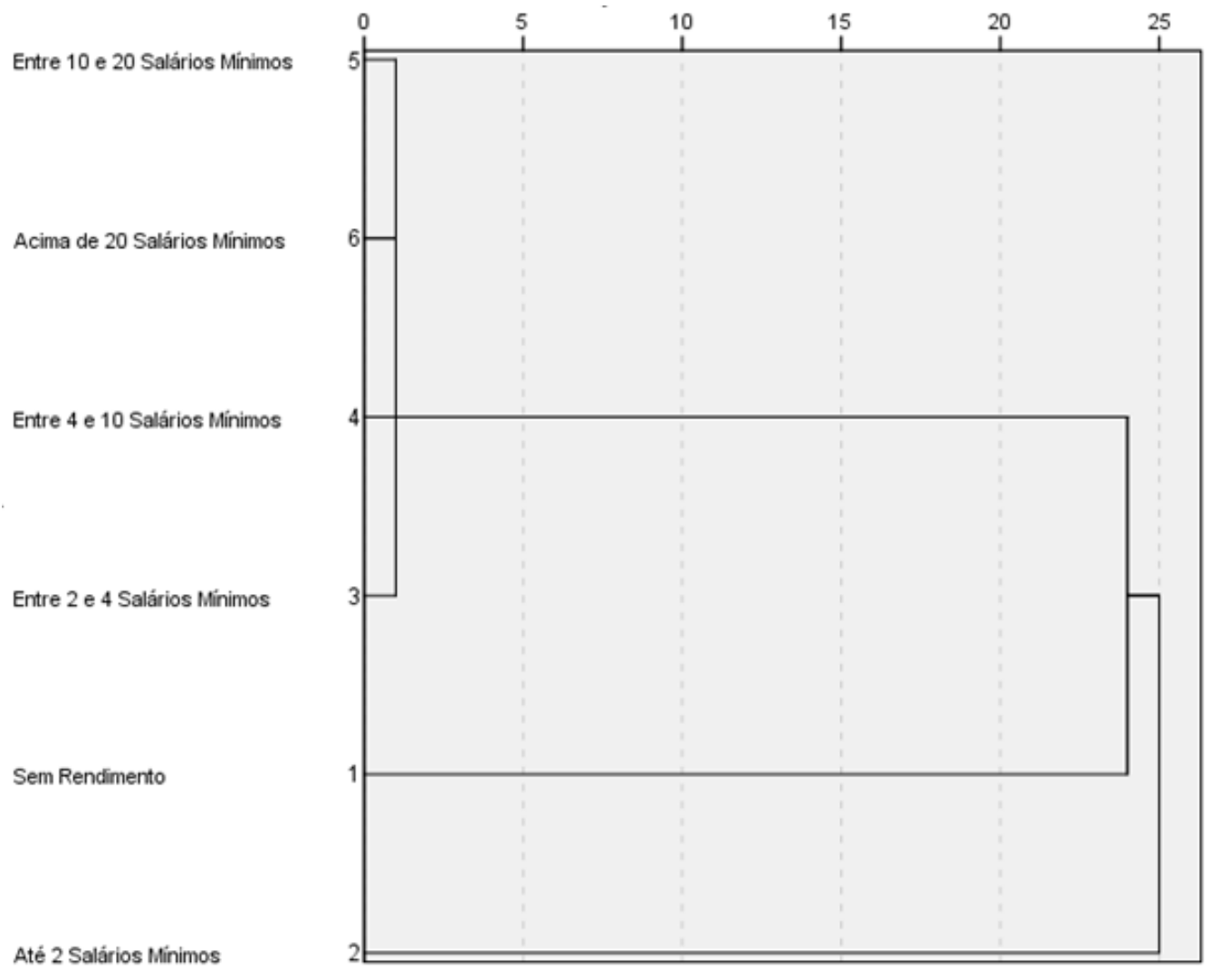

Figura 15 - Agrupamento entre renda e meio de transporte Fonte: Elaborado pelo autor

Através do dendograma verificam-se as associações das faixas de renda em três agrupamentos. A primeira associação é dos sem rendimento, onde 2 pessoas se locomovem de carona, 6 indivíduos de ônibus e 1 a pé. Na segunda associação de respondentes, com renda de até dois salários mínimos, 6 pessoas dirigem automóvel, 5 pegam carona, 3 utilizam a motocicleta, 4 o ônibus, apenas 1 utiliza a bicicleta e 6 vão a pé. A terceira associação, dos(as) respondentes com rendimento de dois salários mínimos até acima de vinte salários mínimos, os resultados mostraram que a escolha do meio de transporte, em geral, ocorre por automóvel, sendo eles(as) os(as) motoristas.

Ao analisar a variável ocupação principal, observou-se uma forte tendência na opção empregado(a), conforme pode ser analisado na Figura 16. Numa análise mais detalhada, através de tabulações cruzadas, tendo o total de 196 mulheres entrevistadas, observou-se que 109 mulheres são empregadas e 183 afirmaram que os deslocamentos aumentaram após o nascimento das crianças. Com isso, conclui-se que, nessa amostra, grande parte das entrevistadas desempenham atividade remunerada e são as principais responsáveis pelos deslocamentos dos filhos, pois foram relatadas apenas 28 ocorrências de 
companheiros ou cônjuges que aumentaram os seus deslocamentos após o nascimento do(a) filho(a).

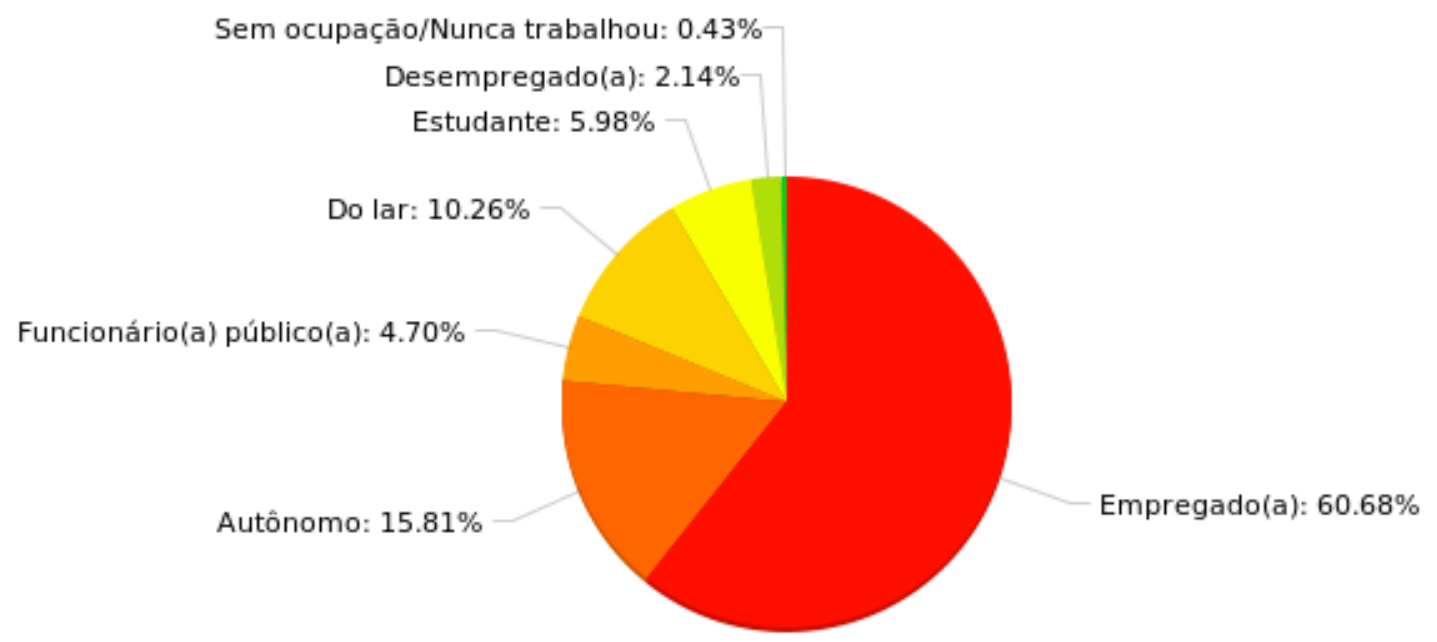

Figura 16 - Ocupações dos (as) participantes Fonte: Elaborado pelo autor

Ao analisar as duas variáveis - renda e ocupação principal - pela análise Anacor, observase que há uma correspondência muito próxima entre o vínculo empregado ao rendimento de 4 a 10 salários, e o de estudante ao sem rendimento. As outras faixas salariais também foram analisadas. $\mathrm{O}$ mapa perceptual figura $\mathrm{n}^{\circ} 1 \mathrm{C}$ e as tabelas de $\mathrm{n}^{\circ} 1 \mathrm{C}$ a $\mathrm{n}^{\circ} 8 \mathrm{C}$ podem ser visualizadas no Anexo C - Análise Anacor.

\subsection{Como o Evento-chave Afeta o Comportamento de Viagem}

O instrumento de pesquisa contemplou a análise em dois momentos distintos, antes e depois do evento-chave. Alguns dos resultados a seguir proporcionarão uma descrição comparativa desses dois momentos ao analisar o comportamento de viagem.

Um dos pré-requisitos para a motorização é a obtenção da carteira de habilitação. Nesse sentido, o estudo procurou analisar se o evento-chave influenciou a aquisição da carteira de habilitação e, consequentemente, a mudança para o transporte individual (automóvel).

A aplicação do teste de McNemar verifica se houve alteração na aquisição da carteira de habilitação, entre o período antes e depois do evento-chave. Para isso faremos o teste de hipótese, sendo: 
$H_{0}$ - Não houve mudanças quanto à aquisição

$H_{1}$ - Houve mudanças quanto à aquisição

Tabela 3 - Carteira de habilitação antes do nascimento e após o nascimento

\begin{tabular}{|c|c|c|c|c|c|}
\hline \multirow{2}{*}{\multicolumn{3}{|c|}{$\begin{array}{l}\text { Carteira de Habilitação } \\
\text { (Antes do Nascimento) }\end{array}$}} & \multicolumn{2}{|c|}{$\begin{array}{c}\text { Carteira de Habilitação } \\
\text { (Após o Nascimento) }\end{array}$} & \multirow{3}{*}{$\begin{array}{c}\text { Total } \\
56 \\
\end{array}$} \\
\hline & & & Não & Sim & \\
\hline & \multirow{2}{*}{ Não } & Contagem & 27 & 29 & \\
\hline & & $\%$ do Total & $11,5 \%$ & $12,4 \%$ & $23,9 \%$ \\
\hline & \multirow{2}{*}{ Sim } & Contagem & 3 & 175 & 178 \\
\hline & & $\%$ do Total & $1,3 \%$ & $74,8 \%$ & $76,1 \%$ \\
\hline \multirow{2}{*}{ Total } & & Contagem & 30 & 204 & 234 \\
\hline & & $\%$ do Total & $12,8 \%$ & $87,2 \%$ & $100,0 \%$ \\
\hline
\end{tabular}

Conforme apresentado na Tabela 3 e no Anexo E - Análise de McNemar, na estatística do teste (Tabela $\left.\mathrm{n}^{\mathrm{o}} 1 \mathrm{E}\right)$ a hipótese $\left(H_{0}\right)$ pode ser rejeitada, com o nível de significância de $5 \%$. Então, há indícios de que ocorre alteração com relação à aquisição da carteira de habilitação após o evento-chave.

Ao analisar as mesmas variáveis através da estatística descritiva, observou-se que houve um aumento no número de carteiras de habilitação após o nascimento da criança. Ao realizar o cruzamento por gênero, observou-se que não houve alteração no aumento da aquisição da carteira de habilitação para os companheiros ou cônjuges. Os dados mostraram que o evento-chave não influenciou a aquisição para o gênero masculino, com isso conclui-se que todo o aumento referente à aquisição da carteira de habilitação aconteceu no gênero feminino, conforme observado na Tabela 4 e na Tabela 5.

Tabela 4 - Gênero e a carteira de habilitação (antes do nascimento)

\begin{tabular}{l|c|c|c}
\hline \multirow{2}{*}{ Gênero } & \multicolumn{2}{|c|}{$\begin{array}{c}\text { Carteira de Habilitação } \\
\text { (Antes do Nascimento) }\end{array}$} & \multirow{2}{*}{ Total } \\
\cline { 2 - 3 } & Não & Sim & \\
\hline Feminino & 55 & 141 & 196 \\
\hline Masculino & $\mathbf{1}$ & $\mathbf{3 7}$ & $\mathbf{3 8}$ \\
\hline Total & 56 & 178 & 234 \\
\hline \multicolumn{3}{l}{} \\
\hline
\end{tabular}


Tabela 5 - Gênero e a carteira de habilitação (após o nascimento)

\begin{tabular}{l|c|c|c}
\hline \multirow{2}{*}{ Gênero } & \multicolumn{2}{|c|}{$\begin{array}{c}\text { Carteira de Habilitação (Após o } \\
\text { Nascimento) }\end{array}$} & \multirow{2}{*}{ Total } \\
\cline { 2 - 3 } & Não & Sim & 196 \\
\hline Feminino & 29 & 167 & $\mathbf{3 8}$ \\
\hline Masculino & $\mathbf{1}$ & $\mathbf{3 7}$ & 234 \\
\hline Total & 30 & 204 & \\
\hline
\end{tabular}

Houve um aumento referente a $11,11 \%$ na aquisição da carteira de habilitação. No Anexo B - Caracterização do Perfil dos Respondentes são apresentados dois gráficos de diagramas circulares, as figuras $n^{\circ} 2 \mathrm{~B}$ e $3 \mathrm{~B}$, para auxiliar nas informações referentes ao estudo da variável aquisição da carteira de habilitação.

Ainda nesse sentido, verificou-se os dados referentes à quantidade de automóveis existentes no domicílio, conforme as ilustrações na Figura 17 e na Figura 18.

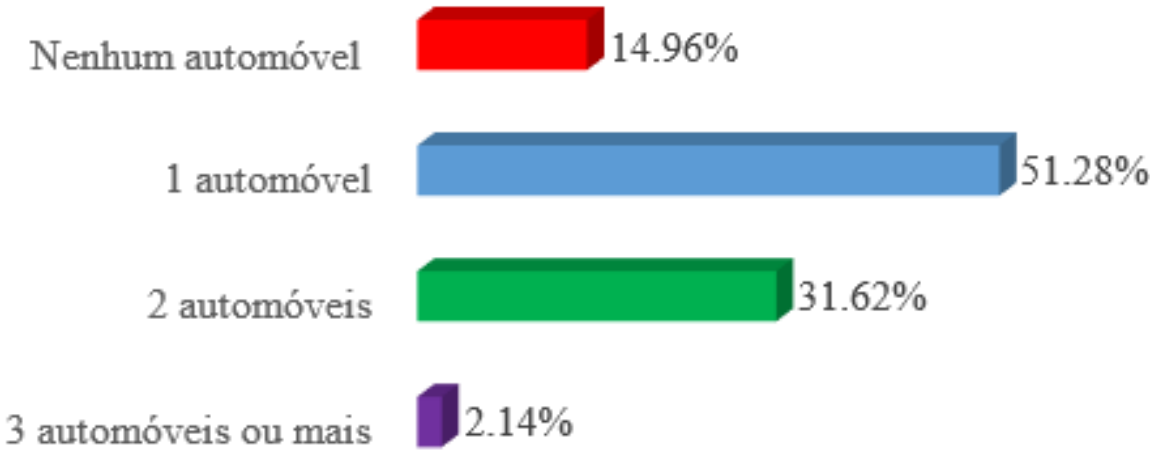

Figura 17 - Quantidades de automóveis (Antes do nascimento) Fonte: Elaborado pelo autor

Observa-se que a quantidade de domicílios que não possuem automóvel ou que possuem apenas um carro é considerável antes da chegada do filho(a). Porém, após o nascimento da criança, observou-se uma alteração referente à aquisição do automóvel, conforme pode ser analisado na Figura 18. 


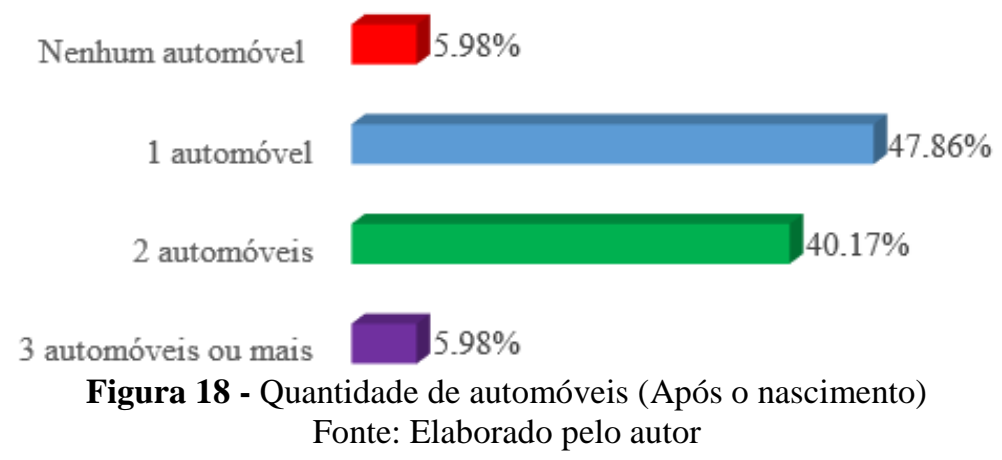

Observa-se que após o nascimento da criança ocorreu o aumento na aquisição do segundo e do terceiro carro. Após o evento-chave, houve a redução nos domicílios que não possuíam carro ou nos que possuíam apenas um, possivelmente devido às novas aquisições. Logo, o evento-chave, na amostra analisada, trouxe alteração no comportamento de viagem, de forma a possibilitar a escolha por meio de transporte individual.

A possibilidade de escolha dos meios de transporte depende de vários fatores, como: custo, segurança, conforto, maior flexibilidade, menor tempo de deslocamento, questões ambientais, e até mesmo a qualidade do sistema de transporte público, como limpeza, frequência e pontualidade. A partir disso, foi solicitado aos respondentes uma avaliação do meio de transporte utilizado com maior frequência em relação ao grau de importância atribuído aos fatores citados acima, tanto antes quanto depois do nascimento do filho(a). Ao questionar sobre o grau de importância para os dois momentos pesquisados, as opções de resposta estavam em Escala Likert, conforme apresentado nas tabelas $\mathrm{n}^{\circ} 1 \mathrm{~F} \mathrm{e} \mathrm{n}^{\circ} 2 \mathrm{~F}$, contidas no Anexo F - Análise do Ranking Médio.

O grau de importância foi mensurado pelo método de análise do cálculo do Ranking Médio (RM) para a Escala de Likert, conforme a Tabela 6.

Tabela 6 - Grau de Importância

\begin{tabular}{c|c|c}
\hline \multirow{2}{*}{ Fatores } & \multicolumn{2}{c}{ Períodos } \\
\cline { 2 - 3 } & Antes do Nascimento & Após o Nascimento \\
\hline Segurança & 4,06 & 4,31 \\
\hline Tempo de deslocamento & 4,16 & 4,37 \\
\hline Conforto / Conveniência & 4,02 & 4,24 \\
\hline Custo & 3,86 & 3,89 \\
\hline Flexibilidade no deslocamento & 4,09 & 4,29 \\
\hline Qualidade do sist. transp. público & 3,82 & 4,01 \\
\hline Questões ambientais & 3,71 & 3,81 \\
\hline
\end{tabular}

Fonte: Elaborado pelo autor 
Não foi observada nenhuma diferença considerável nas opções escolhidas pelos respondentes quanto ao grau de importância de alguns fatores antes e após o evento nascimento do primeiro filho. Isso implica dizer que os fatores como o custo, segurança, conforto, maior flexibilidade, menor tempo de deslocamento, questões ambientais e a qualidade do sistema de transporte público, em geral, são mantidos na percepção dos respondentes para os dois períodos. As pontuações obtidas estiveram entre 3,5 e 4,5 nos dois períodos. Dessa forma, ao serem convencionados pela tabela de parâmetros do ranking médio, os resultados foram considerados "Importantes", isto é, foi mantido o grau de importância para os dois períodos investigados.

\subsection{Como o Evento-chave Afeta a Realização dos Deslocamentos}

A análise da pesquisa contemplou, além dos dados dos respondentes, as informações dos seus respectivos cônjuges ou companheiros(as), quando ambos residiam no mesmo domicílio. O instrumento de pesquisa estava adaptado para essa coleta de informações. Os resultados demostraram que $87,18 \%$ dos respondentes possuíam companheiro(a) ou cônjuge morando no mesmo domicílio (204 registros), enquanto 12,82\% não possuíam os parceiros(as) residindo sob o mesmo teto (30 registros). Dessa forma, as análises a seguir apresentaram os resultados tanto dos respondentes quanto dos seus cônjuges ou companheiros(as), no período após o nascimento do(a) primeiro(a) filho(a).

Entende-se que a realização das viagens é uma demanda derivada da participação em atividades, pois acredita-se que poucas viagens são feitas por si mesmas, sem uma razão lógica, isto é, sem um destino que conduza à realização de alguma atividade, seja ela: trabalho, estudo, compra, lazer, entre outras. A partir disso, a pesquisa procurou identificar se após o nascimento da criança houve um aumento no número de atividades (compromissos) e deslocamentos.

A pesquisa mostrou que houve um aumento no número de atividades de $88,03 \%$ para os respondentes. Estes aumentos nas atividades diárias aconteceram em alguns dias durante a semana, e para outros(as) respondentes durante todos os dias no decorrer da semana, conforme pode ser observado na Figura 19. 


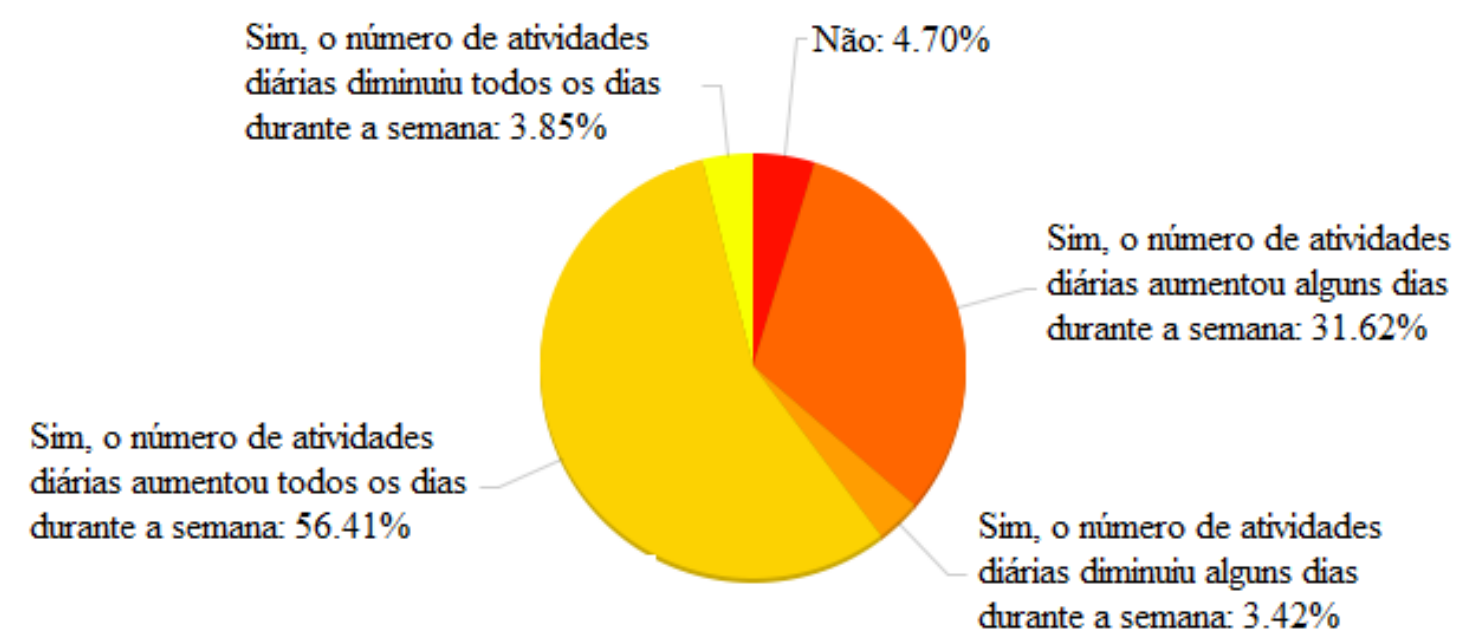

Figura 19 - Atividades diárias (compromissos) após o nascimento Fonte: Elaborado pelo autor

Quanto às atividades diárias (compromissos) do(a) companheiro(a) ou cônjuge, também houve um aumento de 62,93\%, conforme verificado na Figura 20.

Sim, o número de atividades diárias dele(a)

diminuiu todos os dias durante a semana: $0.98 \%$

Sim, o número de atividades diárias dele(a) aumentou todos os dias durante a semana: $27.32 \%$

Sim, o número de atividades diárias dele(a) diminuiu alguns dias durante a semana: $5.85 \%$

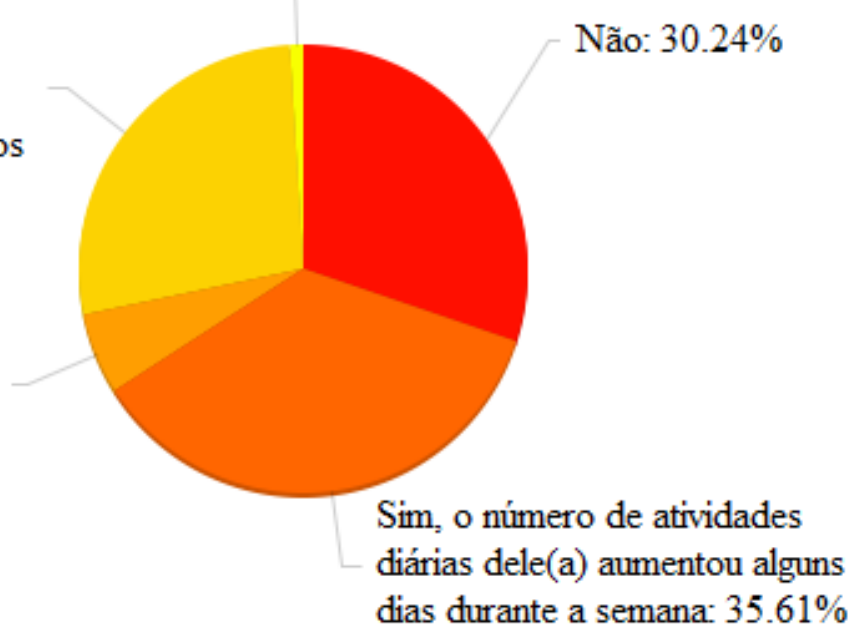

Figura 20 - Atividades diárias (compromissos) do(a) companheiro(a) ou cônjuge após o nascimento Fonte: Elaborado pelo autor

A par dessas informações, conclui-se que o nascimento do(a) primeiro(a) filho(a) traz uma alteração na agenda de atividades dos pais, pois além dos compromissos que já são realizados pelo casal, há o acréscimo de outras atividades da criança, que também precisam ser executadas. Ao analisar o gênero feminino, observou-se que 175 mulheres 
$(89,28 \%)$, de um total de 196 respondentes, afirmaram que as atividades aumentaram em alguns ou em todos os dias, conforme a Tabela $n^{\circ}$ 1B, do Anexo B - Caracterização do Perfil dos Respondentes. Com isso, após o nascimento, os domicílios aumentam os números de atividades, sendo observada uma relevância para o gênero feminino. Se houve aumento nas atividades domiciliares, possivelmente houve mudanças na quantidade de deslocamentos.

Para os respondentes e seus(suas) respectivos(as) companheiros(as) ou cônjuges, o número de deslocamentos tiveram uma alteração. Os dados mostraram um aumento de $83.33 \%$ para o respondente, e de $69.12 \%$ para o(a) parceiro(a), conforme a Figura 21 e a Figura 22, respectivamente.

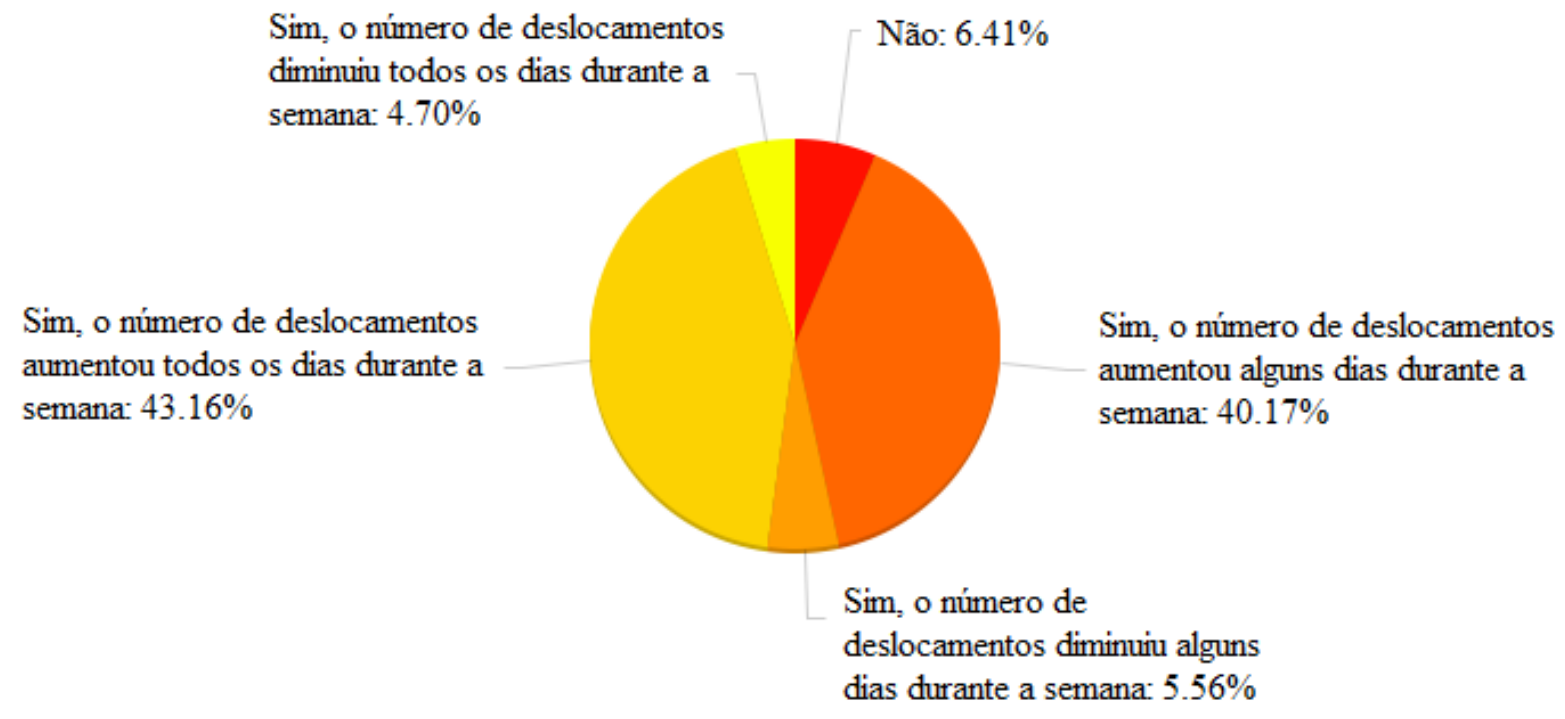

Figura 21 - Deslocamentos após o nascimento

Fonte: Elaborado pelo autor 
Sim, o número de deslocamentos dele(a) diminuiu todos os dias durante a semana: $0.98 \%$

Sim, o número de deslocamentos dele(a) aumentou todos os dias durante a semana: $25.98 \%$

Sim, o número de deslocamentos dele(a) diminuiu em alguns dias durante a semana: $1.96 \%$

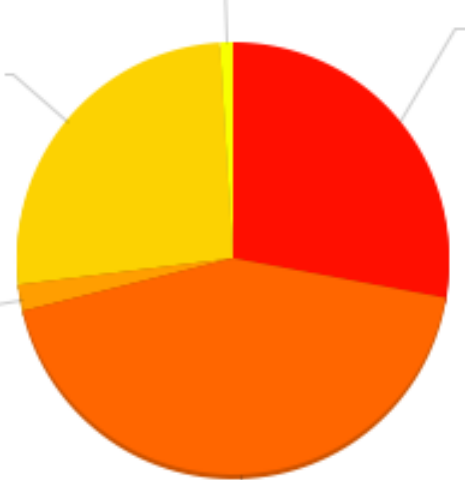

Não: $27.94 \%$

Sim, o número de deslocamentos dele(a) aumentou em alguns dias durante a semana: $43.14 \%$

Figura 22- Deslocamentos do(a) companheiro(a) ou cônjuge após o nascimento

Fonte: Elaborado pelo autor

Ainda nessa vertente, a análise Anacor possibilita estabelecer uma relação entre as atividades e os deslocamentos, conforme apresenta-se nos mapas perceptuais da Figura 23 e da Figura 24, do respondente e do(a) parceiro(a), respectivamente.

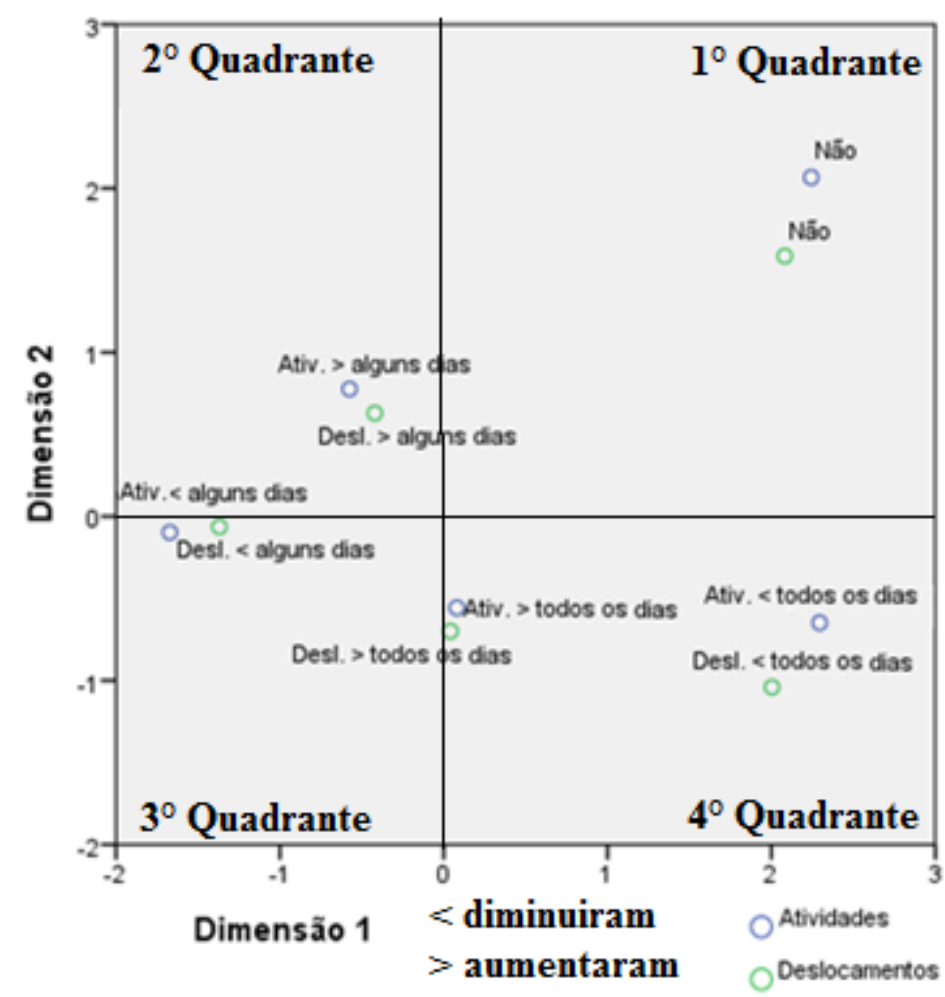

Figura 23 - Mapa perceptual de atividades e deslocamentos após o nascimento Fonte: Elaborado pelo autor 


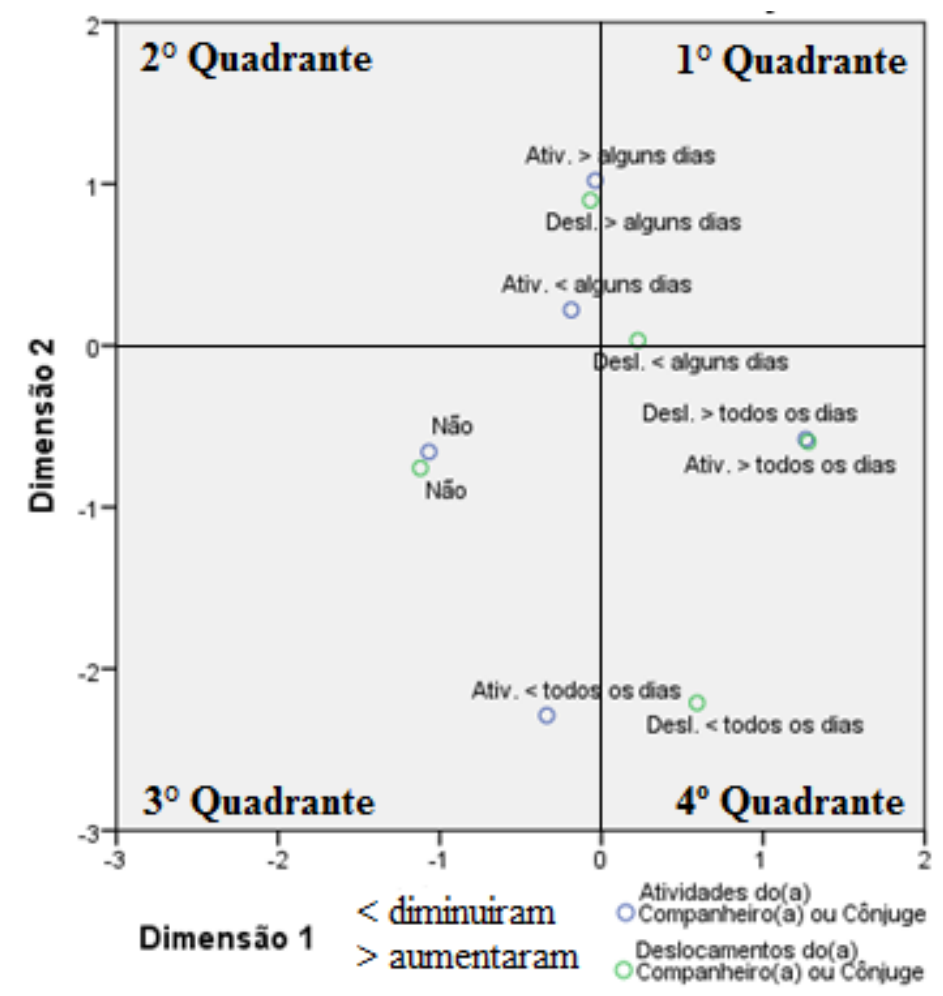

Figura 24 - Mapa perceptual de atividades e deslocamentos do(a) companheiro(a) ou cônjuge após o nascimento

Fonte: Elaborado pelo autor

Através dessa análise, conclui-se que há uma correspondência entre as atividades e os deslocamentos após o nascimento das crianças nos domicílios. Nota-se uma proximidade ou mesmo um alinhamento entre o aumento ou a diminuição de atividades $\mathrm{e}$ deslocamentos, em alguns casos chegaram a quase se sobrepor. Através da divisão em quadrantes, é possível verificar com melhor precisão a localização dos pontos através das linhas e colunas e a respectiva relação com as duas dimensões, porém as pontuações entre as linhas e colunas através das duas dimensões estão apresentadas nas tabelas $\mathrm{n}^{\circ} 9 \mathrm{C}$ a 12C (Figura 23) e tabelas n 13C a 16C (Figura 24) do Anexo C - Análise Anacor.

Observa-se uma relevância para o gênero feminino referente ao aumento na quantidade de deslocamentos. Entre as respondentes, 163 mulheres $(83,16 \%)$ de um total de 196, afirmaram que os deslocamentos aumentaram em alguns ou em todos os dias, conforme a tabela nº 2B, do Anexo B - Caracterização do Perfil dos Respondentes. 


\subsection{Como Ocorre a Tomada de Decisão quanto à Escolha do Meio de Transporte num Tempo Longitudinal}

Sabe-se que os deslocamentos domiciliares são realizados por vários meios de transporte. Devido à impossibilidade de analisar todos os meios de transporte utilizados pelos respondentes em seus deslocamentos, foi então solicitado no instrumento de pesquisa que fosse registrado o meio de transporte utilizado com maior frequência. Os dados mostraram que antes do nascimento do(a) filho(a) já existia uma quantidade considerável de optantes pelos meios de transporte motorizados, conforme pode ser observado na Figura 25.

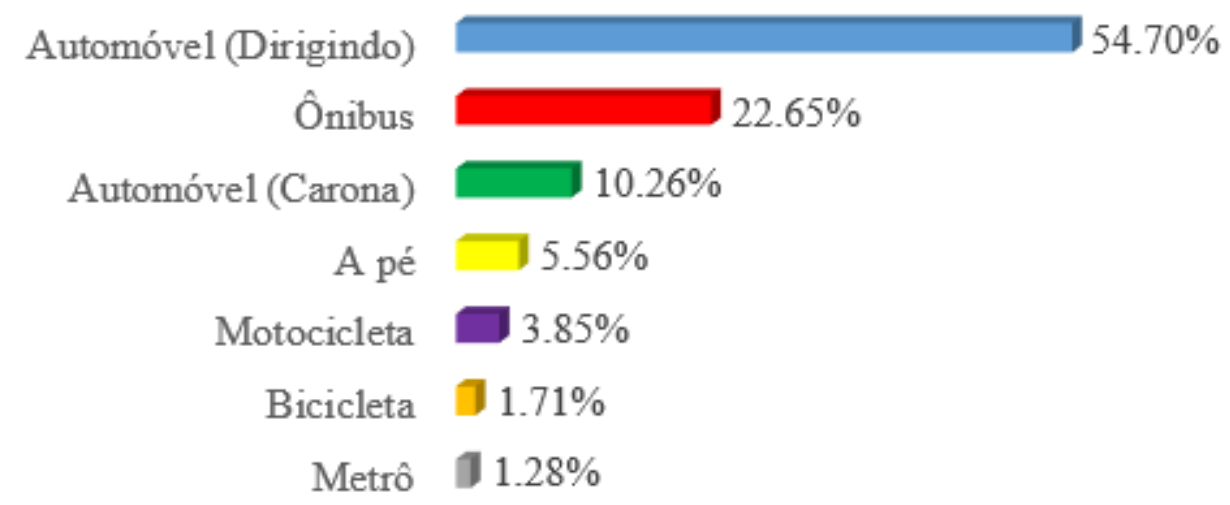

Figura 25 - Modo de transportes utilizado com maior frequência antes do nascimento Fonte: Elaborado pelo autor

Ao avaliar o período após o nascimento da criança, houve registros de diminuição para a motocicleta, ônibus, bicicleta e os deslocamentos a pé. O uso do metrô se manteve constante nos dois períodos investigados. Foi verificado que o meio de transporte realizado por automóvel, seja dirigindo ou de carona, teve um acréscimo, conforme ilustrado na Figura 26. Porém, as diferenças mais consideráveis foram referentes ao ônibus e ao automóvel (dirigindo). 


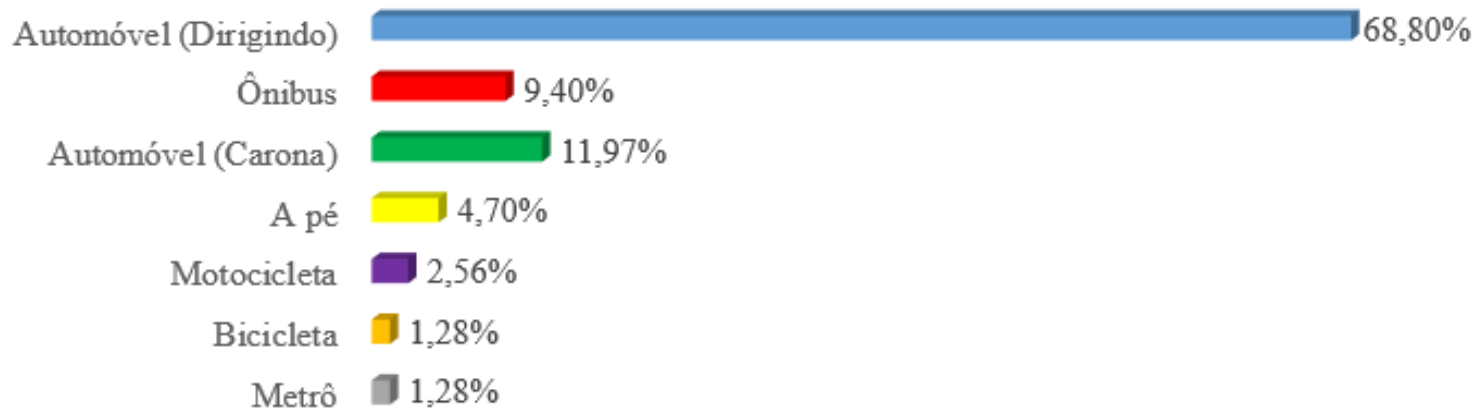

Figura 26 - Modo de transportes utilizado com maior frequência após o nascimento Fonte: Elaborado pelo autor

Para verificar se há alguma mudança significativa entre o meio de transporte utilizado antes e depois do evento-chave, foi utilizado o Teste não paramétrico de McNemar para cada uma das opções de meio de transporte apresentadas no instrumento de pesquisa. Para isso foram consideradas as seguintes hipóteses e o nível de significância de 5\%:

$H_{0}$ - Não houve mudanças significativas no meio de transporte utilizado $H_{1}$ - Houve mudanças significativas no meio de transporte utilizado

Tabela 7 encontram-se os p-valores para cada variável.

\begin{tabular}{c|c} 
Tabela 7 - Resultados Teste McNemar para cada tra \\
\cline { 2 - 2 } Transporte & p-valor \\
\hline A pé & 0,773 \\
Automóvel (Carona) & 0,571 \\
Automóvel (Dirigindo) & $\mathbf{< 0 , 0 0 1}$ \\
Bicicleta & 1 \\
Metrô & 1 \\
Motocicleta & 0,579 \\
Ônibus & $\mathbf{< 0 , 0 0 1}$ \\
\hline
\end{tabular}

Fonte: Elaborado pelo autor

Verifica-se, então, que não houve evidências para recusar $\left(H_{0}\right)$ nos meios a pé, automóvel (carona), bicicleta, metrô e motocicleta. Ou seja, não houve mudanças significativas referentes a esses meios de transporte que tenham sido influenciadas pelo evento-chave. Já o automóvel (dirigindo) e o ônibus apresentaram resultados significativos, segundo o p-valor com 5\% de significância. 
Numa segunda análise será realizado um teste de proporção para verificar se o número de respondentes que usavam cada meio de transporte antes e depois do evento-chave é significativo. Para auxiliar nas análises se há ou não mudanças significativas, o teste de proporção terá o nível de significância de $5 \%$ e as seguintes hipóteses:

$H_{0}$ - A proporção de usuários por meio de transporte antes é igual à proporção de usuários por meio de transporte depois $H_{1}$ - A proporção de usuários por meio de transporte antes é diferente da proporção de usuários por meio transporte depois

Na Tabela 8 encontram-se os p-valores para cada meio de transporte pesquisado.

Tabela 8 - Resultados Teste de Proporção para cada transporte

\begin{tabular}{l|c}
\hline Transporte & p-valor \\
\hline A pé & 0,834 \\
Automóvel (Carona) & 0,659 \\
Automóvel (Dirigindo) & $<\mathbf{0 , 0 0 1}$ \\
Bicicleta & 1 \\
Metrô & 1 \\
Motocicleta & 0,559 \\
Ônibus & $<\mathbf{0 , 0 0 1}$ \\
\hline
\end{tabular}

Fonte: Elaborado pelo autor

Observa-se que apenas os meios de transporte automóvel (dirigindo) e ônibus apresentaram evidências para recusar a hipótese nula $\left(H_{0}\right)$ de que as proporções são iguais. Assim como no teste de McNemar, foram eles que apresentaram mudanças significativas. A Tabela 9 apresenta as informações do transporte utilizado pelas pessoas antes e depois de terem filhos, no caso, se o indivíduo se locomovia dirigindo algum automóvel ou usava outro meio.

Tabela 9 - Frequências do meio de transporte automóvel (Dirigindo)

\begin{tabular}{l|c|c}
\hline \multirow{2}{*}{ Antes } & \multicolumn{2}{|c}{ Depois } \\
\cline { 2 - 3 } & Automóvel (Dirigindo) & Outros \\
\hline Automóvel (Dirigindo) & 114 & 14 \\
\hline Outros & 47 & 59 \\
\hline \multicolumn{2}{c}{ Fonte: Elaborado pelo autor }
\end{tabular}


Observa-se que 114 respondentes continuaram dirigindo automóvel tanto antes quanto depois do nascimento do filho(a). Dos outros, 47 começaram a dirigir e deixaram de utilizar outros transportes, como: 9 pessoas (automóvel carona), 6 pessoas (motocicleta), 25 pessoas (ônibus), 1 pessoa (metrô), 2 pessoas (bicicleta) e 4 pessoas (a pé). Enquanto 14 deixaram de se locomover dirigindo, sendo: 7 indivíduos passaram a pegar carona, 3 pessoas a pilotar motocicleta, 1 começou a pegar ônibus, 1 optou pelo metrô, 1 a usar a bicicleta e outro a se locomover a pé. Já 59 indivíduos (= $234-128-47)$ continuaram a se locomover, sem nenhuma relação antes e depois, dirigindo automóvel. Essas relações podem ser verificadas no Anexo E - Análise de McNemar, tabela nº 3E.

Considerando o p-valor menor que 0,001 no teste de McNemar, houve mudanças significativas no transporte utilizado, e o resultado do teste de proporção representa também essa mudança. Para entendê-la melhor foi feito um teste de proporção unilateral com 5\% de significância e hipóteses:

$H_{0}$ - A proporção de pessoas que dirigem automóveis antes é igual à de depois $H_{1}$ - A proporção de pessoas que dirigem automóveis antes é menor que a de depois

O teste obteve um p-valor menor que 0,001, o que implica que houve evidências para recusar $\left(H_{0}\right)$, ou seja, a proporção de pessoas que dirigiam automóveis antes é menor que daquelas que dirigiam depois de terem filhos, com nível de significância de 5\%.

Quanto aos respondentes que andam de ônibus, a frequência dos transportes utilizados antes e depois são apresentadas na Tabela 10.

Tabela 10 - Frequências do meio de transporte ônibus

\begin{tabular}{l|c|c}
\hline \multirow{2}{*}{ Antes } & \multicolumn{2}{|c}{ Depois } \\
\cline { 2 - 3 } & Ônibus & Outros \\
\hline Ônibus & 16 & 37 \\
\hline Outros & 6 & 175 \\
\hline \multicolumn{2}{c}{ Fonte: Elaborado pelo autor }
\end{tabular}

Observa-se que 16 pessoas continuaram a utilizar o ônibus tanto antes quanto depois do nascimento do filho(a). Apenas 6 indivíduos começaram a utilizar o ônibus: 1 deixou o automóvel (dirigindo), 3 deixaram o automóvel (carona), 1 deixou a motocicleta e outro deixou de andar a pé. Outros 37 indivíduos deixaram de utilizar o ônibus, sendo: 25 
pessoas começaram a dirigir o automóvel, 7 pessoas começaram a pegar carona, 1 indivíduo a pilotar motocicleta, 1 indivíduo a utilizar metrô e 3 pessoas a andar a pé. Já 175 indivíduos (=234 $-53-6)$ continuaram a se locomover com o ônibus, sem nenhuma relação antes e depois. Essas relações podem ser verificadas no Anexo E - Análise de McNemar, tabela $n^{\circ} 3 \mathrm{E}$.

Observa-se que ambos os p-valores dos testes de McNemar e de Proporção foram menores que 0,001, indicando que há evidências de mudanças significativas e diferença de proporção, antes e depois dos filhos. Então, para entender melhor tal mudança, assim como no caso anterior, foi feito um novo teste de proporção, porém com as hipóteses:

$H_{0}$ - A proporção de pessoas que andam de ônibus antes é igual à de depois $H_{1}$ - A proporção de pessoas que andam de ônibus antes é maior que a de depois

O p-valor obtido foi menor que 0,001 , portanto houve evidências para recusar a hipótese nula, ou seja, o teste de proporção apresentou evidências de que a proporção de pessoas que andam de ônibus depois é menor que a daquelas que andavam de ônibus antes do nascimento do filho.

Ao questionar os respondentes se o nascimento da criança influenciou a escolha do meio de transporte, os dados mostraram que $33,76 \%$ dos domicílios não foram influenciados. Já $66,24 \%$ das residências questionadas relataram que houve influência na tomada de decisão quanto à escolha dos meios de transporte. Para os(as) respondentes, o nascimento da criança também influenciou a escolha do meio de transporte do(a) companheiro(a) ou cônjuge. O banco de dados registrou que 53,43\% foram influenciados(as). Então, observa-se que o nascimento de crianças influencia a tomada de decisão. Para certificar essa informação, o teste de McNemar pode avaliar se ocorre ou não a influência ao analisar as duas hipóteses propostas:

$H_{0}$ - O nascimento da criança não influencia a tomada de decisão, quanto a escolha do meio de transporte do respondente e do (a) companheiro (a) ou cônjuge.

$H_{1}$ - O nascimento da criança influencia a tomada de decisão, quanto a escolha do meio de transporte do respondente e do (a) companheiro (a) ou cônjuge. 
Conforme apresentado na Tabela 11, e no Anexo E - Análise de McNemar, a estatística do teste Tabela $\mathrm{n}^{\mathrm{o}} 2 \mathrm{E}$, a hipótese $\left(H_{0}\right)$ pode ser rejeitada, com o nível de significância de 5\%. Então, há indícios de que ocorre a influência na tomada de decisão da escolha do meio de transporte do(a) respondente e do(a) companheiro(a) ou Cônjuge, após o nascimento da criança.

Tabela 11 - Influência na tomada de decisão da escolha do meio de transporte do(a) respondente e do(a) companheiro(a) ou Cônjuge (Após o Nascimento)

\begin{tabular}{|c|c|c|c|c|}
\hline \multirow{2}{*}{\multicolumn{2}{|c|}{$\begin{array}{c}\text { Influência na tomada de decisão da escolha do meio } \\
\text { de transporte do (a) respondente } \\
\text { (Após o Nascimento) }\end{array}$}} & \multicolumn{2}{|c|}{$\begin{array}{c}\text { Influência na tomada de decisão } \\
\text { da escolha do meio de transporte } \\
\text { do (a) companheiro (a) ou cônjuge } \\
\text { (Após o Nascimento) } \\
\end{array}$} & \multirow[t]{2}{*}{ Total } \\
\hline & & Não & Sim & \\
\hline \multirow[t]{2}{*}{ Não } & Contagem & 60 & 11 & 71 \\
\hline & $\%$ do Total & $29,4 \%$ & $5,4 \%$ & $34,8 \%$ \\
\hline \multirow[t]{2}{*}{ Sim } & Contagem & 35 & 98 & 133 \\
\hline & $\%$ do Total & $17,2 \%$ & $48,0 \%$ & $65,2 \%$ \\
\hline \multirow[t]{2}{*}{ Total } & Contagem & 95 & 109 & 204 \\
\hline & $\%$ do Total & $46,6 \%$ & $53,4 \%$ & $100,0 \%$ \\
\hline
\end{tabular}

Fonte: Elaborado pelo autor

Foi questionado ao(à) respondente qual o principal meio de transporte utilizado para os deslocamentos da criança. Foram sugeridos deslocamentos como: levar à escola, ao médico pediatra, atividades esportivas, entre outros. Os resultados mostraram expressivamente que os pais conduzem seus(suas) filhos(as) de automóvel, conforme pode ser observado na Figura 27.

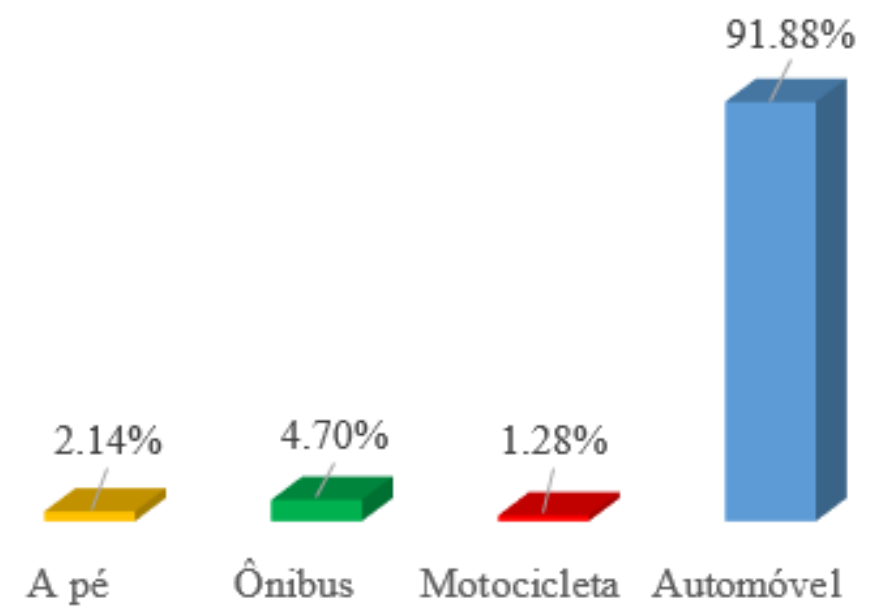

Figura 27 - Principal meio de transporte utilizado nos deslocamentos das crianças Fonte: Elaborado pelo autor 
Desse modo, foi questionado se poderia ser utilizado outro meio de transporte nos deslocamentos feitos com a criança para a escola, médico pediatra, atividades esportivas, entre outros. Verificou-se que 55,98\% mostraram-se inacessíveis à mudança por outro meio de transporte. Já 28, $21 \%$ poderiam até mudar de meio de transporte, mas com certas adaptações nas atividades diárias (compromissos) com relação a horários, localização, etc. e apenas $15,81 \%$ se mostraram acessíveis à mudança. A Figura 278 ilustra essa situação.

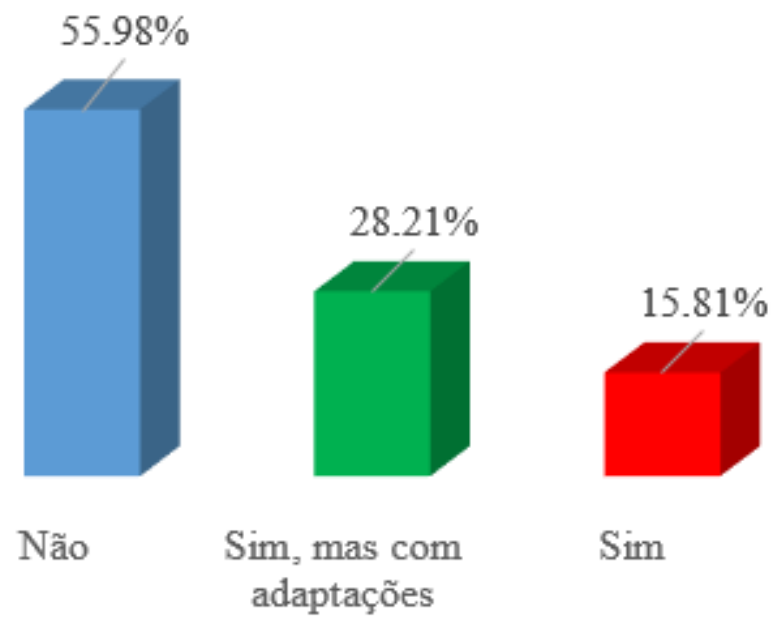

Figura 28 - Utilização de outro meio de transporte nos deslocamentos das crianças Fonte: Elaborado pelo autor

\subsection{A Análise do Evento-chave na Perspectiva do Ambiente Profissional e na Localização Residencial.}

Com o intuito de apresentar as relevantes trajetórias do comportamento de viagem numa perspectiva temporal, a teoria "Biografias de Mobilidade" apresenta três domínios de vida (estilo de vida, acessibilidade, mobilidade), conforme foi mencionado no Capítulo 2 (Figura 4).

O instrumento de pesquisa contemplou a verificação do domínio estilo de vida ao analisar o subdomínio social. Não foi o foco desta pesquisa a análise em profundidade dos domínios de acessibilidade e mobilidade. Porém, o instrumento de pesquisa verificou se o evento-chave trouxe alguma alteração ao ambiente profissional (domínio estilo de vida, 
subdomínio profissional) e à localização residencial (domínio acessibilidade). A investigação estendeu-se aos resultados do(a) respondente e do(a) companheiro(a) ou cônjuge. No tocante ao(à) respondente, o nascimento da criança não afetou diretamente a carreira profissional, apenas 3,42\% pararam de trabalhar definitivamente para cuidar do(a) filho(a) e/ou obrigações domésticas. A maioria voltou normalmente às atividades profissionais, conforme ilustrado na Figura 29.

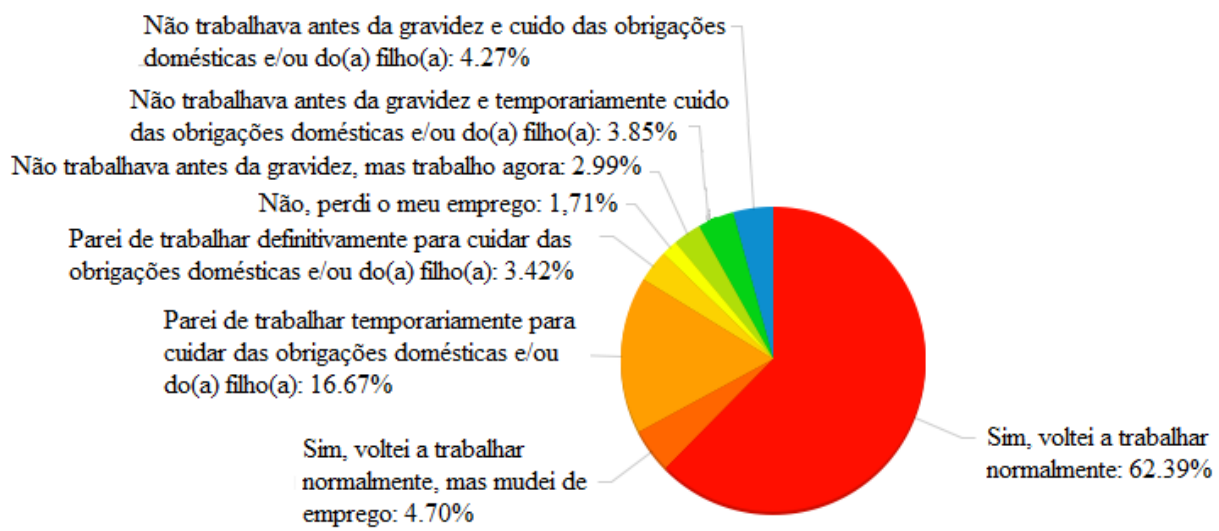

Figura 29 - Situação do trabalho, na perspectiva do respondente, após o nascimento das crianças Fonte: Elaborado pelo autor

Para o(a) companheiro(a) ou cônjuge, também não houve alteração. Os resultados mostraram que $84,80 \%$ voltaram a trabalhar normalmente. Apenas $1,47 \%$ apontaram que o(a) companheiro(a) ou cônjuge parou de trabalhar definitivamente para cuidar das obrigações domésticas e/ou do(a) filho(a). Dessa forma, conclui-se que o nascimento da criança não altera consideravelmente a carreira profissional dos pais. Conforme analisado, em alguns casos altera temporariamente, mas depois, possivelmente com o final da licença maternidade e/ou paternidade, o retorno é verificado, conforme apresentado na Figura 30. 
Ele(a) não trabalhava antes da gravidez e cuida das obrigações domésticas e/ou do(a) filho(a): $0.49 \%$

Ele(a) não trab. antes da gravidez e temporariamente cuida das obrig. domésticas e/ou do(a) filho(a): $2.45 \%$ Ele(a) não trabalhava antes da gravidez, mas trabalha agora: $0.49 \%$

Não, ele(a) perdeu o emprego: $0.49 \%$

Ele(a) parou de trab. definitivamente $p /$ cuidar das obrig. domésticas e/ou do(a) filho(a): $1.47 \%$

Ele(a) parou de trabalhar temporariamente para cuidar das obrigações

domésticas e/ou do(a) filho(a): $3.92 \%$

Sim, ele(a) voltou a trabalhar normalmente, mas mudou de emprego: $5.88 \%$

Sim, ele(a) voltou a trabalhar normalmente: $84.80 \%$

Figura 30- Situação do trabalho, na perspectiva do(a) companheiro(a) ou cônjuge, após o nascimento de crianças

Fonte: Elaborado pelo autor

Outro aspecto verificado foi referente à localização residencial. As considerações de Lanzendorf (2003) a esse respeito fazem parte do segundo domínio (acessibilidade). Os resultados mostraram que o nascimento de crianças não altera a programação familiar para a ocorrência de uma mudança residencial, conforme observado na Tabela 12 e na Tabela 13.

Tabela 12 - Situação da localização residencial na perspectiva do respondente após o nascimento de crianças

Não houve mudança de residência: $52.6 \%$
Saiu ou voltou para a casa dos pais: $5.1 \%$
Para uma residência mais adequada ao filho(a): $25.6 \%$
Saiu do aluguel para o imóvel próprio: $12.4 \%$
Para melhor acessibilidade ao transporte público: $0.4 \%$
Para estar mais próximo do trabalho: $4.3 \%$
Mudei de cidade ou estado: $2.1 \%$

Fonte: Elaborado pelo autor 
Tabela 13 - Situação da localização residencial na perspectiva do(a) companheiro(a) ou cônjuge após o nascimento de crianças

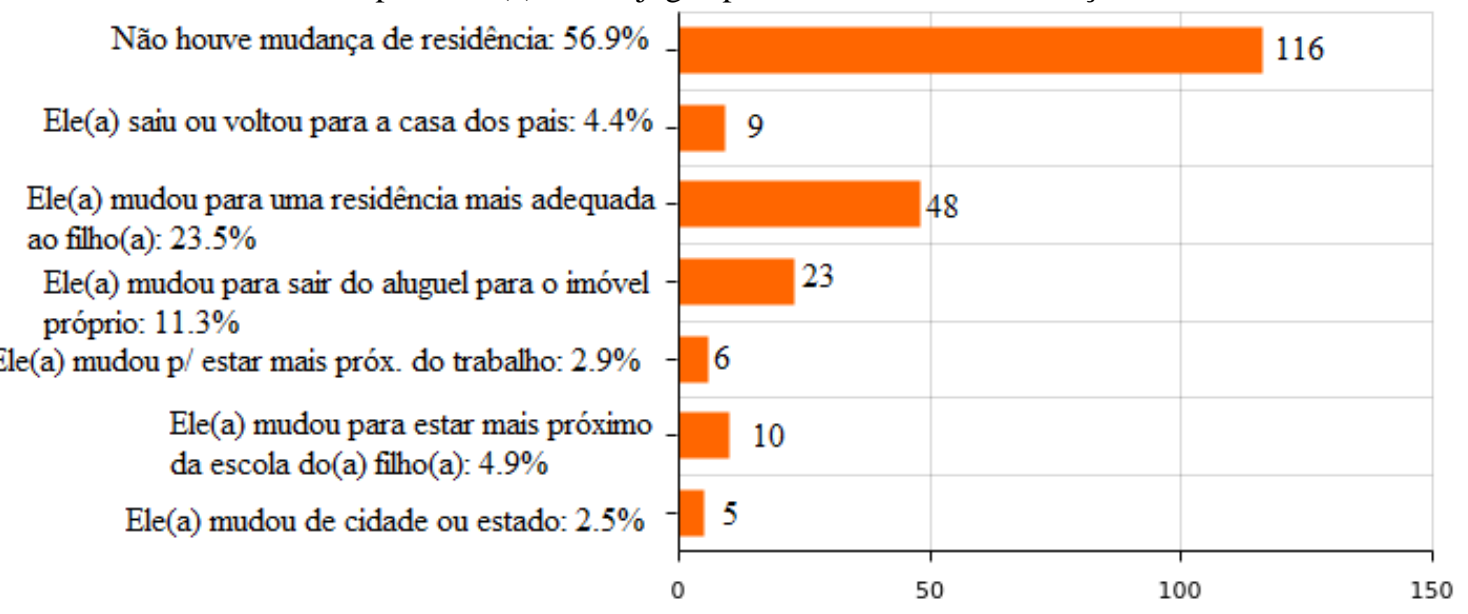

Fonte: Elaborado pelo autor

A opção de mudança para uma residência mais adequada ao filho também apresentou certa relevância. Porém, conclui-se que o nascimento da criança não ocasiona diretamente uma mudança residencial. Verificou-se que outros fatores, como mudança para ficar mais próximo do trabalho, mudança de cidade e aquisição da moradia própria também promovem a alteração da situação da localização residencial. 


\section{CONCLUSÃO}

\subsection{Resultados Obtidos}

O nascimento da criança é um evento marcante na vida dos pais e traz a necessidade de reorganização na estrutura familiar. Sabe-se que as crianças pequenas precisam de alguém para cuidar de suas necessidades, mas além das necessidades há outras atividades que precisam ser realizadas exclusivamente para a criança (consultas médicas, escola, atividades esportivas, lazer). Conforme verificou-se nesta pesquisa, os deslocamentos derivam das realizações das atividades e, por isso, são inevitáveis.

Esta pesquisa buscou analisar o comportamento de viagem e a escolha do meio de transporte em domicílios, a partir do nascimento da criança, numa perspectiva de tempo longitudinal ao analisar a tomada de decisão, tendo como base a teoria "Biografias de Mobilidade". Para isso, foi realizada uma pesquisa via questionário on line, disponível em todo território nacional, que contabilizou 234 registros domiciliares. A decisão de não limitar a pesquisa a uma região geográfica específica foi motivada por uma análise mais abrangente, que pudesse reportar com maior precisão a heterogeneidade do comportamento de viagem e a reorganização domiciliar nas diferentes localidades.

A pesquisa mostrou que após o nascimento do filho(a) há alterações nos domicílios. Estas mudanças são mais consideráveis no gênero feminino. A mulher, certamente, é a responsável por cuidar da(s) criança(s) na maior parte do tempo, inclusive no atendimento das necessidades infantis e nos deslocamentos recorrentes dessas atividades. Os motivos que justificam esse fato, nesta pesquisa, estão relacionados ao maior número de aquisição da carteira de habilitação, ao aumento no número de atividades e, consequentemente, nos deslocamentos. O aumento de todos estes índices foi relacionado ao gênero feminino, após a ocorrência do evento-chave.

Dentre as variáveis pesquisadas, a aquisição da carteira de motorista chamou a atenção neste estudo. Ao analisar esta variável por gênero, observou-se que o aumento aconteceu somente no gênero feminino. Não houve nenhuma ocorrência de aquisição para o gênero 
masculino. Logo, evidenciou-se que o evento-chave estimulou apenas as mães a adquirirem a carteira de habilitação.

Certamente são elas as principais responsáveis pelos cuidados com a(s) crianças(s), pois como foi observado após o nascimento, o número de atividades e os deslocamentos aumentaram. Foi verificado também que a motorização aumentou após o nascimento. A opção por meios de transporte individuais e motorizados ficou mais evidenciada. Possivelmente, nesta pesquisa, a aquisição do outro automóvel nos domicílios seja para o suporte nos deslocamentos das mulheres, pois além de apresentarem as maiores alterações no número de atividades e na realização dos deslocamentos, são as principais responsáveis pela execução das atividades e deslocamentos do(a) filho(a).

Dos processos de validação até a coleta das informações, o instrumento de pesquisa teve três versões diferentes. As validações possibilitaram uma reorganização estrutural do questionário e a tentativa de ser o menos invasivo possível, já que muitas informações a serem coletadas eram num nível familiar e envolviam crianças. Para alguns pais esse fato acarreta um certo desconforto.

Os aperfeiçoamentos oriundos das validações possibilitaram que o processo de coleta dos dados ocorresse sem contratempos ou dúvidas quanto às perguntas formuladas, embora tenham sido disponibilizados recursos para eventuais questionamentos. Notou-se que a versão final estava clara, de acordo com o desejado. Por outro lado, entende-se que quanto maior o grau de instrução, menor são os questionamentos. Conforme mencionado, a pesquisa teve um alto grau de escolaridade. Não houve a interferência do pesquisador para solucionar possíveis questionamentos ou direcionar, mesmo que indiretamente, a opção do(a) entrevistado(a) para alguma das opções da questão.

Ressalva-se que alguns conhecimentos e outras sugestões oriundas da validação do instrumento de pesquisa não foram adaptadas a essa pesquisa. A primeira delas foi quanto à generalização do meio de transporte, isto é, questionou-se qual o tipo utilizado com maior frequência. Sabe-se que alguns indivíduos utilizam mais de um meio de transporte, ou em alguns domicílios mais de três tipos, para a realização dos seus deslocamentos cotidianos. A segunda, com questionamentos mais precisos com relação às atividades das crianças. 
O estudo da variável renda, em geral, é um desafio para as pesquisas, pois nem sempre revela a real situação do(s) respondente(s), muitos podem omitir os ganhos reais. Por ter sido uma pesquisa totalmente on line, subentende-se que a veracidade da informação tenha sido maior por partes dos pesquisados. Dessa forma, esta pesquisa verificou que a variável renda, que foi medida após o nascimento da criança, se relaciona com as escolhas dos meios de transportes. Pela análise multivariada Cluster foi possível verificar esse relacionamento, através de 3 associações.

Contrapondo-se aos resultados encontrados por Lanzendorf (2010) em Leipzig (cidade alemã), observou-se uma divergência no comportamento de viagem no cenário brasileiro. Esta pesquisa verificou que após o nascimento de criança houve um aumento na aquisição da carteira de habilitação, a quantidades de carro aumentou nos domicílios e, consequentemente, a motorização por veículos individuais também, além da utilização do ônibus ter diminuído.

Ao verificar se a alteração no comportamento de viagem foi motivada por fatores como segurança, tempo de deslocamento, conforto/conveniência, custo, flexibilidade no deslocamento, qualidade do sistema de transporte público e questões ambientais, não foi observada nenhuma variação considerável ao analisar o período anterior e posterior ao nascimento de criança.

Se os fatores não demostraram alteração no comportamento de viagem, por outro lado, o nascimento da criança influenciou a tomada de decisão quanto à escolha do meio de transporte. Foi verificado expressivamente que o modo escolhido pelos pais para os deslocamentos da criança é o automóvel. Inclusive, ao questioná-los sobre uma possível mudança por outro meio de transporte, poucos se mostraram acessíveis à alteração, caracterizando-se um forte predomínio do deslocamento motorizado por transporte individual.

Ao questionar se o evento-chave trouxe alguma alteração ao ambiente profissional, não foram verificadas grandes mudanças; em geral, a maioria dos pais voltaram às atividades profissionais normalmente. Em alguns casos, a alteração foi temporária, porém logo depois, possivelmente com o final da licença maternidade e/ou paternidade, o retorno ao trabalho foi estabelecido. 
Ainda nesse tocante, foi perguntado aos pais se o nascimento da criança ocasionou uma mudança na localização residencial, os resultados mostraram que há incidência de mudanças para residências mais adequadas aos(as) filhos(as). Como foi exigido no instrumento de pesquisa que os respondentes fossem pais ou mães que tivessem o(a) primeiro(a) filho(a) com até 6 anos de idade, possivelmente alguns casais procuraram por residências maiores, nas quais a criança tivesse o quarto para si. Porém, a grande maioria dos pais não sinalizou mudanças de localização domiciliar devido ao nascimento da criança.

Em uma dimensão social, esta pesquisa contribuiu para a formulação de políticas públicas em planejamento de transportes, pois verificou o comportamento de viagem e a influência familiar na tomada de decisão quanto à escolha do meio de transporte para a execução das atividades e a realização de deslocamentos. Adicionalmente, a pesquisa revelou algumas restrições nos deslocamentos familiares, uma vez que a realização das atividades dos pais, em conjunto com as atividades das crianças, torna-se mais fácil de ser executada quando realizada por meios de transporte individuais motorizados.

Em uma dimensão acadêmica, esta pesquisa contribuiu para a investigação do comportamento de viagem ao analisar um evento-chave através da teoria "Biografias de Mobilidade". Conforme mencionado no Capítulo 1, até o presente momento não se tem conhecimento da aplicação desta teoria no cenário brasileiro. Além disso, o estudo despertou no grupo de pesquisa "Comportamento em Transportes e Novas Tecnologias", vinculado ao programa de pós-graduação em transportes da Universidade de Brasília, a possibilidade de desenvolver outras pesquisas na área.

Em uma dimensão pessoal, esta pesquisa agregou meritório conhecimento tanto para o pesquisador quanto para a orientadora do projeto, no que tange ao aprendizado da abordagem comportamental em estudo de transportes. Esta pesquisa oportunizou a experiência no aprofundamento do tema e despertou a possibilidade futura de aprimoramento quanto à utilização da teoria. Além disso, o estudo possibilitou o aprendizado relacionado ao comportamento de viagem, perpassando por elementos relacionados a questões socioeconômicas e à influência da estrutura familiar na produção de viagem. 


\subsection{Limitações deste Estudo}

O sistema de mobilidade de pais ou mães abrange um universo tão grande de elementos, fatores e características que, ao considerá-lo para uma análise em sua totalidade, torna-se complexo. Dessas dificuldades decorrem algumas limitações, entre elas a capacidade de realizar uma coleta amostral que seja representativa. Então, esta pesquisa busca contribuir com o tema de estudo, a partir da verificação de viabilidade para a aplicação da teoria. A amostragem alcançada foi satisfatória, o que permitiu o alcance do objetivo proposto.

Outra limitação com relação à amostra foi referente ao grau de instrução. Verificou-se um alto grau de escolaridade entre os entrevistados. Esse fato se deve, possivelmente, por alguns motivos: os encaminhamentos não chegaram de forma igualitária aos respondentes do ensino fundamental, ou não houve o interesse destes em responder ao instrumento de pesquisa. Com isso, a pesquisa limita-se quanto ao grau de escolaridade.

Por motivo de tempo, para a conclusão do estudo, decidiu-se por analisar qual o principal meio de transporte utilizados pelos(as) respondentes, antes e depois do evento chave, e qual o principal meio utilizado para os deslocamentos feitos com os(as) filhos(as). Sabese que alguns indivíduos utilizam mais de um meio de transporte nas viagens diárias. Porém, este estudo limitou-se a verificar apenas o principal, isto é, aquele utilizado na maioria dos deslocamentos realizados.

\subsection{Sugestões e Recomendações para Estudos Futuros}

Esta pesquisa possibilita conclusões particulares quanto ao comportamento de viagem, pois permite a estratificação dos dados por região, idade, renda, entre outros. Porém, sugere-se para futuros trabalhos acadêmicos a avaliação do evento-chave em diferentes faixas etárias (ciclo de vida); e para a variável renda, a utilização do modelo CCEB para a determinação da classe social num melhor nível de precisão.

Nos estudos futuros, sugere-se que a variável renda seja medida num tempo longitudinal, isto é, em dois momentos distintos, nesta pesquisa seria antes e após o nascimento da criança. Como foi medida apenas após o nascimento, não foi possível verificar a evolução das faixas de renda e analisá-las junto ao evento-chave. Caso a variável tivesse sido 
questionada antes do nascimento, consequentemente, outras possibilidades de análises poderiam ser abordadas.

Quanto ao instrumento de pesquisa, houve o entendimento de que a estrutura no formato de diário de atividades levantaria uma melhor precisão nas relações domiciliares existentes entre as atividades e os deslocamentos, entendendo inclusive os reais motivos da viagem, a dimensão temporal da programação de atividades, entre outros. Porém, para a correta análise desse instrumento, os respondentes precisam preenchê-lo várias vezes, durante diferentes dias, inclusive nos finais de semana e feriados, para que se possa captar eventuais atividades que ocorram nesses dias. Com isso, possivelmente, os entrevistados não se sentiriam motivados a respondê-lo, consequentemente, as respostas poderiam apresentar um baixo retorno e altas taxas de inconsistência. Por outro lado, questionamentos extremamente direcionados às crianças poderiam trazer certo desconforto para os respondentes (mães ou pais).

Mas, apesar disso, recomenda-se para futuras pesquisas o instrumento de pesquisa com estrutura do diário de atividades, pois a obtenção de informação referente ao processo de tomada de decisão e os padrões de atividade e viagens mostram-se mais precisos e próximos da realidade. Devido ao tempo para a conclusão do estudo, decidiu-se por realizar o instrumento de pesquisa atendendo a um outro formato e não à estrutura do diário de atividade.

A análise deste estudo foi direcionada ao domínio do estilo de vida, embora a teoria "Biografias de Mobilidade" apresente outros dois domínios, chamados de domínio de acessibilidade e mobilidade. Neste estudo, o instrumento de pesquisa contemplou alguns questionamentos relacionados aos outros dois domínios, porém não com a devida profundidade, por motivo de tempo para a finalização da dissertação. Dessa forma, recomenda-se a futuros estudos a análise dos outros domínios, na perspectiva da teoria, com uma melhor adaptação ao instrumento de pesquisa, de maneira a investigar aspectos relacionados à localização do trabalho, lazer, acesso ao transporte público e um melhor detalhamento das atividades e viagens diárias realizadas pelos pais, que foram ocasionadas pelo nascimento do(a) filho(a). 


\section{REFERÊNCIAS BIBLIOGRÁFICAS}

ALBUQUERQUE, M. A. de. (2005). Estabilidade em análise de agrupamento: cluster analysis. 2005. 53 f. Dissertação (Mestrado) - Curso de Biometria, Departamento Física e Matemática, Universidade Federal Rural de Pernambuco, Recife - PE, 2005. Disponível em: <http://www.pgbiom.ufrpe.br/dissertacoes/2005/d2005-01.pdf>. Acesso em: 05 out. 2015.

ALVES, B. B. (2014). O comportamento de viagens de acesso a aeroportos considerando a confiabilidade do tempo de viagem. Tese (Doutorado) - Curso de Engenharia de Transportes, Escola Politécnica da Universidade de São Paulo, São Paulo, 2014.

ANDRADE, C. A. (2013). Sinistros de trânsito em fluxos de veículos que se cruzam em cruzamentos ortogonais. Dissertação (Mestrado em Transportes). Departamento de Engenharia Civil e Ambiental, Faculdade de Tecnologia, Universidade de Brasília, Brasília, DF.

ARAUJO, F. A. (2014). A influência da infraestrutura cicloviária no comportamento de viagens por bicicleta. Dissertação de Mestrado em Transportes. Departamento de Engenharia Civil e Ambiental. Universidade de Brasília, Brasília, DF.

ARRUDA, F.S. (2000). Integração dos modos não motorizável nos modelos de planejamento dos transportes. Dissertação (Mestrado) - Universidade Federal de São Carlos, UFSCar, São Paulo, São Carlos.

ARRUDA, F. S. (2005). Aplicação de um modelo baseado em atividade para análise da relação uso do solo e transporte no contexto brasileiro. Tese (Doutorado) - Escola de Engenharia de São Carlos, Universidade de São Paulo, São Paulo, São Carlos.

BARIA, I. (2009). Percepção da sociedade e dos especialistas sobre os benefícios dos sistemas de transportes públicos urbanos sobre trilhos. Dissertação (Mestrado) - Escola de Engenharia de São Carlos, Universidade de São Paulo, São Paulo, São Carlos. 
BAUER, U.; HOLZ-RAU, C.; SCHEINER, J.; A. WALTHER, M. (2003): Entscheidungsprozesse regionaler wohnstandortmobilität. Zwischenbericht AP 131 des Projekts Intermobil Region Dresden. Berlin, Herdecke. www.intermobil-dresden.de

BEIGE, S., AXHAUSEN, K., (2012). Interdependencies between turning points in life and long-term mobility decisions. Transportation 39, 857-872.

BERG, S. (1998). Anowball sampling. In: Encyclopedia of statistical sciences 8. 8. New York: Wiley.

BERTAZZO, A.B.S. (2016). Procedimentos para estudos da escolha modal em viagens realizadas por estudantes de instituições de ensino médio, mediado pela psicologia social. Tese de doutorado em Transportes, 2016, Departamento de Engenharia Civil e Ambiental, Universidade de Brasília, DF, 347 p.

BERTAZZO, A. B. S.; JACQUES, M. P. A. (2012). O gerenciamento da mobilidade e a escolha modal em escolas de Brasília. Coope - UFRJ. Rio de Janeiro. Disponível em: $<$ http://redpgv.coppe.ufrj.br/index.php/es/produccion/articulos-cientificos/2012-1/718gerenciamento-da-mobilidade-e-a-escolha-do modo de transporte-escolas-de-brasiliapluris-2012/file>. Acesso em: 30 mar. 2016

BHAT, C. R.; BERNARDO C.; PALETI, R.; HOKLAS, M. (2014). An empirical investigation into the time-use and activity patterns of dual-arner couples with and without young children. Repository UT Faculty/Researcher Works. 2014. Disponível em: <http://repositories.lib.utexas.edu/handle/2152/26233>. Acesso em: 21 mar. 2014.

BHAT, C. R.; SIDHARTHAN, R.; PENDYALA, R. M.; GOULIAS, K. G. (2011). A model of children's school travel mode choice behavior accounting for spatial and social interaction effects. Transportation Research Record: Journal of the Transportation Research Board. Transportation Research Board (TRB) of the National Academies. Volume 2213 /2011 Highway Safety Management; Safety Workforce Development; School Transportation. Pages 78-86. 2011. Disponível em: <http://www.caee.utexas.edu/prof/bhat/ABSTRACTS/SchoolModeChoice_15March20 11.pdf>. Acesso: 21 marc 2014. 
BHAT, C. R.; SERAJ, S.; SIDHARTHAN R.; PENDYALA, R. M.; GOULIAS, K. G. (2012). Parental attitudes towards children walking and bicycling to school: a multivariate ordered response analysis. Transportation Research Record: Journal of the Transportation Research Board. Transportation Research Board (TRB) of the National Academies. Volume 2323 / 2012, Vol. 2 Disponível em: <http://trb.metapress.com/content/11717871p63p3422/>. Acesso em: 21 mar. 2014.

BICAS, H. E. A. (2008). Ineditismo, originalidade, importância, publicidade, interesse e impacto de artigos científicos. Arq Bras Oftalmol. 2008;71(4):473-4.

BONICI, R. M. C.; JUNIOR, C. F. de A. (2011). Medindo a satisfação dos estudantes em relação a disciplina on-line de probabilidade e estatística. Sistema e Instituições de EAD. São Paulo- SP.

BORDALO, A. A. (2006). Estudos transversal e/ou longitudinal. Revista Paraense de Medicina Vol. 20(4) outubro-dezembro 2006. Belém do Pará - PA.

BRASIL. SECRETARIA DE ASSUNTOS ESTRATÉGICOS. Participação feminina no mercado de trabalho está aumentando. Disponível em: <http://www.brasil.gov.br/governo/2015/02/participacao-feminina-no-mercado-detrabalho-esta-aumentando>. Acesso em: 24 fev 2015.

BRASIL. RUBENS SANTOS. IPEA. Somos menos desiguais: A revista de informação do IPEA. Ano 10. Edição 77 - 07/10/2013. Disponível em: <http://www.ipea.gov.br/desafios/index.php?option=com_content\&view=article\&id=29 43: catid=28\&Itemid=23>. Acesso em: 24 fev 2015.

BRASIL. Ministério do Planejamento Orçamento e Gestão. Instituto Brasileiro de Geografia e Estatística - IBGE. Síntese de Indicadores Sociais - Uma análise das condições de vida da população brasileira 2010. Disponível em: <http://www.ibge.gov.br/home/estatistica/populacao/condicaodevida/indicadoresminim os/sinteseindicsociais2010/SIS_2010.pdf>. Acesso em: 24 fev. 2015.

BRASIL. Comunicação Social. Censo 2010. SIS 2013: 74,1\% das mulheres de 25 a 29 anos que não estudam nem trabalham têm ao menos um filho: Síntese de Indicadores 
Sociais (SIS) 2013. 2013. Disponível em: <http://censo2010.ibge.gov.br/noticiascenso?view=noticia\&id=1\&idnoticia=2526\&busca=1\&t=sis-2013-74-1-mulheres-2529-anos-que-nao-estudam-nem>. Acesso em: 24 fev. 2015.

BRASIL. Comunicação Social. Instituto Brasileiro de Geografia e Estatística Ibge. População está mais urbana: reflexões sobre os deslocamentos populacionais no Brasil. 2014. Disponível em: <http://www.ibge.gov.br/home/estatistica/populacao/reflexoes_deslocamentos/deslocam entos.pdf>. Acesso em: 24 fev. 2015.

BUCK, N.; ERMISCH, J. F.; JENKINS, S. P. (1995). Choosing a longitudinal survey design: the issues. ESRC Research Centre on Micro-Social Change, University of Essex. Set. 1995.

CALDERAN, T; DILL, M. A. (2010). Os valores intrínsecos ao poder familiar e a responsabilidade dos pais pelo descumprimento. Âmbito Jurídico, Rio Grande, XIII, n.80, set.

Disponível

em:

<http://www.ambitojuridico.com.br/site/index.php?artigo_id=8315\&n_link=revista_arti gos_leitura>. Acesso em: 17 maio 2016.

CARLINDO, E. P. (2008). Trajetória de vida, formação profissional e atuação docente: Referências significativas para se compreender a estrutura do habitus profissional de professoras atuantes em uma escola municipal do interior paulista. 2008. Artigo publicado no CD dos Anais, do VIII Congresso nacional de educação da PUCPR (EDUCERE) - Edição internacional e III Congresso Ibero - Americano sobre violências nas escolas - com a temática "Formação de professores". Disponível em: <http://www.pucpr.br/eventos/educere/educere2008/anais/pdf/234_125.pdf >. Acesso em: 11 jul. 2015.

CARMO, I. F. (2015). Metodologia de pesquisa científica. Faculdade do Vale do Juruena. Capturado em 21 mar. 2015. Disponível na internet em: 21 mar. 2015 <http://www.pos.ajes.edu.br/arquivos/referencial_20110709101650.pdf> 
CARVALHO, E. C. S. de. (2013). Comportamento de escolha de linha de ônibus sob a influência de painéis eletrônicos com previsões em tempo real sobre a chegada dos veículos aos pontos. Dissertação (Mestrado) - Curso de Engenharia de Transportes, Escola Politécnica da Universidade de São Paulo-SP.

CARVALHO, H. (2004). Análise multivariada de dados qualitativos: utilização da HOMALS com o SPSS. Edições Sílabo. Lisboa.

CASSIANO, R. M. (2005). Estratégias competitivas das empresas produtoras de sementes de soja: um estudo exploratório no Sul de Mato Grosso. CNEC/FACECA. Faculdade Cenecista de Varginha. Dissertação (Mestrado) - Curso em Administração e Desenvolvimento Organizacional. Varginha - MG.

CHAPIN, F.S. (1974). Human activity patterns in the city: things people do in time and space. New York: John Wiley \& Sons.

CHATTERJEE, K., CLARK, B., MELIA, S., KNIES, G. LAURIE, H. (2014). Life events and travel behaviour: Exploring the interrelationship using UK Household Longitudinal Study data. Transportation Research Record, 2413. Pp.54-64. ISSN 0361-1981.

CLIFTON, K.J.; S.L. HANDY (2001). Qualitative methods in travel behaviour research. Paper presented at the International Conference on Transport Survey Quality and Innovation, Kruger National Park, South Africa, August 2001.

COCKERHAM W. C. (1988). Medical Sociology. In: Smelser NJ (Ed,). Handbook of Sociology. London: Sage Publications; p. 575-599.

COELHO JR, F. A. (2009). Suporte à aprendizagem, satisfação no trabalho e desempenho: Um Estudo Multinível. Tese (Doutorado). Curso de Pós-Graduação em Psicologia Social, do Trabalho e das Organizações. Instituto de Psicologia. Universidade de Brasília.

COLELlA, D. A. T. (2008). Comportamento de motoristas em interseções semaforizadas. Dissertação (Mestrado) - Escola de Engenharia de São Carlos, Universidade de São Paulo, São Carlos. 
COSTA, A. P.; SHORT, P. C. A. (2014). Desafios e possibilidades da pesquisa longitudinal com crianças e adolecentes. II Simpósio Luso-Brasileiro em estudos da criança - Pesquisa com criança: Desafios éticos e metodológicos. Faculdade de Educação - UFRGS - Porto Alegre - RS.

COSTA, G. G. de O. (2009). Análise de Homogeneidade do Desempenho de Instituições de Ensino Superior no Rio de Janeiro no ENADE 2007. VI SEGET - simpósio de excelência em gestão e tecnologia. Disponível em: <http://www.aedb.br/seget/arquivos/artigos09/98_Artigo_ENADE_2007.pdf>. Acesso em: 29 mar. 2016.

CZERMAINSKI, A. B. C. (2004). Análise de Correspondência. Seminário na Disciplina do Curso de Análise Multivariada. Universidade de São Paulo Escola Superior de Agricultura "Luiz de Queiroz", Piracicaba. Disponível em: <http://www.lce.esalq.usp.br/tadeu/anabeatriz.pdf>. Acesso em: 04 abr. 2016.

DALFOVO, M. S.; LANA, R. A.; SILVEIRA, A. (2008). Métodos quantitativos e qualitativos: um resgate teórico. Revista Interdisciplinar Científica Aplicada, Blumenau, v.2, n.4, p.0113, Sem II. ISSN 1980-7031

DARGAY, J.; HANLY, M. (2004). Volatility of Car Ownership, Commuting Mode and Time in the UK. World Conference On Transport Research. Istanbul, Turkey. Jul. 2004.

DESLANDES, S. F. et al. (2010). Organizadora MINAYO, M. C. S. Pesquisa Social: teoria, método e criatividade. 29. ed. Petrópolis: Vozes, 80 p. (Temas Sociais). ISBN: 9788532611451. Disponível em: <http://www.ia.ufrrj.br/ppgea/conteudo/conteudo2009-2/2SF/Pesquisa_Social.pdf>. Acesso em: 26 jun. 2015.

DIAS, M.O. (2011). Um olhar sobre a família na perspetiva sistémica o processo de comunicação no sistema familiar. Gestão e Desenvolvimento, 19 (2011), 139-156.

DIGGLE, P. J.; HEAGERTY, P. J.; LIANG, K. Y. ZEGER, S. L. (2002). Analyssis of longitudinal data. 2. Ed. Oxford Statistical Science Series - 25. ISBN 9780198524847 Oxford University published United States. Press Inc., New York - NY. 
DOMENCICH, T. A.; McFADDEN, D. (1975). Urban travel demand - a behavioral analysis. North-Holland Publishing Company - Amsterdam.

ETTEMA, D. (1996). Activity-based travel demand modeling. Eindhoven. 280f. Tese (Doutorado em Planejamento Urbano), Universidade de Eindhoven, Holanda.

FÁVERO, L. P. (2009). et al. Análise de dados: Modelagem multivariada para tomada de decisões. 11. ed. Rio de Janeiro: Elsevier. 646 p.

FERRAND, M. (1999). Para uma leitura simultânea do qualitativo e do quantitativo: o exemplo de "contar sua vida". Caderno CRH, Salvador, n. 30/31, p.339-361, Jan/dez. Trad. Regina Martins da Matta.

FERREIRA, N. G. (2012). Análise dos padrões de viagens do idoso em relação ao transporte público. Dissertação (Mestrado em Transportes). Departamento de Engenharia Civil e Ambiental, Universidade de Brasília, Brasília, DF.

FERRINHO, P.; CRAVEIRO, I. (2011). Representações de mulheres em idade fértil e profissionais de saúde sobre utilização de cuidados de saúde reprodutiva. Salud Pública, Lisboa, p.239-252, jun. Disponível em: <http://www.scielosp.org/pdf/rsap/v13n2/v13n2a06.pdf>. Acesso em: 19 maio 2016.

FIESE, B., TOMCHO, T., DOUGLAS, M., JOSEPHS, K., POLTROCK, S., \& BAKER, T. (2002). A review of 50 years of research on naturally occurring family routines and rituals: Cause for celebration? Journal of Family Psychology, 16, 381-390.

FLICK, U. (2009). Introdução à pesquisa qualitativa. 3 ed. Porto Alegre: Artmed; ISBN 978-85-363-1711-3. Tradução: Joice Elias Costa

FRANKE, S. (2004). Eigentlich ideal, so ein cashcar! Ergebnisse eines Feldversuchs. In: Projektgruppe Mobilität (ed.), Die Mobilitätsmaschine. Versuche zur Umdeutung des Autos. Berlin: WZB, pp. 68-80. 
FRÄNDBERG, L. (2006). International mobility biographies: a means to capture the institutionalisation of long-distance travel? 9. ed. Issue 4-5. Sweden: Current Issues In Tourism, 320-334 p. Department of Human and Economic Geography, University of Göteborg. Disponível em: <http://www.tandfonline.com/doi/abs/10.2167/cit262.0>. Acesso em: 20 set. 2015.

FREIRE, V. R. B. P.; SILVA, S. S. da C.; PONTES, F. A. R.; BORGES, J. de A. R.; MOURA, M. L. S. de. (2013). Psicologia: teoria e pesquisa. Abr-Jun 2013, Vol. 29 n. 2, pp. 159-166.

FREITAS, W. G. (2012). Apoio à tomada de decisão em transportes: aplicação do processo de mineração de dados. Dissertação (Mestrado) - Curso do Programa de Pósgraduação em Transportes, Engenharia Civil e Ambiental, Universidade de Brasilia, Brasilia - DF.

GEERTZ, C. (1966). Religion as a cultural system. Em M. Banton (Org.), Anthropological approaches to religion (pp. 1-46). London: Tavistock.

GIBBS, G. R. (2009). Análise de dados qualitativos. Coleção Pesquisa Qualitativa com coord. de Uwe Flick. Trad. Roberto Cataldo Costa. ISBN 978-85-363-2055-7. Porto Alegre - RS.

GIL, A. C. (2012). Métodos e técnicas de pesquisa social, $6^{\circ}$ edição - 5. Reimpr. - ISBN 978-85-224-5142-5. São Paulo: Atlas, 2012.

GOMES, W. B.; RECK, A. C.; GANZO, C. R. (2012). A experiência retrospectiva de estar em psicoterapia: um estudo empírico fenomenológico. Psicologia: Teoria e Pesquisa, Brasília, v. 4, n. 3, p.187-206, 2012. Trimestral. Disponível em: <https://revistaptp.unb.br/index.php/ptp/article/view/1301>. Acesso em: 15 set. 2015.

GRAWITZS, M. (1975). Métodos y técnicas de las ciências sociales. Barcelona, Hispano Europea, 2 v.

GROSVENOR, T. (2000). Qualitative research in the transport sector. Proceedings for the Internacional Conference on Transport Survey Quality and Innovation. May 24-30, 
1997, Grainau, Germany. Mas de Gibert, France: TBR Transportation Research Circular E-C008.

GÜNTHER, H. (2006). Pesquisa qualitativa versus pesquisa quantitativa: esta é a questão? Psicologia: Teoria e Pesquisa: Teoria e Pesquisa, v. 22, n. 2, p.201-2010, maio 2006. Trimestral.

HÄGERSTRAND, T. (1975). Survival and arena: on the life history of individuals in relation to their geographical environment. The Monadnock 49, 9-29.

HAIR, J. F. J. (2009). et al. Análise multivariada de dados. 6. ed. Porto Alegre: Bookman. 688 p. Tradução Adonai Schlup Sant'Anna.

HEGENBERG, L. (1973). Etapas da investigação científica. São Paulo, E.P.U./EDUSP, 1976. 2 v.

HAUGLAND, B. S. M. (2005). Recurrent disruptions of rituals and routines in families with paternal alcohol abuse. Family Relations, 54, 225-241.

HEINE, H., R. MAUTZS, R., W. ROSENBAUM (2001). Daily Mobility. Why do not we leave the car? Campus, Frankfurt/New York.

HEINE, H., R. MAUTZS, R. (2004). Possibilities and limitations car renunciation. The choice of transport mode in the face mobility constraints and normative claims today's family lifestyle. Möglichkeiten und Grenzen des Autoverzichts. Die Wahl des Verkehrsmittels angesichts der Mobilitätszwänge und normativen Ansprüche der heutigen familiären Lebensweise. Göttingen.

HOCHMAN, B.; NAHAS, F. X.; FILHO, R. S. de O.; FERREIRA, L. M. (2005). Desenho de pesquisa. Research designs. Acta Cirúrgica Brasileira - Vol 20 (Supl. 2) 2005.

HOUSEHOLD Behaviour and the Environment: Reviewing the Evidence (2008). Paris França: OECD - Organisation For Economic Co-operation And Development. 246 p. (OECD 2008). 
ICHIKAWA, S. M. (2002). Aplicação de minerador de dados na obtenção de relações entre padrões de encadeamento de viagem codificados e características socioeconômicas. São Paulo. 136 p. Dissertação (Mestrado) - Escola de Engenharia de São Carlos.

JOLIVET, R. (1979). Curso de Filosofia. 13º ed. Rio de Janeiro, Agir, 1979.

JONES, P.; CLARKE, M.; DIX, M. (1983). Understanding travel behavior. Aldershot: Gower, 1983.

JUNIOR, A. F. G. (2015). Projeto de pesquisa e classificação dos tipos de pesquisas. Capturado em 29 jan. 2015. Disponível na internet em: 29 jan. 2015. < http://www.mural2.com>

JUNIOR, D. J. T. (2010). Análise temporal da demanda por transporte público coletivo urbano em quatro cidades de porte médio do Estado de São Paulo. Dissertação (Mestrado) - Universidade de São Paulo, Escola de Engenharia de São Carlos.

KAMAKURA, W. A.; MAZZON, J. A. (2013). Socioeconomic status and consumption in an emerging economy: Intern. J. Of Research In Marketing, p.4-18. Disponível em: $<$ http://portal.idc.ac.il/en/main/research/ijrm/documents/pdf of 31 nominated papers.pdf>. Acesso em: 19 maio 2016.

KITAMURA, R.; MOKHTARIAN, P. L.; LAIDET, L. (1997). A micro-analysis of land use and travel in five neighborhoods in San Francisco Bay Area. Transportation. 1997.

KLÖCKNER C (2004). How single events change travel mode choice - a life span perspective. Paper presented at the 4th International Conference of Traffic and Transport Psychology, Nottingham, 5-9 September 2004.

KURANI, K.; LEE-GOSSELIN, M.E.H. (1996). Synthesis of past activity analysis applications. In: activity-based travel forecasting conference, 1996. Proceeding... capturado em 19 mar. 2015. Disponível em: <http://trid.trb.org/view.aspx?id=486713\#> 
LAKATOS, E. M.; MARCONI, M. de A. (1989). Metodologia científica: ciência e conhecimento científico; métodos científicos; teoria, hipóteses e variáveis. Ed. Atlas. São Paulo.

LANZENDORF, M. (2003). Mobility biographies. A new perspective for understanding travel behaviour. Edited by 10th International Conference on Travel Behaviour Research. Utrecht University, Urban Research Centre. Lucerne (Moving through nets: The physical and social dimensions of travel, Conference Paper Session I). Available online at http://www.ivt.ethz.ch/news/archive/20030810_IATBR/lanzendorf.pdf, verificado em: 24 fev. 2015.

LANZENDORF, M. (2010). Key events and their effect on mobility biographies: the case of childbirth. International Journal of Sustainable Transportation 4 (5), 272-292.

LANZENDORF, M.; SHOENDUWE, R.; MUELlER, M. G.; PETERS, A. (2015). Analysing mobility biographies with the life course calendar: a retrospective survey methodology for longitudinal data collection. Jornal of Transport Geography 42 (2015) 98-109.

LATORRE, M. do R. D. de O.; CARDOSO, M. R. A. (2001). Análise de séries temporais em epidemiologia: uma introdução sobre os aspectos metodológicos. Rev. bras. Epidemiol. São Paulo, v. 4, n. 3, p. 145-152, nov. 2001 . Disponível em http://www.scielo.br/scielo.php?script=sci_arttext\&pid=S1415-

790X2001000300002\&lng=pt\&nrm=iso Acessos em 09 jul. 2015. http://dx.doi.org/10.1590/S1415-790X2001000300002.

LEITE, P. S. (2011). Análise do comportamento de viagens dos usuários de bicicleta em área rural: estudo de caso em área rural de Teresina. Dissertação em Mestrado em Transportes. Departamento de Engenharia Civil e Ambiental, Universidade de Brasília, Brasília, DF.

LINDEN, R. (2009). Tutorial: Técnicas de agrupamento. Revista de Sistemas de Informação da Fsma, Rio de Janeiro, v. 1000, n. 4, p.18-36, abr. 2009. Disponível em: 
<http://www.fsma.edu.br/si/edicao4/FSMA_SI_2009_2_Tutorial.pdf>. Acesso em: 05 out. 2015.

MALHOTRA, N. (2001). Pesquisa de Marketing: uma orientação aplicada. Porto Alegre: Bookman.

MALLET, W. J. (1999). Long-distance travel by women - result from the 1995 American Travel Survey. Transportation Research Record. Nº 1963.

MANZINI, E. J. (1990/1991). Entrevista semi-estruturada: análise de objetivos e de roteiros. Programa de Pós-Graduação em Educação, Unesp, Marília, São Paulo - SP.

MARTINS, W. T. (2015). Índice de avaliação da qualidade do transporte público por ônibus a partir da definição de serviço adequado. Dissertação (Mestrado em Transportes). Departamento de Engenharia Civil e Ambiental, Universidade de Brasília, Brasília, DF.

MAYER, K. U., TUMA, N. B. (1990). Event history analysis in life course research. London, England: University Of Wisconsin System, 1990. (3). Print in the United States of America. Disponível em: $<$ https://books.google.com.br/books?id=ak8hKTt7h7gC\&printsec=frontcover\&hl=ptBR\&source=gbs_ge_summary_r\&cad=0\#v=onepage\&q\&f;=false $>$. Acesso em: 20 set. 2015.

MCGINNITY, F., RUSSELL, H., (2008). Gender inequalities in time use. The distribution of caring, housework and employment among women and men in Ireland. The Equality Authority, Dublin.

MCNEMAR, Q. (1947). Note on the sampling error of the difference between correlated proportions or percentages. Stanford University: Psychometrika, v. 12, no . 2, jun. 1947.

MEDRANO, R. M. A. (2012). Modelagem de padrões de viagem e expansão urbana. Dissertação de Mestrado em Transportes. Departamento de Engenharia Civil e Ambiental, Universidade de Brasília, Brasília, DF. 
MEDRANO, R. M. A. (2016). O modelo intencional de transporte: contribuições da ontologia de Bunge para formalização da teoria de comportamento em transporte. Tese de Doutorado em Transportes. Departamento de Engenharia Civil e Ambiental, Universidade de Brasília, Brasília, DF.

MINAYO, M.C. de S. (1992). O desafio do conhecimento científico: pesquisa qualitativa em saúde. São Paulo: Hucitec-Abrasco.

MINGOTI, S. A. (2005). Análise de dados através de métodos de estatística multivariada: Uma abordagem aplicada. Belo Horizonte: UFMG. 295 p.

MINUNCHIN, P. (1985). Families and individual development: Provocations from the field of family therapy. Child Development, 56, 289-302.

MOURA, M. V. (2010). Estudos dos impactos causados por pólos geradores de viagens na circulação de pedestres. Departamento de Engenharia Civil e Ambiental, Faculdade de Tecnologia, Universidade de Brasília, DF.

MYERS, S. M. (1999): Residential mobility as a way of life: evidence of intergenerational similarities. In: Journal of Marriage and the Family 61, 871-880.

NELSON, K. (1981). Social cognition in a script framework. Em J. H. Flavell \& L. Ross (Eds.), Social cognitive development (pp. 97-118). New York: Cambridge University Press.

NELSON, K. (1996). Language in cognitive development: The emergence of the mediated mind. New York: Cambridge University Press.

NÉRICI, I. G. (1978). Introdução à Lógica. 5. Ed. São Paulo. Nobel.

OAKIL, A. T. M. (2013). Temporal dependence in life trajectories and mobility decisions. 2013. Thesis of Faculty of Geosciences, Utrecht University 2013.

ORTÚZAR, J. de D. E WILLUMSEN, L. G. (1994). Modelling Transport, Chichester: John Wiley and Sons. 
ORTÚZAR, J. de D.; WILLUMSEN, L. G. (2011). Modelos de transportes. 3. ed. Santander: Universidad de Cantabria, 709 p. Traducción: Ángel Ibeas Portilla y Luigi Dell' Olio.

PAIVA, M. (2013). Fatores que influenciam no uso da bicicleta de forma integrada com o metrô. Tese (Doutorado em Transportes), Departamento de Engenharia Civil e Ambiental, Universidade de Brasília, Brasília, DF.

PAIVA JUNIOR, H. (2006). Segmentação e modelagem comportamental de usuários de serviços de transporte urbano brasileiro. Tese (Doutorado). Escola Politécnica da Universidade de São Paulo, São Paulo, SP.

PEREIRA, H. C. (2015). Fatores viários que afetam a fiscalização eletrônica de avanço de sinal vermelho em interseções urbanas. Dissertação (Mestrado em Transportes), Departamento de Engenharia Civil e Ambiental, Universidade de Brasília, Brasília, DF.

PINHEIRO, L.; GALIA, M.; FONTOURA, N. (2009). Novos arranjos familiares, velhas convenções sociais de gênero: A licença-parental como política pública para lidar com essas tensões. Revista Estudos Feministas, Florianópolis, 17(3), Set-Dez 2009.

PINTO, P. V. H. (2013). Avaliação do comportamento de risco de motociclistas no cenário brasileiro. Dissertação (Mestrado em Transportes), Departamento de Engenharia Civil e Ambiental, Faculdade de Tecnologia, Universidade de Brasília, Brasília, DF.

PITOMBO, C. S. (2003). Análise do comportamento subjacente ao encadeamento de viagens através do uso de minerador de dados. 2003. Dissertação (Mestrado) - Escola de Engenharia de São Carlos, Universidade de São Carlos.

PITOMBO, C.S. (2007). Estudos de relações entre variáveis socioeconômicas, de uso do solo, participação em atividades e padrões de viagem encadeadas urbanas. 2007. 268 p. Tese (Doutorado) - Escola de Engenharia de São Carlos, Universidade de São Paulo, São Carlos.

PRATA, B. de A.; FREITAS, S. M. de. (2007). Uma nova abordagem para a análise de agrupamento com uma aplicação em agronomia. Disponível em: 
<https://web.fe.up.pt/ deg07002/Artigos 2007/SEAGRO2007.pdf>. Acesso em: 05 out. 2015.

RODRIGUES, F. S. P. (2012). Modelos comportamentais desagregados: uma análise conceitual. 55 f. TCC (Graduação) - Curso de Engenharia Civil, Departamento de Engenharia Civil, Universidade Federal do Rio Grande do Sul, Porto Alegre.

RODRIGUES, S. G. (2013). Aplicação da lógica paraconsistente na seleção de alternativas de transporte público. 140 f. Dissertações (Mestrado) - Departamento de Engenharia Civil e Ambiental, Universidade de Brasília, Brasília, DF.

ROSENBLOOM, S. (1987). The impact of growing children on their parents' travel behavior: A comparative analysis. Transportation Research Record, $\mathrm{n}^{\circ} 1135$.

RØE, P. G. (2000). Qualitative research on intra-urban travel: an alternative approach. Journal Of Transport Geography: Elsevier, v. 8, n. 2, p.99-106, jun. 2000. Mensal. <http://www.sciencedirect.com/science/article/pii/S0966692399000393>. Acesso em: 15 set. 2015.

SABÓIA, A. L; SOARES, C. (2004). O conceito de chefia nas pesquisas domiciliares através do recorte por sexo e presença do cônjuge: uma contribuição à discussão da "feminização da pobreza". Gênero, Niterói, v. 4, n. 2, p.53-71.

SAKS, M.; ALLSOP, J. (2011). Métodos qualitativos, quantitativos e mistos. São Paulo: Roca.

SALOMON, I. (1983). Life Styles - a broader perspective on travel behaviour in S. Carpenter and P. Jones (Eds.) Recent Advances in Travel Demand Analysis, 290-310, Gower, Alders-hot, Hants.

SAMARTINI, A. L. S. (2006). Comparação entre métodos de mensuração da importância de atributos em produtos e serviços. Relatório de pesquisa. Fundação Getúlio Vargas. Escola de Administração de Empresa de São Paulo, SP. 
SANTOS, L. S. (2009). Análise da influência da variação espacial da oferta de um modo de transporte público urbano no comportamento de viagem de seus usuários. Dissertação de Mestrado em Transportes. Departamento de Engenharia Civil e Ambiental, Universidade de Brasília, DF.

SANTOS, L. S. (2013). Viagem de lazer na cidade e teoria da atividade: uma abordagem sociohistórica em comportamento para viagens. Departamento de Engenharia Civil e Ambiental, Universidade de Brasília, DF.

SANTOS, M. A. M. (2009 A). O encontro entre crianças e seus pares na escola: entre visibilidades e possibilidades. Dissertação (Mestrado em Educação) - Universidade Federal de Juiz de Fora, MG.

SCHEINER, J. (2006). Housing mobility and travel behavior: a process-oriented approach to spatial mobility. Evidence from a new research field in Germany. In Journal of Transport Geography 14 (4), pp. 287-298.

SCHEINER, J. (2007). Mobility biographies elements of a biographical theory of travel demand. In Erdkunde 61 (2), pp. 161-173.

SCHEINER, J.; HOLZ-RAU, C. (2012). Changes in travel mode use after residential relocation: a contribution to mobility biographies. In Transportation 40, 431-458.

SCHEINER, J.; HOLZ-RAU, C. (2013). A comprehensive study of life course, cohort, and period effects on changes in travel mode use. In Transportation Research Part A: Policy and Practice 47, 167-181.

SCHEINER, J. (2014 A). The gendered complexity of daily life: Effects of life-course events on change in activity entropy and tour complexity over time. Travel Behaviour and Society 1, 91-105.

SCHEINER, J. (2014 B). Gendered key events in the life course: effects on changes in travel mode choice over time. J. Transp. Geogr. 37, 47-60. 
SIEGEL, S. (1956). Nonparametric Statistics: For the behavioral sciences. Pennylvania: Mcgraw-Hill, 1956. 350 p. Tradução de Alfredo Alves de Faria. Estatística nãoparamétrica para ciências do comportamento, em 1975.

SILVA, E. F. F.; MELO, W. C.; BERTAZZO, A. B. S; ARRUDA, F.S.; TAKANO, M.S.M.; (2014). Fatores que influenciam a escolha do modo automóvel em viagens a instituições de ensino superior em Brasília. In. Anais do 6o Congresso luso-brasileiro de planejamento urbano, regional e integração sustentável - PLURIS 2014. Fundação Calouste Gulbekian, Lisboa.

SILVA, M. A. (2006). Verificação da aplicabilidade da técnica de mineração de dados na previsão da demanda por transporte de passageiros urbanos usando dados da região metropolitana de São Paulo. 2006. Dissertação (Mestrado) - Escola de Engenharia de São Carlos, Universidade de São Carlos, São Paulo.

SILVA, S. S. C.; PONTES, F. A. R.; SANTOS, T. M.; BUCHER-MALUSCHKE, J.; MENDES, L.S.A.; REIS, D. C. e SILVA, S. D. B. (2010). Rotinas familiares de ribeirinhos amazônicos: uma possibilidade de investigação. Psicologia: Teoria e Pesquisa, 26, 341-350.

SILVA, M. A. (2011). Estudo da incorporação da acessibilidade à atividade na análise da demanda por viagens encadeadas. 2011. Tese (Doutorado) - Escola de Engenharia de São Carlos, Universidade de São Carlos, São Paulo.

SILVA, A. H. (2013). A influência do estilo de vida nas escolhas de transportes: uma análise de classes latentes. Tese (Doutorado em Transportes). Departamento de Engenharia Civil e Ambiental. Universidade de Brasília, Brasília, DF.

SILVA, A. M. M. (2014). Fatores de estresse para motorista e o usuário do transporte coletivo do Distrito Federal e a percepção de um em relação ao outro. Dissertação (Mestrado). Departamento de Engenharia Civil e Ambiental, Universidade de Brasília Distrito Federal.

SILVA, H. H. R. (2015). Metodologia da pesquisa científica. Centro Universitário Católico Salesiano Auxilium. Capturado em 03 mai. 2015. Disponível na internet em: 03 
mai.

<http://www.salesianolins.br/areaacademica/materiais/posgraduacao/Fisioterapia_Derm ato_Funcional/Metodologia/METODOLOGIA\%20DA\%20PESQUISA\%20$\% 201 \%$ AA\%20AULA.pdf>

SILVEIRA, M. O. da; MAIA, M. L. A. (2013). Comportamento e uso da bicicleta. Artigo apresentado no XXVIII Congresso de Pesquisa e Ensino em Transporte - ANPET, Belém do Pará - PA.

SOUZA, H. H. H.; LOUREIRO, C. F. (2014). Modelos comportamentais na compreensão da problemática do sistema de transporte interurbano de passageiros do ceará. Artigo apresentado no XXVIII Congresso de Pesquisa e Ensino em Transporte - ANPET, Curitiba - PR.

SOUSA, P. B. (2004). Análise comparativa do encadeamento de viagem de três areas urbanas. São Carlos, 2004. Dissertação (Mestrado) - Escola de Engenharia de São Carlos, Universidade de São Paulo.

STRAMBI, O.; VAN DE BILT K. (1998). Tendências sócio-demográfica das mulheres e suas implicações para análise da demanda e elaboração de políticas de transportes. Ingeniería de Tránsito y Transporte, X Congressso Panamericano.

SWEENEY, D. J. (2013). et al. Estatística aplicada: à administração e economia. 6. ed. São Paulo: Cengage Learning, 2013. 694 p. Tradução Solange Aparecida Visconti.

TACO, P.W.G (2003). Redes neurais artificiais aplicadas na modelagem individual de padrões de viagem encadeadas a pé. (Doutorado em Engenharia de Transportes). Programa de Pós-graduação em Transporte. Universidade de Brasília, DF.

TAKANO, M. S. M. (2010). Análise de influência da forma urbana no comportamento de viagens encadeadas com base em padrões de atividades. Dissertação (Mestrado em Transportes). Departamento de Engenharia Civil e Ambiental, Universidade de Brasília, Brasília, DF. 
TERRABUIO JUNIOR, D. J. (2010). Análise da demanda por transporte coletivo em quatro cidades médias do Estado de São Paulo. Dissertação (Mestrado). Universidade de São Paulo, Escola de Engenharia de São Carlos. São Paulo, São Carlos.

TIMMERMANS, H.; VAN DER WAERDEN, P.; BORGERS, A., (2003). The influence of key events and critical incidents on transport mode choice switching behaviour: a descriptive analysis. In: 10th International Conference on Travel Behavior Research, Luzern.

TIMMERSMAN, H. J. P.; MAAT, K.; (2009). A causal model relating urban form with daily travel distance thought activity/travel decisions. Transportation Planning and Technology Vol. 32, No. 2, April 2009, 115-134.

TRIVIÑOS, A. N. S. (1987). Introdução à pesquisa em ciências sociais: a pesquisa qualitativa em educação. Atlas. São Paulo- SP.

TRESCA, R. P.; DE ROSE JR, D. (2004). Estudo comparativo da motivação intrínseca em escolares praticantes e não praticantes de dança. Disponível em: http://portalrevistas.ucb.br/index.php/RBCM/article/viewArticle/349 Acesso em: 30 mar. 2016.

TRUJILlO FERRARI, A. (1974). Metodologia da ciência. 2. Ed. Rio de Janeiro, Kennedy.

UNICAMP (2012). (Universidade de Campinas). Departamento de Matemática e Estatística. Tipos de variáveis. São Paulo: Instituto de Matemática e Estatística. 23 slides, color. Disponível em: <http://www.ime.unicamp.br/ lramos/3variaveis.pdf >. Acesso em: 05 out. 2015.

VELLOSO, M. S. (2014). Estudos dos fatores intrínsecos e ambientais que afetam o comportamento do condutor em relação ao respeito à velocidade limite em vias urbanas. Tese (Doutorado em Transportes). Departamento de Engenharia Civil e Ambiental, Faculdade de Tecnologia, Universidade de Brasília, DF. 
VESPUCCI, K. M. (2014). Impacto dos shoppings centers sobre os padrões individuais de atividades e viagens. Tese (Doutorado). Escola politécnica da Universidade de São Paulo. São Paulo.

YIN, R. K. (2011). Estudo de caso: Planejamento e métodos. Tradução Daniel Grassi $2^{\circ}$ ed. - Porto Alegre: Bookman, 2001.

WACHS, M. (1987). Men, women, and wheels: the historical basics of sex differences in travel patterns. Transportation Research Record, $\mathrm{n}^{\circ} 1135$.

WAGNER, M. (1989). Spatial mobility over the life course. Stuttgart. Räumliche Mobilität im Lebensverlauf.

WERLANG, R. B. (2013). Mapas conceituais esqueletos: instrumento para avaliar o processo de ensino-aprendizagem. Experiências em Ensino de Ciências. V.8, No 2. Universidade Federal do Pampa (Unipampa). Caçapava do Sul - RS.

WHITEFORD, L. M.; SZELAG B. J. (2000). Access and utility as reflections of cultural constructions of pregnancy. Primary care update for Ob/Gyns. May 1 2000; p. 98-104. 
ANEXOS 


\section{ANEXO A}

\section{CONCEITOS}

Árvores de Decisão - São diagramas sequenciais de operações ramificadas baseadas em comparações. A árvore de decisão usa modelo preditivo, permitindo representar e avaliar problemas que envolvem decisões sequenciais. As árvores de decisão mapeiam observações sobre determinados itens para relacioná-los a um item central, atendendo às mesmas regras, e colocam em destaque os riscos e resultados identificados nos diversos cursos de ação.

Biografias Individuais - São caracterizadas por eventos como a formação familiar, nascimento de crianças, separação.

Biografias de Mobilidade para Lanzendorf - É uma teoria que enfatiza a importância de analisar as relações entre os principais eventos-chave ao longo do curso de vida, para a investigação do comportamento de viagem durante um longo período de tempo.

Biografias de Mobilidade para Scheiner - Campo do conhecimento empírico voltado para as pesquisas em transportes cujo processo está incorporado a outras biografias parciais.

Biografias Parciais - São caracterizadas pelas biografias individual, residencial, domicílio, trabalho. Entende-se que há uma inter-relação e dependência entre as biografias parciais.

Ciclo de Vida - São os estágios (etapas) que os indivíduos passam ao longo do curso de vida, desde o nascimento até a continuidade da existência.

Comportamento de Viagem - Processo de organização dos indivíduos que leva em consideração as decisões de escolhas, podendo ser afetado por características pessoais (personalidade, renda, gênero, idade, posição no domicílio, fatores socioeconômicos e sociodemográficos), características ambientais ou espaciais (uso do solo, distribuição 
espacial, densidade demográfica, forma urbana) e características psicossociais (estilo de vida, ciclo de vida, hábito, intenção, motivação, preferência), de forma a estruturar a melhor maneira de utilizar um modo de transporte para realizar um deslocamento ou viagem, com a finalidade de executar uma atividade.

Condições Externas - Referem-se a tendências demográficas, avanços tecnológicos e às condições de melhoria das políticas para toda a população.

Deslocamento - Mudança de local ou de posição. Ação de alguém ir de um lugar para outro por qualquer meio de transporte, tendo como propósito a participação ou realização de alguma atividade. O deslocamento pode oscilar entre poucos metros ou quilômetros, dentro de uma região geográfica.

Diário de Viagem - Instrumento de pesquisa utilizado para coletar informações diárias sobre os deslocamentos realizados durante um intervalo de tempo. $\mathrm{O}$ diário de viagem leva em consideração as características sociodemográficas e as referências do contexto espacial no tocante à residência, trabalho e escola.

Domicílio -A unidade doméstica de habitação a uma ou mais pessoas, com ou sem vínculo familiar.

Domínio de vida - De acordo com a teoria "Biografias de Mobilidade" o domínio de vida é caracterizado por outros três domínios (estilo de vida, acessibilidade, mobilidade). Domínio do Estilo de Vida - Refere-se ao ambiente social, cultural, político e profissional; por exemplo, a formação da família, o lazer, a carreira profissional, entre outros.

Domínio de Acessibilidade - Refere-se às localizações residenciais, do trabalho, do lazer ou outras atividades.

Domínio de Mobilidade - Refere-se à disponibilidade de modos (propriedade do carro, bilhete para o transporte público, entre outros). 
Estágios de Vida - Período durante o qual o indivíduo exerce uma experiência pessoal, profissional, entre outras.

Evento-chave - Um acontecimento ou um momento de certa relevância ao longo da trajetória do curso de vida. Como exemplo, tem-se a mudança residencial, primeiro emprego, situação do vínculo empregatício, retirada da carteira de motorista, nascimento do(a) filho(a) e outros acontecimentos que marcam e alteram a trajetória do curso de vida.

Mapa Perceptual (Mapa Espacial) - Representação visual que um respondente tem sobre objeto de uma ou mais dimensões. Cada objeto tem uma posição espacial que representa a similaridade ou preferência relativa aos outros objetos no que se refere às dimensões do mapa perceptual.

Dimensões do Mapa Perceptual - O mapa perceptual tem suas dimensões nos eixos $\mathrm{X}$ e $\mathrm{Y}$.

Métodos Biográficos - Estudo da vida individual no contexto social e histórico.

Mobilidade Espacial - Caracterizada por eventos como tirar a carteira de motorista, compra e venda do veículo e movimento residencial.

Modelo de Regressão - São modelos matemáticos que relacionam o comportamento de uma variável X com o comportamento de outra variável Y. O modelo de regressão determina como o comportamento de uma ou mais variáveis pode influenciar e mudar o comportamento de outra(s).

Padrões de Atividade - Compreendem o conjunto das atividades realizadas por um indivíduo (compras, consultas médicas, lazer, estudo, trabalho), coordenadas ou não com outros indivíduos, no domicílio ou fora dele. Algumas características pertinentes à natureza humana são levadas em consideração quando se analisa o padrão de atividade, como os fatores socioeconômicos, posição no domicílio, mecanismos de aprendizagem, alternativas de escolhas e necessidades para a realização da atividade (urgente, morosidade). 
Padrões de Viagem - Refere-se ao conjunto de viagens realizadas pelo indivíduo, em um determinado intervalo de tempo. O Padrão de viagem leva em consideração algumas características como o status socioeconômico, posição no domicílio, a trajetória do curso de vida, além de considerar alguns atributos de viagem, como o sistema de transporte (distribuição, frequência, acessibilidade, custo), atividades (estudo, trabalho, lazer) e as características urbanas (uso do solo).

Pesquisas de Cortes Longitudinais - Pesquisas amostrais em que são estudadas as variações dentro de uma mesma amostra em um intervalo de tempo.

Pesquisas de Cortes Transversais - Pesquisas amostrais em que é estudado apenas um momento fixo no tempo.

Pesquisas por Painéis - Caracterizadas por pesquisas repetidas e contínuas, ao longo do tempo, tendo a mesma amostra.

Pesquisas por Pseudos Painéis - Análise de cortes ou grupos amostrais que possuem características similares, levando em consideração a dimensão temporal.

Posição no Domicílio - Composição do morador no domicílio. Caracterizada pela relação existente entre a pessoa responsável pelo domicílio e os demais moradores, como o cônjuge ou companheiro(a), filho(a), enteado(a), parente, entre outros.

Processos Biográficos - Caracterizados pelos eventos na biografia individual relacionados com a forma da mobilidade espacial.

Rede Social - Estrutura social que conecta pessoas ou organizações por um ou vários tipos de relações, cujo interesse é compartilhar objetos e valores comuns.

Renda Familiar - É o valor oriundo do somatório das rendas individuais dos moradores de um mesmo domicílio.

Tabela de Contingência - Tabela cruzada ou de correspondência para registrar observações independentes de duas ou mais variáveis aleatórias, normalmente não 
métricas ou categóricas. A utilização desse tipo de tabela é para investigar se as variáveis estudadas têm alguma associação.

Tendências Demográficas - Caracterizadas por ocorrências como o aumento no número de divórcios, incremento da participação da mulher no mercado de trabalho e maior taxa de natalidade em classes econômicas mais baixas.

Tomada de Decisão - É o processo pelo qual se escolhe uma alternativa dentre várias outras possibilidades. A tomada de decisão leva em consideração a melhor escolha de cenários, ambientes, elementos, princípios e fundamentos.

Trajetória do Curso de Vida - São as referências inapagáveis das experiências vivenciadas ao longo do processo de formação pessoal e profissional.

Viagem - Neste trabalho admite-se o termo viagem com definição análoga ao termo deslocamento. 


\section{ANEXO B}

\section{CARACTERIZAÇÃO DO PERFIL DOS RESPONDENTES}

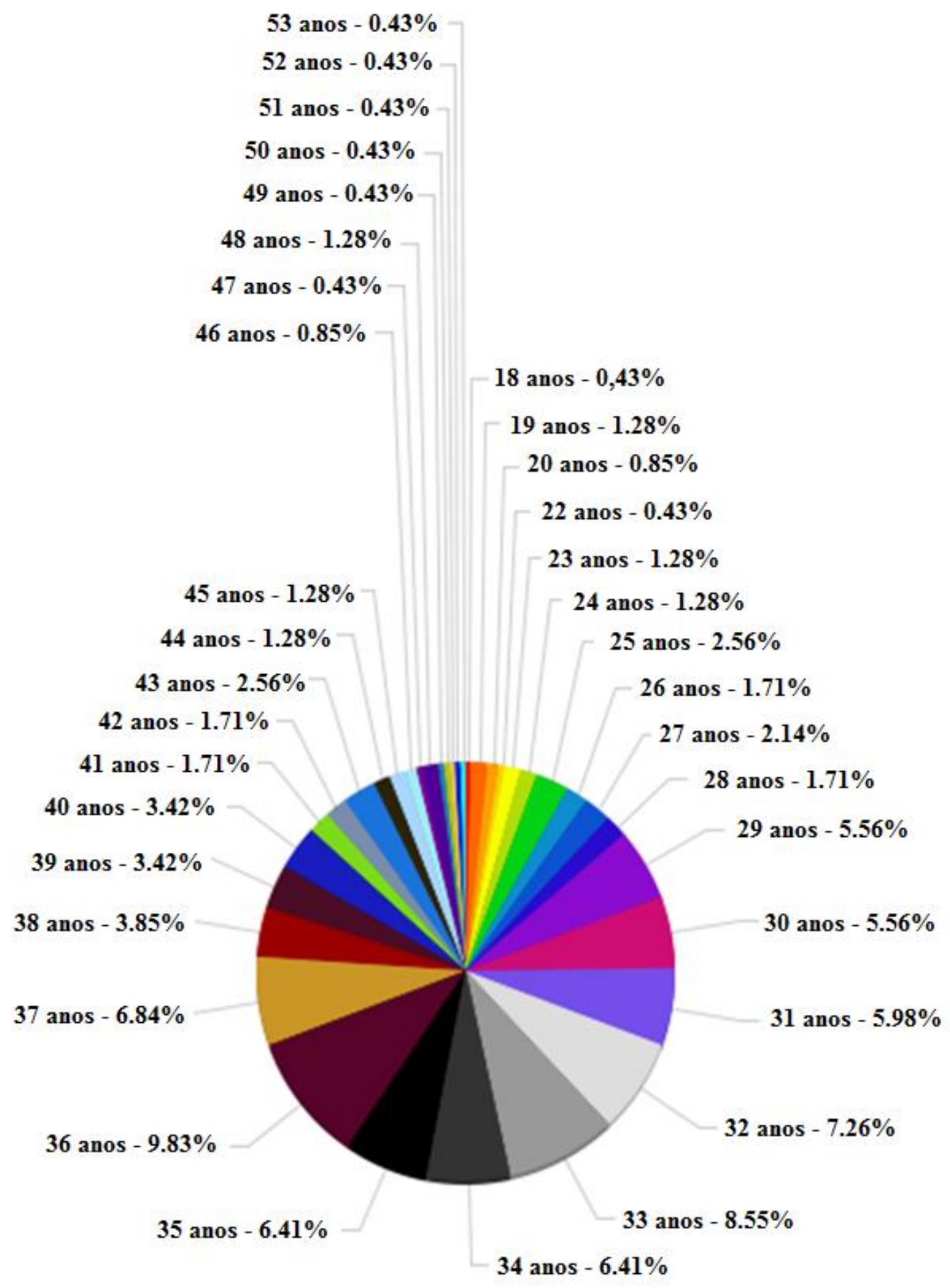

Figura 1B - Representação percentual das idades dos(as) participantes

Fonte: Elaborado pelo autor 
Carteira de Habilitação Representação dos Gráficos de Diagramas Circulares

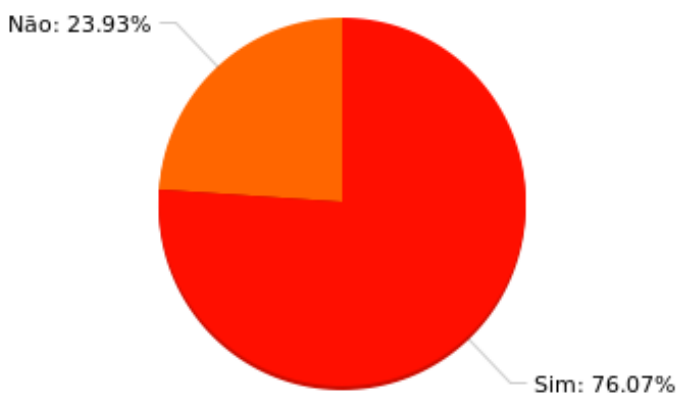

Figura 2B - Carteira de Habilitação (Antes do Nascimento) Fonte: Elaborado pelo autor

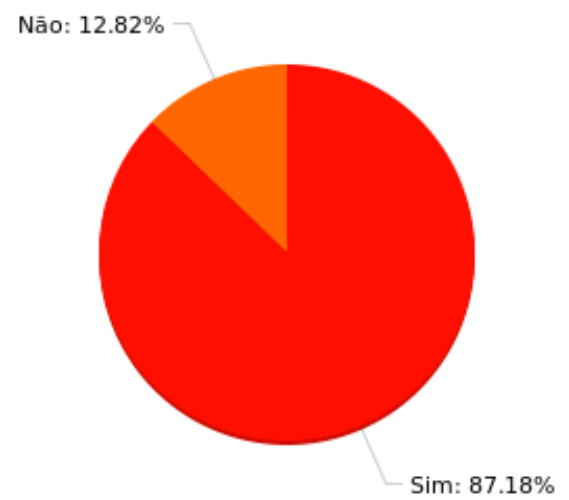

Figura 3B - Carteira de Habilitação (Após o Nascimento)

Fonte: Elaborado pelo autor 
Tabela 1B - Gênero e atividades (Após o nascimento)

\begin{tabular}{cc|c|c|c|c|c|c}
\hline \multirow{2}{*}{} & \multicolumn{5}{|c|}{ Atividades (Após o Nascimento) } \\
\cline { 3 - 8 } Gênero & Não & $\begin{array}{c}\text { Ativ. > alguns } \\
\text { dias }\end{array}$ & $\begin{array}{c}\text { Ativ. < alguns } \\
\text { dias }\end{array}$ & $\begin{array}{c}\text { Ativ. > todos os } \\
\text { dias }\end{array}$ & $\begin{array}{c}\text { Ativ. < todos os } \\
\text { dias }\end{array}$ & Total \\
\hline & Feminino & 6 & 59 & 6 & 116 & 9 & 196 \\
\hline
\end{tabular}

Fonte: Elaborado pelo autor

Tabela 2B - Gênero e deslocamentos (Após o nascimento)

\begin{tabular}{cc|c|c|c|c|c|c}
\hline \multirow{2}{*}{ Gênero } & \multicolumn{5}{|c}{ Deslocamentos (Após o Nascimento) } \\
\cline { 3 - 8 } & Não & $\begin{array}{c}\text { Desl. > alguns } \\
\text { dias }\end{array}$ & $\begin{array}{c}\text { Desl. < alguns } \\
\text { dias }\end{array}$ & $\begin{array}{c}\text { Desl. > todos os } \\
\text { dias }\end{array}$ & $\begin{array}{c}\text { Desl. < todos os } \\
\text { dias }\end{array}$ & Total \\
\hline & Feminino & 11 & 77 & 11 & 86 & 11 & 196 \\
\hline
\end{tabular}

Fonte: Elaborado pelo autor 


\section{ANEXO C}

\section{ANÁLISE ANACOR}

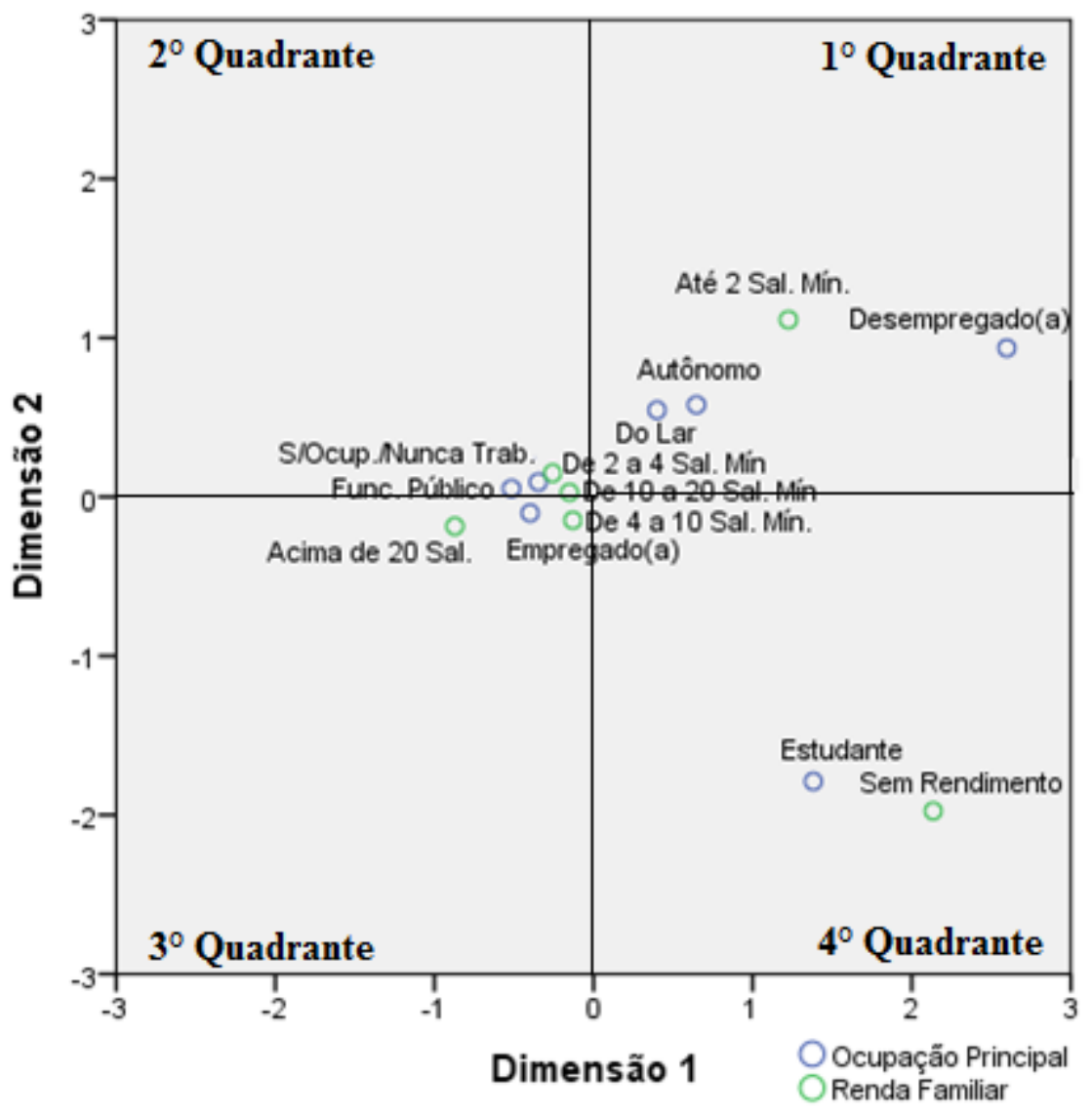

Figura 1C - Mapa Perceptual ocupação principal e renda bruta domiciliar Fonte: Elaborado pelo

autor 
Tabelas da Figura 1C

Tabela 1C - Correspondência entre a Ocupação Principal por Renda Familiar

\begin{tabular}{|c|c|c|c|c|c|c|c|}
\hline Ocupação Principal & $\begin{array}{c}\text { Sem } \\
\text { Rendimento } \\
\end{array}$ & $\begin{array}{c}\text { Até } 2 \\
\text { Salários } \\
\text { Mínimos } \\
\end{array}$ & $\begin{array}{c}\text { Entre } 2 \text { e } 4 \\
\text { Salários } \\
\text { Mínimos } \\
\end{array}$ & $\begin{array}{c}\text { Entre } 4 \text { e } 10 \\
\text { Salários } \\
\text { Mínimos } \\
\end{array}$ & $\begin{array}{c}\text { Entre } 10 \text { e } 20 \\
\text { Salários } \\
\text { Mínimos }\end{array}$ & $\begin{array}{c}\text { Acima de } 20 \text { Salários } \\
\text { Mínimos }\end{array}$ & $\begin{array}{c}\text { Margem } \\
\text { ativa } \\
\end{array}$ \\
\hline Empregado (a) & 2 & 6 & 26 & 55 & 33 & 20 & 142 \\
\hline Autônomo & 1 & 8 & 8 & 14 & 5 & 1 & 37 \\
\hline Funcionário (a) público (a) & 0 & 1 & 1 & 4 & 2 & 3 & 11 \\
\hline Do Lar & 1 & 6 & 3 & 8 & 6 & 0 & 24 \\
\hline Aposentado (a) & 0 & 0 & 0 & 0 & 0 & 0 & 0 \\
\hline Estudante & 4 & 1 & 1 & 6 & 2 & 0 & 14 \\
\hline Desempregado (a) & 1 & 3 & 0 & 0 & 1 & 0 & 5 \\
\hline Sem Ocupação / Nunca Trabalhou & 0 & 0 & 0 & 0 & 1 & 0 & 1 \\
\hline Outros & 0 & 0 & 0 & 0 & 0 & 0 & 0 \\
\hline Margem ativa & 9 & 25 & 39 & 87 & 50 & 24 & 234 \\
\hline
\end{tabular}


Tabela 2C - Resumo - Anacor - Ocupação Principal por Renda Familiar

\begin{tabular}{|c|c|c|c|c|c|c|c|c|}
\hline \multirow[b]{3}{*}{ Dimensão } & \multirow[b]{3}{*}{ Valor singular } & \multirow[b]{3}{*}{ Inércia } & \multirow[b]{3}{*}{ Chi-quadrado } & \multirow[b]{3}{*}{ Sig. } & \multicolumn{2}{|c|}{ Proporção de inércia } & \multicolumn{2}{|c|}{ Valor singular de confiança } \\
\hline & & & & & \multirow{2}{*}{$\begin{array}{c}\text { Contabilizado } \\
\text { para }\end{array}$} & \multirow[b]{2}{*}{ Acumulativo } & \multirow[b]{2}{*}{ Desvio padrão } & Correlação \\
\hline & & & & & & & & 2 \\
\hline 1 & ,436 & , 190 & & & ,580 &, 580 &, 068 &, 297 \\
\hline 2 & ,298 & ,089 & & & ,272 &, 852 & , 102 & \\
\hline 3 &, 162 & ,026 & & & ,080 & ,932 & & \\
\hline 4 &, 143 &, 020 & & &, 062 & ,994 & & \\
\hline 5 & ,044 & ,002 & & & ,006 & 1,000 & & \\
\hline Total & &, 327 & 76,549 &, $000^{\mathrm{a}}$ & 1,000 & 1,000 & & \\
\hline
\end{tabular}

a. 40 graus de liberdade 
Tabela 3C - Perfis de linha - Ocupação Principal por Renda Familiar

\begin{tabular}{|c|c|c|c|c|c|c|c|}
\hline Ocupação principal & $\begin{array}{c}\text { Sem } \\
\text { Rendimento }\end{array}$ & $\begin{array}{c}\text { Até } 2 \\
\text { Salários } \\
\text { Mínimos }\end{array}$ & $\begin{array}{c}\text { Entre } 2 \text { e } 4 \\
\text { Salários } \\
\text { Mínimos } \\
\end{array}$ & $\begin{array}{c}\text { Entre } 4 \text { e } 10 \\
\text { Salários Mínimos } \\
\end{array}$ & $\begin{array}{c}\text { Entre } 10 \text { e } 20 \\
\text { Salários Mínimos }\end{array}$ & $\begin{array}{c}\text { Acima de } 20 \text { Salários } \\
\text { Mínimos }\end{array}$ & $\begin{array}{c}\text { Margem } \\
\text { ativa }\end{array}$ \\
\hline Empregado (a) &, 014 &, 042 &, 183 & ,387 & ,232 &, 141 & 1,000 \\
\hline Autônomo & ,027 & ,216 & ,216 & ,378 & ,135 &, 027 & 1,000 \\
\hline Funcionário (a) público (a) & ,000 & ,091 & ,091 & ,364 & ,182 & ,273 & 1,000 \\
\hline Do Lar &, 042 &, 250 &, 125 & ,333 &, 250 &, 000 & 1,000 \\
\hline Aposentado (a) & ,000 &, 000 &, 000 &, 000 &, 000 &, 000 &, 000 \\
\hline Estudante & ,286 &, 071 &, 071 & ,429 &, 143 &, 000 & 1,000 \\
\hline Desempregado (a) & ,200 & 600 &, 000 &, 000 & ,200 &, 000 & 1,000 \\
\hline Sem Ocupação / Nunca Trabalhou & ,000 &, 000 &, 000 & 000 & 1,000 &, 000 & 1,000 \\
\hline Outros & ,000 &, 000 &, 000 & 000 & 000 &, 000 &, 000 \\
\hline Massa &, 038 &, 107 &, 167 & ,372 &, 214 &, 103 & \\
\hline
\end{tabular}


Tabela 4C - Perfis de coluna - Ocupação Principal por Renda Familiar

\begin{tabular}{|c|c|c|c|c|c|c|c|}
\hline Ocupação Principal & $\begin{array}{c}\text { Sem } \\
\text { Rendimento }\end{array}$ & $\begin{array}{c}\text { Até } 2 \\
\text { Salários } \\
\text { Mínimos }\end{array}$ & $\begin{array}{c}\text { Entre } 2 \text { e } 4 \\
\text { Salários } \\
\text { Mínimos } \\
\end{array}$ & $\begin{array}{c}\text { Entre } 4 \text { e } 10 \\
\text { Salários Mínimos }\end{array}$ & $\begin{array}{c}\text { Entre } 10 \text { e } 20 \\
\text { Salários Mínimos }\end{array}$ & $\begin{array}{c}\text { Acima de } 20 \\
\text { Salários Mínimos }\end{array}$ & Massa \\
\hline Empregado (a) &, 222 & ,240 & 667 & ,632 & ,660 &, 833 & 607 \\
\hline Autônomo &, 111 & ,320 & ,205 &, 161 &, 100 &, 042 &, 158 \\
\hline Funcionário (a) público (a) &, 000 &, 040 & ,026 & ,046 &, 040 &, 125 &, 047 \\
\hline Aposentado (a) &, 000 &, 000 &, 000 &, 000 & ,000 &, 000 &, 000 \\
\hline Estudante & ,444 &, 040 & ,026 & 069 &, 040 & 000 &, 060 \\
\hline Desempregado (a) &, 111 &, 120 &, 000 &, 000 & 020 &, 000 &, 021 \\
\hline Sem Ocupação / Nunca Trabalhou &, 000 &, 000 &, 000 &, 000 & ,020 &, 000 &, 004 \\
\hline Outros &, 000 &, 000 &, 000 &, 000 &, 000 & ,000 &, 000 \\
\hline Margem ativa & 1,000 & 1,000 & 1,000 & 1,000 & 1,000 & 1,000 & \\
\hline
\end{tabular}


Tabela 5C - Pontos de linha de visão geral ${ }^{\mathrm{a}}$ - Ocupação Principal por Renda Familiar

\begin{tabular}{|c|c|c|c|c|c|c|c|c|c|}
\hline \multirow[b]{3}{*}{ Ocupação Principal } & \multirow[b]{3}{*}{ Massa } & \multicolumn{2}{|c|}{$\begin{array}{c}\text { Pontuação em } \\
\text { dimensão }\end{array}$} & \multirow[b]{3}{*}{ Inércia } & \multicolumn{5}{|c|}{ Contribuição } \\
\hline & & \multirow[b]{2}{*}{1} & \multirow[b]{2}{*}{2} & & \multicolumn{2}{|c|}{ De ponto para inércia de dimensão } & \multicolumn{3}{|c|}{ De dimensão para inércia de ponto } \\
\hline & & & & & 1 & 2 & 1 & 2 & Total \\
\hline Empregado (a) & 607 &,- 398 &,- 101 &, 044 & ,221 &, 021 & ,951 &, 042 & ,994 \\
\hline Autônomo & , 158 & ,399 &, 546 &, 034 &, 058 &, 158 & ,322 & ,413 & ,736 \\
\hline Funcionário (a) público (a) & ,047 &,- 516 & 053 &, 017 & ,029 &, 000 & ,320 &, 002 & ,322 \\
\hline Do Lar & , 103 &, 647 &, 579 & 032 & ,099 &, 115 &, 578 &, 317 &, 895 \\
\hline Aposentado (a) &, 000 & . & . & . & . & . & . & . & . \\
\hline Estudante &, 060 & 1,381 & $-1,789$ &, 107 & ,262 & ,642 & ,464 &, 533 & ,997 \\
\hline Desempregado (a) & ,021 & 2,597 & ,936 & ,077 & ,331 &, 063 &, 817 &, 073 & ,890 \\
\hline Sem Ocupação / Nunca Trabalhou &, 004 &,- 347 & ,093 & ,016 &, 001 &, 000 &, 014 &, 001 &, 015 \\
\hline Outros &, 000 & . & . & . & . & . & . & . & . \\
\hline Total ativo & 1,000 & & & ,327 & 1,000 & 1,000 & & & \\
\hline
\end{tabular}

a. Normalização simétrica 
Tabela 6C - Pontos de coluna de visão geral ${ }^{\mathrm{a}}$ - Ocupação Principal por Renda Familiar

\begin{tabular}{|c|c|c|c|c|c|c|c|c|c|}
\hline \multirow[b]{3}{*}{ Renda Familiar } & \multirow[b]{3}{*}{ Massa } & \multicolumn{2}{|c|}{$\begin{array}{c}\text { Pontuação em } \\
\text { dimensão }\end{array}$} & \multirow[b]{3}{*}{ Inércia } & \multicolumn{5}{|c|}{ Contribuição } \\
\hline & & \multirow[b]{2}{*}{1} & \multirow[b]{2}{*}{2} & & \multicolumn{2}{|c|}{ De ponto para inércia de dimensão } & \multicolumn{3}{|c|}{ De dimensão para inércia de ponto } \\
\hline & & & & & 1 & 2 & 1 & 2 & Total \\
\hline Sem Rendimento & ,038 & 2,135 & $-1,975$ &, 122 & ,402 &, 503 & ,628 & ,368 & ,997 \\
\hline Até 2 Salários Mínimos & ,107 & 1,225 & 1,114 &, 111 & ,368 & ,445 &, 629 & ,356 & ,985 \\
\hline Entre 2 e 4 Salários Mínimos &, 167 &,- 257 &, 149 &, 014 &, 025 &, 012 & ,354 &, 081 &, 435 \\
\hline Entre 4 e 10 Salários Mínimos & ,372 &,- 130 &,- 148 &, 011 &, 014 &, 027 &, 252 & ,222 &, 474 \\
\hline Entre 10 e 20 Salários Mínimos &, 214 &,- 151 &, 028 &, 020 &, 011 &, 001 &, 105 &, 002 &, 108 \\
\hline Acima de 20 Salários Mínimos &, 103 &,- 872 &,- 185 &, 050 &, 179 &, 012 & ,679 &, 021 & ,700 \\
\hline Total ativo & 1,000 & & & ,327 & 1,000 & 1,000 & & & \\
\hline
\end{tabular}

a. Normalização simétrica 
Tabela 7C - Pontos de linha de confiança - Ocupação Principal por Renda

\begin{tabular}{l|c|c|c} 
& \multicolumn{3}{c|}{ Familiar } \\
& \multicolumn{2}{c}{$\begin{array}{c}\text { Desvio padrão em } \\
\text { dimensão }\end{array}$} & Correlação \\
\cline { 2 - 4 } Ocupação Principal & 1 & 2 & $1-2$ \\
\hline Empregado (a) &, 072 &, 190 &,- 560 \\
Autônomo &, 380 &, 387 &,- 436 \\
Funcionário (a) público (a) &, 421 &, 633 &, 443 \\
Do Lar &, 472 &, 582 &,- 332 \\
Aposentado (a) &. &. &. \\
Estudante & 1,213 &, 608 &, 762 \\
Desempregado (a) & 1,100 & 1,624 &,- 310 \\
Sem Ocupação / Nunca Trabalhou &, 992 & 1,615 &, 162 \\
Outros &. &. &. \\
\hline
\end{tabular}

Tabela 8C - Pontos de coluna de confiança - Ocupação Principal por Renda

\begin{tabular}{l|c|c|c} 
& \multicolumn{3}{c}{ Familiar } \\
& \multicolumn{2}{|c|}{$\begin{array}{c}\text { Desvio padrão em } \\
\text { dimensão }\end{array}$} & Correlação \\
\cline { 2 - 4 } Renda Familiar & 1 & 2 & $1-2$ \\
\hline Sem Rendimento & 1,374 &, 781 &, 857 \\
Até 2 Salários Mínimos &, 768 &, 536 &,- 778 \\
Entre 2 e 4 Salários Mínimos &, 191 &, 287 &, 277 \\
Entre 4 e 10 Salários Mínimos &, 138 &, 177 &,- 075 \\
Entre 10 e 20 Salários Mínimos &, 208 &, 297 &, 085 \\
Acima de 20 Salários Mínimos &, 258 &, 649 &,- 325 \\
\hline
\end{tabular}


Tabelas da Figura 23

Tabela 9C - Correspondência entre a Atividades e Deslocamentos

\begin{tabular}{|c|c|c|c|c|c|c|}
\hline \multirow[b]{2}{*}{$\begin{array}{l}\text { Atividades (Após o } \\
\text { Nascimento) }\end{array}$} & \multicolumn{6}{|c|}{ Deslocamentos (Após o Nascimento) } \\
\hline & Não & Desl. > alguns dias & $\begin{array}{c}\text { Desl. }<\text { alguns } \\
\text { dias }\end{array}$ & $\begin{array}{c}\text { Desl. > todos os } \\
\text { dias }\end{array}$ & $\begin{array}{c}\text { Desl. }<\text { todos os } \\
\text { dias }\end{array}$ & Margem ativa \\
\hline Não & 8 & 2 & 0 & 1 & 0 & 11 \\
\hline Ativ. $>$ alguns dias & 1 & 61 & 3 & 9 & 0 & 74 \\
\hline Ativ. $<$ alguns dias & 0 & 1 & 6 & 1 & 0 & 8 \\
\hline Ativ. $>$ todos os dias & 5 & 28 & 4 & 90 & 5 & 132 \\
\hline Ativ. $<$ todos os dias & 1 & 2 & 0 & 0 & 6 & 9 \\
\hline Margem ativa & 15 & 94 & 13 & 101 & 11 & 234 \\
\hline
\end{tabular}

Tabela 10C - Resumo - Anacor - Atividades e Deslocamentos

\begin{tabular}{|c|c|c|c|c|c|c|c|c|}
\hline \multirow[b]{3}{*}{ Dimensão } & \multirow[b]{3}{*}{ Valor singular } & \multirow[b]{3}{*}{ Inércia } & \multirow[b]{3}{*}{ Chi-quadrado } & \multirow[b]{3}{*}{ Sig. } & \multicolumn{2}{|c|}{ Proporção de inércia } & \multicolumn{2}{|c|}{ Valor singular de confiança } \\
\hline & & & & & \multirow{2}{*}{$\begin{array}{c}\text { Contabilizado } \\
\text { para }\end{array}$} & \multirow[b]{2}{*}{ Acumulativo } & \multirow[b]{2}{*}{ Desvio padrão } & Correlação \\
\hline & & & & & & & & 2 \\
\hline 1 & ,643 & ,413 & & & ,298 & ,298 & ,067 & ,470 \\
\hline 2 &, 583 & ,340 & & & ,246 &, 544 &, 057 & \\
\hline 3 & ,566 & ,321 & & & ,232 & ,776 & & \\
\hline 4 &, 557 & ,310 & & &, 224 & 1,000 & & \\
\hline Total & & 1,383 & 323,641 &, $000^{\mathrm{a}}$ & 1,000 & 1,000 & & \\
\hline
\end{tabular}

a. 16 graus de liberdade 
Tabela 11C - Pontos de linha de visão geral ${ }^{\mathrm{a}}$ - Atividades e Deslocamentos

\begin{tabular}{|c|c|c|c|c|c|c|c|c|c|}
\hline \multirow{3}{*}{$\begin{array}{l}\text { Atividades (Após o } \\
\text { Nascimento) }\end{array}$} & \multirow[b]{3}{*}{ Massa } & \multicolumn{2}{|c|}{ Pontuação em dimensão } & \multirow[b]{3}{*}{ Inércia } & \multicolumn{5}{|c|}{ Contribuição } \\
\hline & & & & & \multicolumn{2}{|c|}{ De ponto para inércia de dimensão } & \multicolumn{3}{|c|}{ De dimensão para inércia de ponto } \\
\hline & & 1 & 2 & & 1 & 2 & 1 & 2 & Total \\
\hline Não &, 047 & 2,243 & 2,066 &, 346 & ,368 & ,344 & ,440 & ,339 & ,778 \\
\hline Ativ. > alguns dias & ,316 &,- 575 &, 776 &, 240 &, 163 & ,327 & ,280 & 463 & ,743 \\
\hline Ativ. $<$ alguns dias &, 034 & $-1,672$ &,- 097 &, 315 &, 149 &, 001 &, 195 &, 001 &, 196 \\
\hline Ativ. $>$ todos os dias &, 564 &, 080 &,- 557 &, 146 &, 006 & ,301 & ,016 & ,700 & ,716 \\
\hline Ativ. $<$ todos os dias &, 038 & 2,294 &,- 648 &, 337 &, 315 & ,028 & ,385 & ,028 & ,413 \\
\hline Total ativo & 1,000 & & & 1,383 & 1,000 & 1,000 & & & \\
\hline
\end{tabular}

a. Normalização simétrica

Tabela 12C - Pontos de coluna de visão geral ${ }^{\mathrm{a}}$ - Atividades e Deslocamentos

\begin{tabular}{|c|c|c|c|c|c|c|c|c|c|}
\hline \multirow{3}{*}{$\begin{array}{l}\text { Deslocamentos (Após o } \\
\text { Nascimento) }\end{array}$} & \multirow[b]{3}{*}{ Massa } & \multicolumn{2}{|c|}{ Pontuação em dimensão } & \multirow[b]{3}{*}{ Inércia } & \multicolumn{5}{|c|}{ Contribuição } \\
\hline & & & & & \multicolumn{2}{|c|}{ De ponto para inércia de dimensão } & \multicolumn{3}{|c|}{ De dimensão para inércia de ponto } \\
\hline & & 1 & 2 & & 1 & 2 & 1 & 2 & Total \\
\hline Não &, 064 & 2,082 & 1,587 &, 345 &, 432 &, 277 &, 518 & ,273 & ,791 \\
\hline Desl. > alguns dias & ,402 &,- 421 & ,629 & ,206 &, 111 &, 273 &, 221 & ,449 &, 671 \\
\hline Desl. < alguns dias &, 056 & $-1,369$ &,- 064 &, 309 &, 162 &, 000 &, 216 &, 000 &, 217 \\
\hline Desl. > todos os dias & ,432 & 040 &,- 700 &, 189 &, 001 & ,363 &, 002 & ,652 &, 655 \\
\hline Desl. < todos os dias &, 047 & 2,004 & $-1,041$ & ,334 & ,294 & ,087 & ,363 & ,089 & ,452 \\
\hline Total ativo & 1,000 & & & 1,383 & 1,000 & 1,000 & & & \\
\hline
\end{tabular}

a. Normalização simétrica 


\section{Tabelas da Figura 24}

Tabela 13C - Correspondência entre a Atividades e Deslocamentos Companheiro (a) ou Cônjuge

\begin{tabular}{|c|c|c|c|c|c|c|}
\hline \multirow{2}{*}{$\begin{array}{l}\text { Atividades do (a) } \\
\text { Companheiro (a) ou Cônjuge } \\
\text { (Após o Nascimento) }\end{array}$} & \multicolumn{6}{|c|}{ Deslocamentos do (a) Companheiro (a) ou Cônjuge (Após o Nascimento) } \\
\hline & Não & $\begin{array}{c}\text { Desl. > alguns } \\
\text { dias }\end{array}$ & $\begin{array}{c}\text { Desl. < alguns } \\
\text { dias }\end{array}$ & $\begin{array}{c}\text { Desl. > todos os } \\
\text { dias }\end{array}$ & $\begin{array}{c}\text { Desl. }<\text { todos os } \\
\text { dias }\end{array}$ & Margem ativa \\
\hline Não & 47 & 12 & 0 & 2 & 0 & 61 \\
\hline Ativ. $>$ alguns dias & 5 & 62 & 0 & 6 & 0 & 73 \\
\hline Ativ. $<$ alguns dias & 3 & 5 & 3 & 1 & 0 & 12 \\
\hline Ativ. $>$ todos os dias & 1 & 9 & 1 & 44 & 1 & 56 \\
\hline Ativ. $<$ todos os dias & 1 & 0 & 0 & 0 & 1 & 2 \\
\hline Margem ativa & 57 & 88 & 4 & 53 & 2 & 204 \\
\hline
\end{tabular}

Tabela 14C - Resumo - Anacor - Atividades e Deslocamentos Companheiro (a) ou Cônjuge

\begin{tabular}{|c|c|c|c|c|c|c|c|c|}
\hline \multirow[b]{3}{*}{ Dimensão } & \multirow[b]{3}{*}{ Valor singular } & \multirow[b]{3}{*}{ Inércia } & \multirow[b]{3}{*}{ Chi-quadrado } & \multirow[b]{3}{*}{ Sig. } & \multicolumn{2}{|c|}{ Proporção de inércia } & \multicolumn{2}{|c|}{ Valor singular de confiança } \\
\hline & & & & & \multirow{2}{*}{$\begin{array}{c}\text { Contabilizado } \\
\text { para }\end{array}$} & \multirow[b]{2}{*}{ Acumulativo } & \multirow[b]{2}{*}{ Desvio padrão } & Correlação \\
\hline & & & & & & & & 2 \\
\hline 1 & ,782 & ,612 & & & ,424 & ,424 & 039 & ,482 \\
\hline 2 & 649 & ,421 & & & ,291 &, 715 &, 051 & \\
\hline 3 & ,486 &, 237 & & &, 164 &, 879 & & \\
\hline 4 & ,418 &, 175 & & &, 121 & 1,000 & & \\
\hline Total & & 1,444 & 294,614 &, $000^{\mathrm{a}}$ & 1,000 & 1,000 & & \\
\hline
\end{tabular}

a. 16 graus de liberdade 
Tabela 15C - Pontos de linha de visão geral ${ }^{\mathrm{a}}$ - Atividades e Deslocamentos Companheiro (a) ou Cônjuge

\begin{tabular}{|c|c|c|c|c|c|c|c|c|c|}
\hline \multirow{3}{*}{$\begin{array}{l}\text { Atividades do(a) } \\
\text { Companheiro(a) ou Cônjuge } \\
\text { (Após o Nascimento) }\end{array}$} & \multirow[b]{3}{*}{ Massa } & \multicolumn{2}{|c|}{ Pontuação em dimensão } & \multirow[b]{3}{*}{ Inércia } & \multicolumn{5}{|c|}{ Contribuição } \\
\hline & & & & & \multicolumn{2}{|c|}{ De ponto para inércia de dimensão } & \multicolumn{3}{|c|}{ De dimensão para inércia de ponto } \\
\hline & & 1 & 2 & & 1 & 2 & 1 & 2 & Total \\
\hline Não & ,299 & $-1,067$ &,- 658 & ,364 & ,435 & ,199 &, 731 &, 230 & ,961 \\
\hline Ativ. $>$ alguns dias & ,358 &,- 038 & 1,021 &, 256 &, 001 &, 575 &, 002 & ,945 & ,947 \\
\hline Ativ. $<$ alguns dias & 059 &,- 186 &, 221 &, 167 & ,003 & ,004 &, 010 &, 011 & ,021 \\
\hline Ativ. $>$ todos os dias &, 275 & 1,264 &,- 580 & ,408 &, 560 &, 142 &, 841 &, 147 & ,988 \\
\hline Ativ. $<$ todos os dias & ,010 &,- 338 & $-2,288$ & ,249 & ,001 & ,079 &, 004 & ,134 &, 137 \\
\hline Total ativo & 1,000 & & & 1,444 & 1,000 & 1,000 & & & \\
\hline
\end{tabular}

a. Normalização simétrica

Tabela 16C - Pontos de coluna de visão geral ${ }^{\mathrm{a}}$ - Atividades e Deslocamentos Companheiro (a) ou Cônjuge

\begin{tabular}{|c|c|c|c|c|c|c|c|c|c|}
\hline \multirow{3}{*}{$\begin{array}{l}\text { Deslocamentos do(a) } \\
\text { Companheiro(a) ou Cônjuge } \\
\text { (Após o Nascimento) }\end{array}$} & \multirow[b]{3}{*}{ Massa } & \multicolumn{2}{|c|}{ Pontuação em dimensão } & \multirow[b]{3}{*}{ Inércia } & \multicolumn{5}{|c|}{ Contribuição } \\
\hline & & & & & \multicolumn{2}{|c|}{ De ponto para inércia de dimensão } & \multicolumn{3}{|c|}{ De dimensão para inércia de ponto } \\
\hline & & 1 & 2 & & 1 & 2 & 1 & 2 & Total \\
\hline Não & ,279 & $-1,120$ &,- 758 & ,384 & ,448 &, 247 & ,714 & ,271 & ,985 \\
\hline Desl. > alguns dias &, 431 &,- 069 &, 898 &, 234 & ,003 &, 537 &, 007 & ,965 & ,972 \\
\hline Desl. $<$ alguns dias &, 020 &, 225 &, 032 &, 172 & 001 &, 000 &, 005 &, 000 & ,005 \\
\hline Desl. > todos os dias &, 260 & 1,279 &,- 596 & 405 &, 544 &, 142 &, 822 &, 148 & ,970 \\
\hline Desl. $<$ todos os dias &, 010 &, 592 & $-2,210$ &, 249 & ,004 &, 074 &, 011 &, 125 & ,136 \\
\hline Total ativo & 1,000 & & & 1,444 & 1,000 & 1,000 & & & \\
\hline
\end{tabular}

a. Normalização simétrica 


\section{ANEXO D}

\section{ANÁLISE DE CLUSTER}

Tabela 1D - Matriz de proximidade / dissimilaridade

\begin{tabular}{|c|c|c|c|c|c|c|}
\hline \multirow[b]{2}{*}{ Caso } & \multicolumn{6}{|c|}{ Distância Euclidiana Quadrática } \\
\hline & $\begin{array}{c}\text { Sem } \\
\text { Rendimento } \\
\end{array}$ & $\begin{array}{c}\text { Até } 2 \\
\text { Salários } \\
\text { Mínimos }\end{array}$ & $\begin{array}{c}\text { Entre } 2 \text { e } 4 \\
\text { Salários } \\
\text { Mínimos } \\
\end{array}$ & $\begin{array}{c}\text { Entre } 4 \text { e } 10 \\
\text { Salários } \\
\text { Mínimos } \\
\end{array}$ & $\begin{array}{c}\text { Entre } 10 \text { e } 20 \\
\text { Salários } \\
\text { Mínimos } \\
\end{array}$ & $\begin{array}{c}\text { Acima de } 20 \\
\text { Salários } \\
\text { Mínimos } \\
\end{array}$ \\
\hline Sem Rendimento & ,000 & 2,333 & 1,727 & 1,900 & 2,037 & 2,021 \\
\hline Até 2 Salários Mínimos & 2,333 &, 000 & 1,851 & 2,018 & 2,172 & 2,165 \\
\hline $\begin{array}{l}\text { Entre } 2 \text { e } 4 \text { Salários } \\
\text { Mínimos }\end{array}$ & 1,727 & 1,851 & ,000 & ,032 & ,052 & ,071 \\
\hline $\begin{array}{l}\text { Entre } 4 \text { e } 10 \text { Salários } \\
\text { Mínimos }\end{array}$ & 1,900 & 2,018 & ,032 & ,000 & ,024 & ,055 \\
\hline $\begin{array}{l}\text { Entre } 10 \text { e } 20 \text { Salários } \\
\text { Mínimos }\end{array}$ & 2,037 & 2,172 & ,052 & ,024 & 000, & ,010, \\
\hline $\begin{array}{l}\text { Acima de } 20 \text { Salários } \\
\text { Mínimos }\end{array}$ & 2,021 & 2,165 & ,071 & 055 &, 010 &, 000 \\
\hline
\end{tabular}

Fonte: Elaborado pelo autor

Tabela 2D - Planejamento de aglomeração

\begin{tabular}{|c|c|c|c|c|c|c|}
\hline \multirow[b]{2}{*}{ Estágio } & \multicolumn{2}{|c|}{ Cluster combinado } & \multirow[b]{2}{*}{ Coeficientes } & \multicolumn{2}{|c|}{$\begin{array}{c}\text { O cluster de estágio é exibido } \\
\text { primeiro }\end{array}$} & \multirow[b]{2}{*}{ Próximo estágic } \\
\hline & Cluster 1 & Cluster 2 & & Cluster 1 & Cluster 2 & \\
\hline 1 & 5 & 6 &, 010 & 0 & 0 & 2 \\
\hline 2 & 4 & 5 & ,024 & 0 & 1 & 3 \\
\hline 3 & 3 & 4 &, 032 & 0 & 2 & 4 \\
\hline 4 & 1 & 3 & 1,727 & 0 & 3 & 5 \\
\hline 5 & 1 & 2 & 1,851 & 4 & 0 & 0 \\
\hline
\end{tabular}

Fonte: Elaborado pelo autor 


\begin{tabular}{l|c} 
Tabela 3D - Associação do cluster & \\
\hline Caso & 3 Clusters \\
\hline Sem Rendimento & 1 \\
Até 2 Salários Mínimos & 2 \\
Entre 2 e 4 Salários Mínimos & 3 \\
Entre 4 e 10 Salários Mínimos & 3 \\
Entre 10 e 20 Salários Mínimos & 3 \\
Acima de 20 Salários Mínimos & 3 \\
\hline
\end{tabular}

Fonte: Elaborado pelo autor

Tabela 4D - Renda Familiar por modo de transporte (Após o Nascimento)

\begin{tabular}{|c|c|c|c|c|c|c|c|c|c|}
\hline \multirow[b]{2}{*}{ Renda Familiar } & & \multicolumn{7}{|c|}{ Modo de Transporte (Após o Nascimento) } & \multirow[b]{2}{*}{ Total } \\
\hline & & $\begin{array}{c}\text { Automóvel } \\
\text { (Dirigindo) }\end{array}$ & $\begin{array}{c}\text { Automóvel } \\
\text { (Carona) }\end{array}$ & Motocicleta & Ônibus & Metrô & Bicicleta & A pé & \\
\hline & Sem Rendimento & 0 & 2 & 0 & 6 & 0 & 0 & 1 & 9 \\
\hline & Até 2 Sal. Mín. & 6 & 5 & 3 & 4 & 0 & 1 & 6 & 25 \\
\hline & De 2 a 4 Sal. Mín. & 26 & 4 & 3 & 5 & 0 & 1 & 0 & 39 \\
\hline & De 4 a 10 Sal. Mín. & 67 & 14 & 0 & 5 & 1 & 0 & 0 & 87 \\
\hline & De 10 a 20 Sal. Mín. & 42 & 3 & 0 & 1 & 1 & 1 & 2 & 50 \\
\hline & Acima de 20 Sal. Mín. & 20 & 0 & 0 & 1 & 1 & 0 & 2 & 24 \\
\hline Total & & 161 & 28 & 6 & 22 & 3 & 3 & 11 & 234 \\
\hline
\end{tabular}

Fonte: Elaborado pelo autor 


\section{ANEXO E}

\section{ANÁLISE DE MCNEMAR}

Tabela 1E - Estatísticas de teste ${ }^{\mathrm{a}}$

\begin{tabular}{l|lr}
\hline & \multicolumn{3}{|c}{ Carteira de Habilitação (Após o Nascimento) } \\
& \multicolumn{2}{|c}{ X } \\
\hline $\mathrm{N}$ & Carteira de Habilitação (Antes do Nascimento) & 234 \\
Significância Sig. & & 0,000010 \\
\hline
\end{tabular}

Fonte: Elaborado pelo autor

\begin{tabular}{l|rr}
\hline & $\begin{array}{l}\text { Influencia na tomada de decisão da escolha } \\
\text { do meio de transporte do (a) respondente e } \\
\text { do (a) companheiro (a) ou Cônjuge (Após o } \\
\text { Nascimento) }\end{array}$ \\
\hline N & \multicolumn{2}{|c|}{204} \\
Significância Sig. & 0,001 \\
\hline
\end{tabular}

Fonte: Elaborado pelo autor 
Tabela 3E - Meio de Transporte (Antes do Nascimento) e Meio de Transporte (Após o Nascimento)

\begin{tabular}{|c|c|c|c|c|c|c|c|c|c|}
\hline & \multirow[b]{2}{*}{$\begin{array}{c}\text { Modo de Transporte } \\
\text { (Antes do Nascimento) }\end{array}$} & \multicolumn{7}{|c|}{ Modo de Transporte (Após o Nascimento) } & \multirow[b]{2}{*}{ Total } \\
\hline & & $\begin{array}{l}\text { Automóvel } \\
\text { (Dirigindo) }\end{array}$ & $\begin{array}{l}\text { Automóvel } \\
\text { (Carona) }\end{array}$ & Motocicleta & Ônibus & Metrô & Bicicleta & A pé & \\
\hline & Automóvel (Dirigindo) & 114 & 7 & 3 & 1 & 1 & 1 & 1 & 128 \\
\hline & Automóvel (Carona) & 9 & 12 & 0 & 3 & 0 & 0 & 0 & 24 \\
\hline & Motocicleta & 6 & 1 & 1 & 1 & 0 & 0 & 0 & 9 \\
\hline & Ônibus & 25 & 7 & 1 & 16 & 1 & 0 & 3 & 53 \\
\hline & Metrô & 1 & 0 & 0 & 0 & 1 & 0 & 1 & 3 \\
\hline & Bicicleta & 2 & 0 & 0 & 0 & 0 & 2 & 0 & 4 \\
\hline & A pé & 4 & 1 & 1 & 1 & 0 & 0 & 6 & 13 \\
\hline Total & & 161 & 28 & 6 & 22 & 3 & 3 & 11 & 234 \\
\hline
\end{tabular}


ANEXO F

\section{ANÁLISE DO RANKING MÉDIO}

Tabela 1F - Grau de Importância (Antes do Nascimento)

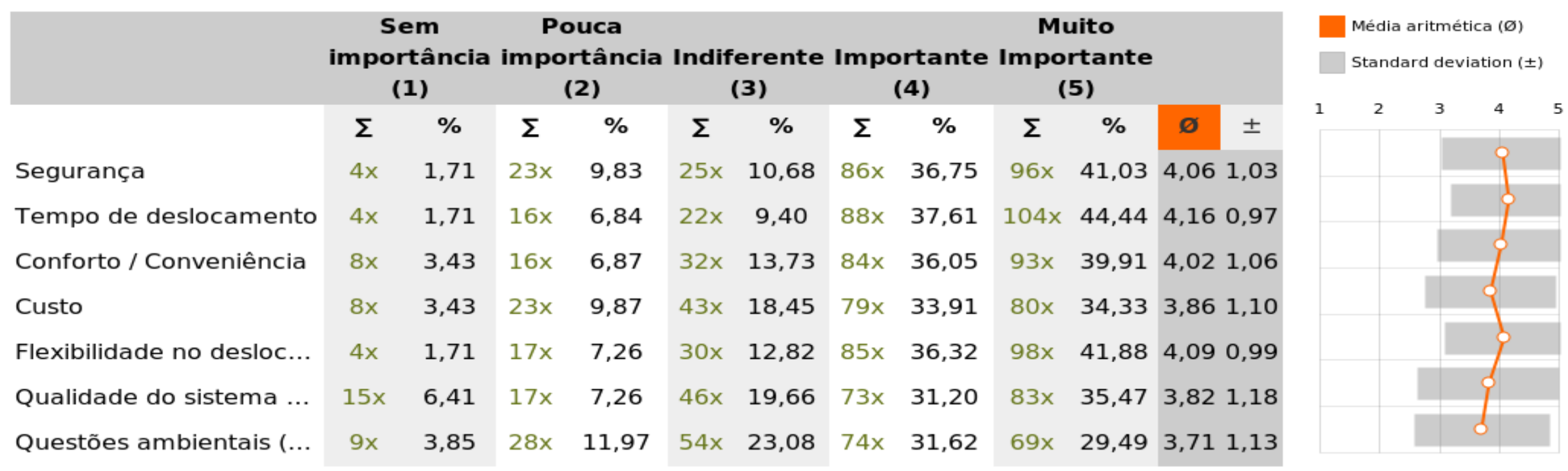

Fonte: Elaborado pelo autor 
Tabela 2F - Grau de Importância (Após o Nascimento)

\begin{tabular}{|c|c|c|c|c|c|c|c|c|c|c|c|c|}
\hline & \multirow{2}{*}{\multicolumn{2}{|c|}{$\begin{array}{c}\text { Sem } \\
\text { importância } \\
\text { (1) }\end{array}$}} & \multirow{2}{*}{\multicolumn{2}{|c|}{$\begin{array}{c}\text { Pouca } \\
\text { importância } \\
\text { (2) }\end{array}$}} & \multirow{2}{*}{\multicolumn{6}{|c|}{$\begin{array}{ll}\text { Muito } & \\
\text { Indiferente Importante Importante } \\
\text { (3) }\end{array}$}} & \multirow[b]{3}{*}{$\boldsymbol{\varnothing}$} & \multirow[b]{3}{*}{ \pm} \\
\hline & & & & & & & & & & & & \\
\hline & $\Sigma$ & $\%$ & $\Sigma$ & $\%$ & $\Sigma$ & $\%$ & $\Sigma$ & $\%$ & $\Sigma$ & $\%$ & & \\
\hline Segurança & $3 x$ & 1,29 & $14 x$ & 6,03 & $12 x$ & 5,17 & $83 x$ & 35,78 & $120 x$ & 51,72 & 4,31 & 0,91 \\
\hline Tempo de deslocamento & $2 x$ & 0,87 & $15 x$ & 6,49 & $14 x$ & 6,06 & $64 x$ & 27,71 & $136 x$ & 58,87 & 4,37 & 0,92 \\
\hline Conforto / Conveniência & $5 x$ & 2,16 & $14 x$ & 6,03 & $17 x$ & 7,33 & $80 x$ & 34,48 & $116 x$ & 50,00 & 4,24 & 0,98 \\
\hline Custo & $6 x$ & 2,59 & $21 x$ & 9,05 & $40 x$ & 17,24 & $91 x$ & 39,22 & $74 x$ & 31,90 & 3,89 & 1,04 \\
\hline Flexibilidade no desloc... & $3 x$ & 1,30 & $16 x$ & 6,93 & $16 x$ & 6,93 & $73 x$ & 31,60 & $123 x$ & 53,25 & 4,29 & 0,96 \\
\hline Qualidade do sistema ... & $16 x$ & 6,93 & $11 x$ & 4,76 & $35 x$ & 15,15 & $61 x$ & 26,41 & $108 x$ & 46,75 & 4,01 & 1,20 \\
\hline Questỗes ambientais (... & $7 x$ & 3,03 & $25 x$ & 10,82 & $47 x$ & 20,35 & $78 x$ & 33,77 & $74 x$ & 32,03 & 3,81 & 1,09 \\
\hline
\end{tabular}

Média aritmética (Ø)

Standard deviation ( \pm )

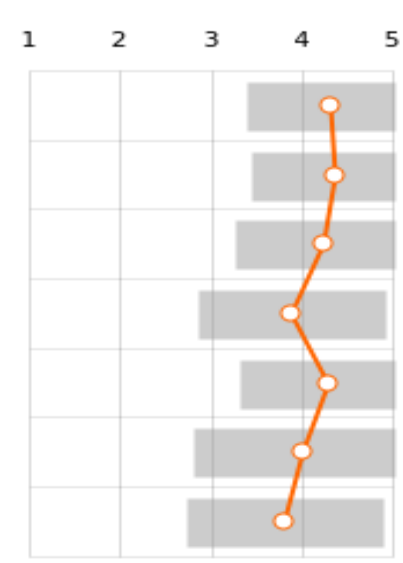




\section{ANEXO G}

\section{VARIÁVEIS}

Quadro 1G - Composição das Variáveis

\begin{tabular}{|c|c|}
\hline Nome & Rótulo / Descrição \\
\hline Gênero_1 & Gênero \\
\hline Idade_1 & Idade \\
\hline Posic_Fam_1 & Posição Familiar \\
\hline Esc_1 & Escolaridade \\
\hline Ocup_Princ_1 & Ocupação Principal \\
\hline Renda_1 & Renda Familiar \\
\hline Local_1 & Localização \\
\hline Cart_Hab_Atual_1 & Carteira de Habilitação (Após o Nascimento) \\
\hline Qt_Aut_Atual_1 & Quantidade Automóvel (Após o Nascimento) \\
\hline Modo_Atual_1 & Modo de Transporte (Após o Nascimento) \\
\hline Cart_Hab_Pass_2 & Carteira de Habilitação (Antes do Nascimento) \\
\hline Qt_Aut_Pass_2 & Quantidade Automóvel (Antes do Nascimento) \\
\hline Modo_Pass_2 & Modo de Transporte (Antes do Nascimento) \\
\hline Ativid_Resp_3 & Atividades (Após o Nascimento) \\
\hline Desloc_Resp_3 & Deslocamentos (Após o Nascimento) \\
\hline Influenc_Resp_3 & Influenciou na Escolha do Modo de Transporte (Após o Nascimento) \\
\hline Desloc_Crianc_3 & Modo de Transporte Utilizado no Deslocamento da Criança \\
\hline Desloc_Crianc_Dif_3 & Mudança na Utilização de Outro Modo de Transporte para o Deslocamento da Criança \\
\hline Trabalh_Resp_3 & Continuou trabalhando (Após o Nascimento) \\
\hline Mudanc_Resp_3 & Houve Mudanças Residencial (Após o Nascimento) \\
\hline Ativid_Comp_4 & Atividades do (a) companheiro (a) ou Cônjuge (Após o Nascimento) \\
\hline Desloc_Comp_4 & Deslocamentos do (a) companheiro (a) ou Cônjuge (Após o Nasc.) \\
\hline Influenc_Comp_4 & $\begin{array}{l}\text { Influenciou na Escolha do Modo de Transporte do (a) companheiro (a) ou Cônjuge } \\
\text { (Após o Nascimento) }\end{array}$ \\
\hline Troc_Modo_Comp_4 & $\begin{array}{l}\text { Houve Mudança no Modo de Transporte do (a) companheiro (a) ou Cônjuge (Após o } \\
\text { Nascimento) }\end{array}$ \\
\hline Trabalh_Comp_4 & Companheiro (a) ou Cônjuge Continuou Trabalhando (Após o Nasc.) \\
\hline Mudanc_Comp_4 & Houve Mudanças Residencial do (a) companheiro (a) ou Cônjuge (Após o Nascimento) \\
\hline
\end{tabular}




\section{ANEXO H}

\section{INSTRUMENTOS DE PESQUISA}

\section{Instrumento de Pesquisa $\mathbf{n}^{0} \mathbf{1}$}

\begin{tabular}{|c|c|c|c|}
\hline \multicolumn{4}{|c|}{ Quadro H.1 - Descrição dos Veículos } \\
\hline \multicolumn{4}{|c|}{ Parte A } \\
\hline \multicolumn{2}{|r|}{ Carro A } & \multicolumn{2}{|r|}{ Carro B } \\
\hline \multirow{2}{*}{$\begin{array}{l}\text { Período de Posse } \\
\text { do Carro (anos) }\end{array}$} & de & \multirow{2}{*}{$\begin{array}{l}\text { Período de Posse } \\
\text { do Carro (anos) }\end{array}$} & de \\
\hline & para & & para \\
\hline Marca & & Marca & \\
\hline Modelo & & Modelo & \\
\hline Troca do Motor & & Troca do Motor & \\
\hline \multirow{3}{*}{ Combustível } & Gasolina ( ) & \multirow{3}{*}{ Combustível } & Gasolina ( ) \\
\hline & Diesel ( ) & & Diesel ( ) \\
\hline & Outros ( ) & & Outros ( ) \\
\hline \multirow{3}{*}{ Transmissão } & Manual ( ) & \multirow{3}{*}{ Transmissão } & Manual ( ) \\
\hline & Automática ( ) & & Automática ( ) \\
\hline & Tiptronica ( ) & & Tiptronica ( ) \\
\hline Modelo (ano) & & Modelo (ano) & \\
\hline \multirow{3}{*}{ Comprado } & Usado ( ) & \multirow{3}{*}{ Comprado } & Usado ( ) \\
\hline & Carro Demostrativo ( ) & & Carro Demostrativo ( ) \\
\hline & Carro Novo ( ) & & Carro Novo ( ) \\
\hline \multicolumn{2}{|l|}{ Carro C } & \multicolumn{2}{|l|}{ Carro D } \\
\hline \multirow{2}{*}{$\begin{array}{l}\text { Período de Posse } \\
\text { do Carro (anos) }\end{array}$} & de & \multirow{2}{*}{$\begin{array}{l}\text { Período de Posse } \\
\text { do Carro (anos) }\end{array}$} & de \\
\hline & para & & para \\
\hline Marca & & Marca & \\
\hline Modelo & & Modelo & \\
\hline Troca do Motor & & Troca do Motor & \\
\hline \multirow{3}{*}{ Combustível } & Gasolina ( ) & \multirow{3}{*}{ Combustível } & Gasolina ( ) \\
\hline & Diesel ( ) & & Diesel ( ) \\
\hline & Outros ( ) & & Outros ( ) \\
\hline \multirow{3}{*}{ Transmissão } & Manual ( ) & \multirow{3}{*}{ Transmissão } & Manual ( ) \\
\hline & Automática ( ) & & Automática ( ) \\
\hline & Tiptronica ( ) & & Tiptronica ( ) \\
\hline Modelo (ano) & & Modelo (ano) & \\
\hline \multirow{3}{*}{ Comprado } & Usado ( ) & \multirow{3}{*}{ Comprado } & Usado ( ) \\
\hline & Carro Demostrativo ( ) & & Carro Demostrativo ( ) \\
\hline & Carro Novo ( ) & & Carro Novo ( ) \\
\hline
\end{tabular}

Fonte: Lanzendorf et al.(2015) 
Quadro H.2 - Relacionamentos Cronológicos

\begin{tabular}{|c|c|c|c|c|c|c|c|c|c|c|c|c|c|c|}
\hline \multicolumn{15}{|c|}{ Parte B } \\
\hline & 2003 & 2004 & 2005 & 2006 & 2007 & 2008 & 2009 & 2010 & 2011 & 2012 & 2013 & 2014 & 2015 & 2016 \\
\hline \multicolumn{15}{|l|}{ Dados do Histórico Familiar } \\
\hline \multicolumn{15}{|l|}{ Nascimentos / Mortes } \\
\hline \multicolumn{15}{|l|}{ Casamento / União Estável / Separação } \\
\hline \multicolumn{15}{|l|}{ Outros Eventos (ex.: Aposentadoria) } \\
\hline \multicolumn{15}{|l|}{ Dados sobre o local da residência, de educação ou trabalho } \\
\hline \multicolumn{15}{|l|}{ C.E. P Municipal do Local de Residência } \\
\hline \multicolumn{15}{|l|}{ C.E. P Municipal do Local de Estudo / Trabalho } \\
\hline \multicolumn{15}{|l|}{ Dados das pessoas que residem no seu domicílio } \\
\hline \multicolumn{15}{|l|}{ Número de pessoas (Total Geral) } \\
\hline \multicolumn{15}{|l|}{ Número de Crianças Abaixo dos 18 anos } \\
\hline \multicolumn{15}{|l|}{ Número de Pessoas que tem Carteira de Habilitação } \\
\hline \multicolumn{15}{|c|}{ Tipos de Meios de Transportes Utilizados para ir aos Locais de Estudo ou Trabalho } \\
\hline \multicolumn{15}{|l|}{ Carro, Motocicleta, Ciclomotor } \\
\hline \multicolumn{15}{|l|}{ Trem, Bonde, Ônibus } \\
\hline \multicolumn{15}{|l|}{ Bicicleta } \\
\hline \multicolumn{15}{|l|}{ Caminhada } \\
\hline \multicolumn{15}{|l|}{ Dados dos seus Veículos em seu Condomínio } \\
\hline $\begin{array}{l}\text { Por favor relacionar as informações do formulário (Parte A) } \\
\text { descrevendo quais foram os últimos carros que você foi proprietário. O } \\
\text { espaço é suficiente para listar até oito carros. }\end{array}$ & & & & & & & & & & & & & & \\
\hline
\end{tabular}

Fonte: Lanzendorf et al.(2015) 


\section{Instrumento de Pesquisa no 2 - Oakil (2013)}

\begin{tabular}{|c|c|c|}
\hline $\begin{array}{l}\text { Parte 01: Informações Gerais } \\
\text { 1. Endereço do seu domicílio? (Nome da rua ou } \\
\text { 2. Qual é a sua cidade natal? } \\
\text { 3. (Se você não nasceu no Brasil) Desde quano }\end{array}$ & CEP) & \\
\hline \multicolumn{3}{|c|}{ Preencha a tabela abaixo com as informações de cada membro do seu domicílio. Comece por seus próprios dados. } \\
\hline & Pessoa 01 (Você) & Pessoa 02 \\
\hline \multicolumn{3}{|l|}{ 4. Ano de Nascimento } \\
\hline 5. Sexo & $\begin{array}{l}\text { i. Masculino } \\
\text { ii. Feminino }\end{array}$ & $\begin{array}{l}\text { i. Masculino } \\
\text { ii. Feminino }\end{array}$ \\
\hline 6. Posição no Domicílio & $\begin{array}{l}\text { i. Chefe de família } \\
\text { ii. Parceiro(a)/Cônjuje } \\
\text { iii. Filho(a) } \\
\text { iv. Pai/Mãe } \\
\text { v. Outro (especifique) } \\
\end{array}$ & $\begin{array}{l}\text { i. Chefe de família } \\
\text { ii. Parceiro(a)/Cônjuje } \\
\text { iii. Filho(a) } \\
\text { iv. Pai/Mãe } \\
\text { v. Outro (especifique) } \\
\text { ve }\end{array}$ \\
\hline 7. Grau de Escolaridade & $\begin{array}{l}\text { i. Sem escolaridade } \\
\text { ii. Ensino Fundamental Incompleto } \\
\text { iii. Ensino Fundamental Completo } \\
\text { iv. Ensino Médio Incompleto } \\
\text { v. Ensino Médio Completo } \\
\text { vi. Ensino Superior Incompleto } \\
\text { vii. Ensino Superior Completo } \\
\text { viii. Especialização } \\
\text { ix. Mestrado } \\
\text { x. Doutorado } \\
\text { xi. Outro } \\
\end{array}$ & $\begin{array}{l}\text { i. Sem escolaridade } \\
\text { ii. Ensino Fundamental Incompleto } \\
\text { iii. Ensino Fundamental Completo } \\
\text { iv. Ensino Médio Incompleto } \\
\text { v. Ensino Médio Completo } \\
\text { vi. Ensino Superior Incompleto } \\
\text { vii. Ensino Superior Completo } \\
\text { viii. Especialização } \\
\text { ix. Mestrado } \\
\text { x. Doutorado } \\
\text { xi. Outro } \\
\end{array}$ \\
\hline 8. Ocupação & $\begin{array}{l}\text { i. Estudante } \\
\text { ii. Empregado } \\
\text { iii. Autônomo } \\
\text { iv. Desempregado } \\
\text { v. Aposentado } \\
\text { vi. De licença/Afastado } \\
\text { vii. Sem ocupação/ Nunca trabalhou } \\
\text { viii. Prendas domésticas } \\
\text { ix. Outro } \\
\end{array}$ & \begin{tabular}{|l} 
i. Estudante \\
ii. Empregado \\
iii. Autônomo \\
iv. Desempregado \\
v. Aposentado \\
vi. De licença/Afastado \\
vii. Sem ocupação/ Nunca trabalhou \\
viii. Prendas domésticas \\
ix. Outro \\
\end{tabular} \\
\hline 9. Local de Trabalho/Estudo & & \\
\hline 10. Possui carteira de Habilitação & $\begin{array}{l}\text { i. Sim } \\
\text { ii. Não }\end{array}$ & $\begin{array}{l}\text { i. Sim } \\
\text { ii. Não }\end{array}$ \\
\hline 11. Possui desconto para Transporte Público? & $\begin{array}{l}\text { i. Sim } \\
\text { ii. Não }\end{array}$ & $\begin{array}{l}\text { i. Sim } \\
\text { ii. Não }\end{array}$ \\
\hline
\end{tabular}




\begin{tabular}{|c|c|c|}
\hline \multicolumn{3}{|c|}{$\begin{array}{l}\text { 12. Você possui alguma necessidade especial que o impeça de usar algum modo de transporte? } \\
\text { i. Sim }\end{array}$} \\
\hline & & \\
\hline ii. Não & & \\
\hline \multicolumn{3}{|c|}{ 13. Se você respondeu sim à pergunta anterior, quais modos de transporte você não pode utilizar? (Mais de uma resposta pode ser marcada) } \\
\hline \multicolumn{3}{|l|}{ i. Automóvel } \\
\hline \multicolumn{3}{|l|}{ ii. Motocicleta } \\
\hline \multicolumn{3}{|l|}{ iii. Ônibus } \\
\hline \multicolumn{3}{|l|}{ iv. Metrô } \\
\hline \multicolumn{3}{|l|}{ v. Bicicleta } \\
\hline \multicolumn{3}{|l|}{ vi. Caminhada } \\
\hline \multicolumn{3}{|l|}{ vii. Outros (especifique) } \\
\hline \multicolumn{3}{|c|}{ 14. Você pretende se mudar dentro dos próximos 2 anos? } \\
\hline \multicolumn{3}{|l|}{ i. Sim } \\
\hline & & \\
\hline \multicolumn{3}{|l|}{ 15. Se você respondeu sim à pergunte } \\
\hline Domicílio & Residência Atual & Vizinhança Atual \\
\hline i. Casamento/União estável & i. Residência muito pequena & i. Falta de manutenção (limpeza, paisagismo, etc) \\
\hline ii. Divórcio/Separação & ii. Residência muito grande & ii. Falta de segurança \\
\hline iii. Para morar sozinho & iii. Preferência por aluguel a imóvel próprio & iii. Odores desagradáveis, ruído, ou poeira \\
\hline iv. Para dividir moradia & iv. Preferência por imóvel próprio a aluguel & iv. Instalações inadequadas (infraestrutura) \\
\hline v. Nascimento de filhos(as) & v. Preferência por outro tipo de habitação & v. Acessibilidade a transporte público \\
\hline vi. Falecimento de um membro do do & vi. Preferência por condomínio fechado & vi. Outro (especifique) \\
\hline vii. Aumento da renda familiar & vii. Estacionamento & \\
\hline viii Diminuição da renda familiar & viii. Ausência de elevador & \\
\hline \multirow[t]{3}{*}{ ix. Outro (especifique) } & ix. Ausência de DCE & \\
\hline & x. Ausência de "coisas de condomínio" (lav & iscina, churrasqueira, etc) \\
\hline & xii. Outro (especifique) & \\
\hline
\end{tabular}

\begin{tabular}{|l|l|}
\hline Trabalho e Estudo & Rede Social \\
\hline i. Mudou de emprego/local de estudo & i. Estar mais próximo dos amigos \\
$\begin{array}{l}\text { ii. Trocou para emprego em horário integral } \\
\text { iii. Trocou para emprego de meio periodo }\end{array}$ & iii. Estar mais próximo da família \\
$\begin{array}{l}\text { iv. Se aposentou } \\
\text { v. À procura de emprego } \\
\text { vi. Foi demitido/pediu demissão }\end{array}$ & \\
vii. Outro (especifique) & \\
\hline & \\
\hline
\end{tabular}


Parte 02: Informações Pessoais

1. Calendário de Atividades

Responda todas as questões do calendário a seguir em relação ao ano de 1990 e para os anos subsequentes.

Nota: Por favor, use " $X$ " ou " $\sqrt{ }$ " para indicar o ano onde ocorreu o evento descrito.

Use setas ou linhas para indicar um período contínuo.

\section{Ocupação}

1. Preencha sua ocupação em 1990, e toda vez que houve alteração

i. Estudante

ii. A procura de emprego

iii. Empregado(a) por meio periodo

iv. Empregado(a) por tempo integral

v. Aposentado(a)/Sem ocupação

vi. Não lembro

2. Preencha a ocupação do(a) seu(ua) parceiro(a) em 1990, e toda vez que houve alteração, caso aplicável

i. Estudante

ii. A procura de emprego

iii. Empregado(a) por meio periodo

iv. Empregado(a) por tempo integral

v. Aposentado(a)/Sem ocupação

vi. Não lembro

\section{Renda Familiar}

3. Indique a sua renda (bruta, por mês) para cada ano

i. Inferior a $R \$ 500,00$

ii. Entre $\mathrm{R} \$ 500,00$ e $\mathrm{R} \$ 1000,00$

iii. Entre $R \$ 1000,00$ e $R \$ 1500,00$

iv. Entre $\mathrm{R} \$ 1500,00$ e $\mathrm{R} \$ 2000,00$

v. Acima de $\mathrm{R} \$ 2000,00$

vi. Não lembro

4. Indique renda (bruta, por mês) do(a) seu(ua) parceiro(a) para cada ano, caso aplicável

i. Inferior a $\mathrm{R} \$ 500,00$

ii. Entre $R \$ 500,00$ e $R \$ 1000,00$

iii. Entre $R \$ 1000,00$ e $R \$ 1500,00$

iv. Entre $\mathrm{R} \$ 1500,00$ e $\mathrm{R} \$ 2000,00$

v. Acima de $\mathrm{R} \$ 2000,00$

vi. Não lembro

\section{Residência}

5. Mencione quantas pessoas viviam nesta residência em 1990, e toda vez que esse número foi alterado

6. Indique no calendário com " $\mathrm{X}$ " ou " $\sqrt{ }$ " a ocorrência de um ou mais dos seguintes eventos:

i. Você saiu da casa dos pais

ii. Casamento/Dividir moradia

iii. Nascimento de filhos(as)

iv. Seus filhos(as) sairam de casa

v. Divórcio/Separação

vi. Falecimento de um membro do domicílio (por favor, mencione sua relação com o falecido)

Caso outro evento relevante tenha ocorrido, por favor, especifique-o nos espaços abaixo e marque-o no calendário.

vii. Outro (especifique)

viii. Outro (especifique)

ix. Outro (especifique)

x. Outro (especifique) 
Preencha a planilha a seguir com dados referentes à sua residência atual, e as 5 anteriores (no periodo de 1990 até hoje)

\begin{tabular}{l|l|l}
\cline { 3 - 3 } Nota: Omita períodos de menos de seis meses. Use " $\mathrm{X}$ " ou " $\sqrt{ }$ " para indicar sua resposta. & Residência Atual & Residência Anterior 01 \\
\hline
\end{tabular}

\section{Caracterização da Residência}

7. Endereço/CEP (ou ponto de referência/cruzamento entre ruas mais próximo)

8. Em que ano você se mudou para este endereço?

9. Tipo de habitação

0. Condição de propriedade do imóvel

11. Despesa mensal

12. Número de aposentos

13. Estacionamento

14. Condomínio fechado

\begin{tabular}{|l|l}
\hline Residência Atual & Residência Anterior 01 \\
\hline
\end{tabular}

\begin{tabular}{|l|l|}
\hline & \\
\hline & \\
\hline i. Casa & i. Casa \\
ii. Apartamento & ii. Apartamento \\
iii. Quarto/Pensão & iii. Quarto/Pensão \\
iv. República & iv. República \\
v. Outro (especifique) & v. Outro (especifique) \\
\hline i. Alugado & i. Alugado \\
$\begin{array}{l}\text { ii. Imóvel próprio } \\
\text { iii. Outro (especifique) }\end{array}$ & ii. Imóvel próprio \\
\hline iii. Outro (especifique) \\
\hline & \\
\hline i. Garagem & i. Garagem \\
\hline ii. Estacionamento público & ii. Estacionamento público \\
iii. Na rua & iii. Na rua \\
iv. Outro (especifique) & iv. Outro (especifique) \\
\hline $\begin{array}{l}\text { i. Sim } \\
\text { ii. Não }\end{array}$ & i. Sim \\
\hline ii. Não \\
\hline
\end{tabular}

Quais das seguintes circunstâncias foram relevantes na decisão de se mudar para outra residência? (Mais de uma resposta pode ser marcada)

15. Razões pessoais

\begin{tabular}{|c|c|}
\hline Não se aplica & $\begin{array}{l}\text { i. Casamento/União estável } \\
\text { ii. Divórcio/Separação } \\
\text { iii. Para morar sozinho } \\
\text { iv. Para dividir moradia } \\
\text { v. Nascimento de filhos(as) } \\
\text { vi. Falecimento de um membro do domicílio } \\
\text { vi. Outro (especifique) }\end{array}$ \\
\hline Não se aplica & $\begin{array}{l}\text { i. Aumento da renda familiar } \\
\text { ii Diminuição da renda familiar }\end{array}$ \\
\hline Não se aplica & $\begin{array}{l}\text { i. Residência muito pequena } \\
\text { ii. Residência muito grande } \\
\text { v. Preferência por outro tipo de habitação } \\
\text { iv. Estacionamento } \\
\text { v. Ausência de elevador } \\
\text { vi. Ausência de DCE } \\
\text { vii. Preferência por condomínio fechado } \\
\text { viii. Ausência de (lavanderia, piscina, churrasqueira) } \\
\text { ix. Outro (especifique) }\end{array}$ \\
\hline Não se aplica & $\begin{array}{l}\text { i. Preferência por aluguel a imóvel próprio } \\
\text { ii. Preferência por imóvel próprio a aluguel }\end{array}$ \\
\hline Não se aplica & $\begin{array}{l}\text { i. Falta de manutenção } \\
\text { ii. Falta de segurança } \\
\text { iii. Odores desagradáveis, ruído, ou poeira } \\
\text { iv. Instalações inadequadas } \\
\text { v. Outro (especifique) }\end{array}$ \\
\hline Não se aplica & $\begin{array}{l}\text { i. Mudou de emprego/local de estudo } \\
\text { ii. Trocou para emprego em horário integral } \\
\text { iii. Trocou para emprego de meio periodo } \\
\text { iv. Se aposentou } \\
\text { v. À procura de emprego } \\
\text { vi. Foi demitido/pediu demissão } \\
\text { vii. Outro (especifique) }\end{array}$ \\
\hline Não se aplica & $\begin{array}{l}\text { i. Sim } \\
\text { ii. Não }\end{array}$ \\
\hline Não se aplica & $\begin{array}{l}\text { i. Estar mais próximo dos amigos } \\
\text { ii. Estar mais próximo da família } \\
\text { iii. Estar mais próximo dos amigos dos filhos } \\
\text { v. Outro (especifique) }\end{array}$ \\
\hline
\end{tabular}

21. Foi a acessibilidade da residência ao transporte público a razão para a mudança?

22. Foi sua "rede social" a razão para a mudança? 
Preencha a planilha a seguir com dados referentes à sua ocupação atual, e as 5 anteriores (no periodo de 1990 até hoje).

No caso de estudantes, considere o seu local de estudo como ocupação. Responda o mesmo sobre seu parceiro, caso aplicável.

\begin{tabular}{l|l|l|l|l}
\hline & Ocupação Atual & Ocupação Anterior 01 & Ocupação Anterior 02 \\
\hline
\end{tabular}

\section{Ocupação}

23. Local de emprego/estudo

24. Ano que iniciou tal emprego/estudo

25. Local de emprego/estudo de seu(ua) parceiro(a)

26. Ano que seu(ua) parceiro(a) iniciou tal emprego/estudo

\begin{tabular}{l|l|l|l|l|}
\hline & & & & \\
\hline & & & & \\
\hline & & & & \\
\hline & & & & \\
\hline
\end{tabular}


Responda todas as questões do calendário a seguir em relação ao ano de 1990 e para os anos subsequentes, caso hajam alterações. Por favor, especifique a resposta mais adequada à sua situação durante o periodo indicado.

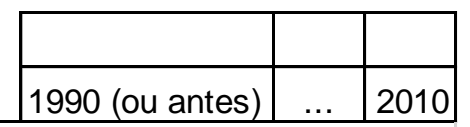

\section{Transporte}

27. Número de automóveis em seu domicílio

28. Com base nos membros do seu domicílio, responda

i. Em que ano você tirou a carteira de habilitação?

ii. Em que ano seu(ua) parceiro(a) tirou a carteira de habilitação?

iii. Em que ano um(a) de seus(uas) filhos(as) tirou a carteira de habilitação?

iv. Em que ano outro membro do seu domicílio tirou a carteira de habilitação?

29. Indique quais destas opções eram acessíveis a você

i. Disponibilidade em tempo integral de automóvel próprio

ii. Disponibilidade em tempo integral de automóvel de trabalho

iii. Disponibilidade parcial de automóvel da família

iv. Disponibilidade de vale transporte

30. Indique quais destas opções eram acessíveis ao(à) seu(ua) parceiro(a)

i. Disponibilidade em tempo integral de automóvel próprio

ii. Disponibilidade em tempo integral de automóvel de trabalho

iii. Disponibilidade parcial de automóvel da família

iv. Disponibilidade de vale transporte

31. Qual o tempo de deslocamento para trabalho/estudo, em minutos, pelo meio de transporte mais utilizado

i. Por você

ii. Pelo(a) seu(ua) parceiro(a)

32. Meio de transporte utilizado para tal deslocamento (automóvel, motocicleta, ônibus, metrô, bicicleta, caminhada)

i. Por você

ii. Pelo(a) seu(ua) parceiro(a)

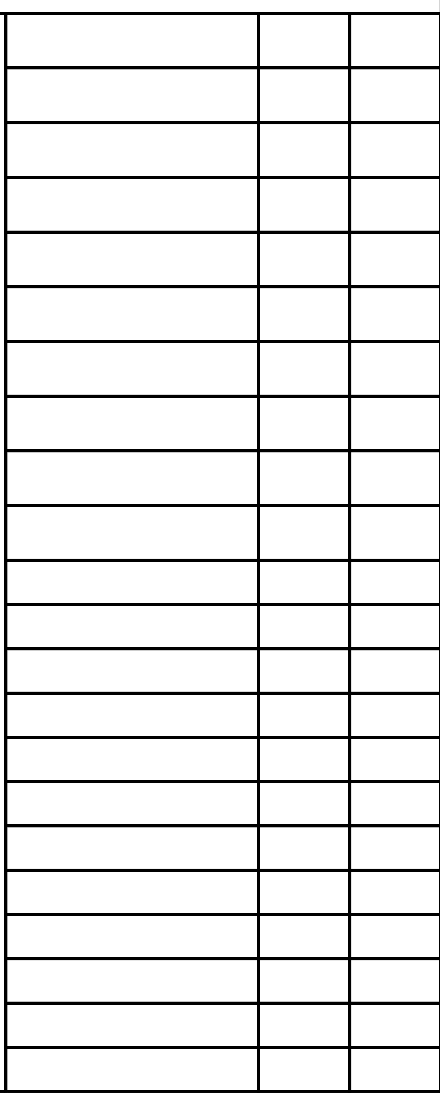


2. Perspectiva de Carreira ou Metas Futuras

Esta seção é composta por perguntas sobre perspectivas de carreira, e metas para o futuro, para você e seu(ua) companheiro(a).

Use "X" ou " $\sqrt{ }$ " para indicar quais dos seguintes objetivos você pretende atingir, e quando pretende atingi-lo.

Responda também sobre sua certeza em relação a capacidade de atingir tal objetivo.

\begin{tabular}{|c|c|c|c|c|c|c|c|}
\hline & \multicolumn{7}{|c|}{ Quando você planeja atingir esta meta? } \\
\hline & É uma meta? & Em 2010 & Em 2011 & Entre $3-5$ anos & Entre 5-10 Anos & Depois de 10 anos & Não sabe \\
\hline \multicolumn{8}{|l|}{ Ocupação } \\
\hline \multicolumn{8}{|l|}{ Você planeja... } \\
\hline \multicolumn{8}{|c|}{ 33. Terminar seus estudos } \\
\hline \multicolumn{8}{|c|}{ 34. Adquirir um diploma de nivel mais elevado } \\
\hline \multicolumn{8}{|c|}{ 35. Conseguir um emprego de meio periodo } \\
\hline \multicolumn{8}{|c|}{ 36. Conseguir um emprego em tempo integral } \\
\hline \multicolumn{8}{|c|}{ 37. Aposentar/deixar de trabalhar } \\
\hline \multicolumn{8}{|c|}{ 38. Aumentar sua renda (melhorando de emprego, ou com mais de um emprego) } \\
\hline \multicolumn{8}{|l|}{ 39. Mudar de emprego } \\
\hline \multicolumn{8}{|c|}{ Seu(ua) parceiro(a) planeja... } \\
\hline \multicolumn{8}{|c|}{ 40. Terminar seus estudos } \\
\hline \multicolumn{8}{|c|}{ 41. Adquirir um diploma de nivel mais elevado } \\
\hline \multicolumn{8}{|c|}{ 42. Conseguir um emprego de meio periodo } \\
\hline \multicolumn{8}{|c|}{ 43. Conseguir um emprego em tempo integral } \\
\hline \multicolumn{8}{|c|}{ 44. Aposentar/deixar de trabalhar } \\
\hline \multicolumn{8}{|c|}{ 45. Aumentar sua renda (melhorando de emprego, ou com mais de um emprego) } \\
\hline 46. Mudar de emprego & & & & & & & \\
\hline
\end{tabular}




\section{Transporte}

Você planeja...

47. Tirar carteira de habilitação

48. Adquirir um automóvel para seu uso em tempo integral

49. Adquirir um automóvel para a família dividir

50. Adquirir um vale transporte

51. Reduzir seu tempo de deslocamento para o trabalho/estudo

i. $10 \mathrm{~min}$

ii. $10-30 \mathrm{~min}$

iii. $30-60 \mathrm{~min}$

iv. mais de $60 \mathrm{~min}$

52. Mudar de meio de deslocamento para o trabalho/estudo

i. Automóvel

ii. Transporte público

iii. Automóvel + transporte público

iv. Bicicleta + transporte público

v. Bicicleta

vi. Outro

Seu(ua) parceiro(a) planeja...

53. Tirar carteira de habilitação

54. Adquirir um automóvel para seu uso em tempo integral

55. Adquirir um automóvel para a família dividir

56. Adquirir um vale transporte

57. Reduzir seu tempo de deslocamento para o trabalho/estudo i. $10 \mathrm{~min}$

ii. $10-30 \mathrm{~min}$

iii. $30-60 \mathrm{~min}$

iv. mais de $60 \mathrm{~min}$

58. Mudar de meio de deslocamento para o trabalho/estudo

i. Automóvel

ii. Transporte público

iii. Automóvel + transporte público

iv. Bicicleta + transporte público

v. Bicicleta

vi. Outro

Quando você planeja atingir esta meta?

\begin{tabular}{|l|l|l|l|l|l|l|}
\hline É uma meta? & Em 2010 & Em 2011 & Entre 3-5 anos & Entre 5-10 Anos & Depois de 10 anos & Não sabe \\
\hline
\end{tabular}

\begin{tabular}{|c|c|c|c|c|c|c|}
\hline & & & & & & INao sabe \\
\hline & & & & & & \\
\hline & & & & & & \\
\hline & & & & & & \\
\hline & & & & & & \\
\hline & & & & & & \\
\hline & & & & & & \\
\hline & & & & & & \\
\hline & & & & & & \\
\hline & & & & & & \\
\hline & & & & & & \\
\hline & & & & & & \\
\hline & & & & 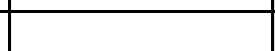 & & \\
\hline & & & & & & \\
\hline & & & & & & \\
\hline & & & & & & \\
\hline & & & & & & \\
\hline & & & & & & \\
\hline & & & & & & \\
\hline & & & & & & \\
\hline & & & & & & \\
\hline & & & & & & \\
\hline & & & & & & \\
\hline & & & & & & \\
\hline & & & & & & \\
\hline & & & & & & \\
\hline & & & & & & \\
\hline & & & & & & \\
\hline & & & & & & \\
\hline & & & & & & \\
\hline & & & & & & \\
\hline & & & & & & \\
\hline & & & & & & \\
\hline & & & & & & \\
\hline & & & & & & \\
\hline & & & & & & \\
\hline
\end{tabular}




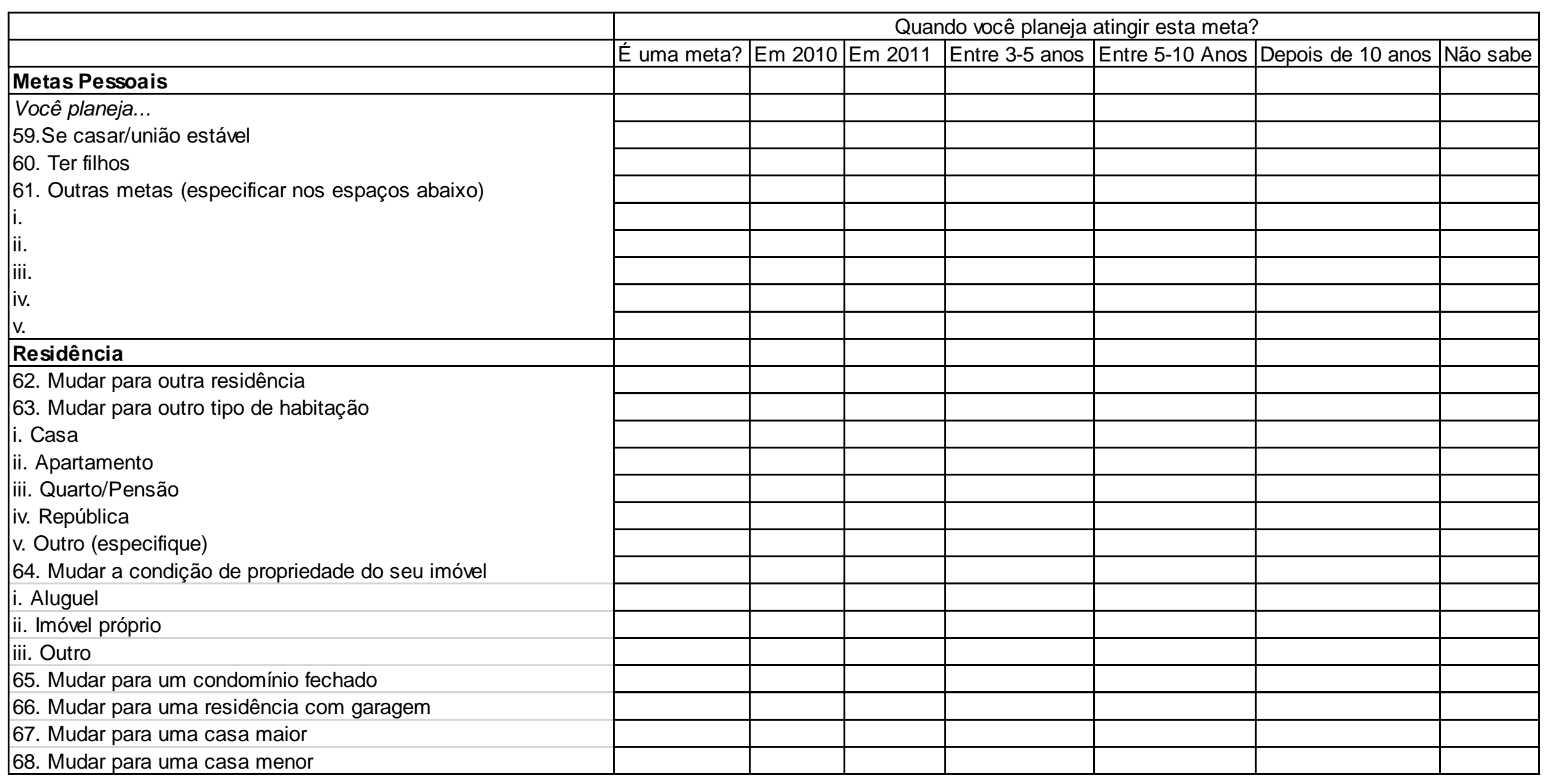


Parte 03: Rede Social e Expectivas de Mercado

1. Rede Social

As seguintes perguntas são sobre pessoas que estão perto de você.

Especifique qualquer pessoa, vida, de trabalho e informações de transporte sobre o 3 pessoa (s) (não relacionados) que são mais importantes para você .. Nota: Não é necessário dar uma resposta precisa aqui; uma estimativa é suficiente.

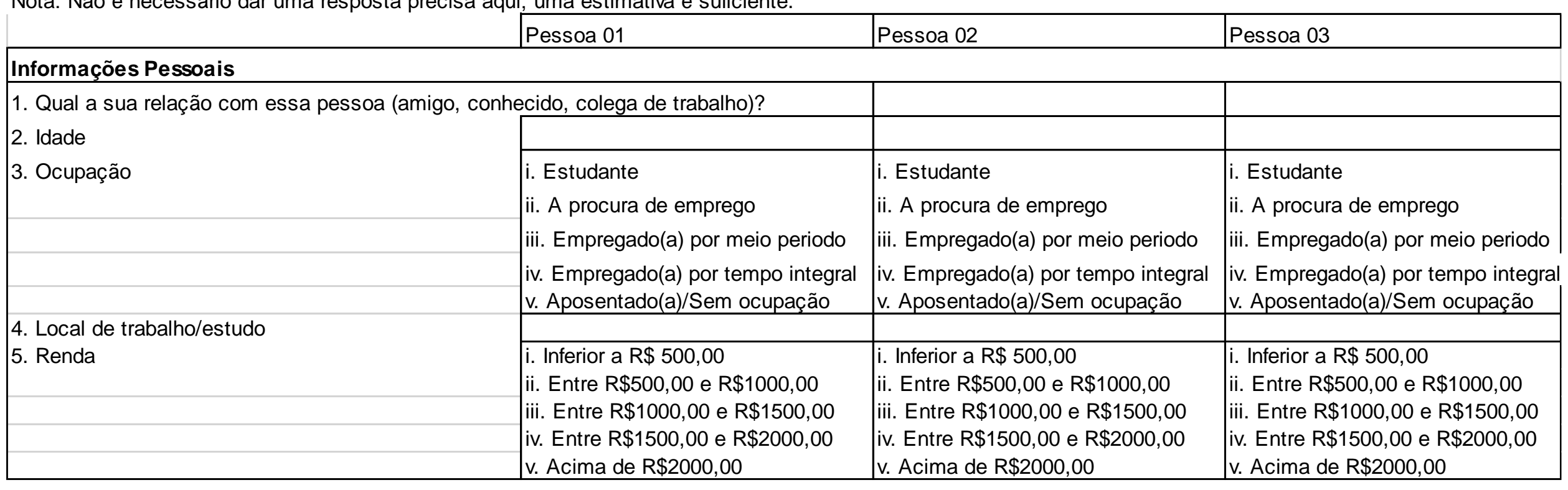




\begin{tabular}{|c|c|c|c|c|}
\hline \multicolumn{5}{|l|}{ Caracterização da Residência } \\
\hline \multicolumn{5}{|c|}{ 6. Endereço/CEP (ou ponto de referência/cruzamento entre ruas mais próximo) } \\
\hline \multirow{6}{*}{$\begin{array}{l}\text { 7. Em que ano ele(a) se mudou para este endereço? } \\
\text { 8. Tipo de habitação }\end{array}$} & & & & \\
\hline & i. Casa & i. Casa & i. Casa & i. Casa \\
\hline & ii. Apartamento & ii. Apartamento & ii. Apartamento & ii. Apartamento \\
\hline & iii. Quarto/Pensão & iii. Quarto/Pensão & iii. Quarto/Pensão & iii. Quarto/Pensão \\
\hline & iv. República & iv. República & iv. República & iv. República \\
\hline & v. Outro (especifique) & v. Outro (especifique) & v. Outro (especifique) & v. Outro (especifique) \\
\hline \multirow[t]{3}{*}{ 9. Condição de propriedade do imóvel } & i. Alugado & i. Alugado & i. Alugado & i. Alugado \\
\hline & ii. Imóvel próprio & ii. Imóvel próprio & ii. Imóvel próprio & ii. Imóvel próprio \\
\hline & iii. Outro (especifique) & iii. Outro (especifique) & iii. Outro (especifique) & iii. Outro (especifique) \\
\hline \multicolumn{5}{|l|}{ 10. Número de aposentos } \\
\hline \multirow[t]{4}{*}{ 11. Estacionamento } & i. Garagem & i. Garagem & i. Garagem & i. Garagem \\
\hline & ii. Estacionamento público & ii. Estacionamento público & ii. Estacionamento público & ii. Estacionamento público \\
\hline & iii. Na rua & iii. Na rua & iii. Na rua & iii. Na rua \\
\hline & iv. Outro (especifique) & iv. Outro (especifique) & iv. Outro (especifique) & iv. Outro (especifique) \\
\hline \multirow[t]{2}{*}{ 12. Condomínio fechado } & i. $\operatorname{Sim}$ & i. Sim & i. Sim & i. Sim \\
\hline & ii. Não & ii. Não & ii. Não & ii. Não \\
\hline \multicolumn{5}{|l|}{ Transporte } \\
\hline 13. Possui carteira de habilitação & i. $\operatorname{Sim}$ & i. Sim & i. Sim & i. Sim \\
\hline \multirow{4}{*}{ 14. Número de automóveis no domicílio } & ii. Não & ii. Não & ii. Não & ii. Não \\
\hline & i. Um & i. Um & i. Um & i. Um \\
\hline & ii. Mais de um & ii. Mais de um & ii. Mais de um & ii. Mais de um \\
\hline & iii. Nenhum & iii. Nenhum & iii. Nenhum & iii. Nenhum \\
\hline \multirow{4}{*}{$\begin{array}{l}\text { 15. Tempo de deslocamento para trabalho/estudo } \\
\text { 16. Meio de transporte utilizado para tal deslocamento }\end{array}$} & & & & \\
\hline & i. Automóvel & i. Automóvel & i. Automóvel & i. Automóvel \\
\hline & ii. Transporte público & ii. Transporte público & ii. Transporte público & ii. Transporte público \\
\hline & iii. Bicicleta/Caminhada & iii. Bicicleta/Caminhada & iii. Bicicleta/Caminhada & iii. Bicicleta/Caminhada \\
\hline
\end{tabular}




\section{Previsões de Mercado}

Perguntas sobre as suas expectativas em relação aos mercados e transporte de habitação e de trabalho.

Por favor, envie a sua opinião sobre a habitação, emprego e transportes.

Nota: Escolha a resposta que melhor reflete a sua opinião

17. Você espera que nos próximos três anos, mais casas estão disponiveis no seu setor social?

I. Eu. Sim, em seu ambiente atual

II. Sim, em um ambiente diferente, que é semelhante ao seu ambiente atual

iii. Sem change

iv. Eu não sei / Sem opinião

18. Qual a sua expectativa quanto ao preço de imóveis para os próximos 3 anos?

i. Aumentar significativamente

ii. Aumentar ligeiramente

iii. Se manter estável

iv. Cair ligeiramente

v. Cair significativamente

vi. Não sei/Não tenho opinião

19. Qual a sua expectativa para a disponibilidade de empregos para sua classe social para os próximos 3 anos?

i. Mais empregos

ii. Menos empregos

iii. Nenhuma alteração

iv. Não sei/Não tenho opinião

20. Qual a sua expectativa quanto ao preço de automóveis para os próximos 3 anos?

i. Aumentar significativamente

ii. Aumentar ligeiramente

iii. Se manter estável

iv. Cair ligeiramente

v. Cair significativamente

vi. Não sei/Não tenho opinião

21. Qual sua expectativa sobre o congestionamento do trânsito para os próximos 3 anos?

i. Aumentar significativamente

ii. Aumentar ligeiramente

iii. Se manter estável

iv. Cair ligeiramente

v. Cair significativamente

vi. Não sei/Não tenho opinião 


\section{Instrumento de Pesquisa no 3 - Lanzendorf (2010)}

\section{Projeto "Biografias de Mobilidade" - Entrevista Guiada}

(Antes de ligar a fita de áudio)

Obrigado por participar da entrevista.

Declaração sobre a entrevista: estudo sobre a "Biografias de Mobilidade", abordagem técnica: gravação e transcrição, garantia de anonimato

(Ligando fita)

\section{I - Disponibilidade de Transporte, Uso e Atividades Diárias}

1a. Qual é o modo de transporte que você normalmente usa em suas atividades diárias?

1b. O que você gosta / não gosta em seu modo de transporte [carro, ônibus, trem, bicicleta, a pé]?

- Diversão

- O estresse

- "Para ter tempo para mim"

- Custo

- Rapidez

- Conveniência/Comforto

- Segurança

2. Você possui Carteira de motorista?

Um carro?

Uma bicicleta?

Um bilhete de passage / estação de transportes públicos?

\section{Diário de Atividade}

À sua frente há um mapa da cidade de Leipzig. Eu gostaria que você mostrasse os lugares mais importantes e recorrentes e as atividades que você prática na sua vida diária.

(Responda às duas perguntas abaixo, de acordo com a lista a seguir)

- Onde você executa as suas atividades (em que lugar)?

- Quais são as suas atividades?

\section{Trabalho / Educação}

2 Escola / Jardim de Infância, outras atividades com as crianças (lazer / passatempo)

3 Compras

Pequenas compras (pão, leite, etc.)

Compras maiores de supermercado

Outras compras regulares (têxteis, necessidades domésticas)

Outras compras (por exemplo, compras em Shopping) 


\section{Lazer longe de casa}

Visitar os pais / amigos

Encontros Sociais

Sports

Cultura

Passeios

Finais de Semana (caminhadas, passeios a parques de diversões, piscina)

\section{Outros (Segunda residência / camping de longo prazo)}

\section{II - Gravando a Biografia}

\section{Olhe novamente para o esboço.}

Estamos interessados em como e se o seu comportamento de tráfego tem mudado ao longo dos últimos anos. (Tempo horizonte: nos últimos 15 anos)

Você sempre usou o modo de transporte mencionado acima ou você mudou para outros modos de transporte?

- Quando?

- Por quê?

(Houve algum determinado acontecimento na sua vida que coincidiu com as suas mudanças no comportamento do tráfego? Informe o motivo para a referida mudança de comportamento)

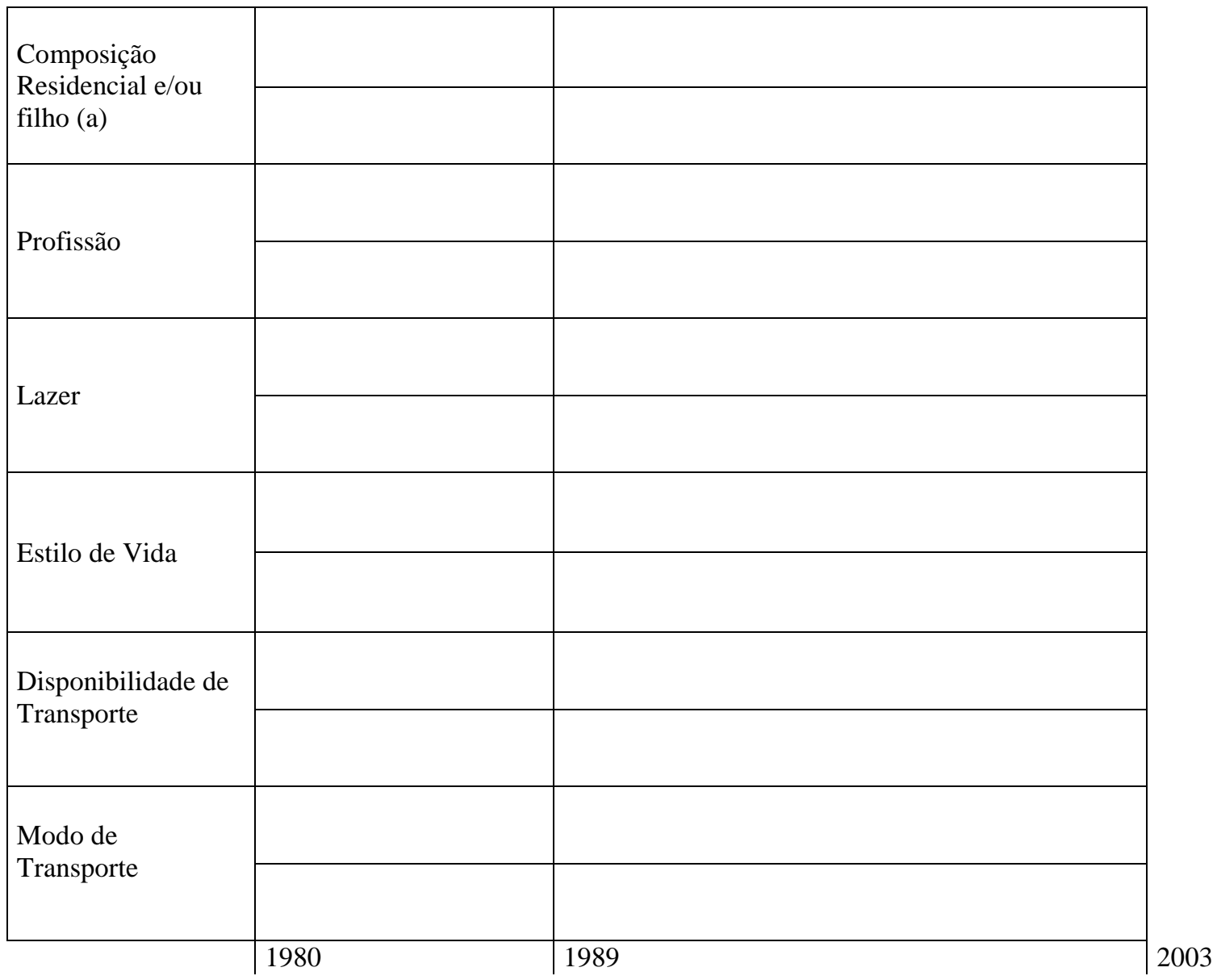


Nós já havíamos perguntado sobre sua avaliação aos diferentes modos de transporte.

Você pensa em voltar novamente ao modo antigo? Quando e como mudou ao longo dos últimos anos?

- Carro

- Ônibus / Bonde

- Bicicleta

- A pé

\section{III - Inquérito de Eventos Especiais}

$\mathrm{Na}$ seção seguinte, nós gostaríamos de perguntar sobre eventos especiais, se podem ter influenciado as mudanças no modo de transporte (Informe quando não abordado).

\section{Estilo de Vida}

Você mudou-se no período de tempo acima mencionado?

$\mathrm{O}$ seu modo de transporte mudou?

(Se Sim) Qual foi a razão para a transferência e mudança de modo de transporte?

A disponibilidade de transporte no novo local afetou a sua decisão?

\section{Composição Residencial e Filho(a)}

Será que a composição familiar teve um impacto sobre a sua utilização do transporte? (Ex.: Nascimento de crianças, as crianças envelhecendo, sozinho, ou com um parceiro / sair da casa dos pais)

\section{Trabalho e Emprego}

Qual é a sua ocupação e a de seus cônjuges?

Quando você pensa sobre as mudanças na carreira ao longo dos anos, elas trouxeram um impacto na participação no tráfego? Por quê?

Pense, por exemplo, para

Profissão anterior

Ocupações anteriores

Carreira / Primeiro Trabalho

Aprendizagem / estudo

\section{Lazer}

Houve grandes mudanças em suas atividades de lazer nos últimos 15 anos?

Isso mudou o seu uso de transporte?

Existem parentes ou amigos que você visita regularmente?

Há impacto sobre o uso de transporte?

Segunda residência ou algo semelhante?

Há impacto sobre a utilização dos transportes?

Levar sua família para férias? 
Há impacto sobre a utilização dos transportes?

\section{Política "virada" 89/90}

Este evento histórico teve um impacto sobre a sua utilização do transporte?

\section{Pequeno Questionário Socioeconômico}

No final de algumas questões estatísticas ...

1. Há quanto tempo você viveu em Leipzig?

2. Por favor, especifique sexo, idade, ocupação e relacionamento das pessoas que vivem em sua casa.

\begin{tabular}{|l|l|l|l|l|l|l|}
\hline & Respondente & $2^{\circ}$ Pessoa & $3^{\circ}$ Pessoa & $4^{\circ}$ Pessoa & $5^{\circ}$ Pessoa & $6^{\circ}$ Pessoa \\
\hline Gênero & & & & & & \\
\hline Idade & & & & & & \\
\hline $\begin{array}{l}\text { Ocupação } \\
\text { Sim, meio- } \\
\text { período, } \\
\text { desempregado }\end{array}$ & & & & & & \\
\hline Educação & & & & & & \\
\hline
\end{tabular}

4. Listar os graus:

Escola Primária

Ensino Médio

Escola Secundária

Universidade

Outro tipo

3. Qual o rendimento mensal líquido familiar?

5. Você preencheria um registro de rotas ao longo de um período de 14 dias?

o Sim

o Não

6. Você conhece outros pais, na creche dos seus filhos, que poderiam estar dispostos a fazer uma entrevista?

o Sim

o Não

7. Você possivelmente estaria disponível para uma outra entrevista sobre o assunto do tráfego no futuro?

o Sim

o Não

\section{Obrigado pela sua participação!}




\section{Instrumento de Pesquisa no 4 - Lanzendorf (2010)}

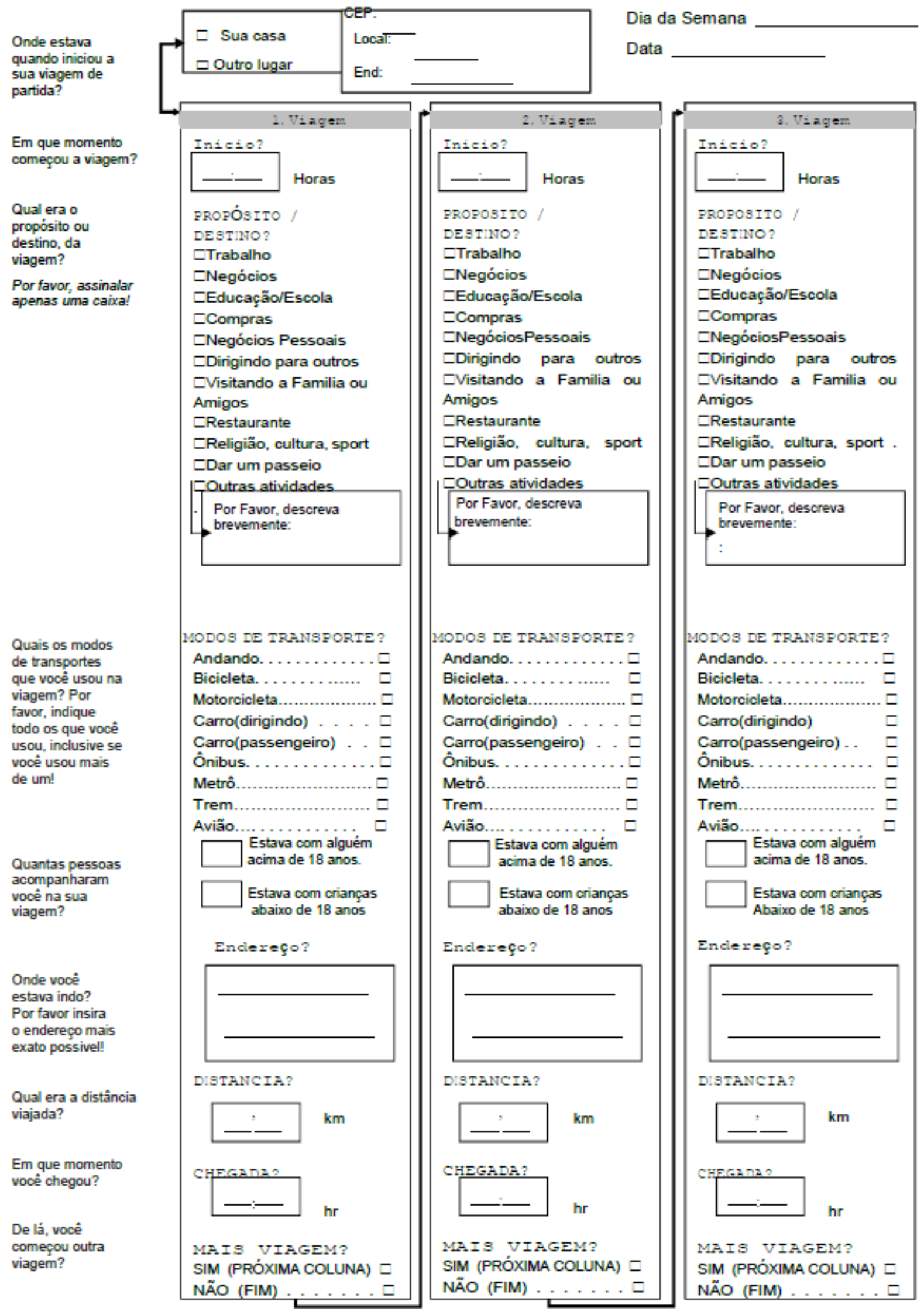




\section{Instrumento de Pesquisa no 5}

Programa de Pós Graduação em Transportes

\section{Biografia de Mobilidade}

\section{Página 1}

Prezado(a) Sr.(a), o questionário enviado é parte da pesquisa em mestrado do Programa de Pós-Graduaçăo em Transportes da Universidade de Brasilia, sob a coordenaçăo do mestrando Marcelo P. Almeida e orientaçăo da professora Dra. Fabiana Serra de Arruda sobre "Comportamento de Viagem". Você estará apto(a) a responder ao questionário, caso o(a) seu(ua) primeiro(a) filho(a) tenha até 6 anos de idade. Caso contrário, solicitamos gentilmente que năo responda ao questionário.

O objetivo do estudo é analisar a realizaçăo dos deslocamentos e a escolha do meio de transporte a partir do nascimento do(a) seu(ua) primeiro(a) filho(a).

Com esse propósito, solicitamos a sua colaboraçăo nesse estudo. Caso concorde, você responderá a questőes socioeconômicas, a um questionário retrospectivo relacionado ao período ANTES do nascimento do(a) seu(ua) primeiro(a) filho(a), a um questionário atual relacionado ao período APÓS o nascimento do(a) seu(ua) primeiro(a) filho(a), bem como as informaçŏes sobre seu(ua) companheiro(a) ou cônjuge, caso o tenha.

Sua participaçăo é voluntária e sua identificaçăo será mantida em sigilo. O questionário não confere riscos e respeita a privacidade dos participantes. Os

resultados dos dados coletados serăo trabalhados de maneira confidencial, somente para fins acadêmicos.

Estima-se que seja necessário cerca de 10 minutos para respondê-lo. Todas as perguntas marcadas com asterisco (") săo obrigatórias. Existem questóes fechadas, múltipla escolha e outras que podem ser respondidas com suas próprias palavras, sem se limitar a escolha entre o rol de alternativas. É permitido responder ao questionário apenas uma vez, mas voce̊ pode editar suas respostas até o seu encerramento.

Sua colaboraçăo será de grande valia para a conclusão da pesquisa.

Desde já, agradeço a sua contribuiçăo e aguardo o retorno do questionário.

Se houver algum questionamento em relação à pesquisa ou ao questionário, por favor, entre em contato.

Marcelo P. Almeida

marceloalmeidagyn@gmail.com

marceloalmeidagyn@hotmail.com

\section{1 - Informações gerais}

1. Gênero *

Masculino

Feminino 
2. Quantos anos você tem? *

Idade $\quad \nabla$

3. Posição familiar *
Chefe de familia
Parceiro(a)/Cônjuge
$($ Filho(a)
$($ Outro

4. Escolaridade *
Sem escolaridade
$\bigcirc$ Ensino fundamental
Ensino médio
Ensino técnico
$\bigcirc$ Ensino superior
Pós graduaçằ

5. Ocupação principal *

$\bigcirc$ Empregado(a)

Autônomo

Funcionário(a) público(a)

$\bigcirc$ Dolar

Aposentado(a)

$\bigcirc$ Estudante

$\bigcirc$ Desempregado(a)

Sem ocupaçăo/Nunca trabalhou

$\bigcirc$ Outro $\square$ 
6. Renda bruta domiciliar (familiar) mensal

(1 Salário Mínimo corresponde a R\$ 880,00) *

$\bigcirc$ Sem rendimento

Até 2 salários mínimos

Entre 2 e 4 salários mínimos

Entre 4 e 10 salários mínimos

Entre 10 e 20 salários mínimos

Acima de 20 salários mínimos

7. Qual localidade você reside? *

Estado $\quad$ -

8. Possui carteira de habilitação? *
$\bigcirc \operatorname{Sim}$
( Năo

9. Quantos automóveis existem em seu domicilio? *
Nenhum automóvel
( 1 automóvel
2 automóveis
3 automóveis ou mais 
10. Atualmente, qual o meio de transporte utilizado com maior frequência para a realização dos seus deslocamentos (ex.: ir ao trabalho e/ou escola)? *

Automóvel (Dirigindo)

Automóvel (Carona)

Motocicleta

$\bigcirc$ Ônibus

Metró

$\bigcirc$ Bicicleta

A pé

11. Qual o grau de importância que você atribui ao meio de transporte escolhido na questão anterior? * Semimportåncia Pouca importåncia Indiferente Importante Muito Importante

Segurança
Tempo de
deslocamento
Conforto/
Conveniência
Custo
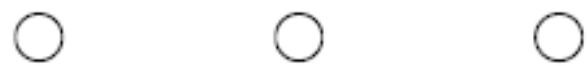

Flexibilidade no

deslocamento<smiles>c1ccccc1</smiles>
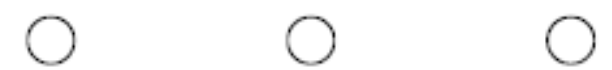

Qualidade do sistema de transporte público
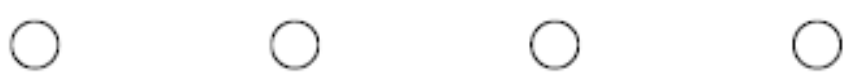

Questões

ambientais

(ex.: poluiçẵo

do ar,

consumo

energético,

ruído)
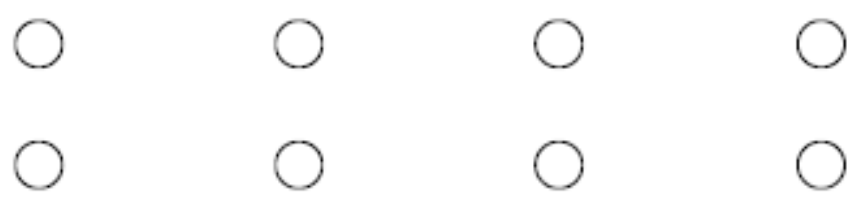

0

0

0
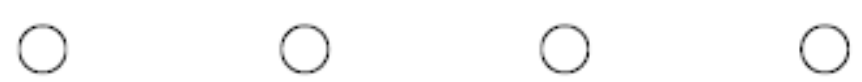<smiles>c1ccccc1</smiles>

(1)


2. Antes do nascimento do(a) seu(ua) primeiro(a) filho(a) quantos automóveis existiam em seu domicílio? *
Nenhum automóvel
○ 1 automóvel
(2) automóveis
(3 automóveis ou mais

3. Antes do nascimento do(a) seu(ua) primeiro(a) filho(a), qual era o meio de transporte utilizado com maior frequência para a realização dos seus deslocamentos (ex.: ir ao trabalho e/ou escola)? *
Automóvel (Dirigindo)
Automóvel (Carona)
$\bigcirc$ Motocicleta
$\bigcirc$ Ônibus
Metró
Bicicleta
A pé

4. Qual era o grau de importância que você atribuía ao meio de transporte escolhido na questão anterior? * Sem importåncia Pouca importância Indiferente Importante Muito Importante
Segurança
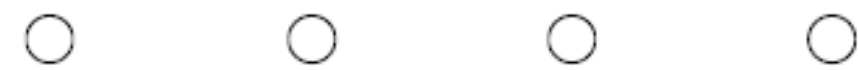
Tempo de
deslocamento
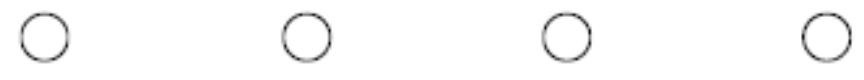
Conforto/
Conveniência
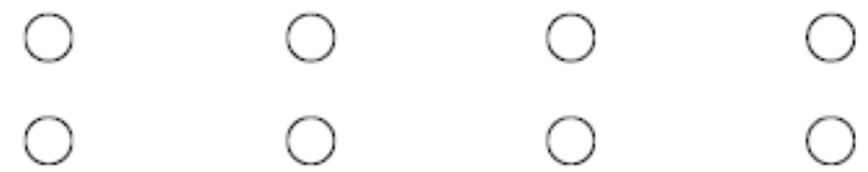
Custo

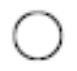
0
0

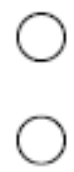
Flexibilidade
no
deslocamento
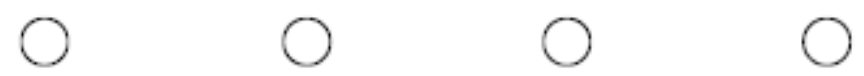
Qualidade do sistema de transporte público
Questões ambientais (ex.: poluiçẵo do ar, consumo energético, ruído) 
1. Após o nascimento do(a) seu(ua) primeiro(a) filho(a) o número de suas ATIVIDADES diárias (compromissos) mudou? *

( Nă̊

Sim, o número de atividades diárias aumentou alguns dias durante a semana

Sim, o número de atividades diárias diminuiu alguns dias durante a semana

Sim, o número de atividades diárias aumentou todos os dias durante a semana

Sim, o número de atividades diárias diminuiu todos os dias durante a semana

2. Após o nascimento do(a) seu(ua) primeiro(a) filho(a) houve alteração no número de DESLOCAMENTOS para a realização das suas atividades diárias? *

Nằ

Sim, o número de deslocamentos aumentou alguns dias durante a semana

Sim, o número de deslocamentos diminuiu alguns dias durante a semana

Sim, o número de deslocamentos aumentou todos os dias durante a semana

Sim, o número de deslocamentos diminuiu todos os dias durante a semana

3. O nascimento do(a) seu(ua) primeiro(a) filho(a) influenciou na sua escolha do meio de transporte utilizado atualmente? *
$\bigcirc \operatorname{Sim}$
Nắo

4. Ao considerar os deslocamentos feitos com seu(ua) filho(a) (ex.: levar a escola, ao médico pediatra, atividades esportivas, etc.) qual o principal meio de transporte utilizado? *

Automóvel

Motocicieta

Ônibus

Metrō

Bicicleta

A pé 
5. Ao considerar os deslocamentos feitos com seu(ua) filho(a) (ex.: levar a escola, ao médico pediatra, atividades esportivas), você usaria outro meio de transporte, diferente do utilizado na questăo anterior?

Sim

Sim, mas teria que fazer adaptações nas minhas atividades diárias (compromissos) com relaçăo a horário, localizaçăo, etc.

Năo

6. Após o nascimento do(a) seu(ua) primeiro(a) filho(a) você continuou trabalhando? *

Sim, voltei a trabalhar normalmente

Sim, voltei a trabalhar normalmente, mas mudei de emprego

Parei de trabalhar temporariamente para cuidar das obrigações domésticas e/ou do(a) filho(a)

Parei de trabalhar definitivamente para cuidar das obrigações domésticas e/ou do(a) filho(a)

Năo, perdi o meu emprego

Năo trabalhava antes da gravidez, mas trabalho agora

Năo trabalhava antes da gravidez e temporariamente cuido das obrigaçōes domésticas e/ou do(a) filho(a)

Năo trabalhava antes da gravidez e cuido das obrigações domésticas e/ou do(a) filho(a)

7. Após o nascimento do(a) seu(ua) primeiro(a) filho(a) houve mudança de residência? (Mais de uma opção pode ser selecionada) *

Năo houve mudança de residência

Saiu ou voltou para a casa dos pais

Para uma residenncia mais adequada ao filho(a)

Saiu do aluguel para o imóvel próprio

Para melhor acessibilidade ao transporte público

Para estar mais próximo do trabalho

Para estar mais próximo da escola do(a) filho(a)

Mudei de cidade ou estado

$\square$ Outro 
8. Possui companheiro(a) ou cônjuge morando no mesmo domicílio? *

$\operatorname{sim}$

năo

4 - Informações sobre seu companheiro(a) ou cônjuge relacionadas ao nascimento do(a) seu(ua) Primeiro(a) Filho(a)

1. Após o nascimento do(a) seu(ua) primeiro(a) filho(a) a agenda de ATIVIDADES diárias (compromissos) do(a) seu(ua) companheiro(a) ou cônjuge mudou? *

Năo

Sim, o número de atividades diárias dele(a) aumentou alguns dias durante a semana

Sim, o número de atividades diárias dele(a) diminuiu alguns dias durante a semana

Sim, o número de atividades diárias dele(a) aumentou todos os dias durante a semana

Sim, o número de atividades diárias dele(a) diminuiu todos os dias durante a semana

2. Após o nascimento do(a) seu(ua) primeiro(a) filho(a) houve alteração no número de DESLOCAMENTOS diários do(a) seu(ua) companheiro(a) ou cônjuge? *

Năo

Sim, o número de deslocamentos dele(a) aumentou em alguns dias durante a semana

Sim, o número de deslocamentos dele(a) diminuiu em alguns dias durante a semana

Sim, o número de deslocamentos dele(a) aumentou todos os dias durante a semana

Sim, o número de deslocamentos dele(a) diminuiu todos os dias durante a semana

3. O nascimento do(a) primeiro(a) filho(a) influenciou seu(ua) companheiro(a) ou cônjuge na escolha do meio de transporte utilizado atualmente? *

Sim

Nằ

4. Após o nascimento do(a) primeiro(a) filho(a) seu(ua) companheiro(a) ou cônjuge mudou o meio de transporte utilizado? *

$\operatorname{sim}$

năo 
5. Após o nascimento do(a) seu(ua) primeiro(a) filho(a) seu(ua) companheiro(a) ou cônjuge continuou trabalhando? *

Sim, ele(a) voltou a trabalhar normalmente

Sim, ele(a) voltou a trabalhar normalmente, mas mudou de emprego

Ele(a) parou de trabalhar temporariamente para cuidar das obrigaçōes domésticas e/ou do(a) filho(a)

Ele(a) parou de trabalhar definitivamente para cuidar das obrigaçōes domésticas e/ou do(a) filho(a)

Năo, ele(a) perdeu o emprego

Ele(a) năo trabalhava antes da gravidez, mas trabalha agora

Ele(a) năo trabalhava antes da gravidez e temporariamente cuida das obrigações domésticas e/ou do(a) filho(a)

Ele(a) năo trabalhava antes da gravidez e cuida das obrigações domésticas e/ou do(a) filho(a)

6. Após o nascimento do(a) seu(ua) primeiro(a) filho(a) houve mudança de residência do(a) seu(ua) companheiro(a) ou cônjuge? (Mais de uma opção pode ser selecionada) *

Năo houve mudança de residência

Ele(a) saiu ou voltou para a casa dos pais

Ele(a) mudou para uma residência mais adequada ao filho(a)

Ele(a) mudou para sair do aluguel para o imóvel próprio

Ele(a) mudou para melhorar a acessibilidade ao transporte público

Ele(a) mudou para estar mais próximo do trabalho

Ele(a) mudou para estar mais próximo da escola do(a) filho(a)

Ele(a) mudou de cidade ou estado

Outro

^Redirection to final page of Online Pesquisa (alterar) 